\title{
Patient payments in the Bulgarian public health care sector: are they feasible?
}

Citation for published version (APA):

Pavlova, M. I. (2002). Patient payments in the Bulgarian public health care sector: are they feasible? [Doctoral Thesis, Maastricht University]. Datawyse / Universitaire Pers Maastricht. https://doi.org/10.26481/dis.20021031mp

Document status and date:

Published: 01/01/2002

DOI:

10.26481/dis.20021031mp

Document Version:

Publisher's PDF, also known as Version of record

\section{Please check the document version of this publication:}

- A submitted manuscript is the version of the article upon submission and before peer-review. There can be important differences between the submitted version and the official published version of record.

People interested in the research are advised to contact the author for the final version of the publication, or visit the DOI to the publisher's website.

- The final author version and the galley proof are versions of the publication after peer review.

- The final published version features the final layout of the paper including the volume, issue and page numbers.

Link to publication

\footnotetext{
General rights rights.

- You may freely distribute the URL identifying the publication in the public portal. please follow below link for the End User Agreement:

www.umlib.nl/taverne-license

Take down policy

If you believe that this document breaches copyright please contact us at:

repository@maastrichtuniversity.nl

providing details and we will investigate your claim.
}

Copyright and moral rights for the publications made accessible in the public portal are retained by the authors and/or other copyright owners and it is a condition of accessing publications that users recognise and abide by the legal requirements associated with these

- Users may download and print one copy of any publication from the public portal for the purpose of private study or research.

- You may not further distribute the material or use it for any profit-making activity or commercial gain

If the publication is distributed under the terms of Article $25 \mathrm{fa}$ of the Dutch Copyright Act, indicated by the "Taverne" license above, 


\section{Patient payments in}

the Bulgarian public health care sector:

Are they feasible? 
Patient payments in the Bulgarian public health care sector: Are they feasible?.

Milena Pavlova. Thesis. Maaastricht University, The Netherlands.

With summary in Dutch and Bulgarian.

Subject headings: patient payments, public health care sector, Eastern Europe, Bulgaria, willingness-to-pay, conjoint analysis.

ISBN 90-9016055-8

(C) 2002, Milena Pavlova

Department Health Organization, Policy and Economics

Faculty of Health Sciences; Maastricht University

Postbox 616; 6200 MD Maastricht; The Netherlands

All rights reserved. No part of this publication may be reproduced, stored in a retrieval system, or transmitted, in any form or by any means, electronic, mechanical, photocopying, recording or otherwise, without the written permission from the publisher.

Printed by Datawyze B.V.| Universitaire Pers Maastricht, Maastricht, the Netherlands. 


\title{
Patient payments in
}

\section{the Bulgarian public health care sector: Are they feasible?}

\author{
PROEFSCHRIFT
}

ter verkrijging van de graad van doctor aan de Universiteit Maastricht,

op gezag van de Rector Magnificus, Prof.dr. A.C. Nieuwenhuijzen Kruseman, volgens het besluit van het College van Decanen, in het openbaar te verdedigen op donderdag 31 oktober 2002 om 16.00 uur

$$
\text { door }
$$

\section{Milena Iordanova Pavlova}

geboren op 23 september 1971 te Varna, Bulgarije 


\section{Promoters:}

Prof. dr. W. Groot

Prof. dr. G.G. van Merode

\section{Beoordelingscommissie:}

Prof. dr. H. Maarse (voorzitter);

Prof. dr. P. Groenewegen (Universiteit Utrecht)

Prof. dr. H. Maassen van den Brink (Universiteit van Amsterdam)

Prof. dr. J-P. Poullier

Prof. dr. B. van Praag (Universiteit van Amsterdam)

Prof. dr. H. Severens

Prof. dr. J. van der Zee

\section{Financial support:}

The first three years of this research were undertaken with support from the European Union's Phare ACE Programme 1997. The content of the publication is the sole responsibility of the author and it in no way represents the views of the Commission or its services. The fourth research year was financed by Stichting Fonds Doctor Catharina van Tussenbroek. All financial support is gratefully acknowledged. 
To my homeland 



\section{Contents}

\section{CHAPTER 1}

General introduction

1.1. Scope of the study $\quad 2$

1.2. Socio-political context of the study $\quad 2$

1.3. The current system of patient payments in Bulgaria 3

1.4. Central and research questions $\quad 4$

1.5. Methodological framework $\quad 5$

1.6. Data collection process $\quad 5$

$\begin{array}{ll}\text { 1.7. Outline of the thesis } & 6\end{array}$

References $\quad 7$

\section{CHAPTER 2}

Appraising the financial reform in the Bulgarian public health care sector 9

$\begin{array}{ll}2.1 \text {. Introduction } & 10\end{array}$

2.2. Predicaments of Bulgarian health care financial reforms $\quad 10$

2.3. Financial reforms in the Bulgarian public health care sector $\quad 12$

2.4. The potential of the contribution-based financing of the health care system 13

2.5. The potential of the contract-based allocation of health care resources $\quad 15$

2.6. The potential effect of the insurance-based finance on health care equity 17

2.7. The insurance-based health care finance and the socio-economic context 18

$\begin{array}{lr}\text { 2.8. Conclusions } & 19\end{array}$

$\begin{array}{ll}\text { References } & 20\end{array}$

\section{CHAPTER 3}

Public attitudes towards patient payments in the Bulgarian public health care sector

3.1. Introduction

3.2. Survey methodology $\quad 25$

$\begin{array}{ll}\text { 3.3. Sample characteristics } & 27\end{array}$

$\begin{array}{ll}\text { 3.4. Method of statistical analysis } & 27\end{array}$

$\begin{array}{ll}3.5 \text {. Survey results } & 28\end{array}$

3.6. Discussion 33

3.7. Possible response biases and prospect for generalization 35

3.8. Conclusions $\quad 36$

$\begin{array}{ll}\text { References } & 37\end{array}$

\section{CHAPTER 4}

The importance of health care attributes to Bulgarian consumers: a self-explicated method

4.1. Introduction $\quad 40$

4.2. Method of research and analysis $\quad 40$

4.3. Sample characteristics $\quad 43$ 
4.4. Results $\quad 43$

4.5. Relevance of the results $\quad 48$

4.6. Possible response biases $\quad 50$

4.7. Conclusions $\quad 51$

References $\quad 52$

\section{CHAPTER 5}

The importance of quality, access and price to Bulgarian health care consumers: a conjoint analysis

5.1. Introduction $\quad 56$

5.2. Preparation of the conjoint study $\quad 57$

5.3. Collection of the conjoint data $\quad 59$

$\begin{array}{ll}\text { 5.4. Analysis of the profile rating } & 60\end{array}$

$\begin{array}{ll}\text { 5.5. Results and discussion } & 62\end{array}$

$\begin{array}{ll}\text { 5.6. Conclusions } & 66\end{array}$

$\begin{array}{ll}\text { References } & 67\end{array}$

\section{CHAPTER 6}

Willingness and ability to pay for public health care services in Bulgaria

$\begin{array}{ll}\text { 6.1. Introduction } & 70\end{array}$

6.2. Survey methodology $\quad 71$

$\begin{array}{ll}\text { 6.3. Data analysis } & 72\end{array}$

6.4. Characteristics of the sample $\quad 76$

$\begin{array}{ll}\text { 6.5. Results } & 76\end{array}$

$\begin{array}{ll}\text { 6.6. Discussion } & 84\end{array}$

$\begin{array}{lr}\text { 6.7. Conclusions } & 86\end{array}$

$\begin{array}{ll}\text { References } & 87\end{array}$

CHAPTER 7

$\begin{array}{lr}\text { General conclusions and policy implications } & 89\end{array}$

$\begin{array}{ll}\text { 7.1. Introduction } & 90\end{array}$

$\begin{array}{ll}\text { 7.2. Main findings } & 90\end{array}$

7.3. The objective of patient payments in Bulgaria 93

7.4. The design of patient payments in Bulgaria 96

$\begin{array}{ll}\text { 7.5. Suggestions for further research } & 99\end{array}$

$\begin{array}{lr}\text { 7.6. Final considerations } & 100\end{array}$

$\begin{array}{ll}\text { References } & 100\end{array}$

APPENDIX A

$\begin{array}{ll}\text { The English wording of the questionnaire } & 103\end{array}$

APPENDIX B

Анкетна карта (The questionnaire in Bulgarian) 


\section{APPENDIX C}

Socio-demographic characteristics of the sample

C.1. Description of the socio-demographic variables collected in the survey

C.2. Bivariate correlation between the socio-demographic variables

C.3. Socio-demographic variables included in the data analysis

C.4. Sample, regional and national statistics 

CHAPTER 1

General introduction 


\subsection{Scope of the study}

During the last decades, many governments have introduced patient payment mechanisms in their public health care systems with the objective of cost sharing or cost-recovery (Creese and Kutzin, 1995; van Adams and Hartnett, 1996). Patient payments have been implemented in both publicly funded and insurance-based health care systems of high-, middle- and low- income countries (AbelSmith, 1985).

The objectives of patient payments differs from country to country and largely depend on the conditions of the health care sector and the general economic circumstances in the country (WHO, 1996). In high-income countries with established health care systems, patient payments are mainly implemented to achieve efficient health care utilisation that can help to prevent unnecessary health care expenditures. In low- and middle-income countries, where the health care sector is under transition or development, the objective of the patient payment is mostly to raise additional revenues in order to ensure a sustainable public health care with adequate quality. In some of these countries formal payments also aims to replace the existing 'under-the-counter' payments (WHO, 1996).

Though patient payments for public health care services are widely spread, the justification of their introduction is still a subject of scientific debate (Rovira et al., 1998; WHO, 1996). There is no clear agreement about the potential effects of patient payments. Economic theory provides evidence that patient payment can improve efficiency in the health care sector (e.g. Jimenez, 1987; Melhado, 1998; McPake, 1993). Such suppositions are, however strongly questioned because of the specificity of the health care commodity (WHO, 1996). Nevertheless, the potentially adverse impact of patient payments on equity is commonly recognised, although ideas for equity improvement through the introduction of patient payments can still be found (e.g. Russell and Gilson, 1997)

In the Bulgarian public health care sector, patient payments have been recently legislated, but the appropriateness of their design has not yet been studied. Questions about the potential of these payments, in the Bulgarian context, remain unanswered. The study presented in this thesis attempts to fill this research gap.

\subsection{Socio-political context of the study}

Bulgaria is one of the former-socialist countries in Eastern Europe, which is in a process of economic transition from a state planned to a market oriented economy. Like in other Eastern European countries, this process was initiated by the abolishment of the communist rule and by the subsequent changes in the fundamental social values. Individuals received freedom of choice through democratic processes. The State was no longer seen as the only institution that can govern the economic and social development of the country. The principles of self-regulation and citizen involvement were accepted in all economic sectors and this initiated a process of decentralisation and privatisation. The need of accountability of the sectors to political, social and economic institutions was reconsidered. The unity of economic and social policies, established by the communist government, was criticised and processes for their reform have been started (Deppe and Oreskovic, 1996; WHO, 1996). Thus, the collapse of communism has not only brought to an end the political system, but also the welfare state established by that system (Deacon, 1992).

The social and economic transformation in Bulgaria, however, was slower than in other formersocialist countries (Deacon and Vidinova, 1992; EOHCS, 1999). The new post-communist governments considered reforms in all social and economic sectors, but frequent changes of 
governments made these reforms inconsistent and tardy. The delay of the reforms resulted in a weak fiscal system, paralysed industry, relatively low GDP per capita (1227 USD in 1997) and high unemployment rates (13,7\% in 1997) (EOHCS, 1999).

The generally slow transition process in Bulgaria affected the reforms in the health care sector as well. The initial reforms were primarily focused on the establishment of a private health care sector. Regarding the tax-based public health care system established during the communist government, it was recognised that immediate reforms were necessary in order to improve its efficiency and quality of service. However, the main outcome was a prolonged discussion about the transformation of the tax-based health care system into a social health insurance. In 1991, a national centre for health insurance was established. In October 1993, the Council of Ministers approved in principle a draft law on social health insurance, but its final approval was postponed. No one of the first post-communist governments actually took the political risk to start the implementation of a social health insurance system. Besides, virtually none of the governments considered it important to discuss a reform of the existing tax-based system.

Like in the other Eastern European countries, the introduction of social health insurance was a more attractive political strategy for several reasons. First, the social health insurance was seen as a departure from the centralised model established during the communist period and as a movement towards a Western type of health care system. It was expected that social health insurance would lead to greater consumer choice which is in accordance with the broad social will for enlarging free choice of individuals. Medical professionals, as providers of health care services, anticipated higher remuneration levels and increased health care budgets after the implementation of the insurance system. In addition, the geopolitical changes in Europe after the unification of Germany turned Germany's national health insurance into a model of how 'the East can meet the West' (Deppe and Oreskovic, 1996; WHO, 1996).

Although, Bulgarian policy makers opted to replace the tax-based health care system with a social health insurance mechanism, they were actually not able to implement it. Thus, public health care in Bulgaria remained unreformed and mainly tax-financed, with total expenditure determined by the financial capacity of the state. The absence of appropriate reforms intensified the low efficiency and poor quality of the public health care sector. Moreover, the instability of the national economy caused deficiencies in the state revenues and, consequently, a reduction of the public health care budget. In 1997, the recourses devoted to health care were only about $3 \%$ of the GDP or 150 USD PPP (EOHCS, 1999). The inadequate health care financing resulted in a further deterioration of the public health care provision.

Ultimately, the government elected in 1997 recognised that the health care reforms were inevitable. On $4^{\text {th }}$ of June 1998, the Bulgarian parliament endorsed a law for establishing a national health insurance system financed by income-based contributions. The actual implementation of the system was, however, delayed mainly because of the shortage of financial resources. It was launched on $1^{\text {st }}$ of July 2000 and still has to be completed. As financial resources collected by the insurance fund are insufficient, its sustainability is questionable.

\subsection{The current system of patient payments in Bulgaria}

The Health Insurance Act of 4.06.1998 settled patient payments for using health care services under Bulgarian social health insurance. Fees are charged for a visit to a physician or dentist and for staying at a hospital. In this regard for every visit to a dentist or physician, a patient has to pay (outof-pocket) a fee that is $1 \%$ of the minimum monthly wage. For each day of hospital care, a patient 
has to pay an amount of $2 \%$ of the minimum monthly wage, but for not more than 20 days a year. Presently, the minimum monthly wage in Bulgaria is fixed at 100.- BGL ( $1 \mathrm{BGL} \approx 0.5 \mathrm{EURO}$ ). This means that patients are required to pay 1.- BGL for a visit to general practitioner, medical specialist and dentist and up to 40.- BGL for a hospital services. The patient charges rise with the increase of the minimum monthly salary and there is no annual maximum related to charges for services outside hospital.

The patient payments under social health insurance do not refer to chronically-sick persons, miners, children, unemployed, conscripts, war veterans/invalids, persons under arrest/prisoners and persons with low or no income (The 38th National Assembly, 1998). These payments are applied when the patient use services of a general practitioner or dentist who have a contract with the social health insurance and with whom the patient is registered.

If patients wish to use a different provider or facility than the one they are referred to or wish to skip the primary health care level, other payment obligations apply. The fees, in case of no referral, are legislated by the government under Directive No22 of 9.12.1997 and they are service specific. Such fees, however, cannot be charged for hospital care after the tenth day, as well as for check-ups and tests (Ministry of Health Care, 1998). Initially, it was decided that the fee amounts should be set by the provider or the health care facility. In 1999, however, a unified fee tariff was drawn up by the Ministry of Health Care (EOHCS, 1999).

According to both regulations, the fees should be paid to the provider or the health care facility directly. The regular patient payments under social health insurance are going to be included in the process of contracting. Physicians, dentists and medical facilities are obliged to give patients a receipt where the amount paid is stated (EOHCS, 1999; Ministry of Health Care, 1998; The 38th National Assembly, 1998).

\subsection{Central and research questions}

Patient payments are becoming a characteristic of the public health care provision in Bulgaria, but there is little information regarding their implementation. Given the on-going transition process, public perceptions regarding patient payments are still largely unknown. Even if individuals are inclined to pay for public health care, however, the relatively low standards of living suggest that they do not always have sufficient resources for such payments. Based on these suppositions, the need and feasibility of patient payments is often debated. To enable a more informed discussion over the patient payments in Bulgaria, this study aims to answer the following central question: Are patient payments feasible for Bulgarian conditions and acceptable to the population?

The answer to this question requires an analysis of the behaviour of Bulgarian consumers under patient payments. At the time the study for this thesis was conducted, the official system of patient payments was not yet fully introduced and the actual behaviour of the consumers under patient payments could not be studied. Therefore, the study is focussed on consumer preferences for health care services and the size of patient payments that the consumers are willing and able to pay.

Thus, to gain more insights into the potential of patient payments in Bulgaria and to answer the central questions, the following research questions are posed:

1.What is the context of patient payments in the public health care sector?

2.What are the public attitudes towards the design of patient payments?

3.Are consumers responsive to prices in health care sector?

4.Are quality and access more important to consumers than the size of patient payments?

5.How much are consumers willing and able to pay for public health care? 


\subsection{Methodological framework}

The study applies quantitative research methods, namely analysis of self-explicated attribute importance, conjoint analysis and contingent valuation. These three methods are analytical tools that can be applied to the analysis of stated preferences and rely on data collected in a survey. A more detailed explanation of the research methods and their application is given throughout the thesis. Here the relation of each method to the research questions is presented.

The analysis of the self-reported attribute importance and the conjoint analysis are used to study how consumers would choose health care services if they have to pay a fee. The results of the application of these methods indicate the relative importance of quality, access and price of health care services to consumers. The results of these two methods are used to analyse the potential responsiveness of consumers to prices of health care and how price effects vary between sociodemographic groups. The results further show the relative importance of quality and access for consumers if they have to pay for health care services. The self-explicated approach is used to validate the conjoint results.

The contingent valuation method is used to study the willingness and ability of consumers to pay for different public health care services if provided with good quality and quick access. The method is applied to three groups of services. These are outpatient services (outside hospital or clinic), inpatient services (inside hospital or clinic) and dental care. The results of the contingent valuation method are used to determine the optimal price levels that can be charged in Bulgarian public health care sector.

In addition to the three research methods outlined above, the study analyses public attitudes towards the design of patient payments in Bulgaria. This analysis also relies on data from the survey and applies statistical methods for their analysis.

\subsection{Data collection process}

The data were collected using a standardised questionnaire. The questionnaire was developed in English and then translated into Bulgarian. The Bulgarian version was sent to a translation office to be translated in English. The original English version and the English version received from the translation office were compared to check for translation errors. No significant differences were found. The English wording of the questionnaire can be found in appendix A.

The questionnaire consists of 38 entries, some of which were multi-part questions. The questions fall into four broad categories:

- Part 1 contains questions that are concerned with the health care services used by the respondent during the previous year and the amounts paid for using these services.

- Part 2 consists of questions about the preferences of the respondent for health care providers and provider's services.

- Part 3 includes questions concerning the willingness and ability of the respondent to pay for health care services with good quality and quick access.

- Part 4 contains questions regarding the socio-demographic characteristics of the respondent.

The questionnaire was tested in a pilot survey in order to test the face validity of the questionnaires, to measure the average duration of the interviews, as well as to find the appropriate selection method. The pilot survey produced 97 completed questionnaires, which were used to adjust the wording of the questions. The results from the pilot study also showed that the average duration of the interviews was about half an hour, which was within the desired time limit. 
Furthermore, the method of randomly selected households had the highest response rate and thus appeared to be the most preferable option.

The main survey was conducted in May and June 2000 by the interviewer staff of APEA BBSS Gallup International - a research company situated in the city of Varna, Bulgaria. The interviewer staff consisted of people with a university or semi-university education. All the interviewers had participated in similar surveys before and it was, therefore, assumed that they had the necessary experience. Furthermore, prior to the survey, the interviewers participated in a group meeting and they received detailed instructions regarding each question and the codes of the responses.

The interviewers were instructed to record the addresses of the respondent. Afterwards, there were check-ups on randomly selected addresses of respondents in order to verify that the interviews had really been conducted. All the check-ups confirm the truthfulness of the interviews. For each person interviewed, immediately after the interview, the interviewer completed a methodological form. The purpose of this methodological form was to provide a basis for an informal evaluation of the reliability of the answers and the efficiency of the pooling technique.

The survey sample was drawn from the population of the region of Varna (Bulgaria's third largest city) using the method of two-stage random selection - first selecting the living area and then randomly selecting a respondent from a particular age/gender group. The number of respondents in each cluster was determined by the official regional statistics for urban/rural distribution of the population, as well as for the age and gender distribution. This was done in order to assure that each residence place is presented in proportion to its population size and age-gender distribution. The research company that conducted the survey calculated an expected sampling error of $3 \%$.

In total, 1094 individuals were contacted. From this sample, 91 individuals refused to answer and 3 were unable to answer the questions. There were 10 interviews, which were terminated before completion due to unwillingness of the respondent to continue the interview. Thus, the survey produced 990 full interviews. Detailed information about the socio-demographic characteristics of the sample can be found in appendix C.1. The numbers of useful interviews for the various analyses differ due to additional partial non-response. Therefore, the response rate varies between $90.5 \%$ and $84 \%$, and its precise values are reported in the chapters.

The relatively high average response rate and the random selection of the respondents in each cluster, defined by age, gender and residence place, suggest that the data for a particular cluster are representative for the relevant population groep itself. Furthermore, as shown in appendix C.4., the distribution of the respondents concerning age, gender and residence place does not differ significantly from the regional statistics. Thus, it can be assumed that the results are representative for the region. Regarding the representativeness of the sample for the country as a whole, the comparison between characteristics of the sample with the national statistic data do not show significantly differences except for the distribution of respondents among residence place (see appendix C.4). Thus, the results might be extrapolated to the country as a whole, but the conclusions related to residence place should be treated with some caution.

\subsection{Outline of the thesis}

Following this introductory chapter, the thesis contains six chapters. Each chapter represents a separate paper that can be read independently. The organisation of a thesis in the form of separate papers comes at a cost. Some repetition of paragraphs in multiple chapters cannot be avoided. 
The second chapter of the thesis analyses the contextual background of patient payments in the Bulgarian public health care sector. The chapter reviews the problems outside and inside the health care system related to the reforms in public health care financing and discusses the potential of this reform in the Bulgarian context. The discussion relies on a review and analysis of the relevant literature.

The next four chapters present and discuss the results of the survey. Chapter three examines the attitudes of Bulgarian health care consumers towards alternative designs of a patient payment mechanism. The analysis of the results is based on a statistical procedure. The chapter outlines the public views regarding the services under payment, the type of the payments, the beneficiaries of the payments, and the system of exemptions.

Chapter four and five present the results of the analysis on the importance of quality, access and price to Bulgarian health care consumers. Chapter four relies on results from the analysis of selfexplicated preferences and chapter five presents the application of the conjoint approach. Both chapters indicate how the revenues collected through patient payments are to be allocated. The chapters also outline the responsiveness of Bulgarian consumers to patient payments when selecting a health care service. The results are used to determine necessary exemptions.

The sixth chapter presents the results of the contingent valuation. The chapter analyses the willingness and ability of Bulgarian consumers to pay for public health care services that are provided with good quality and quick access. The chapter provides an estimation of the potential welfare effect of the implementation of fees for different public health care services and determines an optimal service. The results are also used to determine necessary exemptions.

The last chapter of the thesis, chapter seven, analyses the potential of patient payments in the Bulgarian context and discusses the appropriateness of the payment design introduced in Bulgaria. The analysis relies on the survey results presented throughout the thesis as well as on a review of the literature on patient payments. Finally, the chapter outlines some general conclusions regarding patient payments in Bulgaria.

\section{References:}

Abel-Smith, B. (1985). Global perspectives on health service financing. Social Science and Medicine 21 (9): 957-963.

Creese, A. and Kutzin, J. (1995). Lessons from cost recovery in health. WHO/SHS/NHP/95.5. Geneva: The World Health Organization.

Deacon, B. (1992). East European welfare: past, present and future in comparative context. In: Deacon, B. (ed.). The New Eastern Europe: Social Policy Past, Present and Future. London: Sage Publications.

Deacon, B. and Vidinova, A. (1992). Social policy in Bulgaria. In: Deacon, B. (ed.). The New Eastern Europe: Social Policy Past, Present and Future. London: Sage Publications.

Delcheva, E., Balabanova, D. and McKee, M. (1997). Under-the-counter payments for health care: evidence from Bulgaria. Health Policy 42: 89-100.

Deppe, H.-U. and Oreskovic, S. (1996). Back to Europe: back to Bismarck?. International Journal of Health Services 26 (4): 777-802. 
EOHCS (1999). Health care systems in transition: Bulgaria. European Observatory on health care systems Copenhagen: The World Health Organization/Regional Office for Europe.

Jimenez, E. (1987). Pricing policy in social sector: cost recovery for education and health in developing countries. Baltimore: John Hopkins University Press.

McPake, B. (1993). User charges for health services in developing countries: a review of the economic literature. Social Science and Medicine 36 (11): 1397-1405.

Melhado, E.M. (1998). Economists, public provision, and the market: changing values in policy debate. Journal of Health Politics, Policy and Law 23 (2): 215-263.

Ministry of Health Care (1998). Directive No22/9.12.1997 Conditions and organisation of the payment for medical care in case of patient choice (in Bulgarian). Biblioteka Zakoni APIS 5 (1) №126.

Rovira, J. et al. (1998). Cost-sharing in European union member states; a system oriented framework. In: Leidl, R. (ed.). Health Care and Its Financing in the Single European Market. Amsterdam: IOS Press.

Russell, S. and Gilson, L. (1997). User fee policies to promote health service access for the poor: a wolf in sheep's clothing?. International Journal on Health Services 27 (2): 359-379.

The $38^{\text {th }}$ National Assembly (1998). The health insurance act. Sofia: The $38^{\text {th }}$ National Assembly.

van Adams, A. and Harnett, T. (1996). Cost sharing in the social sector of Sub-Saharan Africa: impact on the poor. World Bank Discussion Paper No 338, African Technical Department Series. Washington: The World Bank.

WHO (1996). European health care reforms: analysis of current strategies. Copenhagen: The World Health Organization/Regional Office for Europe. 


\section{CHAPTER 2}

\section{Appraising the financial reform in the Bulgarian public health care sector}

Published as:

Pavlova, M., Groot, W. and van Merode, F. (2000). Appraising the financial reform in Bulgarian public health care sector: the Health Insurance Act of 1998. Health Policy 53: 185-199. 


\subsection{Introduction}

During the communist period, Bulgaria established a tax-based health care system developed according to the Soviet model. Health care finance and provision were integrated into a strongly centralised and hierarchical state organisation (Borisov and Rathwell, 1996; Delcheva et al., 1997; Minev et al., 1990). The primary objective of this organisation was to ensure free access for all citizens to comprehensive health care services (Minev et al., 1990). However, a number of quality, efficiency, equity and satisfaction problems emerged (Borisov and Rathwell, 1996). Due to the strong Bulgarian commitment to the Soviet policy, most health care reforms were impossible.

The historical changes of 1989 in Eastern Europe affected Bulgarian socio-political life and a process of transition was initiated. Under the pressure of health professionals, trade unions and individual citizens (WHO, 1992), the government recognised that radical health care reforms were necessary (McKee, 1991). The policies of the post-communist governments were oriented towards formation of a private health care sector and decentralisation of the existing public health care organisation (McKee, 1991; WHO, 1992). None of the Bulgarian governments actually took the political risk to reform the mechanism of the public health care finance. However, the unstable national economy considerably undermined the government's ability to subsidise the health care sector. The inefficient allocation of the limited resources resulted in unsustainable public health care system (WHO-Euro, 1999).

The deterioration of the public health care services pressed policy makers to reform the health care finance mechanism. On $4^{\text {th }}$ of June 1998, Bulgarian Parliament passed a law that legislated the introduction of a social health insurance. Thus, the financial mechanism of the public health care sector had to be entirely renewed and a previously non-existing insurance body had to be established.

This paper aims to explore the social benefits of the financial reforms in the Bulgarian public health care system. In order to achieve this goal, the paper first outlines the predicaments of the financial reforms and outlines criteria for appraising the new health care finance mechanism. The review of the reform predicaments is followed by a description of the legislated financial model and its analytical appraisal. Based on the analysis, the paper outlines conclusions about the financial reforms in the Bulgarian public health care system.

\subsection{Predicaments of Bulgarian health care financial reforms}

The public health care services in Bulgaria were continuously suffering from quality, efficiency, equity and satisfaction problems, especially during the decade of the transitional process (Borisov and Rathwell, 1996; Delcheva et al., 1997; Minev et al., 1990; McKee, 1991; WHO, 1992; WHOEuro, 1999). The methods of financing of the health care system, its funding and the remuneration of health care providers were the major reasons for the poor performance of the public health care sector. Each of these methods is further discussed.

The financing of the health care system in Bulgaria was based on general taxation. The health care budget presented a portion of the state budget and its size was determined by the State on an annual base. The state health care revenues were supplemented by municipality funds (Vodenitcharov and Borissov, 1995). Thus, the size of the health care budget depended on the political views for rationing the public budgets and on the financing capacity of the State and the municipalities (Ensor, 1993; Schaapveld et al., 1995). During the communist period, the political priorities for the industry over the service sector brought about a limited health care budget. The 
resources for financing the health care system were insufficient for simultaneously maintaining and developing the health care sector. This resulted in decreased capital investment and subsequently in an absolution of the health care technology and equipment (WHO-Euro, 1999). The shortage of technology investment made it virtually impossible for doctors to practice medicine effectively and to supply services with good quality (Deacon and Vidinova, 1992; WHO-Euro, 1999).

The unstable national economy during the transition period and the weak fiscal system in Bulgaria led to deficits in the public budgets. Thus, the financing capacities of the post-communist government and the municipalities were considerably undermined. This provided the authorities with a reason to cut the health care revenues. The resources devoted to health care were decreased and in 1997 they were only about 3\% of the GNP or 150 USD PPP (WHO-Euro, 1999). These figures are considerably lower than the contemporary averages of both Western and Eastern Europe. The insufficient financial resources resulted in a lack of elementary drugs, materials and instruments and ill-maintained health care facilities. Needless to say that there were not enough financial resources for the much-needed modernisation of the health care equipment. Thus, not only the service quality was worsened, but also the sustainability of the health care system became the 'most pressing system ailment in Bulgaria' (WHO-Euro, 1999).

The funding and remuneration methods of the public health care sector also caused failures. The health care settings were entirely owned by the State and were funded according to their capacities, so called input-related, incremental funding (WHO-Euro, 1999). The annual hospital budgets were based on the number of hospital beds, manpower and equipment of the previous year. Polyclinic budgets were based on the staff size, blend of services and number of visits. Additionally, there were 'non-accountable and obscure' government subsidies for some health care institutions (WHO-Euro, 1999). The health care staff was employed by the State and remunerated by fixed salaries. The size of a provider's salary was solely determined by the income policy of the government and the professional category of the provider. The quality of the services and the working conditions were not accounted for in the remuneration procedure (Vodenitcharov and Borissov, 1995).

This method of resource allocation contributed to territorial imbalances in health care provision (Ensor, 1993; WHO-Euro, 1999). There were no remuneration incentives for the health care providers to work in rural areas. For that reason small villages in the country had visiting specialists and providers with low medical education, so called veldshers (Deacon and Vidinova, 1992; WHO-Euro, 1999). The small health care staff and setting capacity in the rural areas resulted in lower health care budgets compared to the urban areas. Therefore, the village health care settings had poorer equipment for providing health care services (Minev et al., 1990). For similar reasons, there were significant differences in the health care provision within the urban areas. The medical technology and the specialists were over-concentrated in the big cities (McKee, 1991; WHO-Euro, 1999). There were great disparities between the services provided in the city hospitals and the hospital services in the small towns. (Deacon and Vidinova, 1992; WHO-Euro, 1999). Clearly, the territorial imbalance had adverse equity effects in the public health care system.

Inefficiency was another consequence of the health care resource allocation. There were two major failures directly related to the methods of funding and remuneration. First, there was an unnecessary utilisation of hospital diagnostic services. There were no incentives for the primary care provider to avoid unnecessary referrals of patients to hospital specialists. Policlinic doctors preferred to shift the responsibilities for diagnosing the patients to the hospital specialists, whose opinions were trusted more by the patients anyhow. Second, there were many unnecessary hospitalisations. A high number of hospital beds were often filled with patients whose treatment did not really require hospitalisation. This was done with the purpose of retaining hospital capacity and 
protecting the size of the annual hospital budget from cutbacks by the government. Many hospital beds in Bulgaria could not 'be categorised as acute care beds, but rather as social beds' (WHOEuro, 1999).

Further, the size of the salaries in the health care sector was traditionally low. During the communist period, the income of the health care providers was determined solely by their staff grades and was often less than the average wage of the country (Ensor, 1993; McKee, 1991). After the communist period, the remuneration of the health care providers continued to be low and unrelated to the performance of the health care providers. This had a deteriorating effect on the quality of service. There were hardly any incentives for health care providers to improve the quality of the service and to try to satisfy the patients. The low quality and lack of proper attention caused consumers' dissatisfaction (Borisov and Rathwell, 1996; WHO-Euro, 1999).

The low remuneration of medical practice resulted in informal (under-the-table) payments for receiving health care services. It is true that these types of payments could be explained to some extend by the culture of gratitude gifts, which exists in Bulgaria. However, very often patients were requested by the physicians to pay certain amounts. The under-the-counter payments for health care existed for years (WHO-Euro, 1999). During the transition, the limited government capability to finance health care services and to pay health care providers satisfactorily, further increased the level of informal payments (Delcheva et al., 1997; Ivanov et al., 1996; McKinsey, 1997). Under-thecounter payments were common for drugs and hotel services in hospitals, such as bed linen and food, to get access to elective surgery and for a wide variety of out-patient services, including sanatoriums, dental care, abortions, infertility treatment and spectacles (Delcheva et al., 1997; WHO-Euro, 1999). It is important to deal with the informal health care payments because they present an uncontrollable financial barrier for using health care services. These payments introduce incentives for unnecessary supply of health care services and medicines. Further, the existence of informal payments raises obstacles for estimating the actual health care expenditure and for collecting income taxes from the health care providers (Delcheva et al., 1997).

The short overview, presented above, implies that the financial mechanism of the Bulgarian public health care sector needed to be changed. The problems depicted above suggest that the new financial mechanism should ensure a stable financing of the health care system, enhance efficiency, good service quality and health care equity. In addition, the new financial mechanism should be in accordance with Bulgarian socio-economic and political conditions in order to ensure a successful implementation. These two considerations provide criteria for appraising the financial reform in the Bulgarian public health care sector (see box 2.1), which form the analytical framework of the paper.

Box 2.1. Criteria for appraising the financial reforms in the Bulgarian public health care sector

- The method of financing the system should ensure a sufficient and stable health care budget.

- The allocation mechanism should enhance efficiency and service quality.

- The financial model should guarantee equity in the public health care sector.

- The financial reforms should be applicable to the socio-economic conditions in the country.

\subsection{Financial reforms in the Bulgarian public health care sector}

The Health Insurance Act passed by the Bulgarian Parliament in 1998, legislated the establishment of a social health insurance body responsible for the public health care finance. As it is constituted 
by the act, the social health insurance institution presents a single autonomous organisation consisting of a general administration and 28 regional offices. The public health care system is financed through compulsory contributions paid for by the insured individuals. The size of the contributions is settled as a percentage of the gross individual income. The self-employed pay the full amount of the insurance contribution, whereas the contributions of the employed are divided between employees and their employers. The employed and self-employed people cover the contributions of their dependent family members by additional payments. The State pays the contributions of the pensioners and the municipalities pay the contributions of persons with social assistance. Extra resources from grants and loans are expected (The 38th National Assembly, 1998).

The Health Insurance Act settles direct patient payments for using health care services under the social health insurance. For a visit to a doctor or dentist, patients pay 1 per cent of the minimum wage. The fee for each day of hospital equals 2 per cent of the minimum wage, but payments can not be requested for more than 20 days a year (The 38th National Assembly, 1998).

The insurance act constitutes that the social health insurance institution cannot own health care facilities. The relation between the social health insurer and the health care providers is based on contracts. The social health insurance institution is allowed to contract with both public and private providers (The 38th National Assembly, 1998). However, the law does not explicitly legislate the funding and remuneration methods in the public health care sector. The exact reimbursement mechanism is settled by additional regulation called the National Framework Contract.

According to the Health Insurance Act, the social health insurance guarantees a basic universal package of health care services (The 38th National Assembly, 1998). However, the content of this package is not clearly specified. The insurance law relies on the National Framework Contract for determining the scope of service under the social health insurance. Moreover, the law provides an opportunity for redefining the package size under the proposal of the health insurance board in order 'to suit the economic circumstances of the country' (WHO-Euro, 1999). The Health Insurance Act appears to be rather general and relies on supplementing regulations (Rose, 1998).

The insurance act clearly determined a transformation of the Bulgarian public health care finance. In particular, the act required separation of the public health care finance from both the State and the health care provision, and formation of a single financial body - the social health insurance. As a result, the financing of the health care system is not derived anymore from the state budget, but from compulsory insurance contributions. The integration between the health care finance and provision is split up and a contract-based relation is established.

The pattern of financial reforms in the Bulgarian public health care sector is not surprising within the post-communist context. It is grounded on specific political arguments, which have been analysed by many authors (e.g. Borisov and Rathwell, 1996; Cichon, 1992; Deppe and Oreskovic, 1996; Ensor, 1993; WHO, 1996). The political strength of the legislated insurance-based finance in the Bulgarian public health care sector, however, does not necessarily imply its success. The important question is whether the new method of public health care finance can actually enhance the performance of the public health care services. In order to analyse this issue, the criteria for appraising the financial reforms (see box 2.1.) is be applied.

\subsection{The potential of the contribution-based financing of the health care system}

Under the health insurance law, the public health care system is financed through compulsory insurance contributions paid for by the insured individuals. In principle, there are no deductions from the general taxation with exception of the transfers comprising the insurance contributions of 
the pensioners and persons with social assistance. From a theoretical point of view, this type of financing of the health care system have some important advantages compared to the previous taxbased financing mechanism. The collected insurance funds are earmarked for health care. It is not possible to redirect health care resources to finance other economic activities with higher government priorities. The insurance-based public health care sector does not need to compete for financial resources with other sectors of the economy. This means no cuts in the health care budget for general budgetary reasons (Cichon and Normand, 1994).

The earmarked health care finance, under the social health insurance, however, 'does not create new money in the economy for health care' (Kanavos and McKee, 1998). It cannot guarantee by itself a sufficient health care budget. Empirical evidence suggests that the size of the health care expenditure in a country is roughly proportional to its economic performance (Vienonen and Wlodarczyk, 1993). Therefore, no matter how the funds are collected, if there is no economic growth the health care budget cannot be increased significantly (D'Intignano, 1992). This means that the implementation of contribution-based financing of the health care system cannot allow for a higher budget for the Bulgarian public health care sector if the country does not achieve significant economic development.

Furthermore, the Bulgarian context provides arguments against the stability of the contributionbased financing of the health care system. The balance of a health insurance fund depends on the ratio between the contributors and the beneficiaries (Cichon and Normand, 1994) and the level of insurance contributions. Bulgarian social health insurance is aimed at providing universal coverage, as legislated in the Health Insurance Act. This means fewer contributors than beneficiaries and potential adverse effects on the balance of the health insurance fund. The contribution-based financing of health care system cannot ensure a stable financial system in case of universal population coverage without external subsidies. Therefore, the social insurance funds are usually supplemented by governmental revenues (WHO, 1992). The Bulgarian insurance act, also, presupposes transfers from the State and the municipalities covering the contributions of the pensioners and unemployed. However, the high unemployment level and the ageing of the population imply a relatively high number of individuals whose contributions should be paid by the State and the municipalities. Thus, the balance of the insurance fund is actually determined by the ability of the central and local authorities to make the required transfers (Rose, 1999, WHO-Euro, 1999). Consequently, the financial stability of the social health insurance fund is highly dependent on the size of public budgets and the political priorities for the allocation of this budget. Insufficient or delayed transfers from the State or the municipalities can result in structural deficits in the system.

Insufficient insurance funds can also occur due to the collection of contributions, which are lower than necessary. In fact, the plausible contribution rates in Bulgaria are only half of what was initially planned, which raises doubts about the future insurance balance. However, the extremely low earnings in Bulgaria explain why the insurance contributions cannot be raised sufficiently.

In addition to the above, the proportion of non-salaried or self-employed workers in small private firms can also influence the level of contribution payments. This type of employees 'can easily escape paying their contributions since their income are less well known' (D'Intignano, 1992). In Bulgaria, as in most countries in transition, the number of small private companies with non-salaried personal is continuously increasing as result of the process of privatisation. If the State fails to determine the real incomes of the employees in the private sector and the self-employed persons, this can potentially result in decreased health insurance obligations. Thus, the financial capacity of the insurance fund can be additionally limited (D'Intignano, 1992; WHO-Euro, 1999). 
It also has to be added that the contribution-based financing of the health care system can have a negative impact outside the health care sector as well. Under the Bulgarian social health insurance, the burden of financing the health care system is shared between the employees and their employers. When the contributions paid by the employers are defined as a percentage of the employees' income, enlarging employment means higher costs to the employers (Cichon and Normand, 1994). Thus, from an economic point of view, employers' health insurance contributions based on the income of the employees provide disincentives for the companies to hire new workers (D'Intignano, 1992). The probability of such a consequence cannot be favourable given the high unemployment rate.

Further, if the company operates in a competitive labour market, payment of health insurance contributions for the employees based on their income can be compensated by decreased net wages of the staff (Cichon and Normand, 1994). The high number of unemployed persons with no or low social security benefits suggest that the unemployed can be willing to work even in case of decreased remuneration. Thus, at the end, the employees pay the full health insurance contribution.

Employers' contributions for health insurance based on the employees' wages can also lead to informal employment in order to avoid contribution payments (Cichon and Normand, 1994; D'Intignano, 1992). According to WHO-Euro (1999), the Bulgarian social security institution has reported 'a worsening trend in tax compliance'. Further, the statistics show that against the background of a continuously changing unemployment rate (between $11 \%$ and $16 \%$ ) during the period 1993-1998, the registered employment remained quite stable at 3.3 - 3.1 million (National Statistical Institute, 1999). This fact suggests either incorrect registration of the unemployed or informal employment in private companies. Thus, the increase of the labour taxes by adding health insurance payments for each staff member can provide an incentive for informal employment.

It can be concluded from the above that the contribution-based financing of the health care system does not guarantee by itself sufficient and stable health care budgets. The size of the health care budget is still dependent on political priorities and economic constraints. The necessary conditions for achieving sustainable financing of the health care system are economic development and improvement of the fiscal system. In such conditions, a tax-based financial system would also have been a stable source of adequate health care revenues. In this sense, reforming the method of financing the Bulgarian health care system was not sufficient to improve the public health care services. Unlike social health insurance, the preservation of the tax-based financing of the health care system would have avoided the additional burden on the labour taxes paid by the employers. This would have been an important advantage for the level and lawfulness of employment. In this sense, the tax-based financing of the health care system would have been a more preferable option.

\subsection{The potential of the contract-based allocation of health care resources}

As it is constituted by the Bulgarian insurance law, the insurance-based health care finance is separated from the health care provision. The relation between the insurer and the health care providers is based on contracts. Thus, health care resources collected by the social health insurer are allocated to the health care providers based on contracts. Theoretically, the contract-based recourse allocation in health care sector offers preconditions for efficiency and good quality. The social health insurer acts as an independent purchaser when contracting with service suppliers. As such, the insurer is motivated to engage in contracts that ensure an efficient use of the allocated resources in order to protect its sustainability. In this sense, it can be expected that a contract-based resource allocation can enhance efficiency in the public health care sector. Furthermore, the contract-based 
funding and remuneration allows the application of the principle of 'money follows the patient'. Therefore, it is possible to empower the patient with the right to make choices between the health care providers. This facilitates competition among providers and provides incentives for quality improvement and patient satisfaction (Cichon and Normand, 1994).

The contract-based relation between the insurer and the health care providers, however, cannot guarantee, by itself, efficiency and good quality in the public health care sector. It is the type of contract and the motivation of the insurer to evaluate the providers' performance, which determines the level of health care efficiency and service quality (Sheiman, 1994). In order to ensure efficiency and good quality a method of competitive contracting should be implemented. The contracts should contain strictly specified requirements on quantity and quality of health care services. A system of careful monitoring of the providers' work has to be established. Furthermore, there should be sufficient information, appropriate management and adequate funding in order to facilitate the contractual process (Savas et al., 1998).

The potential of the contract-based resource allocation, under social health insurance, to enhance efficiency and service quality has been proved by the Western European experience. However, the contract-based social health insurance systems of the advanced European countries resulted in a considerable increase of the health care expenditure. The reason for this failure can be found in the fact that the insurance mechanism does not provide cost controlling incentives. If there are no additional cost-containment arrangements, the most frequent result under social health insurance is unnecessary use, over supply and increased financing requirements of the system. In case of insufficient government control, the insurance institution can 'just increase the contribution rates in order to cover the additional costs' (Cichon and Normand, 1994). Therefore, it is not surprising that the problem of uncontrollable cost increase has been high on the policy agenda in countries with insurance-based health care sectors. Cost explosion under social health insurance has been the experience in Eastern European countries as well. In the Czech Republic and Hungary, for example the period immediately following the introduction of the insurance system has resulted in substantial increases of the health care expenditures (WHO, 1996).

It is true that the current health care expenditures in Bulgaria are quite low compared to the health expenditures of the insurance-based health care systems of Western Europe. The insufficient health care spending in Bulgaria has contributed to the decrease of life expectancy and the increase of infant mortality. However, the correlation between the health indicators and the expenditure level exists only up to a certain level. This can be confirmed by the fact that the relation between health expenditure and health status in advanced European countries is insignificant (D'Intignano, 1992). Furthermore, health care expenditures cannot be left to grow uncontrollably if the fiscal balance and macro-efficiency of the health care system is to be sustained (Preker and Feachem, 1995). For that reason, the implementation of an insurance-based health care finance in Bulgaria also requires the introduction of a cost-controlling mechanism.

In order to avoid a cost explosion in the insurance-based health care sector, appropriate incentives for containing health care expenditures have to be introduced. The expenditure control is typically focused on the behaviour of health care providers. The most frequent cost-controlling measures on the side of the supplier are in form of payment mechanism (e.g. capitation and casebased reimbursement), contracting technique (e.g. block contracts) or mechanisms for restricted capital accumulations (Schwurts et al., 1996). In Bulgaria, supply-side measures to control health care cost is probably be realised, since capitation and case-based reimbursement are considered.

Expenditure control focused on behaviour of health care consumers in terms of cost sharing, however, appears to be ineffective. Evidence from the high-income countries shows that cost- 
sharing measures have limited cost-containing capacity. This is because health care costs are 'primarily driven by supply-side factors' (Kutzin, 1998). This fact should be considered by Bulgarian decision-makers when determining the role of cost sharing and in developing costcontaining measures for the health care sector.

The lack of cost controlling incentives in the insurance mechanism is not the only reason for the high health care expenditure under the insurance-based health care finance. The functioning of the insurance institutions requires a much larger management and administrative staff, compared to a tax-based health care finance (Cichon and Normand, 1994). The larger staff definitely leads to higher administrative cost in the system. The fund management of a contribution-based health care system requires 2 to 4 times more financial resources than the tax-based system (D'Intignano, 1992). The management complexity of the social health insurance is not necessarily a negative feature. As Cichon and Normand (1994) point at, some of the tax-financed health care systems in Western Europe have already introduced administrative structures that resemble those of the social insurance. Yet, the complex insurance administration requires significant financial resources (WHO-Euro, 1999).

It has to be underlined that the reforms in the advanced European countries show that the contract-based allocation of health care resources can be introduced within a tax-based health care system as well. Managed competition between health care providers within a tax-based health care system may also improve health care efficiency and quality. Consequently, a modification of the allocation mechanism in a tax-based health care system can offer similar advantages as the social health insurance. Furthermore, the State controlled financing of a tax-based health care system naturally keeps the expenditures on health care in accordance with the available social resources (D'Intignano, 1992). The above facts imply that the preservation and modification of the tax-based health care system in Bulgaria should have enhanced the public health care performance at lower social cost.

\subsection{The potential effect of the insurance-based finance on health care equity}

The social health insurance in Bulgaria is provided by a single insurance body and covers the entire population of the country. The contributions for social health insurance are compulsory for the working population. The insurance contributions are a percentage of individual income and are related to the individual's ability to pay. Consequently, individuals with higher earnings pay higher insurance contributions. This ensures horizontal equity in financing of the health care (Ensor, 1993). Furthermore, the financial burden of the health care contributions is shared between employees and employers, which decreases the weight of the health care payments for the employees. The nonworking population groups such as unemployed, pensioners and students are covered for free. The Bulgarian insurance mechanism relies on the principle of solidarity - paying for health care according to ability and receiving according to needs. Thus, it appears that under social health insurance there is equal access to health care services for all citizens.

The social health insurance, however, can increase the health care inequity inherited from the tax-based financing of the health care system. There are two main reasons for such a concern.

First, insurance-based health care systems are usually characterised by less equity in the financing of the system compared to health care systems financed by the general revenues (Chinitz et al., 1998; Wagstaff et al, 1992). This is because the contributions for social health insurance are usually determined as a flat percentage of individual income from particular sources and under certain conditions. Thus, unlike the tax-based financing of the health care system, the individual 
contributions for health care under social health insurance are not always calculated on the total individual income. Consequently, individuals with equal total income can have different insurance obligations and high-income individuals can be required to pay a lower proportion of their total income.

Second, under the social health insurance, access to health care is not anymore guaranteed for every citizen like in a tax-based health care system. In an insurance-based health care system the right to health care is determined by the right to insurance (Ensor, 1993; WHO, 1992). This can result in exclusion of some disadvantaged population groups if the authorities cannot or do not pay their contributions (Szalai and Orosz, 1992). A failure to collect the expected contributions can have an adverse effect on equity in the health care sector (Preker and Feachem, 1995). The legislated cost-sharing obligations can also raise financial barriers to the vulnerable population groups in need of health care services.

Reducing inequity in the insurance-based public health care system presupposes well functioning organisations of pressure groups. Such groups do not exist in some of the former planned economies and can be built up only very slowly (Curtis et al., 1992). In addition to this, Bulgarian social health insurance institution relies on the principle of self-governing. The selfgovernance of the heath insurance institution does not allow the pursuit of government policy in the health care sector and can affect the adequacy of the service package (Cichon and Normand, 1994). The absence of direct government control on the health care policy can be seen to some extend as an advantage for a country with incidents of 'political corruption' (Sheiman, 1994). Yet, it has to be kept in mind that the management of the health insurance system does not always have sufficient policy-making capacity. Furthermore, Bulgarian insurance law allows redefinition of the basic insurance package if the economic circumstances in the country change. Thus, under social health insurance, consumer rights to health care are determined by economic and political constraints.

Based on the above it can be expected that the existing inequities in the Bulgarian health care sector may escalate under the social health insurance. Consequently, from an equity perspective, the preservation and modification of the current tax-based health care system would have been a much more preferable option. An improved tax-based system could have enhanced the public health care performance, but could simultaneously have guaranteed access to public health care services for every citizen.

\subsection{The insurance-based health care finance and the socio-economic context}

The political and economic conditions in Bulgaria may frustrate the health insurance reforms. Frequent changes in the ruling party, insufficient resources for reforms, lack of experience with reform implementation, ill-timed introduction and unclear health insurance legislation have pushed back the insurance reforms in the former socialist countries (Curtis et al., 1992; Deppe and Oreskovic, 1996; WHO, 1996). This confirms that the success of any reform has little to do with its content, but with the actual conditions in the country (WHO, 1996).

The introduction of a social health insurance system in a country is a political decision. In case that new governments introduce new political priorities and views about health care finance, the health insurance reforms can fail. Consequently, crucial reforms in the public health care sector can be delayed. It has to be noted that the social health insurance systems in Western Europe were established gradually in conditions of strong political governance (Marree and Groenewegen, 1997; Vienonen and Wlodarczyk, 1993). Although, Bulgaria has currently a stabilised political system 
oriented towards democracy, changes in the ruling party are possible. Thus, the frustration of the health insurance reforms due to political reasons is a plausible option.

An immediate introduction of social health insurance can eliminate the political risk. However, this is not always a feasible option. In Bulgaria, the initial implementation period of one year was doubled and the launch of the social health insurance was still delayed. The major reason for the delay of the insurance implementation was the fact that Bulgaria has not much experience with the practice of health insurance. For comparison, most of the social health insurance systems in Western Europe started their development from an occupation-based insurance and were later extended to universal health care provision. The absence of practical experience in Bulgaria made the development of social health insurance even more challenging.

The establishment of the previously non-existing insurance institution involved huge preparatory work, especially for the development of a reliable information system. Furthermore, the social health insurance system required experienced human capacity and managerial skills, which were not readily available in Bulgaria. The necessary insurance staff had to be educated and trained. This made the implementation process difficult and slow. Therefore, the launch of the health insurance system was postponed once with a period of six months, although the collection of contributions had already been initiated (WHO-Euro, 1999). In addition to the preparation, the establishment of the social health insurance institution required significant financial resources, particularly for building the infrastructure and for training the staff. However, the economic recession in the country frustrated the collection of the necessary implementation budget. Although it was not clearly recognised by the authorities, the lack of resources was a major reason for a second six-months postponement of the actual implementation of the health insurance system.

Two more factors can frustrate the functioning of the social health insurance. First, the legislation on health insurance is rather general and relies on additional arrangements. If the supplements to the insurance act do not provide strict directions, the introduction of the insurance reforms depends on individual interpretations of the legislation. Second, insufficient public information about the financial reform in the public health care sector can result in a meagre public support. A lack of adequate public support can cause failure in the process of reforms (WHO, 1996). It can be concluded from the above that the insurance-based financing system in Bulgarian can be easily frustrated by political and economic factors. If this happens, the Bulgarian health care sector can further deteriorate. In this sense, modification of the existing tax-based system could have been a much more feasible option for reform than the establishment of an insurance-based finance.

\subsection{Conclusions}

From the foregoing discussion, it becomes clear that the insurance-based health care finance, legislated in Bulgarian insurance act of 1998, provides, in principle, a basis for improving microefficiency and quality of the public health care services. However, this type of health care finance can cause an uncontrollable cost increase and can have a negative impact on the equity in the public health care sector. Furthermore, the economic recession, low employment rate, unstable fiscal system and the incidents of informal employment do not allow for sufficient and stable financing of the health care system even under the insurance mechanism. Besides, the insurance-based financing of the health care system can negatively affect the level and conditions of employment in the country. These analytical conclusions suggest that, at present, the implemented insurance-based health care finance is not beneficial for the Bulgarian society. Moreover, its implementation seems 
to be irrational at this stage of the Bulgarian economic development due to a lack of sufficient financial resources.

Thus, the tax-based financial mechanism of the public health care services should have been retained at least until there are suitable economic circumstances in the country. The preservation of the tax-based health care finance would not mean that modification of the allocation mechanism also had to be postponed. The introduction of managed competition between the suppliers in the tax-based system could have enhanced efficiency, quality and patient satisfaction.

With increased economic growth rates, decreased unemployment and stable fiscal system, the benefits and feasibility of a social health insurance could have been re-examined and the insurance implementation might have been tested locally. Such assessment could have determined whether the introduction of an insurance-based health care finance was essential and feasible in the public health care sector. Furthermore, the analysis of local trials could also have revealed whether the implementation of social health insurance was acceptable for the population. This incremental and flexible approach to the financial reform in the Bulgarian public health care sector would have offered greater advantages. Importantly, the social health insurance system could have been extended to the country as a whole only if the social and economic conditions were suitable for it. In this sense, the financial reform in the Bulgarian public health care sector should have been a part of the broader socio-economic reforms in the country.

\section{References:}

Borisov, V. and Rathwell, T. (1996). Health care reforms in Bulgaria: an initial appraisal. Social Sciences and Medicine 42 (11): 1501-1510.

Chinitz, D. Preker, A. and Wasem, J. (1998). Balancing competition and solidarity in health care financing. In: Saltman, R.B., Figueras, J. and Sakellarides, C. (eds.). Critical Challenges for Health Care Reform in Europe. Buckingham: Open University Press.

Cichon, M. (1992). Development of health insurance. Consultation on Health Care Reform in the CCEE. ICP/PHC 210/7 8323n. Copenhagen: The World Health Organization/Regional Office for Europe.

Cichon, M. and Normand, C. (1994). Between Beveridge and Bismark - options for health care financing in Central and Eastern Europe. World Health Forum 15: 323-328.

Curtis, S., Petukhova, N. and Taket, A. (1992). Health care reform in Russia: the example of St.Petersburg. Social Science and Medicine 40: 755-765.

Deacon, B. and Vidinova, A. (1992). Social Policy in Bulgaria. In: Deacon B, (ed.). The new Eastern Europe: social policy past, present and future. London: Sage Publications.

Delcheva, E., Balabanova, D. and McKee, M. (1997). Under-the-counter payments for health care: evidence from Bulgaria. Health Policy 42: 89-100.

Deppe, H.-U. and Oreskovic, S. (1996). Back to Europe: back to Bismark?. International Journal of Health Services 26 (4): 777-802.

D'Intignano, B.M. (1992). Health care finance in Europe. EUR/RC42/Tech.Disc./1 0519K. Copenhagen: The World Health Organization/Regional Office for Europe. 
Ensor, T. (1993). Health system reform in former socialist countries of Europe. International Journal of Health Planning and Management 8: 169-187.

Ivanov, L., Glutnokova, Z. and Kalinov, K. (1996). Sociological survey: adequacy and quality of primary health care. Bulletin of National Centre of Public Health 1 (December): 47-78.

Kanavos, P. and McKee, M. (1998). The context for health reform. In: Saltman, R.B., Figueras, J. and Sakellarides, C. (eds.). Critical Challenges for Health Care Reform in Europe. Buckingham: Open University Press.

Kutzin, J. (1998). The appropriate role for patient cost-sharing. In: Saltman, R.B., Figueras, J. and Sakellarides, C. (eds.). Critical Challenges for Health Care Reform in Europe. Buckingham: Open University Press.

Marree, J. and Groenewegen, P.P. (1997). Back to Bismark: Eastern European health care systems in transition. Aldershot: Avebury.

McKee, M. (1991). Health services in Central and Eastern Europe: past problems and features. Journal of Epidemiology and Community Health 45: 260-265.

McKinsey, K. (1997). Bulgaria / Romania: a study of two falling health - care systems. http://www.rferl.org/nca/features/1997/05/F.RU.97052090817.html, 20 May, 1997.

Minev, D., Dermendjieva, B. and Mileva, N. (1990). The Bulgarian country profile: the dynamics of some inequalities in health. Social Sciences and Medicine 31 (8): 837-846.

National Statistical Institute (1999). Statistical Yearbook 1999 (in Bulgarian). Sofia: National Statistical Institute.

Preker, A.S. and Feachem, R.G.A. (1995). Market mechanisms and the health sector in Central and Eastern Europe. World Bank Technical Paper 293. Washington: The World Bank.

Rose, L. (1998). Nobody has an interest in an increased insurance burden (in Bulgarian). An interview taken by A. Aleksova. Capital 15-21 June: 31 .

Savas, S., Sheiman, I., Tragakes, E. and Maarse, H.(1998). Contracting models and provider competition. In: Saltman, R.B., Figueras, J. and Sakellarides, C. (eds.). Critical Challenges for Health Care Reform in Europe. Buckingham: Open University Press.

Schaapveld, K., Krleza-Jeric, K. and Stiphout, J.G.A. (1995). Management aspects of the Bulgarian health care reforms. TNO Report PG 95.075. Leiden: TNO Prevention and Health.

Schwarts, F.W., Glennerster, H. and Saltman, R.B. (1996). Introduction. In: Schwarts, F.W., Glennerster, H. and Saltman, R.B. (eds.). Fixing Health Budgets: Experience from Europe and North America. Chichester: John Wiley.

Sheiman, I. (1994). Forming the system of health insurance in the Russian Federation. Social Science and Medicine 39 (10): 1425-1432.

Szalai, J. and Orosz, E. (1992). Social policy in Hungary. In: Deacon, B. (ed.). The new Eastern Europe: social policy past, present and future. London: Sage Publications.

The 38th National Assembly (1998). The health insurance act. Sofia: The 38th National Assembly.

Vienonen, M.A. and Wlodarczyk, W.C. (1993). Health care reform on the European scene: evolution, revolution or seesaw?. World Health Statistics Quarterly 46: 166-169. 
Vodenitcharov, T. and Borissov, V. (1995). The health system and policy in Bulgaria: problems and trend s. Cahiers de Sociologie et de Demographie Medicales 32 (2-3): 177-190.

Wagstaff, A., van Doorslaer, E, Calonge, S. et al. (1992). Equity in the finance of health care: some $_{\mathrm{e}}$ international comparisons. Journal of Health Economics 11: 361-381.

WHO (1992). Organization and financing of health care reform in countries of Central and Eastern Europs. Journal d'Economie Medicale 10 (1/2): 5-40.

WHO (1996). European health care reforms: analysis of current strategies. Copenhagen: The World Health Organization/Regional Office for Europe.

WHO-Euro (1999). Better health for better future in Bulgaria: a health policy proposal. Draft 2. Unedited $23^{\text {rd }}$ February, 1999. 


\section{CHAPTER 3}

\section{Public attitudes towards patient payments in the Bulgarian public health care sector}

Published as:

Pavlova, M., Groot, W. and van Merode, G. (2002). Public attitudes towards patient payments in Bulgarian public health care sector: results of a household survey. Health Policy 59: 1-24. 


\subsection{Introduction}

About a decade ago, the subject of patient payments in Bulgaria would have been in conflict with the socio-political circumstances in the country. At that time, free-of-charge provision of health care to the whole population was considered as one of the greatest achievements and responsibilities of the communist government. After the abolishment of the communist rule, the potential of patient charges in Bulgaria was reconsidered and formally settled. Directive No22 of 9.12.1997 legislated fees in the public health care sector. The charges apply to all patients who wish to use a different provider or facility than the one they are referred to or wish to skip the primary health care level. The fees cannot be charged for hospital care after the tenth day, as well as for check-ups and tests (Ministry of Health care, 1998). The Health Insurance Act of 4.06 .1998 settled patient payments for using health care services under the Bulgarian social health insurance. Fees are charged for a visit to a doctor or dentist and for each day of hospital care, with a limit of 20 days a year. These charges do not apply to chronically-sick persons, miners, children, unemployed, conscripts, war veterans/invalids, persons under arrest/prisoners and persons with low or no income (The $38^{\text {th }}$ National Assembly, 1998). According to both regulations, the fees should be paid to the provider or the health care facility directly.

Officially, the system of patient payments in Bulgaria aims to enhance the efficiency of health care utilisation (Editorial Team of Capital, 1998). The contribution of fees to the achievement of this objective has not been sufficiently studied. Hitherto, the empirical evidence indicates that patient payments might improve health care use only when combined with supply-side measures. Such measures include the introduction of 'gate-keepers' to specialised care and cost sharing on the provider side (Ros et al., 2000; WHO, 1996).

Despite the official objective, however, the slashed health budget in Bulgaria suggests that patient payments might acquire 'more a fund raising dimension than a deterrent against overuse' (WHO-Euro, 1999). Yet, there is little scope for applying health care charges as a financing strategy at a national level. The advantage of a nation-wide payment schemes will most probably be absorbed by the administration costs. The evidence implies that fees are more successful as an additional financing for local health care structures (Bennett and Ngalande-Banda, 1994; Creese, 1991; Litvack and Bodart, 1993; Creese and Kutzin, 1995).

In Bulgaria, official patient charges might be also seen as a tool to regulate the widely spread informal payments (Delcheva et al., 1997). The success of such objective is, however, doubtful. The solution to the problem of illegal payments is primarily a question of an adequate supply and provider remuneration. The introduction of official fees without eliminating the informal ones can increase the financial burden for consumers (WHO, 1996).

Irrespective of the policy objectives, the implementation of patient payments causes a change in the financing of the health care system. As a result, it can influence the overall efficiency and equity of the system (Creese, 1991). Although the impact on efficiency is disputable, it is commonly believed that patient payments can have adverse effects on equity (Rubin and Mendelson, 1995; WHO, 1996). Generally, equity means paying according to ability and receiving according to need, whereas patient payments imply fees related to health status and access determined by income. This implies inequity in both access and financing of the health care system. In particular, patient payments can preclude health care use by low-income people and those in frequent need of care. Patient payments can also cause a greater financial burden on poor than on wealthier (Huber, 1993; Sprinkle, 1994; Street et al., 1997; Wagstaff and Doorslaer, 1992; WHO, 1996). Due to these essential drawbacks, patient fees often lead to scientific and political debates (WHO, 1996). 
While the scientific and political views on this issue are widely known and published, societal attitudes towards fees in the public health care sector have rarely been studied (Arubjerg et al., 1996; Gooder et al., 1993). The lack of research in this field can be a major disadvantage in the design and the implementation of the patient payments (Delcheva et al., 1997). In particular, the neglect of the public views in the design process can result in a payment mechanism that lacks an overall public acceptance. The implementation of such mechanism can be impeded even in case of political will and providers conformity (Delcheva et al., 1997; Gilson et al., 1995; Shaw and Griffin, 1995). In view of this, the study of the public attitudes towards patient charges is an important part of the development of an adequate payment mechanism.

Thus, in Bulgaria, where patient charges are currently being implemented, a study of societal attitudes to the design of patient payments is essential. However, little is known in this respect. The present paper aims to provide the first broad study of public attitudes towards patient payments in Bulgaria. The attention is focused on four aspects of patient payment mechanisms considered as highly relevant for policy analysis (e.g. Bennett and Ngalande-Banda, 1994; WHO, 1996; Kutzin, 1995, Lee, 1989). These aspects include the services under payment, the type of the payments, the beneficiaries of the payments, and the system of exemptions. In order to achieve this aim, data from a household survey are used. The paper first outlines the survey methodology, the features of the sample and the method of analysis. Next, the results on the sample and the sample groups are reported and discussed. The paper concludes by drawing implications for Bulgarian health policy.

\subsection{Survey methodology}

The data in this survey were collected through interviews based on a standardised questionnaire. The questionnaire was tested in a pilot study. The main survey was conducted in May and June 2000 by the interviewer staff of APEA BBSS Gallup International - Varna. The sample was drawn from municipalities in the city of Varna (the third largest city in Bulgaria) and in other small towns and villages in this region. The method of two-stage random selection was used - first selecting the municipality and then selecting respondents from particular age-gender groups. The respondents were chosen in proportion to the urban/rural distribution and the age-gender characteristics of the population in the region. The overall response rate is $90.5 \%$.

Part of the data collected in this survey shows the opinion of the respondents regarding the design of patient payment mechanism. In particular, the survey results disclose respondents' views on the services under payment, the type and the beneficiary of the payments, and the system of exemptions.

Three groups of services are studied: outpatient, inpatient and dental care. By "outpatient", it is meant those services that are provided in a physicians' office or an ambulatory setting (Getzen, 1997). In this paper, outpatient care refers to services of a general practitioner, medical specialist, medical laboratory and nurse at patient's home. The term "inpatient" is used to denote services provided in a hospital, sanatorium or nursing home (Getzen, 1997). Inpatient care is represented here by hospital services (maternity care, operations and physiotherapy), physiotherapeutic services outside hospital and emergency care. Finally, in case of dental care, check-ups, treatments, extractions and placement of prostheses are considered.

The opinions in the sample regarding payments for the three service groups are found out by respondents' answers to questions on willingness and ability to pay. The respondents are asked to indicate the amount of money that they are willing and able to pay in order to use a particular health care service provided with good quality and quick access. The wording of the questions is presented 
in appendix A (questions Q11 $\div$ Q18). The exact amounts of money people are willing and able to pay are not analysed in this paper. It is assumed that respondents who state a zero amount for a specific health care service do not accept to pay for it and those who state a non-zero amount agree with charges for that service.

In addition to the questions on specific services, a general willingness-and-ability-to-pay question is posed. Specifically, the respondents are asked to state the amount of money they are willing and able to pay from their family budget per year in order to use health care services with good quality and quick access (see appendix A, Q19). It is supposed that respondents who give a zero reply to this question in general do not agree to pay for public health care services and those who provide non-zero answers accept to pay.

For all willingness-and-ability-to-pay questions, the answers are transformed into binary response variables. The answers containing zero amounts are coded as "l" and the answers with non-zero amounts are coded as " 2 ".

Regarding the type of patient payment, the respondents were asked whether the size of patient charges should be related to the actual service cost and to its quality (see appendix A, Q21 $\div$ Q22). The respondents are further questioned whether these payments should be limited. Those respondents who approve of limitations are presented with three different methods (limitation per year, per service utilisation and per income) and are asked about the methods they prefer (see appendix A, Q23). The above questions are used instead of a direct inquiry about the appropriate type of patient payments (e.g. co-payment, co-insurance, deductibles). The pilot survey revealed that respondents are often not able to discriminate between the different types of patient payment even after detailed explanations. This is, most probably, due to lack of experience with different types of co-payments.

The opinions about the appropriate beneficiary of the fees are obtained by presenting the interviewed with four alternatives and asking them to select the most preferred. These alternatives include the physician who provides the service, the institution where the service is provided, the municipality or the health insurance fund (see appendix A, Q24). The list of alternatives is based on a literature review.

Regarding the system of exemptions, the respondents are asked to state their opinion regarding the exclusion of six vulnerable population groups. These groups include children, pensioners, unemployed, chronically sick, pregnant women and disabled people. A multiple choice among the categories is allowed. The option of no exemptions is also included (see appendix A, Q25). The questionnaire includes only these six categories, since the pilot survey did not suggest any other relevant exemptions.

The respondents' answers about the payment types, beneficiaries and exemptions are also transformed into binary response variables. The negative replies are coded as "1" and the positive are denoted as " 2 ".

Thus, all responses regarding the design of the patient payment mechanism are transformed into binary variables. Following the latent variable model (e.g. Long, 1997), it is assumed that the observed response variables are generated by unobserved attitude variables. Thus, a positive opinion is observed if the value of the unobserved attitude variable is larger than a threshold point. When the unobserved attitude variable is smaller than this threshold, the observed opinion is negative (Long, 1997).

In order to identify the model, it is necessary to make an assumption about the threshold point. It is supposed here that this point equals zero. Thus, a positive answer corresponds to a positive attitude and a negative answer to a negative attitude. 


\subsection{Sample characteristics}

The survey gathered data on the respondents' age, gender, education, occupation, perceived health, marital status and place of residence. The respondents were also asked about their family size, number of under-aged, chronically ill and working persons in their families, as well as about their net family budget per month. Data for occupation, marital status, number of under-aged and working family members are excluded from the analysis due to their strong correlation with other socio-demographic features, i.e. a bivariate correlation coefficient higher than 0.5 at significance level lower than 0.05 (see appendix C.2). Information on the socio-demographic variables included in the analysis is presented in appendix C.3.

The average age of the interviewed persons is about 46 years. The sample is evenly divided among the gender groups. The majority of the respondents reside in a big city and only about one third live in small towns or villages. Half of the sample has completed 10-12 years of education and the rest is split between lower and higher education. Most often, respondents perceive themselves as healthy. The respondents' families include on average three household members and less than one chronically sick individual. The mean family budget per month is around 235 Bulgarian levas (BGL). One BGL equals approximately half Euro.

\subsection{Method of statistical analysis}

Given the binary nature of the dependent response variables, non-parametric statistical analysis is used. Due to the independence of the observations within each dependent variable, the MannWhitney $\mathrm{U}$ test is applied to detect significant differences between the opinions of various social groups and the rest of the sample (Norušis, 1998; Siegel, 1988). These groups include the elderly, female, low educated, unhealthy, respondents living in rural areas, alone, in families with chronically sick persons and low family budget. The significant differences in the opinions are analysed in order to outline the variations in the underlying attitudes.

In order to estimate the impact of the social variables on the approval of fees for health care services, binary logistic regression is applied. The regression coefficients $\beta$ determine the probability that an individual with social status $x$ will accept paying fees, i.e. $y=2$. This probability is given by equation (3.1):

$$
\operatorname{Pr}(y=2 \mid x)=\frac{\exp (x \beta)}{1+\exp (x \beta)}
$$

The net effect $\Delta$ of a socio-demographic variable $x_{k}$ on the probability that an individual will accept paying fees for a service is calculated when the variable changes from its minimum $x_{k}{ }^{\min }$ to its maximum $\mathrm{x}_{\mathrm{k}}^{\max }$ and all other variables are at their average values. The calculation is based on equation (3.2),

$$
\frac{\Delta \operatorname{Pr}(\mathrm{y}=2 \mid \mathrm{x})}{\Delta \mathrm{x}_{\mathrm{k}}^{\text {range }}}=\operatorname{Pr}\left(\mathrm{y}=2 \mid \mathrm{x}, \mathrm{x}_{\mathrm{k}}^{\max }\right)-\operatorname{Pr}\left(\mathrm{y}=2 \mid \mathrm{x}, \mathrm{x}_{\mathrm{k}}^{\min }\right)
$$

A theoretical background for the above formulas and their interpretation can be found in Long (1997). The net effects of the socio-demographic variables on the respondents' opinions are 
compared. The impact of each socio-demographic variable on the underlying attitude towards paying fees is discussed.

\subsection{Survey results}

The valid percentage of respondents who approve of charges for public health care in general and for particular services are presented in table 3.1 . The table shows that nearly $81 \%$ of the respondents accept to pay for public health care in general if it is provided with good quality and quick access.

Regarding the particular services, the data in the table suggest that on average the fees for outpatient and dental services receive a higher acceptance than the inpatient services. With respect to outpatient care, nearly $85 \%$ of the total sample agrees to pay for specialist services and approximately $77 \%$ accept fees for services of a general practitioner and medical laboratory. About $70 \%$ of the sample tolerates charges for nursing care at patient's home. Regarding dental care, only $68 \%$ of the interviewed agree to pay for check-ups and around $80 \%$ approve of payments for treatments, extractions and placement of prostheses. Concerning the inpatient care, about 8 out of 10 respondents are prepared to pay for hospital operations, whereas for physiotherapeutic procedures inside or outside a hospital this number is about 7 out of 10 respondents. In case of emergency and maternity care, the approval of charges is the lowest. The agreement amounts to less than $58 \%$ and slightly more than $60 \%$ of the sample respectively. Regarding the maternity services, only the opinions of the female respondents are gathered since the questions refer to service used by the respondents themselves. In order to outline the overall sample agreement with charges for the particular health care services, the share of respondents willing and able to purchase at least one of the services is calculated. The result shows that more than $95 \%$ of sample accepts payment for at least one of the services. Compared with the above-mentioned agreement of the sample to pay for public health care in general, this result is considerably higher. This is because about $13 \%$ of the respondents disapprove of paying for public health care in general but agree to pay for at least one health care services. The reverse situation is also registered. Three respondents accept in principle to pay for health care, but do not approve of paying for any health care services mentioned in the survey.

Table 3.1 also presents the valid percentage of respondents in different socio-demographic groups who approve of charges for public health care in general and for particular health care services. These percentages show that all social groups in this survey, more or less, accept to be charged.As indicated in the table, however, some socio-demographic groups constantly exhibit a significantly lower agreement with charges for the particular services compared to the rest of the sample. These are respondents, who are older than 60 years, low educated, unhealthy, living alone, with chronically ill family members and a low family budget. In addition, the cross tabulation of the results shows that the group with the highest family income virtually never expresses a negative opinion regarding charges for public health care services.

In order to compare the effect of the socio-demographic characteristics on the respondents' opinions regarding patient payments a regression analysis is performed. Table 3.2 presents the estimated regression parameters, the standard errors of their estimates and the total impact of the socio-demographic variable. The signs of the regression parameters indicate the direction of the relation between the opinions in the sample regarding fees and the socio-demographic variables. A positive sign implies that when a social factor increases more respondents agree with certain payment and vice verse. A regression parameter with a negative sign suggests that the level of respondents' agreement is decreased by an increase of that factor. 
Table 3.1. Valid percent of respondents who approve of fees for public health care services

\begin{tabular}{|c|c|c|c|c|c|c|c|c|c|c|c|c|c|c|c|c|c|c|}
\hline & & \multirow[b]{2}{*}{ 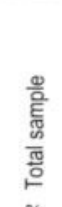 } & \multicolumn{2}{|c|}{$\begin{array}{l}\text { Gender } \\
\text { groups }\end{array}$} & \multicolumn{2}{|c|}{$\begin{array}{c}\text { Age } \\
\text { groups }\end{array}$} & \multicolumn{2}{|c|}{$\begin{array}{l}\text { Education } \\
\text { groups }\end{array}$} & \multicolumn{2}{|c|}{$\begin{array}{c}\text { Groups by } \\
\text { perceived health }\end{array}$} & \multicolumn{2}{|c|}{$\begin{array}{l}\text { Groups by } \\
\text { residence place }\end{array}$} & \multicolumn{2}{|c|}{$\begin{array}{l}\text { Groups by } \\
\text { family size }\end{array}$} & \multicolumn{2}{|c|}{$\begin{array}{l}\text { Groups by sick } \\
\text { family members }\end{array}$} & \multicolumn{2}{|c|}{$\begin{array}{c}\text { Groups by } \\
\text { family budget }\end{array}$} \\
\hline \multirow{2}{*}{\multicolumn{2}{|c|}{ Approve of fees for: }} & & $\frac{\frac{0}{10}}{2}$ & 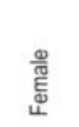 & 응 & 竞 & $\begin{array}{l}\text { 유 } \\
\text { 을 }\end{array}$ & 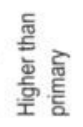 & 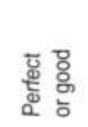 & 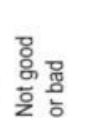 & 要 & ल & 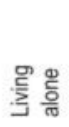 & 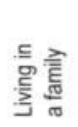 & 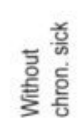 & 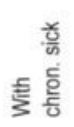 & 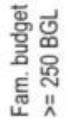 & 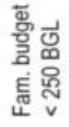 \\
\hline & & $\%$ & $\%$ & $\%$ & $\%$ & $\%$ & $\%$ & $\%$ & $\%$ & $\%$ & $\%$ & $\%$ & $\%$ & $\%$ & $\%$ & $\%$ & $\%$ & $\%$ \\
\hline \multicolumn{2}{|c|}{ Health care } & 80.7 & 80.4 & 80.9 & 85.3 & $68.0^{\prime}$ & 69.1 & $84.5^{1}$ & 87.1 & $72.1^{1}$ & 80.5 & 80.3 & 69.4 & $82.1^{1}$ & 86.2 & $74.0^{1}$ & 93.8 & $77.1^{1}$ \\
\hline \multirow{4}{*}{ 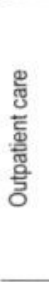 } & $\begin{array}{l}\text { Services of general } \\
\text { practitioner }\end{array}$ & 77.5 & 79.7 & 75.4 & 83.0 & $61.0^{\prime}$ & 66.7 & $66.7^{1}$ & 83.1 & $69.7^{1}$ & 78.0 & 75.0 & 62.7 & $79.3^{1}$ & 81.2 & $72.9^{1}$ & 91.0 & $73.8^{1}$ \\
\hline & $\begin{array}{l}\text { Services of medical } \\
\text { specialist }\end{array}$ & 84.8 & 85.4 & 84.3 & 89.8 & $70.7^{1}$ & 75.1 & $88.1^{1}$ & 88.5 & $79.9^{1}$ & 84.8 & 84.9 & 68.2 & $86.9^{1}$ & 87.8 & $81.2^{1}$ & 96.6 & $81.9^{1}$ \\
\hline & $\begin{array}{l}\text { Laboratory } \\
\text { services }\end{array}$ & 76.3 & 79.6 & $73.3^{1}$ & 81.9 & $59.7^{\prime}$ & 63.3 & $80.7^{\prime}$ & 81.7 & $68.9^{1}$ & 77.4 & 71.3 & 63.0 & $78.0^{1}$ & 80.6 & $71.2^{1}$ & 92.7 & $71.8^{1}$ \\
\hline & $\begin{array}{l}\text { Nursing care } \\
\text { at patient's home }\end{array}$ & 68.7 & 70.7 & 66.9 & 73.8 & $52.8^{1}$ & 62.7 & $70.8^{1}$ & 73.0 & $62.9^{1}$ & 70.1 & $62.2^{1}$ & 50.9 & $71.0^{1}$ & 73.4 & $63.0^{1}$ & 79.3 & $66.1^{1}$ \\
\hline \multirow{5}{*}{ 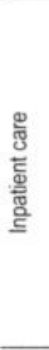 } & $\begin{array}{l}\text { Maternity care } \\
\text { in hospital }\end{array}$ & 60.5 & .2 & 60.5 & 67.5 & $69.7^{1}$ & 46.4 & $64.2^{1}$ & 67.6 & $51.2^{1}$ & 63.0 & $48.1^{1}$ & 28.8 & $64.5^{1}$ & 67.1 & $52.0^{1}$ & 76.0 & $56.0^{1}$ \\
\hline & $\begin{array}{l}\text { Hospital } \\
\text { operations }\end{array}$ & 78.6 & 83.0 & $74.6^{1}$ & 85.6 & $58.1^{1}$ & 65.0 & $83.1^{1}$ & 85.8 & $68.4^{1}$ & 80.0 & $72.1^{1}$ & 60.0 & $80.9^{1}$ & 83.1 & $73.1^{1}$ & 92.2 & $74.8^{1}$ \\
\hline & $\begin{array}{l}\text { Hospital } \\
\text { procedures }\end{array}$ & 69.0 & 71.0 & 67.2 & 76.2 & $48.4^{\prime}$ & 55.9 & $73.4^{1}$ & 76.7 & $58.4^{1}$ & 70.0 & 64.3 & 50.0 & $71.4^{1}$ & 74.9 & $61.9^{1}$ & 84.5 & $64.6^{\prime}$ \\
\hline & $\begin{array}{l}\text { Sanatorium } \\
\text { procedures }\end{array}$ & 71.2 & 74.9 & $67.8^{1}$ & 77.7 & $51.9^{\prime}$ & 55.2 & $76.4^{\prime}$ & 78.8 & $60.7^{1}$ & 72.5 & 65.1 & 54.6 & $73.2^{1}$ & 76.5 & $64.7^{1}$ & 86.7 & $66.9^{1}$ \\
\hline & $\begin{array}{l}\text { Emergency } \\
\text { care }\end{array}$ & 57.7 & 60.2 & 55.4 & 62.9 & $42.4^{1}$ & 46.4 & $61.5^{1}$ & 64.2 & $48.7^{1}$ & 58.6 & 53.5 & 43.1 & $59.5^{1}$ & 62.2 & $52.2^{1}$ & 70.0 & $54.4^{1}$ \\
\hline \multirow{4}{*}{ 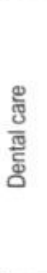 } & $\begin{array}{l}\text { Dental } \\
\text { check-ups }\end{array}$ & 67.8 & 69.1 & 66.6 & 73.8 & $49.2^{1}$ & 53.2 & $72.7^{\prime}$ & 74.6 & $58.3^{1}$ & 69.1 & 61.6 & 55.6 & $69.3^{1}$ & 74.4 & $59.8^{1}$ & 81.1 & $643^{1}$ \\
\hline & $\begin{array}{l}\text { Dental treatments } \\
\text { or fillings }\end{array}$ & 82.3 & 84.6 & 80.1 & 89.3 & $61.2^{1}$ & 68.3 & $87.0^{1}$ & 88.9 & $73.2^{1}$ & 82.3 & 82.4 & 66.4 & $84.2^{1}$ & 88.0 & $75.3^{1}$ & 95.7 & $78.9^{1}$ \\
\hline & $\begin{array}{l}\text { Dental } \\
\text { extractions }\end{array}$ & 80.3 & 82.7 & 78.2 & 86.7 & $61.2^{1}$ & 68.3 & $84.4^{\prime}$ & 86.4 & $71.9^{1}$ & 80.3 & 80.6 & 62.6 & $82.5^{\prime}$ & 85.2 & $74.4^{\prime}$ & 93.5 & $76.8^{1}$ \\
\hline & $\begin{array}{l}\text { Placement of } \\
\text { dental prostheses }\end{array}$ & 80.6 & 83.8 & $77.8^{1}$ & 86.0 & $66.1^{1}$ & 70.3 & $84.1^{\prime}$ & 86.3 & $73.1^{1}$ & 81.0 & 79.0 & 61.9 & $85.9^{1}$ & 85.1 & $75.2^{1}$ & 93.3 & $77.4^{1}$ \\
\hline
\end{tabular}

The percentages of respondents who are willing and able to pay in the two subgroups are statistically different at significance level p<0.05 (Mann-Whitney $U$ test)

${ }^{2}$ Only the female respondents were questioned with regards to hospital maternity care 
Table 3.2. Results from binary logistic regression

\begin{tabular}{|c|c|c|c|c|c|c|c|c|c|c|c|c|c|c|c|}
\hline & & \multicolumn{14}{|c|}{ Approval of fees for different public health care service: } \\
\hline & & \multirow[b]{2}{*}{ 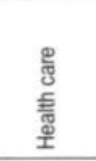 } & \multicolumn{4}{|c|}{ Outpatient care } & \multicolumn{5}{|c|}{ Inpatient care } & \multicolumn{4}{|c|}{ Dental care } \\
\hline & & & 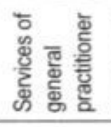 & 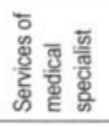 & 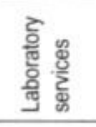 & 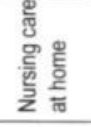 & 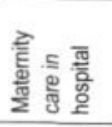 & 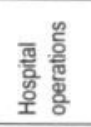 & 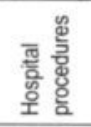 & 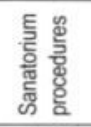 & 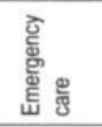 & 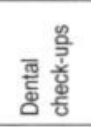 & 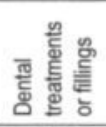 & 릉 & 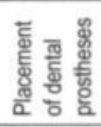 \\
\hline Constant & $\begin{array}{l}\text { parameter } \\
\text { std. error }\end{array}$ & $\begin{array}{c}2.239^{1} \\
0.608\end{array}$ & $\begin{array}{c}1.685^{\prime} \\
0.565\end{array}$ & $\begin{array}{c}1.8591 \\
0.667\end{array}$ & $\begin{array}{l}1.6981 \\
0.561\end{array}$ & $\begin{array}{l}1.062^{\prime} \\
0.492\end{array}$ & $\begin{array}{l}1.846^{1} \\
0.782\end{array}$ & $\begin{array}{l}2.4621 \\
0.603\end{array}$ & $\begin{array}{l}1.103^{1} \\
0.507\end{array}$ & $\begin{array}{l}1.244^{\prime} \\
0.526\end{array}$ & $\begin{array}{l}0.556 \\
0.463\end{array}$ & $\begin{array}{l}1.771^{1} \\
0.501\end{array}$ & $\begin{array}{c}2.4331 \\
0.667\end{array}$ & $\begin{array}{l}1.9631 \\
0.628\end{array}$ & $\begin{array}{l}1.270^{\prime} \\
0.613\end{array}$ \\
\hline $\begin{array}{l}\text { Respondent } \\
\text { gender } \\
\text { (male } \rightarrow \text { female) }\end{array}$ & $\begin{array}{l}\text { parameter } \\
\text { std. error } \\
\text { net effect }\end{array}$ & $\begin{array}{l}-0.105^{1} \\
0.177 \\
-0.014\end{array}$ & $\begin{array}{l}0.145 \\
0.165 \\
0.021\end{array}$ & $\begin{array}{l}-0.011 \\
0.194 \\
-0.001\end{array}$ & $\begin{array}{l}0.287 \\
0.164 \\
0.034\end{array}$ & $\begin{array}{l}0.121 \\
0.144 \\
0.023\end{array}$ & .2 & $\begin{array}{l}0.4441 \\
0.173 \\
0.040\end{array}$ & $\begin{array}{l}0.096 \\
0.178 \\
0.019\end{array}$ & $\begin{array}{l}0.308^{1} \\
0.155 \\
0.046\end{array}$ & $\begin{array}{l}0.125 \\
0.136 \\
0.030\end{array}$ & $\begin{array}{l}0.053 \\
0.146 \\
0.011\end{array}$ & $\begin{array}{l}0.259 \\
0.189 \\
0.022\end{array}$ & $\begin{array}{l}0.223 \\
0.177 \\
0.026\end{array}$ & $\begin{array}{l}0.361 \\
0.179 \\
0.034\end{array}$ \\
\hline $\begin{array}{l}\text { Respondent } \\
\text { age } \\
(18 \rightarrow 85 \text { years })\end{array}$ & $\begin{array}{l}\text { parameter } \\
\text { std. error } \\
\text { net effect }\end{array}$ & $\begin{array}{l}-0.014 \\
0.006 \\
-0.133\end{array}$ & $\begin{array}{l}-0.011 \\
0.006 \\
-0.104\end{array}$ & $\begin{array}{c}-0.024^{1} \\
0.007 \\
-0.176\end{array}$ & $\begin{array}{l}-0.013 \\
0.006 \\
-0.097\end{array}$ & $\begin{array}{l}-0.006 \\
0.005 \\
-0.075\end{array}$ & $\begin{array}{l}-0.042 \\
0.008 \\
-0.605\end{array}$ & $\begin{array}{l}-0.026^{1} \\
0.006 \\
-0.153\end{array}$ & $\begin{array}{l}-0.011^{1} \\
0.005 \\
-0.149\end{array}$ & $\begin{array}{l}-0.012 \\
0.005 \\
-0.114\end{array}$ & $\begin{array}{l}-0.009 \\
0.005 \\
-0.143\end{array}$ & $\begin{array}{l}-0.016 \\
0.005 \\
-0.220\end{array}$ & $\begin{array}{l}-0.0271 \\
0.007 \\
-0.163\end{array}$ & $\begin{array}{l}-0.024^{1} \\
0.006 \\
-0.198\end{array}$ & $\begin{array}{l}-0.007 \\
0.006 \\
-0.040\end{array}$ \\
\hline $\begin{array}{l}\text { Respondent } \\
\text { education } \\
\text { (no } \rightarrow \text { university) }\end{array}$ & $\begin{array}{l}\text { parameter } \\
\text { std. error } \\
\text { net effect }\end{array}$ & $\begin{array}{l}0.135 \\
0.101 \\
0.073\end{array}$ & $\begin{array}{l}0.092 \\
0.092 \\
0.050\end{array}$ & $\begin{array}{l}0.146 \\
0.109 \\
0.056\end{array}$ & $\begin{array}{l}0.062 \\
0.091 \\
0.026\end{array}$ & $\begin{array}{l}0.006 \\
0.080 \\
0.004\end{array}$ & $\begin{array}{l}0.025 \\
0.120 \\
0.024\end{array}$ & $\begin{array}{l}0.117 \\
0.098 \\
0.035\end{array}$ & $\begin{array}{l}0.174^{\prime} \\
0.084 \\
0.137\end{array}$ & $\begin{array}{l}0.2811 \\
0.090 \\
0.153\end{array}$ & $\begin{array}{l}0.111 \\
0.076 \\
0.104\end{array}$ & $\begin{array}{l}0.059 \\
0.082 \\
0.047\end{array}$ & $\begin{array}{l}0.139 \\
0.108 \\
0.042\end{array}$ & $\begin{array}{l}0.094 \\
0.100 \\
0.041\end{array}$ & $\begin{array}{l}0.126 \\
0.101 \\
0.041\end{array}$ \\
\hline $\begin{array}{l}\text { Perceived } \\
\text { health } \\
\text { (perfect } \rightarrow \text { bad) }\end{array}$ & $\begin{array}{l}\text { parameter } \\
\text { std. error } \\
\text { net effect }\end{array}$ & $\begin{array}{l}-0.380^{\prime} \\
0.136 \\
-0.174\end{array}$ & $\begin{array}{c}-0.422^{1} \\
0.129 \\
-0.198\end{array}$ & $\begin{array}{r}-0.145 \\
0.148 \\
-0.044\end{array}$ & $\begin{array}{l}-0.317 \\
0.126 \\
-0.114\end{array}$ & $\begin{array}{r}-0.180 \\
0.113 \\
-0.104\end{array}$ & $\begin{array}{l}0.069 \\
0.171 \\
0.049\end{array}$ & $\begin{array}{l}-0.3211 \\
0.131 \\
-0.83\end{array}$ & $\begin{array}{l}-0.337^{1} \\
0.116 \\
-0.212\end{array}$ & $\begin{array}{l}-0.433^{1} \\
0.121 \\
-0.203\end{array}$ & $\begin{array}{c}-0.2861 \\
0.108 \\
-0.205\end{array}$ & $\begin{array}{l}-0.209 \\
0.113 \\
-0.131\end{array}$ & $\begin{array}{c}-0.365^{1} \\
0.144 \\
-0.098\end{array}$ & $\begin{array}{l}-0.251 \\
0.139 \\
-0.091\end{array}$ & $\begin{array}{l}-0.309^{1} \\
0.137 \\
-0.087\end{array}$ \\
\hline $\begin{array}{l}\text { Residence } \\
\text { Place } \\
\text { (city } \rightarrow \text { village) }\end{array}$ & $\begin{array}{l}\text { parameter } \\
\text { std. error } \\
\text { net effect }\end{array}$ & $\begin{array}{l}0.3021 \\
0.119 \\
0.066\end{array}$ & $\begin{array}{l}0.246^{1} \\
0.110 \\
0.056\end{array}$ & $\begin{array}{l}0.365^{1} \\
0.132 \\
0.053\end{array}$ & $\begin{array}{l}0.177 \\
0.108 \\
0.033\end{array}$ & $\begin{array}{l}0.064 \\
0.096 \\
0.023\end{array}$ & $\begin{array}{l}-0.076 \\
0.140 \\
-0.037\end{array}$ & $\begin{array}{l}0.067 \\
0.109 \\
0.009\end{array}$ & $\begin{array}{l}0.219^{1} \\
0.099 \\
0.078\end{array}$ & $\begin{array}{l}0.188 \\
0.102 \\
0.045\end{array}$ & $\begin{array}{l}0.114 \\
0.091 \\
0.052\end{array}$ & $\begin{array}{l}0.054 \\
0.096 \\
0.021\end{array}$ & $\begin{array}{l}0.359^{1} \\
0.126 \\
0.040\end{array}$ & $\begin{array}{l}0.322 \\
0.119 \\
0.055\end{array}$ & $\begin{array}{l}0.147 \\
0.116 \\
0.021\end{array}$ \\
\hline $\begin{array}{l}\text { Family } \\
\text { |size } \\
\text { ( } 1 \rightarrow 11 \text { persons) }\end{array}$ & $\begin{array}{l}\text { parameter } \\
\text { std. error } \\
\text { net effect }\end{array}$ & $\begin{array}{l}-0.2061 \\
0.070 \\
-0.381\end{array}$ & $\begin{array}{l}-0.038 \\
0.068 \\
-0.055\end{array}$ & $\begin{array}{l}-0.123 \\
0.078 \\
-0.155\end{array}$ & $\begin{array}{l}-0.155^{1} \\
0.067 \\
-0.225\end{array}$ & $\begin{array}{l}0.002 \\
0.059 \\
0.004\end{array}$ & $\begin{array}{l}-0.038 \\
0.096 \\
-0.092\end{array}$ & $\begin{array}{l}-0.103 \\
0.070 \\
-0.099\end{array}$ & $\begin{array}{l}-0.032 \\
0.061 \\
-0.066\end{array}$ & $\begin{array}{l}-0.081 \\
0.063 \\
-0.127\end{array}$ & $\begin{array}{l}0.039 \\
0.056 \\
0.089\end{array}$ & $\begin{array}{l}-0.085 \\
0.059 \\
-0.186\end{array}$ & $\begin{array}{l}-0.087 \\
0.079 \\
-0.081\end{array}$ & $\begin{array}{l}-0.080 \\
0.074 \\
-0.104\end{array}$ & $\begin{array}{l}-0.009 \\
0.017 \\
-0.008\end{array}$ \\
\hline $\begin{array}{l}\text { Chronically } \\
\text { sick members } \\
(0 \rightarrow 4 \text { persons) }\end{array}$ & $\begin{array}{l}\text { parameter } \\
\text { std. error } \\
\text { net effect }\end{array}$ & $\begin{array}{l}-0.108 \\
0.125 \\
-0.064\end{array}$ & $\begin{array}{l}0.005 \\
0.121 \\
0.003\end{array}$ & $\begin{array}{l}-0.002 \\
0.143 \\
-0.001\end{array}$ & $\begin{array}{l}-0.048 \\
0.118 \\
-0.021\end{array}$ & $\begin{array}{r}-0.132 \\
0.103 \\
-0.106\end{array}$ & $\begin{array}{l}-0.251 \\
0.153 \\
-0.245\end{array}$ & $\begin{array}{l}0.014 \\
0.125 \\
0.004\end{array}$ & $\begin{array}{l}-0.100 \\
0.107 \\
-0.084\end{array}$ & $\begin{array}{l}0.015 \\
0.112 \\
0.008\end{array}$ & $\begin{array}{l}-0.037 \\
0.099 \\
-0.035\end{array}$ & $\begin{array}{l}-0.229 \\
0.103 \\
-0.205\end{array}$ & $\begin{array}{l}-0.165 \\
0.135 \\
-0.061\end{array}$ & $\begin{array}{l}-0.084 \\
0.128 \\
-0.040\end{array}$ & $\begin{array}{l}-0.079 \\
0.128 \\
-0.028\end{array}$ \\
\hline $\begin{array}{l}\text { Family } \\
\text { budget } \\
(25 \rightarrow 1200 B G L)\end{array}$ & $\begin{array}{l}\text { parameter } \\
\text { std. error } \\
\text { net effect }\end{array}$ & $\begin{array}{l}0.005^{1} \\
0.001 \\
0.352\end{array}$ & $\begin{array}{l}0.003^{1} \\
0.001 \\
0.256\end{array}$ & $\begin{array}{l}0.006^{1} \\
0.001 \\
0.298\end{array}$ & $\begin{array}{l}0.005^{1} \\
0.001 \\
0.279\end{array}$ & $\begin{array}{l}0.002^{1} \\
0.001 \\
0.283\end{array}$ & $\begin{array}{l}0.003^{1} \\
0.001 \\
0.511\end{array}$ & $\begin{array}{l}0.0041 \\
0.001 \\
0.167\end{array}$ & $\begin{array}{l}0.002^{1} \\
0.001 \\
0.310\end{array}$ & $\begin{array}{l}0.003^{1} \\
0.001 \\
0.255\end{array}$ & $\begin{array}{l}0.270^{1} \\
0.000 \\
0.241\end{array}$ & $\begin{array}{l}0.002^{1} \\
0.001 \\
0.317\end{array}$ & $\begin{array}{l}0.005^{1} \\
0.001 \\
0.203\end{array}$ & $\begin{array}{l}0.0041 \\
0.001 \\
0.246\end{array}$ & $\begin{array}{l}0.004 \\
0.001 \\
0.184\end{array}$ \\
\hline Pseudo R-square & & 0.161 & 0.139 & 0.161 & 0.160 & 0.058 & 0.221 & 0.193 & 0.134 & 0.167 & 0.088 & 0.114 & 0.222 & 0.176 & 0.140 \\
\hline
\end{tabular}

The parameter is statistically different from zero at level $p<0.05$

${ }^{2}$ Only the female respondents were questioned with regards to hospital maternity care

${ }^{3}$ The Nagelkere r-square (adjusted Cox \& Snell r-square) 
The data in table 3.2 show that most of the socio-demographic characteristics influence the respondents' opinions in a variable manner. The respondent's age, education and family income are the only social attributes, which impact on the opinions has a constant direction. For any service, the approval of fees is always reduced when the age increases and is increased when the education level rises. Similarly, the increase in the budget constantly results in a larger fee acceptance. As indicated in table 3.2 , however, the family budget is the only social factor which regression coefficients are significantly different from zero. Besides, it has the strongest impact on the respondent opinions, except on the approval of fees for health care in general and in case of maternity care.

The agreement with payments for health care in general is most strongly influenced by the family size and agreement with fees for maternity services is primarily affected by age. In both cases, however, the family budget is the second strongest determinant.

The opinions regarding the type of patient payment, their beneficiary and the system of exemptions are presented in table 3.3. The table shows the results in the sample and in different social groups. Regarding the type of payments, less than $60 \%$ of the respondents consider that the size of patient payments should be related to the actual service cost and only $40 \%$ agree with fees determined by the level of service quality. As indicated in the table, these figures are significantly lower for respondents who are older than 60 years, with no or primary education, in bad health, who live alone, with chronically sick persons and low family budget. In fact, these are the same groups who most disapprove of fees.

The data in table 3.3 also show that about $93 \%$ of the interviewed support limitations on patient payments. Regarding the type of the limitations, limitations per year receive the lowest approval (that is by only $15 \%$ of the sample). Simultaneously, about $50 \%$ of the respondents favour limitation per service and more than $70 \%$ support the income-based limitation.

Regarding all three methods of limitation, the results in table 3.3 do not show identical significant differences within the social groups. When each limitation method is analysed separately, it is worth to point out that unhealthy respondents and those who belong to families with chronically sick people show a significantly higher agreement with a limit per service compared to healthy individuals and those from families without sick people. Furthermore, the income-based limitation is most often supported by the same social groups that most often disapprove of fees and that less often agree with payment sizes related to service cost and quality.

Regarding the appropriate beneficiary of the patient payments the results in table 3.3 suggest that more than the half of the interviewed are willing to pay the physician and more than a quarter favours paying the health care facility. Thus in total, about three quarters of the sample is in favour of paying fees to those who provide the health care services or where the service is provided. In addition, about $19 \%$ of the sample chooses for the health insurance fund and only $2.2 \%$ agree to pay the municipality. It is not possible to find significant relations between the social attributes and the answers about the beneficiary.

With respect to exemptions, the data in table 3.3 suggest that $95 \%$ agree that some population groups should be excluded from payment obligations. The highest level of overall agreement in the sample concerns the exemptions for disabled people $(80 \%$ of the interviewed favours such exemption). Children, pensioners and the chronically sick also receive a high level of approval for being exempted. The shares of the sample with a positive attitude are $78 \%$ for exemptions for children, $75 \%$ for pensioners and $71 \%$ in case of chronically sick. Free-of-charge health care services for unemployed and pregnant women gather a comparatively lower approval rate, respectively $66 \%$ and $56 \%$. 
Table 3.3. Valid percent of respondents who agree with characteristics of patient payment mechanism

\begin{tabular}{|c|c|c|c|c|c|c|c|c|c|c|c|c|c|c|c|c|c|c|}
\hline \multirow{2}{*}{\multicolumn{2}{|c|}{ Agree with: }} & \multirow[b]{2}{*}{ 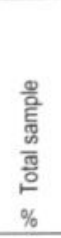 } & \multicolumn{2}{|c|}{$\begin{array}{l}\text { Gender } \\
\text { groups }\end{array}$} & \multicolumn{2}{|c|}{$\begin{array}{l}\text { Age } \\
\text { groups }\end{array}$} & \multicolumn{2}{|c|}{$\begin{array}{l}\text { Education } \\
\text { groups }\end{array}$} & \multicolumn{2}{|c|}{$\begin{array}{c}\text { Groups by } \\
\text { perceived health }\end{array}$} & \multicolumn{2}{|c|}{$\begin{array}{l}\text { Groups by } \\
\text { residence place }\end{array}$} & \multicolumn{2}{|c|}{$\begin{array}{l}\text { Groups by } \\
\text { family size }\end{array}$} & \multicolumn{2}{|c|}{$\begin{array}{l}\text { Groups by sick } \\
\text { family members }\end{array}$} & \multicolumn{2}{|c|}{$\begin{array}{l}\text { Groups by } \\
\text { family budget }\end{array}$} \\
\hline & & & $\frac{\frac{9}{10}}{2}$ & 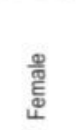 & 용 & 竞市 & 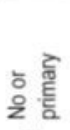 & 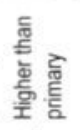 & 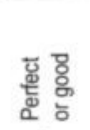 & 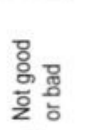 & 敢 & 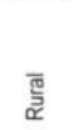 & 总 을 & 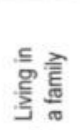 & 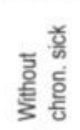 & 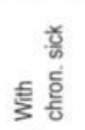 & 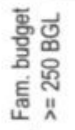 & 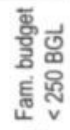 \\
\hline \multirow{7}{*}{ 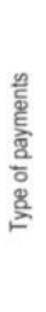 } & & & & & & & & & & & & & & & & & & \\
\hline & Related to service cost & 57.6 & 54.0 & $60.9^{1}$ & 53.2 & $71.3^{1}$ & 71.7 & $53.0^{\circ}$ & 50.6 & $67.6^{1}$ & 58.9 & 51.2 & 67.0 & $56.5^{1}$ & 51.0 & $65.8^{1}$ & 43.8 & $62.3^{1}$ \\
\hline & Related to quality & 41.4 & 38.6 & 44.0 & 36.9 & $55.7^{1}$ & 54.1 & $37.2^{1}$ & 37.9 & $46.6^{1}$ & 43.1 & $33.1^{1}$ & 56.9 & $39.5^{1}$ & 37.1 & $46.7^{1}$ & 25.8 & $46.5^{1}$ \\
\hline & Limited & 93.2 & 92.6 & 93.8 & 92.3 & $96.7^{\prime}$ & 96.0 & $92.3^{\prime}$ & 91.3 & $96.1^{\prime}$ & 93.5 & 91.7 & 91.8 & 93.4 & 92.4 & 94.1 & 91.8 & 93.7 \\
\hline & Limited per year & 14.9 & 15.4 & 14.4 & 14.5 & 16.7 & 10.5 & $16.3^{1}$ & 13.0 & 17.5 & 15.2 & 13.5 & 11.8 & 15.3 & 14.9 & 14.9 & 12.4 & 15.5 \\
\hline & Limited per service & 49.8 & 52.0 & 47.8 & 51.3 & 45.7 & 41.7 & $52.2^{1}$ & 53.9 & $44.0^{1}$ & 50.6 & 45.9 & 46.4 & 50.2 & 54.2 & $44.4^{1}$ & 54.5 & 48.5 \\
\hline & Limited per income & 70.5 & 66.4 & $74.4^{1}$ & 67.4 & $69.6^{1}$ & 80.2 & $67.3^{1}$ & 63.8 & $80.3^{1}$ & 70.4 & 71.2 & 68.2 & 70.8 & 66.2 & $75.9^{1}$ & 57.9 & $47.7^{1}$ \\
\hline \multirow{4}{*}{ 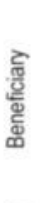 } & The service provider & 52.4 & 53.0 & 51.9 & 51.8 & 54.7 & 53.9 & 51.9 & 49.9 & 55.6 & 53.4 & 47.6 & 52.7 & 52.3 & 50.8 & 54.3 & 48.5 & 54.1 \\
\hline & The healthcare facility & 26.2 & 25.2 & 27.2 & 26.7 & 24.3 & 26.7 & 26.1 & 27.2 & 25.0 & 24.5 & 34.9 & 30.0 & 25.8 & 28.0 & 24.1 & 28.3 & 25.6 \\
\hline & The municipality & 2.2 & 1.5 & 2.9 & 1.7 & 4.1 & 2.9 & 2.0 & 1.6 & 3.2 & 2.1 & 3.0 & 1.8 & 2.3 & 1.3 & 3.4 & 1.3 & 2.6 \\
\hline & The health insurance fund & 19.1 & 20.3 & 18.0 & 19.8 & 16.9 & 16.5 & 20.0 & 21.3 & 16.2 & 20.1 & 14.5 & 15.5 & 19.6 & 19.9 & 18.2 & 21.9 & 18.8 \\
\hline \multirow{7}{*}{ 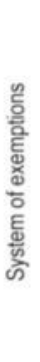 } & To be available & 94.6 & 93.2 & $96.1^{1}$ & 93.8 & 97.21 & 96.4 & 94.2 & 92.9 & $97.3^{1}$ & 94.9 & 94.2 & 90.9 & 95.2 & 93.6 & 96.2 & 95.7 & 94.8 \\
\hline & To include children & 77.8 & 76.5 & 78.9 & 78.5 & 76.0 & 77.0 & 78.0 & 77.3 & 78.6 & 76.0 & $86.0^{\prime}$ & 71.8 & 78.5 & 79.0 & 76.2 & 78.5 & 77.8 \\
\hline & To include pensioners & 74.5 & 72.3 & 76.6 & 69.4 & $89.0^{\prime}$ & 84.7 & $71.1^{1}$ & 67.7 & $83.9^{\prime}$ & 73.5 & 79.5 & 77.3 & 74.2 & 71.1 & $78.7^{\prime}$ & 67.8 & $76.9^{1}$ \\
\hline & To include unemployed & 65.9 & 62.2 & $69.4^{1}$ & 65.8 & $67.1^{1}$ & 76.6 & $62.3^{1}$ & 62.0 & $71.5^{\prime}$ & 64.1 & $64.9^{1}$ & 63.6 & 66.2 & 63.8 & 68.5 & 57.1 & $68.9^{1}$ \\
\hline & To include chronically sick & 71.1 & 70.2 & 71.9 & 68.8 & $77.2^{1}$ & 76.2 & $69.4^{1}$ & 65.5 & $78.8^{1}$ & 70.7 & 76.0 & 70.9 & 71.1 & 67.8 & $75.1^{1}$ & 67.0 & 74.8 \\
\hline & To include pregnant & 56.2 & 55.8 & 56.6 & 56.3 & 56.9 & 59.7 & 55.1 & 53.6 & 59.9 & 54.3 & $65.5^{1}$ & 54.5 & 56.4 & 55.1 & 57.5 & 53.2 & 57.3 \\
\hline & To include disable & 80.3 & 80.0 & 80.5 & 81.4 & 79.3 & 76.2 & 81.6 & 79.2 & 81.8 & 79.5 & 84.2 & 73.6 & 81.1 & 80.1 & 80.4 & 86.7 & $78.5^{1}$ \\
\hline
\end{tabular}


As indicated in table 3.3, the statistical procedure does not find any consistent pattern of significant difference in the socio-demographic groups if all proposed exemptions are considered. If each exemption is analysed separately, it is worth to mention that the group of respondents that are older than 60 years and are usually pensioners, show significantly higher support for the exemption of pensioners than the rest of the sample. In addition, the exemptions for chronically sick people receive significantly higher agreement by those who belong to families with chronically sick family members. The tests fail to find a significant difference between male and female respondents concerning exemptions for pregnant women.

\subsection{Discussion}

The results on respondents' opinion regarding patient payments indicate that the majority of the sample in this survey accepts to pay for public services with good quality and quick access. If it is considered that this opinion is the result of underlying attitudes, it can be concluded that the majority of the sample in this survey is in favour of paying for improved public health care.

These highly positive attitudes could be attributed to the general deterioration of the Bulgarian public health care services. Research on patient satisfaction in Bulgaria reveals a high level of discontent with the quality of public health care facilities (e.g. WHO-Euro, 1999; Ivanov et al., 1996). The perception of low quality, however, does not solely follow from rising patient expectations. It is a result of the continuous under-funding of the health care system due to the unstable economy of the country during the last decades. The insufficient health care resources resulted in a lack of materials and instruments, ill-maintained facilities, long waiting times, underpaid providers irresponsive to patient requests, and widely spread informal payments (WHO-Euro, 1999; Delcheva et al, 1997). If the inadequate health care performance in Bulgaria is taken into account, the considerable approval of fees for improved health care services, revealed by this survey, is not surprising.

The results on the overall approval of paying charges for particular health care services, are rather mixed. The magnitudes of these proportions fluctuate considerably. These findings suggest that overall respondents give their opinion for each service independently from the answer to other service charges. Perhaps, the underlying attitudes towards payments for different services that generate the responses dependent on the type of health care services. Thus, for example the comparatively low agreement, with charges for emergency and maternity care, suggests that some respondents may well consider that emergency and maternity hospital care are essential. The existence of a financial barrier to their utilization may be perceived as life threatening. Therefore, the respondents are least in favour of paying for these two services. The interviewed may also believe that the state should be responsible for the provision of adequate emergency and maternity care, not the patients.

The discrepancy between the opinions regarding charges for public health care in general and charges for specific services, however, show an important inconsistency in the responses. A possible explanation of this difference is that the respondents base their answers on distinct criteria when answering the two types of questions. The questions on the general approval of fees, most likely provoke the objection of more respondents due to negative attitudes towards the principle of being charged. It is also likely that such questions compel individuals to undertake a better look at their income constraints than the questions on service charges. Perhaps, the last supposition is supported by the result that the acceptance of fees in general is mostly influenced by the family size, whereas the approval of fees for particular services is primarily determined by the family income. 
The differences between the opinions in the social groups signify essential differences in the underlying attitudes. The groups that have significantly a lower agreement with patient payments may have only a weak preference for improved public health care. However, the fact, that the respondents with the highest income are the only social category that hardly ever expresses disapproval of patient payments, suggests that the budget size most likely plays a primary role for the negative opinion. Consequently, it can be expected that social groups with stronger income constraints will have lower approval of paying fees. Thus, for example, the low educated and the persons older than 60 years (usually pensioners) are generally people with a low income. They more frequently disagree to pay charges and oppose an increase of their financial burden. The same may apply for respondents who live alone on a single income, and those who belong to families with a low family budget. Both groups of respondents have only limited financial resources and are therefore more likely to disapprove of patient payments. The group of respondents who are in a bad health condition or who have chronically sick family members, probably recognize that accumulated charges in case of frequent service use can put a claim on a considerable part of their budget. Thus, respondents belonging to these two social categories more frequently disapprove of payments. The significance of the family budget for the respondents' opinion and consequently for the underlying attitudes is confirmed by the regression analysis.

The considerable disagreement in the sample to pay charges related to the actual costs of the service or its quality may be because some health care services, particularly hospital operations, are rather expensive. Many respondents probably recognise that payments related to actual service costs (for example co-insurance) may give rise to barriers to utilisation of these services. Regarding the quality-related payments, the negative attitudes may be caused by respondents' believe that all health care services should be provided with good quality regardless of the patient payments. These respondents may foresee that quality-related payments (for example extra-billing) may diminish access to services with appropriate quality, especially for people with low-income. The questions on cost- and quality-related payments, like the questions on charges for particular services, require respondents to approve or disapprove of a potential increase of their own financial burden. This can explain why the significant differences within the social groups regarding the two groups of questions are similar.

The majority of the sample favours the limitations on patient payments. Thus, in general, copayments and deductibles seem to be adequate forms of charges. In the former case, the patients pay fixed amounts for a service and in the latter case, the patients can be charged up to a ceiling. The fees under these two forms are related neither to service cost and nor to service quality, and the size of each payment is in principle restricted. Still, the potential accumulation of the payments requires supplementary measures for limiting the payments. The low agreement with the limitation per services and per year may imply that many respondents consider these two limitations unfair. Under such limitations, the poor have to pay a larger proportion of their income for health care than the rich. The higher support for limits per service than limits per year suggests that more respondents agree with subsidies for frequent use of a particular health care services than for intense health care use in general. Particularly, limitations per service can reduce the financial burden for chronically sick patients. Thus, it is not surprising that respondents who belong to families with chronically sick people show significantly higher agreement with limits per service compared to the rest of the respondents. The overall results imply approval of solidarity in public health care financing in case of low-income and chronic sickness. The high approval of income-related limitations may well be recorded because many respondents perceive themselves as poor and expect that these limitations will apply to them. In this sense, the question on income-based limitations requires judgments about 
their own financial burden as in case of question on payment size related to service cost or quality, as well as in case of payments for health care services. Therefore, it is not surprising that the same socio-demographic groups that are least in favour of paying fees and least in favour of cost- and quality-related payments are most in favour of income-based limitations.

The answers to the beneficiaries of patient payments reveal neither a highly favoured beneficiary nor significant difference between social groups. This does not discard the fact that three quarters of the sample opt for paying the service provider or its facility directly. Thus, most of the respondents support the idea that the patient payment has to be retained at the place of service provision. The respondents may well recognize the danger of revenue absorption by an insurance or municipality account.

The last characteristic of the patient payment mechanism, discussed in this paper, is the system of exemption. The results show considerably strong solidarity in the exclusion of vulnerable populations from payment obligations. The high support of some social groups for their own exemption implies that respondents may recognize that if the respective criterion is applied, they and their family members will be personally exempted from charges. The absence of significant difference concerning exemptions for pregnant women, however, suggests that both men and women may have the same perceptions regarding the liability of pregnant women.

\subsection{Possible response biases and prospect for generalization}

The respondents in this survey are asked about their own willingness and ability to pay charges for particular health care services. There are no indications in the questionnaire that a person might be exempted from payments. This can prevent the generation of overoptimistic answers due to respondents' perceptions that the charges will not apply to them (Gooder et al., 1993). Furthermore, questions are asked about both willingness and ability to pay. This avoids the overoptimistic answers of respondents who do not consider their own budget. Yet, there is a danger of protest responses from persons who are anxious about an increase of their financial burden, rather than opposed to charges themselves (Gooder et al., 1993). The questionnaire, however, specifies that the payments are for improved public health care services. This can avert negative responses due to a fear that the payments might be absorbed by the system or used in other sectors (Gooder et al., 1993).

The questions in this survey involve specified health care services, which permit a comparison between attitudes towards different services. The specification of service type can generate protest answers due to a negative attitude towards charges for certain services rather than charges in general (Gooder et al., 1993). However, if the service type is not specified, the reverse disadvantage can be anticipated. The respondents may disagree due to negative attitudes towards charging, although they may still be willing to pay for certain services. Therefore, in addition to the questions on specific service fees, the interviewed are asked about their general acceptance of payments. The survey thus provides a possibility for comparison.

The evaluation of how representative the sample is, requires the analysis of both the response rate and the sampling model (Ivanov, et al, 1996). A high response rate and random selection of respondents imply representativeness of the sample. In this survey, the response rate $(90.5 \%)$ is relatively high and the respondents in each cluster, defined by type of residence place, age and gender, were randomly selected. This suggests that the data for a particular cluster are representative for the cluster itself. Furthermore, the number of respondents in each cluster was determined by the official regional statistics for urban/rural distribution, as well as for the age and 
gender attributes. Consequently, each residence place is presented in proportion to its population size and age-gender characteristics.

The comparison between the sample characteristics and the corresponding regional statistics (see appendix C.4) shows that the maximum difference between them is $\pm 3 \%$. Furthermore, as it is shown in appendix C.4., these differences are not statistically significant. Thus, it can be assumed that the results are representative for the region. Regarding the representativeness of the sample for the country as a whole, there are no significant differences between the characteristics of the sample and the national statistics with respect to age and gender. The distribution of the respondents among the place of residence significantly differs from the national statistics by $12 \%$. For that reason, the nation-wide representativeness of the sample is uncertain. The analysis in this paper, however, does not find systematic difference between the urban and rural population. The analysis suggests that the opinions are primarily determined by the size of the family budget. The average family budget for the sample, however, approximately equals the respective national statistic. This may indicate that the extension of the conclusion to the country as a whole is still possible

\subsection{Conclusions}

Given the results presented and discussed above, it can be concluded that the majority of the citizens are in favour of the introduction of patient payments in the Bulgarian public health care sector. These results, however, are obtained under the assumption that the services are provided with good quality and quick access. Consequently, a high level of agreement with charges for publicly provided services could be anticipated if they are combined with efforts to enhance quality of and access to these services. Thus, special attention should be paid on the process of converting the fee revenues into service improvement.

The analysis indicates that the patient payment mechanism should differentiate between types of services. Payments for some services may receive considerable public acceptance whereas charges for others may provoke disapproval. The survey findings reveal that charges for non-urgent health care, such as services of general practitioners, medical specialists, and dentists, are most likely to be accepted by the population. However, broad public support for charges for urgent medical services (e.g. emergency and maternity hospital care) cannot be expected. Public health care services with high importance to the health of the population should be excluded from the patient payment mechanism. Further, lower fees at primary health care facilities compared to those at hospitals can encourage efficient use of public health care. For that reason, the decision to charge for a given service needs to be determined by an analysis of the service itself not merely by the general political will to introduce fees.

Concerning the type of patient payment, the results in this paper suggest that co-insurance and extra-billing are two types of payment that most probably will have little acceptance. Higher public approval can be expected in case of co-payments and deductibles. Despite what type of payment is selected, the potential accumulation of the payments will always require additional payment limitations. The strong public support for income-based limitations suggests that the ability of the patients to pay needs to be a primary concern when settling the payment limits. Any financial barrier to the access to the public health care system can be avoided by appropriate fee magnitudes.

Another implication of the results in the paper is the need of an extensive system of exemptions from patient payments. The discussion revealed that public health care for disabled people, children, pensioners and chronically sick should be provided free-of-charge. Exemptions for unemployed and pregnant women should also be considered. 
Any discouragement in using public health care system should be avoided by a well-designed and promptly implemented system of exemptions. If the compliance with these prerequisites results in payments by only a small fraction of the population, the net gain of the patient payments is likely to be small or even negative. The latter can occur if the administrative costs for collecting fees and exempting vulnerable groups exceed the fee revenues. If this happens, the health policy-makers should reconsider the rationality behind the patient payment mechanism.

The final supposition presented here is related to the beneficiary of the patient payments. According to the majority of the population, the charges should be retained at the place of service provision, rather than to be absorbed by an insurance or municipality account. The retention of the payment revenues at the local level, as a supplement to public health care financing, can facilitate the improvement of the same health care services that the patients pay for. This can increase the overall satisfaction with the public health care performance and the approval of charges.

\section{References:}

Arubjer. D., Söderfeldt, B. and Palmqvist, S. (1996). Attitudes towards financing of dental care in a Swedish population. Acta Odontologica Scandinavica 54 (2): $81-86$.

Bennett, S. and Ngalande-Banda, E. (1994). Public and private roles in health: a review and analysis of experience in Sub-Saharan Africa. Geneva: The World Health Organization/Division of Analysis, Research and Assessment.

Creese, A.L. (1991). User charges for health care: a review of recent experience. Health Policy and Planning $6(4): 309-319$.

Creese, A.L. and Kutzin, J. (1995). Lessons from cost-recovery in health. Forum on Health Sector Reform. Discussion Paper No2, WHO/SHS/NHP/95.5. Geneva: The World Health Organization.

Delcheva, E., Balabanova. D. and McKee, M. (1997). Under-the-counter payments for health care: evidence from Bulgaria. Health Policy 42: 89-100.

Editorial Team of Capital (1998). The insurance system model (in Bulgarian). Capital 15 June, 23: 31-32.

Getzen, T.E. (1997). Health economics: fundamentals and flow of funds. New York: John Wile.

Gilson, L., Russell, S. and Buse, K. (1995). The political economy of user fees with targeting: developing equitable health financing policy. Journal of International Development 7 (3): 369-401.

Gooder, P., Charny, M. and Farrow, S. (1993). Public attitudes to charging for some national health service services. Social Science Medicine 36 (4): 565-568.

Huber, J.H. (1993). Ensuring access to health care with the introduction of user fees: a Kenyan example. Social Science and Medicine 36 (4): 485-494.

Ivanov, L., Glutnokova, Z. and Kalinov, K. (1996). Sociological survey: adequacy and quality of primary health care. Bull Nation Centre Public Health 1(December): 47-78.

Kutzin, J. (1995). Experience with organizational and financing reform of the health sector. Geneva: WHO/ Division of Analysis, Research and Assessment. 
Lee, K. (1989). Chapter 1 - Symptoms, causes and proposed solutions. In: Abel-Smith, B. and Creese, A. (eds.). Recurrent Costs in the Health Sector - Problems and Policy Options in Three Countries. Geneva: The World Health Organization

Litvack, J.I. and Bodart, C. (1993). User fees plus quality equals improved access to health care: results of a field experiment in Cameroon. Social Science and Medicine 37 (3): 369-383.

Long, J.S. (1997). Regression models for categorical and limited dependent variables. Thousand Oaks: Sage Publications.

Ministry of Health Care (1998). Directive No22/9.12.1997 Conditions and organisation of the payment for medical care in case of patient choice (in Bulgarian). Biblioteka Zakoni APIS 5 (1) №126.

Norušis, M.J. (1998). SPSS ${ }^{\star}$ 8.0: guide to data analysis. Upper Saddle River: Prentice-Hall, Inc.

Ros, C.C., Groenewegen, P.P. and Delnoij, D.M.J. (2000). All right reserved or can we just copy? The relationship between cost sharing arrangements and characteristics of a health care system. Health Policy 52 (1): $1-13$.

Rubin, R.J. and Mendelson, D.N. (1995). A framework for cost sharing policy analysis. PharmacoEconomics 10 (Suppl.2): 56-67.

Shaw, R.P. and Griffin, C.C. (1995). Financing health care in Sub-Saharan Africa through user fees and insurance. Washington, DC: The International Bank for reconstruction and Development/ The World Bank.

Siegel, S. and Castellan, N.J. (1988). Nonparametric statistics for the behavioral sciences. New York: McGraw-Hill.

Sprinkle, R.H. (1994). Remodelling health care. Journal of Heath Politics, Policy and Law 19 (1): 45-68.

Street, A., Jones, A. and Futura, A. (1997). Cost-sharing and pharmaceutical utilization in Russia: evidence from a household survey. Discussion Paper No155. York: Centre for Health Economics/ University of York.

The $38^{\text {th }}$ National Assembly (1998). The health insurance act. Sofia: The $38^{\text {th }}$ National Assembly.

Wagstaff, A. and van Doorslaer, E. (1992). Equity in the finance of health care: some international comparisons. Journal of Health Economics 11: 361-387.

WHO (1996). European Health care reforms: analysis of current strategies. Copenhagen: The World Health Organization/Regional Office for Europe.

WHO-Euro (1999). Better health for better future in Bulgaria: a health policy proposal. Draft 2. Unedited. $23^{\text {rd }}$ February. 
CHAPTER 4

\section{The importance of health care attributes to Bulgarian consumers: A self-explicated method}

Submitted for publication as:

Pavlova M., Groot, W. and van Merode, F. The importance of the attributes of health care services to consumers: implications for policy of patient payments in Bulgaria 


\subsection{Introduction}

Patient payments are often advised and implemented as an additional source of health care financing (Creese, 1991; WHO, 1996). The ability of patient payments to raise revenues is of particular importance for countries where public health care financing is inadequate. The empirical evidence, however, shows that the revenue raised by fee collection is limited and does not present a significant contribution to the public health care budget. The gross yield from patient payments in the countries varies between $1 \%$ and $15 \%$ of their health care expenditures, with an average of $5 \%$ (Bennett and Ngalande-Banda, 1997; Creese, 1991). If the administrative costs for collecting the payments are considered then the net yield of patient payments is even lower. Thus, there is little scope for applying health care charges as a financing strategy at a national level (Creese, 1991).

In order to decrease the collection costs, the patient payments should be retained locally and should be used as an additional source of financing for local health care structures (Bennett and Ngalande-Banda, 1997; Creese, 1991). Experience shows that payment revenues can be successfully reinvested to improve the local health care services that consumers pay for (Bennett and Ngalande-Banda, 1997; Litvack and Bodart, 1993). Decisions about the reinvestment of the fee revenues should take into account not only political and professional priorities for service improvement, but also the importance that the consumers attach to health care attributes. The allocation of at least a part of the fee revenue to the improvement of those service attributes that the consumer value can help to raise patient satisfaction and the acceptance of fees by consumers. Based on survey data from Bulgaria, this paper analyses the importance of health care attributes stated by the consumers and outlines applications to policy of patient payment.

Bulgaria is a former-socialist country, which is still in the process of reform in all economic sectors, including health care. The reforms in the health care sector are necessitated not only by the political changes in the country, but also by the numerous quality, efficiency and equity problems in health care provision. Lack of materials and instruments, ill-maintained facilities, long waiting times, irresponsive providers, and requests for informal payments characterise the Bulgarian health care system (e.g. Borisov and Rathwell, 1996; Delcheva et al., 1997; WHO-Euro, 1999). Although the public attitudes towards the health care provision in Bulgaria are not thoroughly studied (Zafirova and Kehaiova, 2001), some opinion surveys revealed discontent with public health care sector (e.g. Ivanov et al., 1996, WHO-Euro, 1999). Against the background of the deterioration of the public health care services and the dissatisfaction of the consumers, support for the recently introduced patient charges can be expected if there are significant efforts for converting the fee revenues into actual service improvements.

This paper aims to examine which health care attributes are important to Bulgarian consumers. It also aims to analyse the differences between the social groups regarding the importance they attach to the health care attributes. The study uses data from a household survey. In order to achieve the aims, the paper first outlines the method of data collection and analysis. Next, the sociodemographic features of the sample are presented. The paper continues by a description of the results on attribute importance, the difference between the social groups and the relevance of the results. Finally, the paper outlines implications for Bulgarian health policy.

\subsection{Method of research and analysis}

In May and June 2000 a survey was conducted among individuals of Varna (the third largest Bulgarian city) and in its region. The data were collected through interviews based on a 
questionnaire that had been tested in a pilot study. The respondents were randomly selected in each municipality proportionally to population size and age-gender characteristics. The method of twostage random selection was used - first selecting the municipality and then selecting respondents from particular age-gender groups.

In total, 1094 individuals were contacted. From this sample, 94 individuals refused or were unable to answer the questions. There were 10 interviews, which were terminated before completion due to unwillingness of the respondent to continue to answer. Additionally, one interviewer did not correctly code the answers to the question regarding the importance of the health care attributes. Therefore, data for 39 respondents were excluded. Thus, the overall response rate is $87 \%$.

In order to develop the questionnaire for this survey it was necessary to determine which characteristics of the health care services to include. The primary criterion was the research interest in three basic concepts quality, access and price, and the importance that the Bulgaria health care consumers attach to them. It was considered, however, that asking respondents directly about the importance of quality, access and price could result in misleading answers since different respondents can attach different meaning to these concepts. Therefore, these three concept needed to be operationalised and to be presented to the respondents through tangible service attributes. The operationalisation of the concept price was rather straightforward. The price can be represented to the respondents as the attribute 'size of patient payment'. The operationalisation of the concepts quality and access, however, was more complicated given their numerous aspects. In order to simplify the task the framework of Berki and Ashcraft (1980) developed to analyse consumer preferences for a health plan was used.

In this framework, Berki and Ashcraft (1980) distinguish between clinical quality and social quality. According to the authors, clinical quality is achieved when the health care services are technically competent, clinically appropriate and humanly delivered. Thus, it can be assumed that the clinical quality has two basic aspects related to the technology used and the provider's ability. Therefore, clinical quality was represented by the attributes 'availability of equipment and materials' and 'professional reputation of the physician'. It was expected that health care consumers will use the professional reputation of the provider as a tag for his/her knowledge and expertise.

Social quality, according to Berki and Ashcraft (1980), is achieved if health care services are provided in modern and attractive facilities with prestigious auxiliary benefits. For that reason, the attribute facility maintenance was used as an indication of this quality aspect.

With respect to access to health care services, Berki and Ashcraft (1980) specify two dimensions: spatial and temporal access. Spatial access refers to the locational proximity of the health care facility to the consumer, whereas temporal access refers to the time lag between the attempted and the actual contact with the provider. In the survey reported here, spatial access was represented by the attribute 'travelling time' and temporal access by the attribute 'waiting time'. In their framework, Berki and Ashcraft (1980) also include psychological access with the meaning of 'perceived social distance' between patient and physician. This aspect of the concept access is not incorporated in this survey.

Based on the above considerations, the set of service attributes included in the questionnaire consist of availability of equipment and materials; physician's professional reputation; maintenance of the building and the office; travelling time; waiting time and size of patient payment. In order to elucidate the perceived importance of these attributes, the respondents were confronted with the following assignment: 'Below, there is a list with six attributes of health care services. What is the importance of each of these attributes to you when you are selecting a health care provider? Please, 
write 1 next to the attribute you consider most important, 2 next to the attribute you consider second most important, 3 to the next important attribute, 4, 5 to 6. Please do not repeat the numbers.' (See appendix A, Q9)

The data collected by the attribute ranking are organised into six response variables. Each variable contains the ranks assigned to one service attribute. Consequently, it possesses six distinctive values corresponding to the six level of importance. The variable values are ordered, but the distance between them is unknown. For that reason the paper relies on ordered regression for analysing the relations between the response variables and the socio-demographic characteristics. The ordered logit regression model is chosen over the probit because of its computational advantages (Van Beek et al., 1997).

The regression is applied to estimate the thresholds $\tau$ and the coefficients $\beta$ of the ordered regression model. The regression results are used to estimate the rank probabilities of the attributes. If $y$ is the response variable that represents the ranking of an attribute, the probability that an individual with socio-demographic features $\mathrm{x}$ will assign the rank $\mathrm{m}$ to the attribute is given by equations $(4.1) \div(4.3)$.

$$
\text { for } \mathrm{m}=1 \quad \operatorname{Pr}(\mathrm{y}=1 \mid \mathrm{x}, \beta, \tau)=\frac{\exp \left(\tau_{1}-\mathrm{x} \beta\right)}{1+\exp \left(\tau_{1}-\mathrm{x} \beta\right)}
$$

$$
\text { for } \mathrm{m}=2 \div 5 \operatorname{Pr}(\mathrm{y}=\mathrm{m} \mid \mathrm{x}, \beta, \tau)=\frac{\exp \left(\tau_{\mathrm{m}}-\mathrm{x} \beta\right)}{1+\exp \left(\tau_{\mathrm{m}}-\mathrm{x} \beta\right)}-\frac{\exp \left(\tau_{\mathrm{m}-1}-\mathrm{x} \beta\right)}{1+\exp \left(\tau_{\mathrm{m}-1}-\mathrm{x} \beta\right)}
$$

$$
\text { for } m=6 \operatorname{Pr}(y=6 \mid x, \beta, \tau)=1-\frac{\exp \left(\tau_{5}-x \beta\right)}{1+\exp \left(\tau_{5}-x \beta\right)}
$$

The rank probabilities determine the effect $\Delta$ of a socio-demographic variable $x_{k}$ on a response $y$. The variable $x_{k}$ changes form its minimum $x_{\min }$ to its maximum $x_{\max }$, while all other variables at their average values. The calculation is based on the equation (4.4).

$$
\Delta=\frac{1}{6} \sum_{m=1}^{6}\left|\frac{\Delta \operatorname{Pr}(\mathrm{y}=\mathrm{m} \mid \mathrm{x}, \beta, \tau)}{\Delta \mathrm{x}_{\mathrm{k}}}\right|=\frac{1}{6} \sum_{\mathrm{m}=1}^{6}\left|\operatorname{Pr}\left(\mathrm{y}=\mathrm{m} \mid \mathrm{x}, \mathrm{x}_{\mathrm{k}_{\max }}, \beta, \tau\right)-\operatorname{Pr}\left(\mathrm{y}=\mathrm{m} \mid \mathrm{x}, \mathrm{x}_{\mathrm{k}_{\min }}, \beta, \tau\right)\right|
$$

The rank probabilities also determine the change in each rank probability $\Delta \mathrm{Pr}$ when a variable $\mathrm{x}_{\mathrm{k}}$ deviates from its average value $\mathrm{x}_{\mathrm{aver}}$ by a discrete step $\mathrm{d}$. All other variables are set at their averages values. The equation (4.5) is used to calculate the probability changes.

$$
\frac{\Delta \operatorname{Pr}(\mathrm{y}=\mathrm{m} \mid \mathrm{x}, \beta, \tau)}{\Delta \mathrm{x}_{\mathrm{k}}}=\operatorname{Pr}\left(\mathrm{y}=\mathrm{m} \mid \mathrm{x}, \mathrm{x}_{\mathrm{k}}=\mathrm{x}_{\mathrm{aver}}+\mathrm{d}, \beta, \tau\right)-\operatorname{Pr}\left(\mathrm{y}=\mathrm{m} \mid \mathrm{x}, \mathrm{x}_{\mathrm{k}}=\mathrm{x}_{\text {aver }}, \beta, \tau\right)
$$

where $\mathrm{m}=1$ to 6 . A theoretical background for the above formulas is given in Long (1997). 


\subsection{Sample characteristics}

The average age of the interviewed persons is about 46 years. The sample is evenly divided among the gender groups. The majority of the respondents reside in a big city and only about a quarter live in small towns or villages. Half of the sample has completed 10-12 years of study and the rest is split between lower and higher education. Most often, the respondents perceive themselves as healthy. The respondents' families include on average three household members and less than one chronically sick individual. Approximately, half of the families live on monthly budgets lower than 201 BGL (Bulgarian levas) One BGL equals half Euro. Detailed information on the sociodemographic variables included in the regressions is presented in appendix C.3.

\subsection{Results}

The results of the attribute ordering are presented in table 4.1. The table shows the shares of respondents who assign a particular rank of importance to a given attribute. The total sums in the rows and columns equal the sample size, because the respondents rank all attributes without repeating the ranks.

Table 4.1. Importance of the health care attributes to the respondents

\begin{tabular}{|c|c|c|c|c|c|c|c|}
\hline \multirow[b]{2}{*}{ Service Attribute } & \multirow{2}{*}{$\begin{array}{c}\text { Most } \\
\text { important } \\
\text { Rank } 1 \\
\%\end{array}$} & \multirow[b]{2}{*}{$\begin{array}{c}\text { Rank } 2 \\
\%\end{array}$} & \multirow[b]{2}{*}{$\begin{array}{c}\text { Rank } 3 \\
\%\end{array}$} & \multirow[b]{2}{*}{$\begin{array}{c}\text { Rank } 4 \\
\%\end{array}$} & \multirow[b]{2}{*}{$\begin{array}{c}\text { Rank } 5 \\
\%\end{array}$} & \multirow{2}{*}{$\begin{array}{c}\text { Least } \\
\text { important } \\
\text { Rank } 6 \\
\%\end{array}$} & \multirow[b]{2}{*}{$\begin{array}{c}\text { Total } \\
\%\end{array}$} \\
\hline & & & & & & & \\
\hline Equipment and materials & 8.2 & 37.0 & 26.2 & 14.1 & 11.2 & 3.3 & 100.0 \\
\hline Professional reputation & 64.7 & 22.3 & 6.9 & 3.9 & 1.5 & 0.7 & 100.0 \\
\hline Facility maintenance & 0.8 & 3.6 & 14.9 & 20.4 & 21.0 & 39.3 & 100.0 \\
\hline Traveling time & 2.6 & 6.2 & 13.9 & 21.5 & 30.0 & 25.8 & 100.0 \\
\hline Waiting time & 4.4 & 8.2 & 18.4 & 25.4 & 24.4 & 19.2 & 100.0 \\
\hline Patient payment & 19.3 & 22.7 & 19.7 & 14.7 & 11.9 & 11.7 & 100.0 \\
\hline Total & 100.0 & 100.0 & 100.0 & 100.0 & 100.0 & 100.0 & 100.0 \\
\hline
\end{tabular}

The data in table 4.1. show that, overall, professional reputation has the highest ranking. It is the only attribute that is most often ranked as first/most important (by nearly $65 \%$ of the sample). The range of medical equipment and the size of patient payments are the next most important attributes. They are most frequently pointed out as second most important attribute (by respectively $37 \%$ and $23 \%$ of the sample respectively) and half of the respondents place them on a position up to third. Next in the attribute ordering is waiting time. It is most often ranked as fourth most important ( $25 \%$ of the sample) and half of the respondents rank it as the fourth or more important attribute. The service characteristics with the lowest ranking values are travelling time and office maintenance. Both characteristics are placed on a position up to fifth by half of the respondents. However, travelling time is most frequently ranked as fifth important $(30 \%)$, whereas office maintenance most often occupies the last sixth position (39\%).

The above results show the overall sample perceptions. In order to outline the differences between the socio-demographic groups a regression is performed as specified in section 3 of this 
paper. The response variables containing the ranks of the different attributes are regressed on the eight socio-demographic characteristics.

The results of the regression are given in table 4.2. The signs of the regression coefficients indicate the direction of the relation between the rank ordering of specific attribute and the sociodemographic variable.

Table 4.2. Results from the ordered logit regression

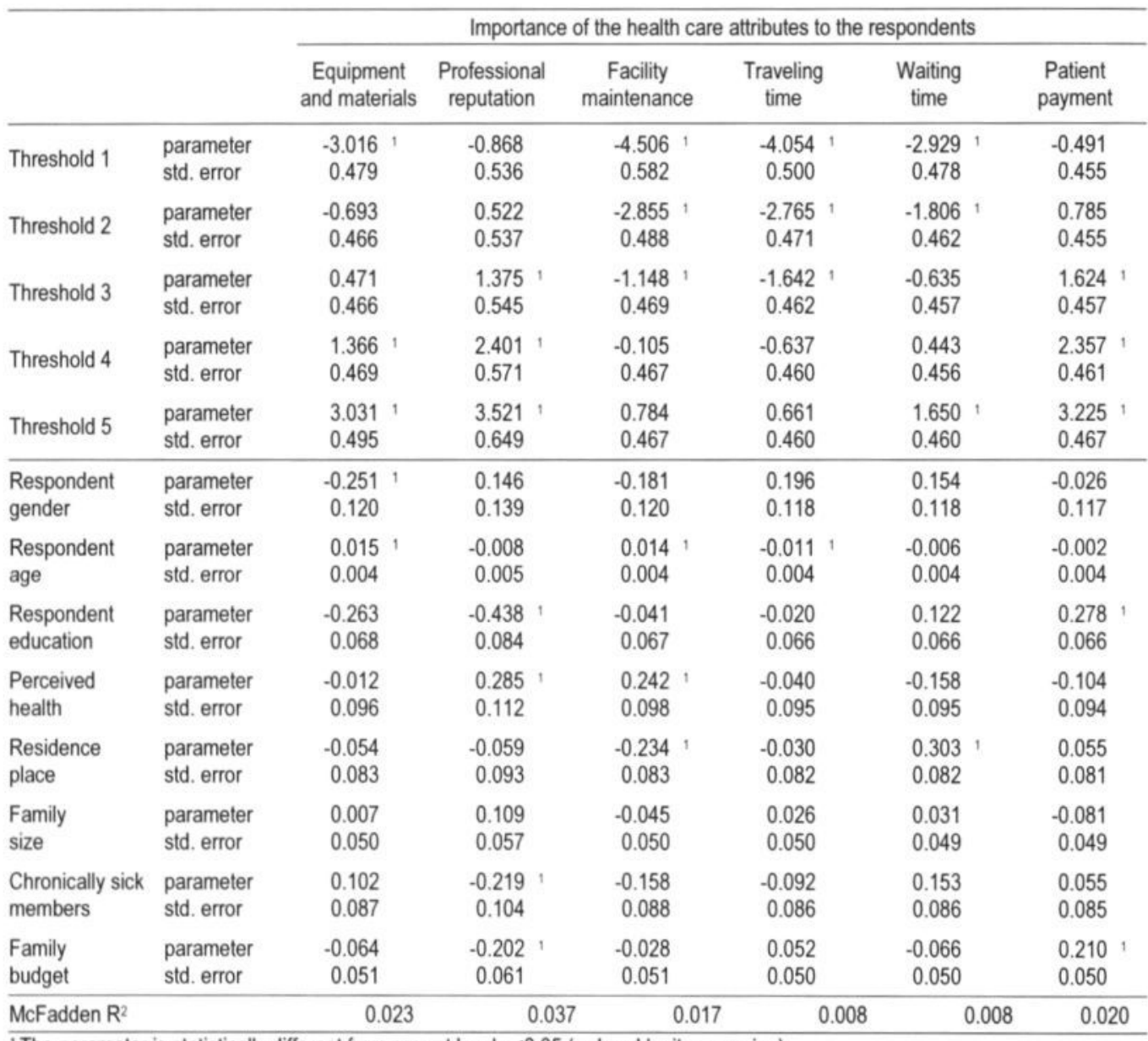

${ }^{1}$ The parameter is statistically different from zero at level $p<0.05$ (ordered logit regression)

It can be seen from table 4.2. that the importance attached to medical equipment is higher for respondents who are male, younger, higher educated, unhealthier and dwellers of smaller living areas. The same applies for the respondents who belong to smallest families, with fewer chronically ill members and higher incomes. Regarding professional reputation, the upper positions are largely supported by female, older, higher educated and healthier individuals, and by those who live in smaller settlements. The importance attached to professional reputation is higher for smaller families, with more chronically sick members and higher budgets. Compared to the ranking of professional reputation, the importance attached to patient payment is just oppositely related to all 
socio-demographic characteristics except for age. Office maintenance is placed at higher positions by male, younger, higher educated, healthier respondents and those living in smaller living areas. The importance attached to this attribute is also positively affected by an increase in the family characteristics. Travelling time, as well as waiting time, is more important to female people and those who are older, unhealthier and belong to smaller families. Contrary to travelling time, waiting time is more often ranked higher by lower educated persons and those who live in larger settlements, in families with less chronically ill members and higher incomes.

With the aim of comparing the influence of the social variables on the attribute rankings, the effects of the variables are computed using the equations $(4.1) \div(4.4)$. The results are presented in table 4.3 . A change in the rank probability by at least 0.5 is considered high.

Table 4.3. Total average absolute change in the predicted probabilities ${ }^{1,2}$

\begin{tabular}{|c|c|c|c|c|c|c|}
\hline \multirow[b]{2}{*}{ Variable } & \multicolumn{6}{|c|}{ Average absolute discrete change in the predicted probabilities } \\
\hline & $\begin{array}{l}\text { Equipment and } \\
\text { materials }\end{array}$ & $\begin{array}{l}\text { Professional } \\
\text { reputation }\end{array}$ & $\begin{array}{c}\text { Facility } \\
\text { maintenance }\end{array}$ & $\begin{array}{l}\text { Traveling } \\
\text { time }\end{array}$ & $\begin{array}{l}\text { Waiting } \\
\text { time }\end{array}$ & $\begin{array}{l}\text { Patient } \\
\text { payment }\end{array}$ \\
\hline $\begin{array}{l}\text { Respondent gender } \\
\text { (male } \rightarrow \text { female) }\end{array}$ & 0.02 & 0.01 & 0.01 & 0.02 & 0.01 & 0.00 \\
\hline $\begin{array}{l}\text { Respondent age } \\
(18 \rightarrow 85 \text { years })\end{array}$ & 0.08 & 0.04 & 0.07 & 0.06 & 0.03 & 0.01 \\
\hline $\begin{array}{l}\text { Respondent education } \\
\text { (no } \rightarrow \text { university) }\end{array}$ & 0.09 & 0.13 & 0.01 & 0.01 & 0.04 & 0.09 \\
\hline $\begin{array}{l}\text { Perceived health } \\
\text { (perfect } \rightarrow \text { bad) }\end{array}$ & 0.00 & 0.07 & 0.06 & 0.01 & 0.04 & 0.03 \\
\hline $\begin{array}{l}\text { Residence place } \\
\text { (city } \rightarrow \text { village) }\end{array}$ & 0.01 & 0.01 & 0.04 & 0.00 & 0.05 & 0.01 \\
\hline $\begin{array}{l}\text { Family size } \\
\text { ( } 1 \rightarrow 11 \text { persons) }\end{array}$ & 0.01 & 0.09 & 0.04 & 0.02 & 0.03 & 0.07 \\
\hline $\begin{array}{l}\text { Chronically sick members } \\
\text { ( } 0 \rightarrow 4 \text { persons) }\end{array}$ & 0.03 & 0.06 & 0.05 & 0.03 & 0.05 & 0.02 \\
\hline $\begin{array}{l}\text { Family budget } \\
(25 \rightarrow 1200 \mathrm{BGL})\end{array}$ & 0.04 & 0.10 & 0.02 & 0.03 & 0.04 & 0.11 \\
\hline
\end{tabular}

TThe probabilities are calculated when a variable changes from its min to its max, holding all other variables at their average values ${ }^{2}$ The discrete probability changes for male and female are approximately equal

The data in table 4.3. can be used to determine which socio-demographic characteristics have the strongest impact on the attribute ranking. A total change of a socio-demographic characteristic (from its minimum to its maximum value) that results in an average probability change higher than 0.05 is accepted to be strong. Thus, the strongest effects (probability changes $\geq 0.1$ ) are related to variations in the education level and in the family budget. Other strong effects (probability change of 0.6 up to 0.9 ) can be found regarding the changes in age, perceived health, family size and the number of chronically sick family members.

In order to examine the exact effect of changes in a socio-demographic variable on the attribute ranking, the average probabilities and discrete probability changes are calculated using the equations $(4.1) \div(4.3)$ and $(4.5)$. The computational results are presented in table 4.4. The table shows how the average rank probabilities alter if a particular socio-demographic factor changes from its average while all other variables are hold at the average values. 
Table 4.4. Discrete change in the predicted probabilities due to a change in a variable

\begin{tabular}{|c|c|c|c|c|c|c|c|}
\hline \multirow[b]{2}{*}{ Variable } & \multirow[b]{2}{*}{ Change $^{3}$} & \multicolumn{6}{|c|}{ Discrete change in the predicted probability 1.2} \\
\hline & & $\begin{array}{c}1^{\text {st }} \\
\text { important }\end{array}$ & $\begin{array}{c}2^{\text {nd }} \\
\text { important }\end{array}$ & $\begin{array}{c}3^{\text {rd }} \\
\text { important }\end{array}$ & $\begin{array}{c}4^{\text {th }} \\
\text { important }\end{array}$ & $\begin{array}{c}5^{\text {th }} \\
\text { important }\end{array}$ & $\begin{array}{c}6^{\text {th }} \\
\text { important }\end{array}$ \\
\hline Average probability & & 0.06 & 0.34 & 0.28 & 0.16 & 0.13 & 0.04 \\
\hline Respondent gender & +1 category & 0.02 & 0.05 & -0.01 & -0.02 & -0.02 & -0.01 \\
\hline$\frac{n}{\pi}$ Respondent age & +1 st. dev. & -0.01 & -0.05 & 0.00 & 0.02 & 0.03 & 0.01 \\
\hline 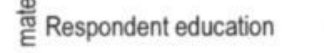 & +1 category & 0.02 & 0.05 & -0.01 & -0.02 & -0.02 & -0.01 \\
\hline ट్ల్ Perceived health & +1 category & 0.00 & 0.00 & -0.00 & -0.00 & -0.00 & -0.00 \\
\hline E్을 Residence place & +1 category & 0.00 & 0.01 & -0.00 & -0.00 & -0.01 & -0.00 \\
\hline 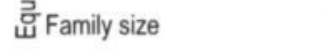 & + 1 st. dev. & -0.00 & -0.00 & 0.00 & 0.00 & 0.00 & 0.00 \\
\hline Chronically sick members & +1 st. dev. & -0.00 & -0.01 & 0.00 & 0.01 & 0.01 & 0.00 \\
\hline Family budget & +2 categories & 0.01 & 0.02 & -0.00 & -0.01 & -0.01 & -0.00 \\
\hline Average probability & & 0.67 & 0.22 & 0.06 & 0.03 & 0.01 & 0.01 \\
\hline Respondent gender & +1 category & -0.03 & 0.02 & 0.01 & 0.00 & 0.00 & 0.00 \\
\hline 들 Respondent age & +1 st. dev. & 0.03 & -0.02 & -0.01 & -0.00 & -0.00 & -0.00 \\
\hline 㽬 Respondent education & +1 category & 0.09 & -0.05 & -0.02 & -0.01 & -0.00 & -0.00 \\
\hline 등 Perceived health & +1 category & -0.07 & 0.03 & 0.02 & 0.01 & 0.00 & 0.00 \\
\hline Residence place & +1 category & 0.01 & -0.01 & -0.00 & -0.00 & -0.00 & -0.00 \\
\hline ฉ̊ Family size & +1 st. dev. & -0.03 & 0.02 & 0.01 & 0.00 & 0.00 & 0.00 \\
\hline Chronically sick members & +1 st. dev. & 0.04 & -0.02 & -0.01 & -0.01 & -0.00 & -0.00 \\
\hline Family budget & +2 categories & 0.08 & -0.05 & -0.02 & -0.01 & -0.00 & -0.00 \\
\hline Average probability & & 0.01 & 0.03 & 0.13 & 0.20 & 0.22 & 0.42 \\
\hline Respondent gender & +1 category & 0.00 & 0.01 & 0.02 & 0.02 & 0.00 & -0.04 \\
\hline$\Phi_{\mathscr{E}}^{\text {Respondent age }}$ & +1 st. dev. & -0.00 & -0.01 & -0.02 & -0.02 & -0.00 & 0.06 \\
\hline స్ల్ Respondent education & +1 category & 0.00 & 0.00 & 0.00 & 0.00 & -0.01 & -0.01 \\
\hline 돞 Perceived health & +1 category & -0.00 & -0.01 & -0.02 & -0.02 & -0.00 & 0.06 \\
\hline Residence place & +1 category & 0.00 & 0.01 & 0.03 & 0.02 & -0.01 & -0.06 \\
\hline${ }^{4}$ Family size & +1 st. dev. & 0.00 & 0.00 & 0.01 & 0.01 & 0.00 & -0.02 \\
\hline Chronically sick members & +1 st. dev. & 0.00 & 0.00 & 0.01 & 0.01 & 0.00 & -0.03 \\
\hline Family budget & +2 categories & 0.00 & 0.00 & 0.01 & 0.01 & 0.00 & -0.01 \\
\hline
\end{tabular}

The probabilities are calculated when a variable changes from its average value holding all other variables at their average

2 The discrete probability changes for male and female are approximately equal

${ }^{3}$ When a variable decreases with the same quantity the probability changes approximately equally but with an opposite sign 
Table 4.4. Discrete change in the predicted probabilities due to a change in a variable (continued)

\begin{tabular}{|c|c|c|c|c|c|c|c|}
\hline \multirow[b]{2}{*}{ Variable } & \multirow[b]{2}{*}{ Change $^{3}$} & \multicolumn{6}{|c|}{ Discrete change in the predicted probability 1.2} \\
\hline & & $\begin{array}{c}1^{\text {st }} \\
\text { important }\end{array}$ & $\begin{array}{c}2^{\text {nd }} \\
\text { important }\end{array}$ & $\begin{array}{c}3^{\text {rd }} \\
\text { important }\end{array}$ & $\begin{array}{c}4^{\text {th }} \\
\text { important }\end{array}$ & $\begin{array}{c}5^{\text {th }} \\
\text { important }\end{array}$ & $\begin{array}{c}6^{\text {th }} \\
\text { important }\end{array}$ \\
\hline Average probability & & 0.03 & 0.07 & 0.15 & 0.22 & 0.30 & 0.24 \\
\hline Respondent gender & +1 category & -0.00 & -0.01 & -0.02 & -0.01 & 0.01 & 0.04 \\
\hline Respondent age & +1 st. dev. & 0.01 & 0.01 & 0.02 & 0.01 & -0.01 & -0.03 \\
\hline E్ Respondent education & +1 category & 0.00 & 0.00 & 0.00 & 0.00 & -0.00 & -0.00 \\
\hline$\frac{\text { S. }}{\mathbf{s}}$ Perceived health & +1 category & 0.00 & 0.00 & 0.00 & 0.00 & -0.00 & -0.01 \\
\hline 莺 Residence place & +1 category & 0.00 & 0.00 & 0.00 & 0.00 & -0.00 & -0.01 \\
\hline Family size & +1 st. dev. & -0.00 & -0.00 & -0.00 & -0.00 & 0.00 & 0.01 \\
\hline Chronically sick members & +1 st. dev. & 0.00 & 0.00 & 0.01 & 0.00 & -0.01 & -0.01 \\
\hline Family budget & +2 categories & -0.00 & -0.01 & -0.01 & -0.01 & 0.01 & 0.02 \\
\hline Average probability & & 0.05 & 0.09 & 0.20 & 0.26 & 0.24 & 0.17 \\
\hline Respondent gender & +1 category & -0.01 & -0.01 & -0.02 & -0.00 & 0.01 & 0.02 \\
\hline Respondent age & +1 st. dev. & 0.00 & 0.01 & 0.01 & 0.00 & -0.01 & -0.01 \\
\hline 䛼 Respondent education & +1 category & -0.01 & -0.01 & -0.01 & -0.00 & 0.01 & 0.02 \\
\hline Derceived health & +1 category & 0.01 & 0.01 & 0.02 & 0.00 & -0.02 & -0.02 \\
\hline 3 Residence place & +1 category & -0.01 & -0.02 & -0.03 & -0.01 & 0.03 & 0.05 \\
\hline Family size & +1 st. dev. & -0.00 & -0.00 & -0.00 & -0.00 & 0.00 & 0.01 \\
\hline Chronically sick members & +1 st. dev. & -0.01 & -0.01 & -0.01 & -0.00 & 0.01 & 0.02 \\
\hline Family budget & +2 categories & 0.01 & 0.01 & 0.01 & 0.00 & -0.01 & -0.02 \\
\hline Average probability & & 0.20 & 0.25 & 0.20 & 0.14 & 0.11 & 0.10 \\
\hline Respondent gender & +1 category & 0.00 & 0.00 & -0.00 & -0.00 & -0.00 & -0.00 \\
\hline$=$ Respondent age & +1 st. dev. & 0.01 & 0.00 & -0.00 & -0.00 & -0.00 & -0.00 \\
\hline E Respondent education & +1 category & -0.04 & -0.03 & 0.00 & 0.02 & 0.02 & 0.03 \\
\hline 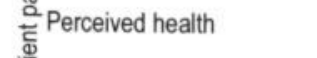 & +1 category & 0.02 & 0.01 & -0.00 & -0.01 & -0.01 & -0.01 \\
\hline ฮై Residence place & +1 category & -0.01 & 0.00 & 0.00 & 0.00 & 0.00 & 0.00 \\
\hline Family size & +1 st. dev. & 0.02 & 0.01 & -0.00 & -0.01 & -0.01 & -0.01 \\
\hline Chronically sick members & +1 st. dev. & -0.01 & 0.00 & 0.00 & 0.00 & 0.00 & 0.00 \\
\hline Family budget & +2 categories & -0.06 & -0.04 & -0.00 & 0.02 & 0.03 & 0.04 \\
\hline
\end{tabular}

\footnotetext{
1 The probabilities are calculated when a variable changes from its average value holding all other variables at their average

${ }^{2}$ The discrete probability changes for male and female are approximately equal

${ }^{3}$ When a variable decreases with the same quantity the probability changes approximately equally but with an opposite sign
} 
It can be seen from table 4.4. that the deviation from the average socio-demographic characteristics do not change the overall attribute ordering. The results in the table can be used to outline the trends in the probability modification resulting from a change in socio-demographic status. The table shows that for each service attribute, one of the rank probabilities always has the greatest absolute changes. The table also shows that for most attributes the probabilities of the highest ranks change in the same direction for all socio-demographic features. The probabilities of the remaining lower ranks always alter in the opposite direction and with the same total magnitude. For medical equipment, the changes in the first- and second-rank probabilities are opposite to the changes in the lower rank probabilities. However, variations in socio-demographic status primarily alter the probability that medical equipment is ranked second.

With respect to professional reputation, the likelihood of the first rank is most affected by changes in the socio-demographic status. The changes in the first-rank probability oppose changes in the lower levels. An increase in the importance attached to professional reputation indicates reinforcement of its first position and reduction in the low-rank probabilities. With respect to patient payment, the changes in the socio-demographic characteristics most strongly alter the first-rank probability. Thus, in general, an increased importance attached to patient payment means a higher chance that this attribute is ranked as most important.

Regarding office maintenance, travelling and waiting time, the changes in the social status most strongly influence their chances of being last. For travelling and waiting time, the changes in the probabilities of the four upper ranks are opposite to the changes in the probabilities of the two lowest ranks. With respect to the importance attached to office maintenance, the changes in the lowest-rank probabilities most often compensate the changes in the probabilities of the upper ranks.

\subsection{Relevance of the results}

The overall results on attribute ordering conclusively show that professional reputation is the most important attribute of health care services for the respondents. If it is accepted that the professional reputation is used by the consumers as a tag of the provider's knowledge and expertise, it can be assumed that the proficiency of the health care provider is what respondents value most. Similar result is reported in Zafirova and Kehaiova (2001), when studying he consumers' evaluation regarding the hospitals and hospital services in the region of Varna. The authors also report that proficiency of the health care provider is the most important attribute for the Bulgarian health care consumers.

Similarly to the study of Zafirova and Kehaiova (2001), the equipment and materials appears to be a second major concern of the Bulgarian health care consumer. The high importance attached to medical technology suggests that the respondents are not merely interested in the provider's personal ability, but also in the technical appropriateness of the services offered. Following Berki and Ashcraft (1980), the proficiency of the provider and the state of medical technology are referred to as clinical quality in the health care system. The high importance attached to professional reputation and medical equipment indicates that clinical quality is highly valued. This is, however, not surprising given the low quality of Bulgarian health care services and the considerable consumer dissatisfaction (see Delcheva et al, 1997; Ivanov et al, 1996; WHO-Euro, 1999).

While professional reputation and medical equipment are associated with clinical quality, the maintenance of the provider's working place is a hallmark of service quality not directly related to the medical treatment. Berki and Ashcraft (1980) refer to this as a social quality. However, the results in this paper reveal a very low importance attached to office maintenance among the 
respondents compared to the importance attached to range of equipement and materials, and professional reputation. This implies that the respondents are primary pursuing a competent and appropriate medical help rather than comfortable facilities.

The significance of social quality is even lower than the overall importance attached to travelling and waiting time. This finding however, differs from the results reported by Zafirova and Kehaiova, (2001), where facility maintenance is found to be more important than the location of the health care facility.

Regarding the travelling time it can be accepted that this service attribute indicates the proximity of the health care facility. Consequently, it can be assumed that its importance shows the value of the spatial access to the respondents. Similarly, if it is assumed that waiting time signifies the time before the actual contact with the provider then the importance attached to waiting time shows the value attached to the temporal access (Berki and Ashcraft, 1980). If a comparison is made between the significance of the spatial and temporal access, the latter is generally viewed as more important to the sample than the former. Thus, shorter queues in front the doctor's office is of higher value to the respondents than proximity of the facility location. Hence, both access aspects are more important to people in the sample than facility maintenance, but less important than clinical quality. A lower importance of the special access compare to clinical quality is reported by Zafirova and Kehaiova (2001) as well. A plausible explanation for these research findings can be found in the wide network of health care facilities that exists in Bulgaria (see EOHCS, 1999; WHOEuro, 1999).

Patient payment is also a service attribute with considerable significance to the respondents. The high significance of patient payment for the choice of health care provider can be explained to some extend by the low standard of living in Bulgaria (see NSI, 2000). Patient payment clearly symbolises a price that needs to be paid for using health care services. The results in this paper show that on average the patient payment is seen as more important than access and facility maintenance, but less important than clinical quality. Similar findings are also reported by Zafirova and Kehaiova (2001). Probably, the respondents more often accept to pay for competent and appropriate medical aid than for easy accessible service and a comfortable facility. The results further show that the opinion of the sample regarding the importance of patient payments is diverse. The respondents are more equally distributed over the rank ordering than for the other attributes. The rank of patient payment might be influenced by external factors and not merely by attitudes towards payments. One probable external factor might be economic constraints

The regression analysis provides rather mixed results regarding the ranking of the attributes and socio-demographic status. There are no two attributes, which rankings are identically related to the set of the socio-demographic variables. For each pair of attributes, the directions of the respective relations differ for at least one characteristic. Additionally, there is no socio-demographic characteristic that considerably affects the ranking of all attributes. The deviations from the average socio-demographic status do not modify the overall attribute ordering. This suggests that the interviewed probably give an answer based on complex criteria not solely based on their social status. Moreover, psychological factors and experience unrevealed by the survey might also determine the individual attribute ordering.

The results of data analysis, however, can be used to indicate some important differences between the various socio-demographic groups. For instance, the effect of gender on the rank of all attributes is rather small and virtually insignificant. Men and women most probably attach similar importance to the attributes included in the survey. The move from a larger to a smaller residence 
place, although significant in case of facility maintenance and waiting time, also has a relatively minor total effect on the perceived importance.

Major and significant effects on the attribute rankings are found for age. An increase of age diminishes the likelihood that medical equipment is generally ranked on the second place. It also strengthens the overall probabilities that office maintenance is seen as least important. Finally, it increases the probability that travelling time is ranked high. Thus, older persons are more concerned with the proximity of the services, whereas the younger value well-equipped and maintained facilities more. The former is not surprising given that, in Bulgaria, older persons are living mainly in rural areas where fewer health care facilities are available.

The move to a higher education level has a considerably effect on the rank of medical equipment, professional reputation and patient payment. It significantly increases the perception that professional reputation is most important. It also leads to an increase in the odds that medical equipment is ranked second and significantly reduces the probability that patient payment is ranked first. Thus, individuals with low education are less interested in quality and are more concerned with patient payment than those with a higher education. If it is considered, however, that lower educated persons generally have lower incomes than persons with a high education, the higher importance of patient payments attached by the former is to be expected.

A reduction in perceived health has a strong and significant effect on the importance attached to professional reputation and office maintenance. A reduction in the perceived health status diminishes the importance attached to both attributes. Thus, persons in bad health attach less value to professional reputation and office maintenance than healthier persons.

Regarding family characteristics, a larger family size has a strong, although not significant effect on the importance attached to professional reputation and patient payment. Bigger families are more concerned with patient payments and less with provider's qualities compared to smaller families. The higher income constraints of bigger families may well explain why they attach a high importance to patient payments.

An increase in the number of chronically sick persons notably elevates the ranking of professional reputation. Thus, in families with a high number of chronically sick persons, the provider's skills are higher valued than in families with no chronically sick persons. Members of families with many chronically sick persons probably recognise the importance of quality of health care services for the health status of their relatives.

Finally, the family budget considerably and significantly affects the rank of professional reputation and patient payments. The rise of the median family income increases the odds that professional reputation is ranked first. It also reduces the chance that patient payment is ranked first. The rise in family wealth increases the importance attached to the provider's expertise and lowers the rank of patient payment. This confirms that the income constraints have an impact on the importance that the consumers attach to patient payment.

\subsection{Possible response biases}

The importance of the health care attributes in this survey is elucidated by asking the respondents to rank the attributes according to their significance to them. This survey approach to the revelation of the attribute importance is characterised by an easier application and data analysis than the alternative analysis of either actual or hypothetical consumers' choice of provider.

Compared to the analysis of actual consumers' choice of provider, the used survey approach has some additional advantages. It allows to study the attributes independently from each other, as 
well as to analyse the attributes even if they are actually inaccessible (Vriens, 1995). Yet, the set of attributes presented to the respondents represent only a part of the real attribute set. This may have biased the importance attached to some of the attributes because other attributes are not included in the survey (Chakraborty, 1993).

Compared to the analysis of the hypothetical consumers' choice of provider, the survey method applied possesses some disadvantages. Most of them are related to biased responses and a problematic utility measure. Although this paper is not concerned with the measurement of utility and the later weakness can be consider as insignificant, the possibility for biased responses should be considered. These response biases may primary be caused by a misunderstanding of the ordering task or by an attempt to give socially acceptable answers. In both cases, the important attributes can be underestimated and less important ones can be over-estimated (Vriens, 1995; Ettenson et al., 1988).

\subsection{Conclusions}

The results and the discussion in this paper suggest that the provider's expertise is the primary concern of Bulgarian health care consumers. The range of medical equipment and materials appears to be the next important attributes of Bulgarian health care service. The high importance attached to professional reputation and medical equipment suggests that clinical quality is a highly valued feature. If consumer values are regarded as a criterion for the reinvestment of the revenue of patient payments in Bulgaria, the allocation of at least a part of this revenue to the improvement of clinical quality should be a high priority.

While competent and appropriate medical help is of considerable importance for the consumers, the appearance of the facilities is the least important of the attributes included in this survey. Thus, spending the revenues of patient payments to improve the maintenance of the health care facility will be less appreciated by consumers.

The access-related attributes of the health care services appear to be more important than the facility maintenance, but less important than the clinical quality of the health care services. This may suggest that the allocation of payment revenues to the improvement of access should be of lower priority than the allocation of payment revenues to the improvement of clinical quality.

Still, if it is decided that part of the patient payments collected are going to be spend for the improvement of access it should be considered that the temporal access is generally more important for the consumers than the spatial one. Thus, shorter waiting times and queues in front the doctor's office is of higher value to the respondents than proximity of the facilities. This may imply that spending the payment revenues for the enlargement of existing health care facilities is preferred over building new ones closer to the users.

Patient payments also appear to be a service attribute of considerable significance. This means that the sample is generally price sensitive and this should be considered when dealing with the patient payment mechanism. In particular, the willingness and ability to pay should be taken into account when settling fees.

Regarding the impact of the social status, its changes do not alter the overall attribute ordering. Therefore, it can hardly be expected that discrete changes in the socio-demographic features can modify the overall attribute ordering. In some instances, however, the discrete socio-demographic changes have a considerable effect on the rank probabilities of the attributes. Relations between the socio-demographic characteristics and the attribute importance can be taken into consideration 
when deciding how to allocate the payment revenues within health care facilities predominantly utilised by a particular social group.

For instance, the analysis reveals that the younger persons in general value well-equipped and maintained facilities more than older people. Thus, in health care facilities with mostly young patients, the allocation of payment revenue to the enhancement of the facility equipment and maintenance can be of higher priority than the priority level in other facilities.

Further, the inhabitants of smaller settlements are less attracted by short queues than individuals who live in cities. This implies that spending the payment revenues for the enlargement of existing health care facilities is more valued in the big cities, but not in the rural areas. Bigger and less wealthy families are more concerned with patient payment and less with the provider's qualities compared to smaller and richer families. Health care facilities that are mostly utilised by members of big or poor families should collect lower patient payments although at the cost of employing less experienced physicians.

The awareness of the relation between the social status and the attribute importance can also help to foresee the appropriate allocation of payment revenues in the future. Thus, for example, the aging of the population may require resources for the improvement of the physicians' reputation, since these feature is more valued by the elderly than by younger people. The increasing number of people living in the big cities implies that spending the payment revenues for the enlargement of existing health care facilities may become essential in the future. The decreasing family size and the increasing family wealth suggest that gradually the size of patient payment can become less important than it is at the present, but the value of the good professional can be higher. Thus, in the future the size of patient payment may well be raised in order to gather larger revenues for improving of the physician competency.

\section{References:}

Bennett, S. and Ngalande-Banda, E. (1997). Public and private roles in health: a review and analysis of experience in Sub-Saharan Africa. WHO/ARA/CC/97.6. Geneva: The World Health Organisation.

Berki, S.E. and Ashcraft, M.L.F. (1980). HMO enrolment: who joints what and why: a review of literature. Milbank Memorial Fund Quarterly/Health and Society 58: 588-632.

Borisov, V. and Rathwell, T. (1996). Health care reforms in Bulgaria: an initial appraisal. Social Science and Medicine 42: 1501-1510.

Chakraborty, G., Gaeth, G.J. and Cunningham, M. (1993). Understanding consumers' preferences for dental services. Journal of Health Care Marketing (Fall): 48-58.

Creese, A. (1991). User charges for health care: a review of recent experiences. Health Policy and Planning 6: 309-319.

Delcheva, E., Balabanova, D. and McKee, M. (1997). Under-the-counter payments for health care: evidence from Bulgaria. Health Policy 42: 89-100.

Ettenson, R., Wagner, J. and Gaeth, G. (1988). Evaluating the effect of country of origin and "made in USA" campaign: a conjoint approach. Journal of Retailing 64: 223-238. 
EOHCS (1999). Health care systems in transition: Bulgaria. European Observatory on health care systems Copenhagen: The World Health Organization/Regional Office for Europe.

Ivanov, L, Glutnokova, Z. and Kalinov, K. (1996). Sociological survey: adequacy and quality of primary health care. Bulletin of National Centre of Public Health 1(December): 47-78.

Litvack, J.I. and Bodart, C. (1993). User fees and improved quality of health care equals improved access: results from a field experiment in Cameroon. Social Science Medicine 37: 369-383.

Long, J.S. (1997). Regression models for categorical and limited dependent variables. Thousand Oaks: Sage Publications.

Mooney, G. (1994). What else do we want from our health services?. Social Science and Medicine 39: 151154.

NSI (2000). Statistical reference book 2000 (in Bulgarian). Sofia: National Statistical Institute.

Van Beek, K.W.H., Koopmans, C.C. and van Praag, B.M.S. (1997). Shopping at the labour market: a real tale of fiction. European Economic Review 41: 295-317.

Vriens, M. (1995). Conjoint analysis in marketing: developments in stimulus representation and segmentation methods. PhD Thesis. Groningen: Labyrint Publication.

WHO-Euro (1999). Better health for better future in Bulgaria: a health policy proposal. Draft 2. Unedited. 23rd February.

WHO (1996). European health care reforms: analysis of current strategies. Copenhagen: The World Health Organization/Regional Office for Europe.

Zafirova, T. and Kehaiova, M. (2001). An investigation of the consumers' evaluation regarding the hospitals and hospital services in the region of Varna and its application to strategic decision making (in Bulgarian). Godishnik na Ikonomicheskia Universitet Varna 73(1): 1-47. 


\section{CHAPTER 5}

\section{The importance of quality, access and price to Bulgarian health care consumers: A conjoint analysis}

An abstract of the chapter is published In: Abstracts from the $23^{\text {th }}$ Annual Meeting of the Society for Medical Decision Making, Medical Decision Making 2001, 21(6): 517-554 under the heading Pavlova M., Groot W. and van Merode G. The importance of quality, access and price to health care consumers: results of a conjoint analysis. 


\subsection{Introduction}

Given the competitive challenges that face health care providers and health insurance institutions, the understanding of consumers' preferences for health care services is becoming an important task. To be able to respond to the needs of their patients and to attract particular patient segments, health care providers need to know how consumers select their physicians and hospitals. (Chakraborty et al., 1994; Chakraborty et al., 1993; Graf et al., 1993; Scotti et al. 1986). The understanding of consumers' choices in the health care sector is essential for public decision makers as well. The development of a public health programme that reflects consumer preferences for the various programme characteristics can strengthen the participation level (Spoth and Redmond, 1993). The understanding of consumer preferences can also facilitate the optimal location of public health care institutions and their improvement (Parker and Srinivasan, 1976).

The importance of knowledge on consumer preferences regarding multi-attributed health care services, programmes and insurance plans for policy making has been already recognised. However, there is still little insight into how these preferences should be studied and interpreted. The interest in their proper analysis is growing continuously (Singh et al., 1998).

Outside the health car sector, consumer preferences for multi-attributed commodities have been a major topic in consumer research since the end of 1960's (Green and Srinivasan, 1978, Moore, 1980). A review of the literature indicates two main approaches to the modelling of consumer preferences: the revealed preference and the stated preference approach. The revealed preference approach relies on data from an observation of the actual consumers' behaviour at a real market place. The stated preference approach is based on data stated in a survey by potential consumers with regard to their behaviour in a specified hypothetical market situation. Both approaches have their advantages and disadvantages. The revealed preference approach, for example, does not always allow to analyse the separate effect of each commodity characteristic (due to natural correlations) and to make casual inferences (due to absence of an experimental design). The stated preference approach can circumvent these disadvantages and furthermore, it can be applied even if an actual market does not exist or if true consumer preferences cannot be revealed. However, the stated preference approach, in contrast to the revealed preference approach, usually offers lower internal validity and its ability to predict actual consumer behaviour is often questionable (Vriens, 1995).

Nevertheless, one representative of the stated preference approach, the conjoint analysis, has gained recognition as a rigorous and valid method for studying consumer preferences. Conjoint analysis has become a widely applied technique for the marketing of commercial goods (Carroll and Green, 1995; Singh et al., 1998). It belongs to the group of quantitative research methods. Its foundations are rooted in the area of mathematical psychology concerned with information processing and complex decision-making (Neil, 1992; Wind and Spitz, 1976). The work of Luce and Tukey (1946) has been often mentioned as the start of the development of the conjoint measure. Except for marketing of commercial goods, the technique has been applied in transport and environmental economics (Ryan and Hughes, 1997). In the health care sector, the potential of conjoint analysis is also recognised, but until recently, it has received little attention. (Ryan et al., 1998; Singh et al., 1998).

The aim of this paper is to study the importance of the attributes of health care services to the Bulgarian consumers using a conjoint analysis and to show how these results can be used in health policy making. The study examines the joint impact of hypothetical quality, access and price levels on the evaluation of a health care service by Bulgarian consumers. Following this introduction, a 
description of the conjoint approach is presented in three subsequent sections: survey preparation, data collection and data analysis. The paper further presents the results of the conjoint study conducted in Bulgaria and their discussion. The paper is completed by outlining possible applications of the results in health policy making.

\subsection{Preparation of the conjoint study}

The conjoint analysis aims to measure the joint effect of the attributes of a commodity on the individual response (Wind and Spitz, 1976). It supposes that each commodity is a bundle of potential attributes with specific attribute levels and each individual derives unique utility from each attribute level. The specific combination of attribute levels in a profile determines the individual preferences for that profile (Singh et al., 1998). In a conjoint study, each respondent is presented with a description of a commodity, which is called a profile. The profile consists of $\mathrm{p}$ attributes and each attribute is represented in the profile by one of its levels. Lets assume that $x_{i j m}$ is the $j^{\text {th }}$ level of the attribute $\mathrm{i}$ that is present in the profile $\mathrm{m}$ and $\mathrm{u}_{\mathrm{ijk}}$ is the part-worth utility derived by the individual $\mathrm{k}$ from that attribute level. The classical conjoint analysis assumes that the preference $\mathrm{Y}_{\mathrm{mk}}$ of an individual $\mathrm{k}$ for a profile $\mathrm{m}$ is given by the equation (5.1).

$$
Y_{m k}=U_{m k}+\varepsilon_{m k}=\sum_{i=1}^{p} u_{i j k}\left(x_{i j m}\right)+\varepsilon_{m k}
$$

where $\mathrm{U}_{\mathrm{mk}}$ is the utility of a p-attributed profile $\mathrm{m}$ derived by the individual $\mathrm{k}$ and $\varepsilon_{\mathrm{mk}}$ is a random error term associated with the stated preference (Singh et al., 1998; Vriens, 1995). The equation (5.1) suggests that, in conjoint analysis, the preference for a profile is assumed to be equal to the sum of the part-worth utilities related to the attribute levels in this profile. The higher an individual overall utility for a specific profile, the greater is the individual preference for that profile (Singh et al., 1998; Wind and Spitz, 1976). Thus, based on (5.1) and using multivariate techniques, the conjoint analysis, decomposes the individual preferences for alternative profiles into part-worth utilities derived from the various attribute levels included in the study (Wind and Spitz, 1976).

In order to specify the conjoint model, three main issues should be considered. First, it is necessary to identify which attributes will be included in the survey and what will be their levels. Second, the attribute levels should be combined in order to determine the profiles that will be shown to the respondents. Finally, it should be decided how to elicit the consumer preference regarding each profile.

There are no strict rules how to select the attributes. The attributes may describe, for example, physical properties, benefits, price and brand names. However, they should be determinants of consumer choice and should convey meaningful information (Neil, 1992). A number of methods exist to define the attributes of interest in a conjoint analysis. This includes literature reviews, group discussions, individual interviews and direct questioning of individuals. Alternatively, it may be that the researcher is interested in given attributes from a predefined policy questions, or that results from previous studies indicate attributes that need to be valued (Ryan and Hughes, 1997).

In the survey, presented in this paper, the commodity of interest is the health care service and it is described by six attributes. These are the availability of equipment and materials, the professional reputation of the physician, the maintenance of the health care facility, the time for travelling to physician's office, the time for waiting in front the office and the amount of money that has to be 
paid by the patient. The selection of these attributes is a result of research interests in three basic concepts quality, access and price, and the importance that the Bulgaria health care consumers attach to them. These three concepts are operationalised through tangible service attributes. The possibility to represent the concept price through the attribute 'size of patient payment' is rather obvious. The operationalisation of the concepts quality and access is, however, more complicated given their numerous aspects. In order to simplify the task, the framework of Berki and Ashcraft (1980) for analysing consumer preferences for a health plan was used. Berki and Ashcraft (1980) distinguish between clinical and social quality, and between spatial, temporal and psychological access.

Clinical quality has two basic aspects related to the technology used and to the provider's ability. Therefore, it is represented by the attributes 'availability of equipment and materials' and 'professional reputation of the physician'. The attribute 'professional reputation' is used as a tag for the provider's knowledge and proficiency. The attribute 'facility maintenance' is used as an indication of social quality, and 'travelling time' and 'waiting time' represent spatial and temporal access respectively. The psychological access was not considered in the study.

There are no strict rules about the selection of the attribute levels either. The attribute levels can be metric, scaled, ordinal or nominal. The levels should be meaningful, informative and realistic, as well as relevant to policy. The range of attribute levels should be narrow enough in order to compare truly competitive products. The number of the levels per attribute should be similar across all attributes in order to avoid artificially impacted attribute's importance due to a high number of levels (Neil, 1992).

The attribute levels included in the survey are presented in table 5.1. The table shows that two of these attributes (the professional reputation and the size of patient payment) have three levels. The professional reputation is not good, unknown or good, whereas the size of patient payment can be 10.-, 5.- or 2.50 BGL. (One Bulgarian lev equals half Euro.) The other four attributes have two levels. The medical equipment is characterised with either major lacks or full range. For the maintenance of the health care facility, the attribute levels are good and bad, and for both travelling time and waiting time, the levels are short and long. The attribute levels are ordered in this study from presumably less preferred levels to levels that are expected to be more preferred. It is expected that the level 1 is less preferred than level 2 and level 2 is less preferred than level 3 (if applicable).

Table 5.1. Attributes and attribute levels

\begin{tabular}{lllll}
\hline Attributes & \multicolumn{1}{c}{ Level 1 } & Level 2 & Level 3 \\
\hline 1.Materials and equipment & $x_{11}=$ major lacks & $x_{12}=$ full range & - \\
2.Professional reputation & $x_{21}=$ not good & $x_{22}=$ unknown & $x_{23}=$ good \\
3.Facility maintenance & $x_{31}=$ bad & $x_{32}=$ good & - \\
4.Travelling time & $x_{41}=$ long & $x_{42}=$ short & - \\
5.Waiting time & $x_{51}=$ long & $x_{52}=$ short & - \\
6.Patient payment & $x_{61}=10 .-$ BGL & $x_{62}=5$. BGL & $x_{63}=2.50$ BGL \\
\hline
\end{tabular}

After determining the attributes and their levels, they need to be combined in order to generate the profiles that will be given to the respondents for evaluation. In the profiles, each attribute appears once with one of its levels. Generally, all possible combinations between the levels of the 
attributes need to be studied, but this will results in a very high number of profiles. Having in mind that in this survey there are 2 attributes with 3 levels and 4 attributes with 2 levels, there are 144 possible combinations.

Asking a respondent to evaluate 144 profiles is ineffective and unnecessary. This number can be reduced to a more manageable level using a specific class of procedures called fractional factorial designs. These procedures determine a specific subset of all possible combinations that permits the interpolation of the preferences for the unmeasured combinations. The procedures, however, rely on the assumption that there is no interaction between the attributes and their application allows analysing only the main effects of the attributes (Green, 1974; Ryan and Hughes, 1997). Based on such procedure in the statistical package SPSS 10, the number of the combinations in this survey was reduced to 16. The combinations of attribute levels included in the survey are presented in table 5.2. The combinations are subsequently notated with letters from A to P. Each combination of attribute levels determines a particular profile with an identical name. Thus, for example, the combination A determines the profile $\mathrm{A}$. This profile is characterised with a full range of equipment and materials (level $\mathrm{x}_{12}$ ), a bad professional reputation (level $\mathrm{x}_{21}$ ), a badly maintained facility (level $\mathrm{x}_{31}$ ), short travelling time (level $\mathrm{x}_{42}$ ), long waiting time (level $\mathrm{x}_{51}$ ) and 5.- BGL paid by the patient (level $\mathrm{x}_{62}$ ). The rest of the profiles can be described in a similar manner.

Table 5.2. The combinations of attribute levels in the profiles

\begin{tabular}{|c|c|c|c|c|c|c|c|c|c|c|c|c|c|c|c|c|}
\hline \multirow[b]{2}{*}{ Attributes } & \multicolumn{16}{|c|}{ Identification of the profiles } \\
\hline & A & $\mathrm{B}$ & $\mathrm{C}$ & D & $E$ & $\mathrm{~F}$ & G & $\mathrm{H}$ & 1 & $\mathrm{~J}$ & $\mathrm{~K}$ & L & M & $\mathrm{N}$ & 0 & $\mathrm{P}$ \\
\hline Equipment and materials & $x_{12}$ & $x_{11}$ & $x_{12}$ & $x_{12}$ & $x_{12}$ & $x_{11}$ & $\mathbf{x}_{12}$ & $x_{11}$ & $x_{12}$ & $x_{11}$ & $x_{11}$ & $x_{11}$ & $x_{11}$ & $x_{12}$ & $x_{11}$ & $x_{12}$ \\
\hline Professional reputation & $x_{21}$ & $\mathrm{x}_{22}$ & $\mathrm{x}_{23}$ & $\mathrm{x}_{21}$ & $\mathrm{x}_{22}$ & $\mathrm{x}_{23}$ & $\mathrm{x}_{21}$ & $\mathrm{x}_{23}$ & $\mathrm{x}_{21}$ & $\mathrm{x}_{23}$ & $x_{21}$ & $\mathrm{x}_{21}$ & $\mathrm{x}_{22}$ & $\mathrm{x}_{22}$ & $\mathrm{x}_{21}$ & $x_{21}$ \\
\hline Facility maintenance & $x_{31}$ & $\mathrm{x}_{31}$ & $\mathrm{x}_{32}$ & $x_{31}$ & $\mathrm{x}_{31}$ & $\mathrm{x}_{31}$ & $x_{31}$ & $x_{31}$ & $\mathrm{x}_{32}$ & $x_{32}$ & $x_{31}$ & $\mathrm{x}_{32}$ & $\mathrm{x}_{32}$ & $\mathrm{x}_{32}$ & $\mathrm{x}_{32}$ & $\mathrm{x}_{32}$ \\
\hline Travelling time & $x_{42}$ & $x_{42}$ & $x_{42}$ & $x_{41}$ & $x_{42}$ & $\mathrm{x}_{41}$ & $x_{41}$ & $x_{41}$ & $x_{42}$ & $x_{42}$ & $x_{42}$ & $x_{41}$ & $x_{41}$ & $x_{41}$ & $x_{42}$ & $x_{41}$ \\
\hline Waiting time & $x_{51}$ & $x_{51}$ & $x_{51}$ & $\mathrm{x}_{52}$ & $\mathrm{X}_{52}$ & $x_{52}$ & $x_{51}$ & $x_{51}$ & $\mathrm{x}_{52}$ & $x_{52}$ & $x_{52}$ & $x_{52}$ & $x_{51}$ & $\mathrm{x}_{52}$ & $x_{51}$ & $x_{51}$ \\
\hline Patient payment & $x_{62}$ & $x_{63}$ & $x_{61}$ & $x_{63}$ & $x_{61}$ & $x_{62}$ & $x_{61}$ & $x_{61}$ & $x_{62}$ & $x_{63}$ & $x_{61}$ & $x_{61}$ & $x_{62}$ & $x_{61}$ & $x_{61}$ & $x_{63}$ \\
\hline
\end{tabular}

Regarding the elucidation of the consumers' preferences, there are three alternative methods: rating, ranking and choice-based. The first method involves the presentation of the respondents with one profile at a time and asking them to rate their preferences for this profile on a predetermined scale. The second one requires presenting to the respondents all profiles at once and asking them to rank the profiles in the order of their preference. The third method requires the presentation of the respondents with two profiles at a time and asking them to choose the profile, they prefer more (Singh et al., 1998). Although the last two methods are more realistic, the study reported here uses rating because the results of the pilot survey showed that it is less time consuming.

\subsection{Collection of the conjoint data}

The conjoint data presented in this paper are collected in a household survey. The survey was conducted in May and June 2000 among citizens of Varna (the third largest Bulgarian city) and in its region. The survey relied on interviews based on a standard questionnaire, which were pre-tested 
in a pilot survey. The interviews were performed by the interviewer stuff of APEA (a local branch of BBSS Gallup International). Each interviewer performed on average 15 interviews.

The respondents were randomly selected in each municipality in the Varna region in proportional to population size and age-gender characteristics. In total, 1094 individuals were contacted. With respect to the conjoint analysis, the survey produced 917 useful interviews. Thus, the overall response rate is $84 \%$. Detailed information on the socio-demographic variables included in the analysis is presented in appendix C. 3

During the interviews, the respondents were presented with one profile of physician's services and were asked to rate the level of their preferences for that profile on a Likert scale. The Likert ranged from 1 (very low preference) to 5 (very high preference). This task was repeated 16 times for each of the 16 profiles included in the study. The English wording of the questions is given in appendix A (see Q10)

The profiles were presented to the respondents in a diverse order. The interviewers presented their first respondent with a standard sequence of profiles, starting with the profile A and finishing with the profile $\mathrm{P}$. The starting point of every next respondent was the third profile in the sequence presented to the previous respondents. Thus, starting point for the second respondent of each interviewer was the profile $\mathrm{C}$, for the third respondents it was the profile $\mathrm{E}$ and similarly, for the rest of the respondents. The variation of the starting point is used to avoid biases related to the order in which the profiles are presented to the respondents.

\subsection{Analysis of the profile rating}

Based on the responses, part-worth utilities derived from the attribute levels for each respondent are extracted through a linear regression with dummy variables. This is a relatively simple procedure that is successfully applied to analyse rating data from conjoint studies (Malhotra, 1993). In a dummy ordinary least square regression, the dependent variable is the set of preference rates $Y_{k}$ for all profiles stated by an individual $\mathrm{k}$. The independent variables are dummy variables that code the levels of the attributes. The dummy variables can take values 1 or 0 . The levels of each attribute are coded by $\mathrm{h}-1$ dummy variables, where $\mathrm{h}$ is the maximum number of attribute levels in the particular conjoint. For example, in the conjoint study presented here, the maximum number of attribute levels is three and therefore, the levels of one attribute are coded by two dummy variables.

The highest level of each attribute is coded by dummy variables with value 0 and this level is called the base level. The total number of dummy variables is determined by the number of attributes and the maximum number of attribute levels. In case, there are $\mathrm{p}$ attributes and maximum $\mathrm{h}$ attribute levels it necessary to use $\mathrm{p}(\mathrm{h}-1)$ dummy variables (Malhotra, 1993). In the survey presented here, there are six attributes and the levels of one attribute are coded by two dummy variables. Thus, totally twelve dummy variables are used. If $\mathrm{X}_{\text {in }}$ is the $\mathrm{n}^{\text {th }}$ dummy variable that code the levels of attribute $\mathrm{i}$, the model to be estimated in the optimal least square regression is given by equation (5.2).

$$
Y_{k}=\sum_{i=1}^{p} \sum_{n=1}^{h-1} a_{i n k} X_{i n}
$$

Given the coding with dummy variables, in which the highest level is the base level, the coefficients $\mathrm{a}_{\text {ink }}$ can be related to the part-worth utilities derived by an individual $\mathrm{k}$ from the levels of the attribute i. Each coefficient $\mathrm{a}_{\text {ink }}$ represents the differences in the part-worth utilities derived 
from one level of the attribute i minus the part-worth utility derived by the base level of the same attribute. In order to calculate the part-worth utilities, however, it is necessary to assume that the sum of the part-worth utilities derived from the levels of one attribute equal zero. This constraint is applied because the part-worth utilities are estimated on an interval scale which origin is arbitrary. The application of this constraint suggests that the values that represent the part-worth utilities calculated in conjoint analysis based on dummy regression analysis can not be interpreted as absolute numbers (Malhotra, 1993). The dummy regression analysis, described above, is performed in this study using the conjoint procedure in the statistical package SPSS 10.1. The conjoint procedure calculates the part-worth utilities derived by each individual and stores them in a separate data file.

The part-worth utilities for an individual can be further used to estimate the relative importance of an attribute for that individual. As shown in equation (5.3), the relative importance $\mathrm{I}_{\mathrm{ik}}$ of an attribute $\mathrm{i}$ for an individual $\mathrm{k}$ is determined as the ratio between the range of the part-worth utilities of that attribute $r_{i k}$ and the sum of the part-worth ranges of all $p$ attributes included in the study. The range of the part-worth utilities of the attribute $\mathrm{i}$ is calculated by subtracting the minimum partworth utility $\mathrm{u}_{\mathrm{ik}}^{\min }$ from the maximum part-worth utility $\mathrm{u}_{\mathrm{ik}}^{\max }$ related to that attribute (Malhotra, 1993). Based on (5.3), the relative importance of the six attributes included in the survey is estimated for each respondent.

$$
\mathrm{I}_{\mathrm{ik}}=\frac{\mathrm{r}_{\mathrm{ik}}}{\sum_{\mathrm{i}=1}^{\mathrm{p}} \mathrm{r}_{\mathrm{ik}}}=\frac{\mathrm{u}_{\mathrm{ik}}^{\max }-\mathrm{u}_{\mathrm{ik}}^{\min }}{\sum_{\mathrm{i}=1}^{\mathrm{p}}\left(\mathrm{u}_{\mathrm{ik}}^{\max }-\mathrm{u}_{\mathrm{ik}}^{\min }\right)}
$$

The disaggregated conjoint analysis has demonstrated a good predictive validity and therefore it is often preferred over the aggregated analysis. However, the set of individual attribute importance cannot help to understand consumer preferences (Moore, 1980). In order to be able to outline the implications of the conjoint analysis for policy, some kind of aggregation must be performed.

In this study, the individual results are aggregated by estimating the average attribute importance. The average results can easily be used to determine the type of health care services that is preferred by an average individual. It is considered, however, that such interpretation of the conjoint results can be associated with a problem called by Kuehn and Day (1962) the majority fallacy. The majority fallacy appears when a part of the respondents have high preferences for a certain attribute level and the other part has low preferences for the same attribute level. In this case, it will be concluded that the individuals will on average have medium preferences, although no one in the sample has such. The majority fallacy is caused by the heterogeneity of the consumer preferences, which are anyway expected in every conjoint study (Moore, 1980).

In order to determine whether the importance of the health care attributes in this study actually differ between the sample groups, a ordinary least square regression is performed. For that purpose the individual results are organised into six dependent variables, each of which contains the individual's relative importance of one attribute. Each dependent variable is regressed on eight socio-demographic characteristics collected in the survey. These are age, gender, education, perceived health status, residence place, family size, number of sick family members and monthly family budget. The rest of the socio-demographic characteristics collected in the survey are excluded from the analysis, because their correlation to the first eight is considered too high. The binary correlation coefficients is higher than 0.5 (see appendix C.2). 


\subsection{Results and discussion}

The average rating of the physicians' profiles is presented in table 5.3. The table shows the attribute levels in each profile, the mean rating of each profile and the respective standard deviation. Those attribute levels that are assumed to be the most desirable (see the section on study preparation) are marked with a plus.

Table 5.3. Descriptive results of the conjoint analysis

\begin{tabular}{|c|c|c|c|c|c|c|c|c|c|c|c|c|c|c|c|c|}
\hline & \multicolumn{16}{|c|}{ Identification of the profiles } \\
\hline & $A$ & $B$ & $\mathrm{C}$ & D & $\mathrm{E}$ & $\mathrm{F}$ & G & $\mathrm{H}$ & 1 & $J$ & K & L & M & $\mathrm{N}$ & 0 & $\mathrm{P}$ \\
\hline Equipment and materials & + & & + & + & + & & & + & + & & & & & + & & + \\
\hline Professional reputation & & & + & & & + & & + & & + & & & & & & \\
\hline Facility maintenance & & & + & & & & & & + & + & & + & + & + & + & + \\
\hline Travelling time & + & + & + & & + & & & & + & + & + & & & & + & \\
\hline Waiting time & & & & + & + & + & & & + & + & + & + & & + & & \\
\hline Patient payment & & + & & + & & & & & & + & & & & & & + \\
\hline Mean & 2.0 & 1.8 & 3.6 & 2.3 & 2.2 & 2.9 & 1.3 & 2.8 & 2.6 & 3.8 & 1.7 & 1.7 & 2.0 & 2.4 & 1.7 & 2.2 \\
\hline Std.dev. & 0.8 & 0.8 & 1.0 & 0.8 & 0.9 & 0.9 & 0.6 & 1.0 & 0.9 & 0.9 & 0.8 & 0.7 & 0.8 & 1.0 & 0.7 & 0.8 \\
\hline
\end{tabular}

It can be seen from the table that the profile $\mathrm{J}$ is the only profile with the highest number of most desirable levels, and the profile $\mathrm{G}$ is the only profile with no desirable level at all. As can be expected, the profile $\mathrm{J}$ has the highest overall rating of 3.8 , which correspondents to a high preference level. Similarly, the overall preference for the profile $\mathrm{G}$ has the lowest rating of 1.3 which correspondents to a very low preference level. These results suggest overall consistency of the profile ratings in the sample.

It can be also seen from table 5.3. that profiles with an equal number of most desirable attribute levels do not necessary have the same average rating. Thus, for example, each of the profiles $\mathrm{C}$ and I has four most desirable attribute levels, but the profile $\mathrm{C}$ has an average rating of 3.6 , is which indicates a high preference level, while the average rating of the profile $\mathrm{I}$ is 2.6 which indicates moderate preferences. This fact implies that the most desirable attribute do not have the same impacts on the profile rating. Apparently, the respondents derive different part-worth utilities from the different attribute levels.

In order to determine the individual part-worth utilities that underline the profile rating by each respondents a conjoint analysis is performed. As an illustration of the analysis at individual level, figure 5.1 presents the estimation results for the respondent with identification number 0001 .

The results, in figure 5.1., suggest that the respondent 0001 derives the highest utility from services provided by a physician with a good professional reputation (1.04). The same respondent derives the lowest utility if the professional reputation of the physician is not good $(-0.58)$. The part-worth utilities regarding the other attribute levels are between these two extremes. Except for patient payment, for all other attributes, the respondent 0001 derives a lower part-worth utility from attribute levels with lower numbers, which are presumably less desirable. In case of patient payment, however, the estimated part-worth utilities are different than the expected. Although it is supposed that the first attribute level $\left(\mathrm{x}_{61}\right)$, i.e. 10.- BGL, is less desirable than the second attribute 
level $\left(\mathrm{x}_{62}\right)$ i.e. 5.- $\mathrm{BGL}$, the results for the respondent 0001 are reversed. This suggests possible discrepancies between the expected and the estimated part-worth utilities at the individual level.

Figure 5.1. Part-worth utilities and the relative attribute importance for respondent 0001

\begin{tabular}{|c|c|c|c|c|c|}
\hline \multicolumn{6}{|c|}{ Part-worth utilities (Respondent id $=0001$ ): } \\
\hline $\begin{array}{c}\text { Equipment and } \\
\text { materials }\end{array}$ & $\begin{array}{c}\text { Professional } \\
\text { reputation }\end{array}$ & $\begin{array}{c}\text { Facility } \\
\text { maintenance }\end{array}$ & $\begin{array}{c}\text { Travelling } \\
\text { time }\end{array}$ & $\begin{array}{c}\text { Waiting } \\
\text { time }\end{array}$ & $\begin{array}{l}\text { Patient } \\
\text { payment }\end{array}$ \\
\hline$u_{11}=-0.31$ & $u_{21}=-0.58$ & $u_{31}=-0.19$ & $u_{41}=-0.19$ & $\mathrm{u}_{51}=-0.19$ & $\mathrm{u}_{61}=-0.08$ \\
\hline$u_{12}=0.31$ & $\begin{array}{l}U_{22}=-0.46 \\
U_{23}=1.04\end{array}$ & $\mathrm{u}_{32}=0.19$ & $u_{42}=0.19$ & $u_{52}=0.19$ & $\begin{array}{l}U_{62}=-0.33 \\
U_{63}=0.42\end{array}$ \\
\hline
\end{tabular}

Relative attribute importance (Respondent id $=0001$ ):

Attribute

1.Materials and equipment

2.Professional reputation

3.Facility maintenance

4.Travelling time

5.Waiting time

6.Patient payment
Part-worth utility range

$r_{1}=u_{12}-u_{11}=0.625$

$r_{2}=u_{23}-u_{21}=1.625$

$r_{3}=u_{32}-u_{31}=0.375$

$r_{4}=u_{42}-u_{41}=0.375$

$r_{5}=u_{52}-u_{51}=0.375$

$r_{6}=u_{63}-U_{62}=0.750$
Sum of ranges

Attribute importance

$I_{1}=0.152$

$I_{2}=0.394$

$I_{3}=0.091$

$\Sigma r=4.125$

$I_{4}=0.091$

$I_{5}=0.091$

$I_{6}=0.182$

Figure 5.1 further shows the relative importance that the respondent 0001 attaches to different attributes. The results suggest that for this respondent the professional reputation is the most important attribute $(0.394)$ from those included in the study. The next important attribute for the respondent is patient payment $(0.182)$, followed by the medical equipment $(0.152)$. The importance of facility maintenance, travelling time and waiting time for the respondent are equally low (0.091).

The calculations of the utilities and attribute importance, shown for respondent 0001 , are performed for each of the 917 respondents included in the study. The aggregated results for the whole sample are presented in tables 5.4. and 5.5.

Table 5.4. Part-worth utilities of the attribute levels for the sample

\begin{tabular}{|c|c|c|c|c|c|c|c|c|c|c|c|c|c|c|}
\hline \multirow[b]{2}{*}{$\begin{array}{l}\text { Attribute } \\
\text { levels } \\
\end{array}$} & \multicolumn{2}{|c|}{$\begin{array}{c}\text { Equipment and } \\
\text { materials }\end{array}$} & \multicolumn{3}{|c|}{$\begin{array}{c}\text { Professional } \\
\text { reputation }\end{array}$} & \multicolumn{2}{|c|}{$\begin{array}{c}\text { Facility } \\
\text { maintenance }\end{array}$} & \multicolumn{2}{|c|}{$\begin{array}{l}\text { Travelling } \\
\text { time }\end{array}$} & \multicolumn{2}{|c|}{$\begin{array}{l}\text { Waiting } \\
\text { time }\end{array}$} & \multicolumn{3}{|c|}{$\begin{array}{l}\text { Patient } \\
\text { payment }\end{array}$} \\
\hline & $\begin{array}{l}\text { major } \\
\text { lacks }\end{array}$ & $\begin{array}{l}\text { full } \\
\text { range }\end{array}$ & bad & unknowr & good & bad & good & long & short & long & short & $\begin{array}{l}\text { 10.- } \\
\text { BGL }\end{array}$ & 5.- & $\begin{array}{l}2.50 \\
B G L\end{array}$ \\
\hline Mean & -0.20 & 0.20 & -0.49 & -0.36 & 0.86 & -0.19 & 0.19 & -0.15 & 0.15 & -0.14 & 0.14 & -0.17 & 0.02 & 0.16 \\
\hline Std. dev. & 0.21 & 0.21 & 0.31 & 0.33 & 0.42 & 0.21 & 0.21 & 0.18 & 0.18 & 0.19 & 0.19 & 0.30 & 0.26 & 0.33 \\
\hline
\end{tabular}

Table 5.4. shows the mean part-worth utilities of the attribute levels and the respective standard deviations. It can be seen from the table that overall the respondents in the sample derive the highest utility from a good professional reputation of the physician $(0.86)$, followed by the full range of equipment and materials $(0.20)$ and a well-maintained facility $(0.19)$. The utilities derived from the other attribute levels are lower.

It is interesting to point out that the average part-worth utilities conform to the expectations for desirability of the attribute levels. Overall, the individuals in the sample derive lower part-worth 
utility from attribute levels with a lower number, which are expected to be less desirable. The partworth utilities related to higher attributes levels (supposedly more desirable) are greater. Thus, despite the possible discrepancies at the individual level, at the aggregated level the average partworth utilities are consistent with the expected ones.

Table 5.5. presents the mean values and the standard deviations for the sample, regarding the overall attribute importance. The data in table 5.5. suggest that professional reputation is the most important attribute for the sample $(0.395)$, followed by patient payment $(0.170)$, medical equipment $(0.126)$ and facility maintenance $(0.123)$. The importance attached to waiting and travelling time is lower (not more than 0.100 ).

Table 5.5. Relative attribute importance of the attributes for the sample

\begin{tabular}{lcccccc}
\hline & $\begin{array}{c}\text { Equipment and } \\
\text { materials }\end{array}$ & $\begin{array}{c}\text { Professional } \\
\text { reputation }\end{array}$ & $\begin{array}{c}\text { Facility } \\
\text { maintenance }\end{array}$ & $\begin{array}{c}\text { Travelling } \\
\text { time }\end{array}$ & $\begin{array}{c}\text { Waiting } \\
\text { time }\end{array}$ & $\begin{array}{c}\text { Patient } \\
\text { payment }\end{array}$ \\
\hline Mean & 0.126 & 0.395 & 0.123 & 0.086 & 0.100 & 0.170 \\
Std. Dev. & 0.086 & 0.136 & 0.085 & 0.069 & 0.077 & 0.104 \\
\hline
\end{tabular}

The aggregated results on the relative attribute importance suggest that the provider's expertise is probably the primary concern of respondents in the sample when they select a health care provider. Separate from the patient payment, the medical equipment and the facility maintenance appear to be the next most important attributes of health care services. If it is considered that professional reputation, medical equipment and facility maintenance characterise quality in the health care sector, their high importance for the respondents in the sample suggest that quality is a highly valued feature.

Compared to quality, the access-related attributes (waiting and travelling time) appear to be less significant for the respondents. Still waiting time, which characterised temporal access in the health care sector, is generally more important than travelling time (spatial access). Thus, shorter queues in front the doctor's office is of higher value to respondents than proximity of the facilities.

Regarding patient payments, its overall importance is considerable. It appears to be the second important attribute for respondents. This implies that individuals in the sample are generally sensitive to prices for health care services. Given the relatively low monetary incomes in Bulgaria, these results are not surprising.

In order to analyse the differences in the relative attribute importance within the sociodemographic groups in the sample, as explained in the section on data analysis, a linear regression analysis is performed. The results are presented in table 5.6. The signs of the coefficients in table 5.6. show the differences between the social groups. A positive sign indicates that the increase on the socio-demographic characteristics results in an increase in attribute importance and vice versa. A regression coefficient with a negative sign suggests that the increase in the socio-demographic characteristics causes a reduction of the importance of the respective attribute.

Thus, for example, older persons find the professional reputation of the physician and the patient fee more important, whereas younger persons are more concerned with the equipment and the maintenance of the facility as well as with access to care. Female respondents, compared to males, find the reputation of the health care provider, the maintenance and the proximity of the facility where the service is provided more important. Women find the other service features less important. Individuals with a university education are more interested in the professional reputation, the maintenance of the facilities and the waiting time, while those with no education are more 
concerned with the size of patient payments, the medical equipment and the travelling time. Persons with health problems, compared to the healthier individuals, find medical equipment, the office maintenance and the payment size less important, but value the professional reputation of the physician, and the access to services higher.

Table 5.6. Results from the linear regression analysis

\begin{tabular}{|c|c|c|c|c|c|c|c|}
\hline \multirow{2}{*}{$\begin{array}{l}\text { Socio-demographic } \\
\text { variables }\end{array}$} & & \multicolumn{6}{|c|}{ Relative attribute importance } \\
\hline & & $\begin{array}{c}\text { Materials and } \\
\text { equipment }\end{array}$ & $\begin{array}{l}\text { Professional } \\
\text { reputation }\end{array}$ & $\begin{array}{c}\text { Facility } \\
\text { maintenance }\end{array}$ & $\begin{array}{l}\text { Travelling } \\
\text { time }\end{array}$ & $\begin{array}{l}\text { Waiting } \\
\text { time }\end{array}$ & $\begin{array}{l}\text { Patient } \\
\text { payment }\end{array}$ \\
\hline Constant & $\begin{array}{l}\text { parameter } \\
\text { std. error }\end{array}$ & $\begin{array}{l}0.208^{\prime} \\
0.023\end{array}$ & $\begin{array}{l}0.279 \\
0.036\end{array}$ & $\begin{array}{l}0.124 \\
0.023\end{array}$ & $\begin{array}{l}0.081^{\prime} \\
0.018\end{array}$ & $\begin{array}{l}0.0911^{1} \\
0.020\end{array}$ & $\begin{array}{l}0.217^{\prime} \\
0.027\end{array}$ \\
\hline $\begin{array}{l}\text { Respondent age } \\
\text { ( } 18 \rightarrow 85 \text { years) }\end{array}$ & $\begin{array}{l}\text { parameter } \\
\text { std. error }\end{array}$ & $\begin{array}{c}-5.4 \mathrm{E}-04 \\
0.000\end{array}$ & $\begin{array}{c}9.6 \mathrm{E}-04 \\
0.000\end{array}$ & $\begin{array}{r}-3.6 \mathrm{E}-04 \\
0.000\end{array}$ & $\begin{array}{r}-1.8 \mathrm{E}-05 \\
0.000\end{array}$ & $\begin{array}{r}-1.1 \mathrm{E}-04 \\
0.000\end{array}$ & $\begin{array}{r}7.5 \mathrm{E}-05 \\
0.000\end{array}$ \\
\hline $\begin{array}{l}\text { Respondents gender } \\
\text { (male } \rightarrow \text { female) }\end{array}$ & $\begin{array}{l}\text { parameter } \\
\text { std. error }\end{array}$ & $\begin{array}{r}-1.0 \mathrm{E}-02 \\
0.006\end{array}$ & $\begin{array}{r}9.1 \mathrm{E}-03 \\
0.009\end{array}$ & $\begin{array}{r}6.4 \mathrm{E}-03 \\
0.006\end{array}$ & $\begin{array}{r}7.8 \mathrm{E}-03 \\
0.005\end{array}$ & $\begin{array}{r}-3.0 \mathrm{E}-03 \\
0.005\end{array}$ & $\begin{array}{r}-1.0 \mathrm{E}-02 \\
0.007\end{array}$ \\
\hline $\begin{array}{l}\text { Education } \\
\text { (no } \rightarrow \text { university) }\end{array}$ & $\begin{array}{l}\text { parameter } \\
\text { std. error }\end{array}$ & $\begin{array}{r}-2.5 \mathrm{E}-03 \\
0.003\end{array}$ & $\begin{array}{c}1.1 \mathrm{E}-02 \\
0.005\end{array}$ & $\begin{array}{r}4.5 \mathrm{E}-03 \\
0.003\end{array}$ & $\begin{array}{r}-1.5 \mathrm{E}-03 \\
0.003\end{array}$ & $\begin{array}{r}2.5 \mathrm{E}-03 \\
0.003\end{array}$ & $\begin{array}{c}-1.4 \mathrm{E}-02 \\
0.004\end{array}$ \\
\hline $\begin{array}{l}\text { Perceived health } \\
\text { (perfect } \rightarrow \text { bad) }\end{array}$ & $\begin{array}{l}\text { parameter } \\
\text { std. error }\end{array}$ & $\begin{array}{r}-6.9 \mathrm{E}-03 \\
0.005\end{array}$ & $\begin{array}{r}3.6 \mathrm{E}-03 \\
0.007\end{array}$ & $\begin{array}{r}-5.9 \mathrm{E}-03 \\
0.005\end{array}$ & $\begin{array}{r}3.2 \mathrm{E}-03 \\
0.004\end{array}$ & $\begin{array}{r}6.2 \mathrm{E}-03 \\
0.004\end{array}$ & $\begin{array}{r}-3.3 E-04 \\
0.006\end{array}$ \\
\hline $\begin{array}{l}\text { Residence place } \\
\text { (city } \rightarrow \text { village) }\end{array}$ & $\begin{array}{l}\text { parameter } \\
\text { std. error }\end{array}$ & $\begin{array}{c}-9.5 E-03 \\
0.004\end{array}$ & $\begin{array}{r}-5.5 \mathrm{E}-04 \\
0.006\end{array}$ & $\begin{array}{r}1.4 \mathrm{E}-03 \\
0.004\end{array}$ & $\begin{array}{r}1.4 \mathrm{E}-04 \\
0.003\end{array}$ & $\begin{array}{r}-6.0 \mathrm{E}-03 \\
0.004\end{array}$ & $\begin{array}{c}1.5 \mathrm{E}-02 \\
0.005\end{array}$ \\
\hline $\begin{array}{l}\text { Family size } \\
(1 \rightarrow 11 \text { persons) }\end{array}$ & $\begin{array}{l}\text { parameter } \\
\text { std. error }\end{array}$ & $\begin{array}{r}-1.6 \mathrm{E}-03 \\
0.002\end{array}$ & $\begin{array}{r}1.3 \mathrm{E}-03 \\
0.004\end{array}$ & $\begin{array}{r}1.1 \mathrm{E}-03 \\
0.002\end{array}$ & $\begin{array}{r}-3.7 \mathrm{E}-03 \\
0.002\end{array}$ & $\begin{array}{r}1.9 \mathrm{E}-03 \\
0.002\end{array}$ & $\begin{array}{r}1.0 \mathrm{E}-03 \\
0.003\end{array}$ \\
\hline $\begin{array}{l}\text { Sick family members } \\
(0 \rightarrow 4 \text { members })\end{array}$ & $\begin{array}{l}\text { parameter } \\
\text { std. error }\end{array}$ & $\begin{array}{r}-2.9-04 \\
0.004\end{array}$ & $\begin{array}{r}-6.2 \mathrm{E}-03 \\
0.007\end{array}$ & $\begin{array}{r}-6.5 \mathrm{E}-04 \\
0.004\end{array}$ & $\begin{array}{r}1.7 \mathrm{E}-03 \\
0.003\end{array}$ & $\begin{array}{r}-2.9 \mathrm{E}-04 \\
0.004\end{array}$ & $\begin{array}{r}5.7 E-03 \\
0.005\end{array}$ \\
\hline $\begin{array}{l}\text { Family budget } \\
(25 \rightarrow 1200 \mathrm{BGL})\end{array}$ & $\begin{array}{l}\text { parameter } \\
\text { std. error }\end{array}$ & $\begin{array}{r}1.4 \mathrm{E}-05 \\
0.000\end{array}$ & $\begin{array}{r}6.1 \mathrm{E}-05 \\
0.000\end{array}$ & $\begin{array}{r}1.4 \mathrm{E}-09 \\
0.000\end{array}$ & $\begin{array}{r}4.5 E-06 \\
0.000\end{array}$ & $\begin{array}{r}-8.2 E-06 \\
0.000\end{array}$ & $\begin{array}{c}-7.0 \mathrm{E}-05 \\
0.000\end{array}$ \\
\hline$R^{2}$ & & 0.036 & 0.023 & 0.021 & 0.012 & 0.008 & 0.077 \\
\hline
\end{tabular}

The coefficient is statistically different from zero $(p<0.05)$

The inhabitants of smaller settlements, compared to the individuals who live in cities are less attracted by short queues, good professional reputation and a well-equipped facility. They are more concerned with the size of patient payments, the travelling time and the facility maintenance. The higher importance of travelling time attached by village dwellers compared to those living in a big city is to be expected because the health care facilities are usually concentrated in the cities.

Bigger families valued the state of equipment and the time of travelling less but value the other four attributes more. One or more chronically sick family members increases the value attached to the size of patient payments and the travelling time. The attributes related to quality and waiting time are less valued. Finally, wealthier families find all quality of care and the proximity of the facility more important. The waiting time and payment size are less important. The negative relation between the importance of the patient payment and the family budget is to be expected, given that the marginal utility of income is diminishing.

It should be mentioned, however, that not all coefficients are statistically different from zero. For instance, in case of facility maintenance, travelling and waiting time no significant relations between social status and attribute importance are found. With respect to gender, perceived health, 
family size and the number of sick family members, the importance of the attributes does not appear to differ significantly. Regarding the importance of the equipment and materials, significant differences are found with respect to age and residence place. In case of professional reputation, significant differences in the importance of this attribute are found with respect to age, education and family budget. In case of patient payments, three regression coefficients appear to be statistically different from zero. These are the ones related to education, residence place and family budget. Thus, significant deviations from the average attribute importance can be expected with respect to age, education, residence place and family budget. Variations in the rest of the sociodemographic characteristics do not significantly alter the relative attribute importance.

\subsection{Conclusions}

The results on the overall attribute importance and the impact of the socio-demographic status have some important implications for health care providers, health insurance institutions and public decision makers. For example, the aggregated findings from the conjoint analysis indicate that quality of health care provision is the most important attribute for Bulgarian consumers. If Bulgarian health care providers intend to respond to the needs of their patients and to attract new patients, they should try to enhance their professional reputation. Furthermore, they may invest in the enlargement of the medical equipment and materials, as well as in the maintenance of the facility where they provide their services.

Bulgarian health care providers who aim to attract patients from a particular segment may consider the distinctive perceptions of this segment regarding the importance of the service attributes. For instance, the conjoint study reveals that a good professional reputation is significantly more valued by highly educated and wealthy people. The same social groups attach significantly less importance to the size of patient payments. Consequently, these groups can be easily attracted by health care providers who show a high medical competence even if they charge higher prices.

The considerable importance of quality of health care services may facilitate policy making in Bulgarian health insurance companies as well. The insurance companies can try to assure that health care services included in their packages are provided in well-equipped and maintained facilities by highly qualified physicians. This will not only rise the satisfaction of those already insured, but may also attract new clients. The enrolment of a sufficiently large number of people in an insurance institution is necessary for its sustainability. The considerable importance of the size of patient payments for Bulgarian consumers suggests that health insurance plans with out-of-pocket payments may not be attractive. The insurance institutions may either reconsider the inclusion of payment obligations in the insurance plan, or may offer benefits that are more important to consumers than the size of patient payment. For instance, if Bulgarian insurance institutions offer services that are provided by highly skilled physicians, to share the service costs between insurers and insured may well be acceptable for consumers.

Bulgarian public policy makers may use the results of the conjoint study when they allocate the scarce public budget devoted to service improvement. Given the considerably higher importance attached by consumers to quality than to access, the improvement of access should be a lower priority than the allocation of revenues to the improvement of quality. Thus, the public budget may preferably be spent for the enhancement of providers' reputation, for the enlargement of health care equipment and materials, as well as for the improvement of the facilities where public health care services are provided. Nevertheless, if an improvement of access is going to be undertaken, it 
should be considered that the waiting time is more important for consumers than the travelling time. Consequently, shorter queues in front of the physician's office are of higher value to consumers than the proximity of the facilities. This may imply that spending the public revenues for the enlargement of existing health care facilities is more preferable than building new ones closer to the users. The considerable importance of patient payments suggests that Bulgarians are most probably responsive to the size of patient payments. This implies that their willingness and ability to pay should be taken into account when developing a patient payment mechanism for the public health care sector. Patient payments that are not related to consumers' perceptions and monetary constraints may discourage the utilisation of the public health care facilities.

The results of the impact of socio-demographic factors on the importance of patient payments further imply that the responsiveness to the size of patient payments is even higher among the elderly, the village dwellers, the less wealthy individuals, the members of big families and families with chronically sick persons. The need to exclude these groups from patient payments for publicly provided services should be considered when developing a system of exemptions.

The relation between the socio-demographic characteristics and the importance of the service attributes can be used by policy makers to foresee changes in consumer preferences in the future. For example, the conjoint study suggests that a good professional reputation is more valued by the elderly, higher educated people and those living in city, than the rest of the respondents. Consequently, in the future, the expected ageing of Bulgarian population, the increasing number of people living in the big cities and the increased education level may increase the value attached to physicians' qualifications. This may even require allocation of additional revenues to the improvement of the physicians' competencies. The negative relation between the importance of patient payments and the family budget, on the one side, and the expected increase in the family wealth in the country, on the other, suggest that gradually the size of patient payments may become less important than it is at present. Thus, future insurance plans with out-of-pocket payments may not necessarily be unattractive for Bulgarian consumers. Furthermore, the rise in family wealth may allow an increase of patient payments for public health care services.

\section{References:}

Carroll, J.D. and Green, P.E. (1995). Psychometric methods in marketing research: part I, conjoint analysis. Journal of Marketing Research XXXII (November): 385-391.

Chakraborty, G., Ettenson, R. and Gaeth, G.J. (1994). How consumers choose health insurance: analyzing employees' selection process in a multiplan environment identifies the trade-offs consumers make and the benefits that affect their decision making. Journal of Health Care Marketing 14 (1): 21-32.

Chakraborty, G., Gaeth, G.J. and Cunningham, M. (1993). Understanding consumers' preferences for dental services. Journal of Health Care Marketing (Fall): 48-58.

Graf, M. A., Tanner, D.D. and Swinyard, W.R. (1993). Optimizing the delivery of patient and physician satisfaction: a conjoint analysis approach. Health Care Management Review 18 (4): 34-43.

Green, P. E. and Srinivasan, V. (1978). Conjoint analysis in consumer research: issues and outlook. Journal of Consumer Research 5: 103-123. 
Green, P.E. (1974). On the design of choice experiments involving multifactor alternatives. Journal of Consumer Research 1 (September): 61-68.

Kuehn, A.A. and Day, R.L. (1962). Strategy of product quality. Harvard Business Review 40: 100-110.

Luce, D.R. and Tukey, J.W. (1964). Simultaneous conjoint measurement: a new type of fundamental measurement. Journal of Mathematical Psychology 1: 1-27.

Malhotra, N.K. and Briks, D.F. (1993). Marketing research: an applied approach. Harlow: Prentice Hall.

Moore, W.L. (1980). Levels of aggregation in conjoint analysis: an empirical comparison. Journal of Marketing Research XVII (November): 516-523.

Neil, A. (1992). Conjoint analysis: a guide for designing and interpreting conjoint studies. Chicago, IL, American Marketing Association, Market Research Division.

Parker, B.R. and Srinivasan, V. (1976). A consumer preference approach to the planning of rural primary health-care facilities. Operations Research 24?: 991-1025.

Ryan, M. and Hughes, J. (1997). Using conjoint analysis to assess women's preferences for miscarriage management. Health Economics 6: 261-273.

Ryan, M., McIntosh, E. and Shackley, P. (1998). Methodological issues in the application of conjoint analysis in health care. Health Economics 7: 373-378.

Scotti, D.J., Bonner, P.G. and Wiman, A.R. (1986). An analysis of the determinants of HMO reenrolment behaviour: implications for theory and policy. Journal of Health Care Marketing 6 (2): 7-16.

Singh, J., Cuttler, L., Shin, M., Silvers, J.B. and Neuhauser, D. (1998). Medical decision-making and the patient: understanding preference patterns for growth hormone therapy using conjoint analysis. Medical Care 36 (8): AS31-AS45.

Spoth, R. and Redmond, C. (1993). Identifying program preferences through conjoint analysis: illustrative results from a parent sample. American Journal of Health Promotion 8 (2): 124-133.

Vriens, M. (1995). Conjoint analysis in marketing: developments in stimulus representation and segmentation methods. PhD Thesis. Groningen: Labyrint Publication.

Wind, Y. and Spitz, L.K. (1976). Analytical approach to marketing decisions in health-care organizations. Operations Research 24 (5): 973-990. 


\section{CHAPTER 6}

\section{Willingness and ability to pay for public health care services in Bulgaria}

Submitted for publication as:

Pavlova M., Groot, W. and van Merode, G. Using Tobit regression to analyse stated willingness-topay amounts. 


\subsection{Introduction}

A major problem in policy decisions on publicly funded services is that there is usually little information about the preferences of the population for such services. The preferences for publicly funded services, however, are difficult to elicit. Alternative methods have been developed and applied in order to gain insight in this issue. The willingness-to-pay (WTP) technique is one of these methods. It measures the individual preferences in terms of WTP amounts (Jones-Lee et al., 1985; Mitchell and Carson, 1989).

The WTP amount is defined as the maximum amount of income that an individual is willing to sacrifice in order to obtain a given benefit (Phillips et al., 1997). The benefit can either be a good, service, programme or policy, or their subsequent improvement. There are two basic methods for obtaining WTP estimates. These are the revealed preference approach and the stated preference approach. The former method requires an observation of the real purchasing behaviour of individuals regarding a given benefit and the latter involves direct inquiry of the individuals about their hypothetical WTP for that benefit (Jones-Lee et al., 1985; Russell et al., 1995). Both methods have their strengths and weaknesses, but the revealed preference approach can only be applied when the benefit under consideration can actually be purchased (Jones-Lee et al., 1985; Russell et al., 1995). Thus, for example, in case of public goods, the application of the revealed WTP approach is not feasible. For that reason, transport and environmental economists developed the stated WTP technique (Diener et al., 1998; Russell et al., 1995).

In recent years, the WTP technique was increasingly applied in the health care sector (Morrison and Gyldmark, 1992; Phillips et al., 1997). The technique is primarily seen as an aid to place a monetary value on health care programmes and their comparison (Diener et al., 1998; Hoevenagel, 1994). The monetary quantification of health care programmes is significant since it is a comprehensive benefit measure (Phillips et al., 1997) and allows comparison of programmes even when the nature of their outcomes is entirely different. In this sense, the WTP estimates facilitate decision-makers to put priorities when allocating financial resources (Russell et al., 1995).

Although rarely described, in the health care sector, the WTP method has found another application. It was applied to study the demand for particular health care services (Diener et al., 1998). Such studies used the WTP method to obtain data about the quantities of health care services that will be demanded at different price levels on a hypothetical market. Thus, the WTP method was applied to construct a hypothetical demand curve for given services. This application of the WTP method is of particular importance when developing a policy of patient payments or when such policy needs to be adjusted.

Given the increased application of patient payments in public health care sectors (Creese and Kutzin, 1995), the development of the techniques with reference to demand analysis is essential. Despite the objective of patient payments, decision makers at the government and community level are faced with the difficult but important policy question how to price or to reform prices in the health care sector. The results of WTP surveys can be used to determine consumers' responses to changes in the price of health care services. If it is considered that the response to service prices influences the utilisation of these services, the WTP method can help to set appropriate charges in the health care sector that will not cause an unforeseen utilisation decline or under-utilisation among the vulnerable social groups (Russell et al., 1995). The WTP method can also aid the estimation of potential revenues that can be raised through these charges and to analyse the financial sustainability of the changes. 
This paper presents an application of the WTP method for the purpose of demand analysis in the Bulgarian public health care sector. Bulgaria is one of the former socialist countries in Europe that is in a process of reforms in all economic sectors including health care. Recently, the reforms in Bulgarian public health care sector resulted in the introduction of social health insurance under which the patient payments are officially settled (see Ministry of Health Care, 1998; The $38^{\text {th }}$ National Assembly, 1998).

This paper aims to study the impact of the socio-demographic status on the stated WATP and to assess the welfare effect that can be generated by different levels of patient payments. The study uses data from a WTP survey conducted among Bulgarian individuals. The paper first outlines the method of data collection, analysis and the social and demographic features of the sample. Next, a description of the results from the contingent valuation and of the consequent welfare analysis are presented. The paper concludes by policy implications.

\subsection{Survey methodology}

The survey took place in May and June 2000 just before the actual insurance implementation, when the public health care services were still provided free of charge. The data in this survey were collected through interviews based on a standardised questionnaire. The questionnaire was tested in a pilot study. The main survey was carried out by the interviewer staff of APEA BBSS Gallup International - Varna.

The sample was drawn from municipalities in the city of Varna (the third largest city in Bulgaria) and in other small towns and villages in this region. The method of two-stage random selection was used - first selecting the municipality and then selecting respondents from particular age-gender groups in proportion to the regional statistic. The survey produced 990 useful questionnaires. The overall response rate is $90.5 \%$. Inspection of the survey suggests a high reliability of the data.

The main purpose of the survey was to investigate the respondents' WTP for three groups of services - outpatient, inpatient and dental care. By "outpatient", it is meant those services that are provided in a physicians' office or an ambulatory setting and by "inpatient", services provided in a hospital, sanatorium or nursing home (Getzen, 1997). Based on the WTP methodology, the questionnaire used has the following components:

- Questions about past health care utilization and expenditure;

- Creation of a plausible hypothetical market;

- Questions which elicit the respondents' WTP for public health care services;

- Questions about the respondent's social and demographic characteristics.

The questions about the past health care utilisation aim to encourage the respondents to consider their current payments for health care services (WASH, 1988). The respondents were asked to state the quantity of the particular health care service that they used during the past year, the amounts they paid for it (including formal and informal payments), and their ability to pay these

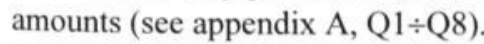

The creation of a plausible hypothetical market upon which the respondents state their WTP is necessary to ensure comparability of the stated WTP amounts. The description of the hypothetical market includes information about the institutional circumstances, the method of payment and the actual benefit for the respondents. The respondents were asked to consider payments for public health care services, which payments are going to be used to improve quality and access in the public health care sector (see appendix A, the textbox in the beginning of Part 3). In the description 
of the hypothetical market, it was not specified whether informal payments were present. It is assumed that the respondents included possible gratitude payments when stating their maximum WTP.

The question for eliciting the respondents' WTP for public health care services can be asked in different manners and under various assumptions. As suggested by Russell et al. (1995), in economic theory it is assumed that the term WTP is equivalent with the term WATP (willing-andable-to-pay). This assumption implies that if an individual is willing to pay a price, he/she also finds a way to pay that price. With respect to health care services, however, paying does not necessarily mean that the expenses are covered from the individual budget. Many authors report payments for health care services based on asset sales or loans (e.g. Russell et al., 1995). It is quite possible that some individuals can consider these payment options when answering the WTP questions and thus state higher amounts. Furthermore, some individuals may well differentiate between the willingness and the ability to pay. These individuals may state WTP amounts that are much higher than the ones than can actually pay simply because they greatly value the improved provision of a public health care services. Therefore, asking WATP questions directly seems to be more appropriate since they can help to overcome the above-mentioned biases.

Furthermore, in the survey discussed here, the WATP for each public health care service is elicited trough a sequence of questions that represents a combination of interval checklist and openended questions. For each service, the respondents are simultaneously presented with three intervals of payment amounts and are asked to choose the interval that corresponds to their WATP. After the respondents select an interval, they are asked to indicate the precise amount of money that they are WATP (see appendix A, Q11 $\div$ Q19). The combination of an interval checklist and open-ended questions has two important strengths. First, it facilitates the respondents' answers by providing a price tag, which is absent in case only open-ended questions are used. Second, it allows measuring the WATP on a continuous scale, which cannot be achieved with only an interval checklist. The combination of an interval checklist and open-ended questions can also avoid the value cues in the closed-ended questions.

Finally, the questions on the respondents' social and demographic characteristics concerned the respondents' age, gender, education, occupation, perceived health, marital status and place of residence. Data about the respondents' family size and family budgets, the number of under-aged, chronically sick and working family members are also collected (see appendix A, Q26 $\div$ Q37).

\subsection{Data analysis}

The impact of the social and demographic characteristics on the stated WATP is examined by a type of Tobit regression to account for the limitation of the dependent variables (the stated WATP) below zero (see Amemiya, 1985, Long, 1997). In order to define the Tobit regression model, some assumptions are made. First, it is supposed that there is a latent continuous variable $\mathrm{y}_{\mathrm{li}}^{*}$ that represents the attitude of the respondent towards paying for a particular health care service. If the respondent has a positive attitude towards paying for this service (i.e. $\dot{y}_{1 i}^{*}>0$ ), a positive WATP amount is observed. If the respondent has a negative or neutral attitude towards payment (i.e. $y_{1 i}^{*} \leq 0$ ), the stated WATP amount is zero. The latent attitude variable $y_{1 i}^{*}$ is assumed to be linearly related to social and demographic characteristics $x_{i}$ of the individual $i$. The relation between $y_{1 i}^{*}$ and $x_{i}$ is given by $(6.1)$.

$$
y_{1 i}^{*}=c_{1}+\beta_{1} x_{i}+\varepsilon_{1 i}
$$


where $c_{1}$ is a constant, $\beta_{1}$ is a vector of coefficients and $\varepsilon_{1 \mathrm{i}}$ is an error term associated with $y_{1 i}^{*}$.

Secondly, it is supposed that the latent attitude variable $y_{1 i}^{*}$ determines a binary variable $y_{1 i}$, which indicates whether the respondent approves of paying for health care. The binary variable $y_{1 i}$ is ' 1 ' when the respondents has a positive attitude towards payment and is ' 0 ' when the respondent's attitude is negative. This assumption is given by (6.2).

$$
\begin{array}{l|ll}
y_{\mathrm{li}}=1 & \text { if } & \mathrm{y}_{\mathrm{li}}^{*}>0 \\
\mathrm{y}_{\mathrm{li}}=0 & \text { if } & \mathrm{y}_{\mathrm{li}}^{*} \leq 0
\end{array}
$$

The third assumption, relates to the functional form of the relation between the WATP amounts, and the social and demographic characteristics of the respondents. It is expected that the WATP increase when the characteristics change in a particular direction, but this increase may come at a decreasing rate. In order to account for the decreasing marginal quantity of the stated WATP amounts when the social and demographic characteristics alter, as well as for the potential heteroscedasticity in the data, a log-linear relation is assumed. More precisely, if $\mathbf{y}_{2 i}^{*}$ is an unlimited latent variable that determines the level of the stated WATP amounts, its relation to the social and demographic characteristics $x_{i}$ is assumed to be given by (6.3)

$$
\ln \dot{y}_{2 i}^{*}=c_{2}+\beta_{2} x_{i}+\varepsilon_{2 i}
$$

where $c_{2}$ is a constant, $\beta_{2}$ is a vector of coefficients, and $\varepsilon_{2 i}$ is an error term associated with $y_{2 i}^{*}$.

The latent variable $\dot{y}_{2 i}^{*}$ is, however, observable through the stated WATP, but only if the respondent approves of paying for a particular health care service. If the respondent does not approve of fees, the latent variable $y_{2 i}^{*}$ is not observed. What is observed is a zero stated WATP amount. Therefore, as a forth assumption, it is supposed that the latent variable $\dot{y}_{2 i}^{*}$ determines a limited observed variable $y_{2 i}$, which is, in fact, the stated WATP amount. The relation between the latent and the observed WATP is presented by (6.4).

$$
\begin{array}{l|ll}
\mathrm{y}_{2 \mathrm{i}}=\mathrm{y}_{2 \mathrm{i}}^{*} & \text { if } & \mathrm{y}_{1 \mathrm{i}}=1 \\
\mathrm{y}_{2 \mathrm{i}}=0 & \text { if } & \mathrm{y}_{1 \mathrm{i}}=0
\end{array}
$$

The equations $(6.1) \div(6.4)$ determine the Tobit regression model to be estimated. This is a type of a generalised Tobit model, where the mechanism that selects the observations as being censored is explicitly modelled through a variable (in this case, through the latent attitude variable $y_{i i}^{*}$ ). The model is estimated using the SAMPSEL procedure in the statistical package TSP 4.5. The estimation of the model, by TSP 4.5., relies on the assumption that the error terms in equations (6.1) and (6.3) are normally distributed with expected values $E\left(\varepsilon_{1 i}\right)=E\left(\varepsilon_{2 i}\right)=0$, and variances $\operatorname{Var}\left(\varepsilon_{1 \mathrm{i}}\right)=1$ and $\operatorname{Var}\left(\varepsilon_{2 \mathrm{i}}\right)=\sigma_{\varepsilon_{2}}^{2}$. The correlation coefficient is $\operatorname{Corr}\left(\varepsilon_{1 \mathrm{i}} \varepsilon_{2 \mathrm{i}}\right)=\rho$ (Hall and Cummins, 1999).

The predicted probability that a respondent approves of fees, and the expected conditional and unconditional values of the stated WATP is given by (6.5). 


$$
\begin{aligned}
& \operatorname{Pr}\left(y_{1 i}=1 \mid x_{i}\right)=\Phi\left(c_{1}+\beta_{1} x_{i}\right)=\int_{-\infty}^{c_{i}+\beta_{1} x_{i 1}} \varphi(t) d t=\int_{-\infty}^{\alpha_{1}+\beta_{1} x_{i i}} \frac{1}{\sqrt{2 \pi}} \exp \left(-\frac{t^{2}}{2}\right) d t \\
& E\left(y_{2 i} \mid y_{1 i}=1, x_{i}\right)=\operatorname{EXP}\left[c_{1}+\beta_{1} x_{i}+\rho \sigma \lambda\left(-c_{1}-\beta_{1} x_{i}\right)\right] \\
& E\left(y_{2 i} \mid x_{i},\right)=\operatorname{EXP}\left[\operatorname{Pr}\left(y_{1 i}=1 \mid x_{i}\right) E\left(y_{2 i} \mid y_{1 i}=1, x_{i}\right)\right]
\end{aligned}
$$

where $\varphi$ and $\Phi$ are respectively the probability and the cumulative density functions of the standard normal distribution, $\lambda\left(-c_{1}-\beta_{1} x_{i}\right)$ is known as Mills ratio and it equals $\varphi\left(-c_{1}-\beta_{1} x_{i}\right) / \Phi\left(-c_{1}-\beta_{1} x_{i}\right)$.

Based on (6.5), the average values of $\operatorname{Pr}\left(\mathrm{y}_{1}=1 \mid \mathrm{x}_{\mathrm{av}}\right), E\left(\mathrm{y}_{2} \mid \mathrm{y}_{\mathrm{i}}=1, \mathrm{x}_{\mathrm{av}}\right)$ and $\mathrm{E}\left(\mathrm{y}_{2} \mid \mathrm{x}_{\mathrm{av}}\right)$ are calculated when all social and demographic characteristics are kept at their mean/median values. The total possible effect of a characteristic $x_{k}$ on the predicted probability and the expected values are determined by the changes $\Delta \operatorname{Pr}\left(\mathrm{y}_{1}=1 \mid \mathrm{x}_{\mathrm{av}}\right), \mathrm{E}\left(\mathrm{y}_{2} \mid \mathrm{y}_{\mathrm{i}}=1, \mathrm{x}_{\mathrm{av}}\right)$ and $\Delta \mathrm{E}\left(\mathrm{y}_{2} \mid \mathrm{x}_{\mathrm{av}}\right)$ when $\mathrm{x}_{\mathrm{k}}$ changes from its minimum to its maximum, holding all other social and demographic characteristics at their mean/median values. The formulas are given by (6.6).

$$
\begin{aligned}
& \frac{\Delta \operatorname{Pr}\left(\mathrm{y}_{1}=1 \mid \mathrm{x}_{\mathrm{av}}\right)}{\Delta \mathrm{x}_{\mathrm{k}}^{\text {lotal }}}=\operatorname{Pr}\left(\mathrm{y}_{1}=1 \mid \mathrm{x}_{\mathrm{av}}, \mathrm{x}_{\mathrm{k}}^{\max }\right)-\operatorname{Pr}\left(\mathrm{y}_{1}=1 \mid \mathrm{x}_{\mathrm{av}}, \mathrm{x}_{\mathrm{k}}^{\min }\right) \\
& \frac{\Delta \mathrm{E}\left(\mathrm{y}_{2} \mid \mathrm{y}_{1}=1, \mathrm{x}_{\mathrm{av}}\right)}{\Delta \mathrm{x}_{\mathrm{k}}^{\text {total }}}=\mathrm{E}\left(\mathrm{y}_{2} \mid \mathrm{y}_{1}=1, \mathrm{x}_{\mathrm{av}}, \mathrm{x}_{\mathrm{k}}^{\max }\right)-\mathrm{E}\left(\mathrm{y}_{2} \mid \mathrm{y}_{1}=1, \mathrm{x}_{\mathrm{av}}, \mathrm{x}_{\mathrm{k}}^{\min }\right) \\
& \frac{\Delta \mathrm{E}\left(\mathrm{y}_{2} \mid \mathrm{x}_{\mathrm{av}}\right)}{\Delta \mathrm{x}_{\mathrm{k}}^{\text {total }}}=\mathrm{E}\left(\mathrm{y}_{2} \mid \mathrm{x}_{\mathrm{av}}, \mathrm{x}_{\mathrm{k}}^{\max }\right)-\mathrm{E}\left(\mathrm{y}_{2} \mid \mathrm{x}_{\mathrm{av}}, \mathrm{x}_{\mathrm{k}}^{\min }\right)
\end{aligned}
$$

In order to simulate the welfare effect of different fees for health care services (6.3) is rewritten as (6.7).

$$
\ln y_{2 i}^{*}=c_{2}+\beta_{2} x_{i}+\varepsilon_{2 i}=c_{2}+\beta_{21} x_{1 i}^{\text {age }}+\ldots+\beta_{28} x_{8 i}^{\text {budget }}+\beta_{29} x_{9 i}^{s}{ }^{\text {use }}+\varepsilon_{2 i}
$$

where $\mathrm{x}_{9_{i}}^{5}$ use refers to the quantity of a particular health care service used during the previous year. Based on the equation (6.7), the quantity of the used services is determined as a function of the stated WATP, and the rest of the social and demographic characteristics. These results in the equation (6.8), which describes the demand for a given health care services.

$$
x_{9 i}^{s}=\frac{\ln y_{2 i}^{\cdot}-\left(c_{2}+\beta_{21} x_{1 i}^{\text {age }}+\ldots+\beta_{28} x_{8 i}^{\text {budget }}\right)}{\beta_{29}}
$$

If it is considered that the quantity of the used services is a non-negative value, it is necessary to determine the limitations of the model. These limitations are given by (6.9).

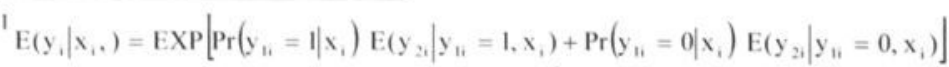
but $E\left(y_{3} \mid y_{14}=0, x_{i}\right)=0 \Rightarrow E\left(y_{1} \mid x_{i},\right)=\operatorname{EXP}\left[\operatorname{Pr}\left(y_{14}=1 \mid x_{i}\right) E\left(y_{2 i} \mid y_{14}=1, x_{i}\right)\right]$
} 


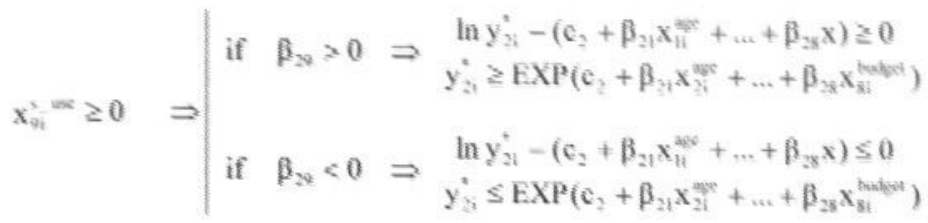

The model limitations $(6.9)$ suggest that if $x_{y_{i}}^{5}$ and $y_{2 i}^{*}$ are positively related, $y_{2 i}^{*}$ should be higher than EXP( $\left.c_{2}+\beta_{21} x_{2 i}^{\text {agse }}+\ldots+\beta_{28} x_{3 i}^{\text {hudet }}\right)$ and vice versa. If $x_{4 i}^{3}$ and $y_{2 i}^{*}$ are negatively related, $y_{2 i}^{*}$ should be lower than EXP( $\left.c_{2}+\beta_{21} x_{2 i}^{\text {ase }}+\ldots+\beta_{28} x_{3 i}^{\text {hudge }}\right)$. Based on (6.8) and given the WATP $P_{i}^{\text {WatP }}$ stated by the respondent $i$, the individual welfare effect of a service fee $P_{k e c}$ can be determined by $(6.10)$.

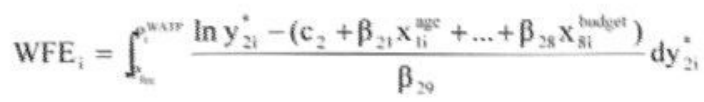

where $y_{2 i}^{*}$ (respectively $P_{f e e}$ and $P_{i}^{\text {wart }}$ ) is held within the intervals determine by (6.9).

The solution of the integral ${ }^{2}$ in $(6.10)$ results in (6.11).

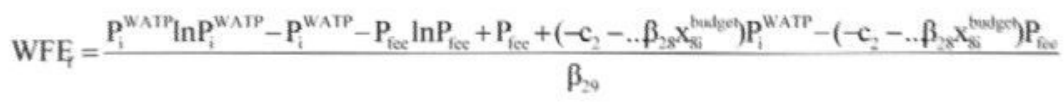

The equation (6.11) is used to calculate, the individual welfare effect of a fee change.

The equation (6.11) can be used to analyse how the increase of $P_{\text {fec }}$ affects the values of WFE . For that reason the first derivative of WFE $\mathrm{F}_{\mathrm{i}}$ with respect to $\mathrm{P}_{\text {fee }}$ has to be derived. This yields (6.12).

$$
\frac{\mathrm{d}\left(\mathrm{WEF}_{\mathrm{i}}\right)}{\mathrm{dP}_{\mathrm{fee}}}=-\frac{\ln \mathrm{P}_{\mathrm{fee}}-\left(\mathrm{c}_{2}+\ldots \beta_{28} \mathrm{x}_{8 \mathrm{i}}^{\text {budget }}\right)}{\beta_{29}}
$$

It can be seen from (6.12) that within the valid intervals determined by (6.9), the first derivative of $\mathrm{WFE}_{\mathrm{i}}$ with respect to $\mathrm{P}_{\mathrm{fec}}$ is negative. This implies that an increase in $\mathrm{P}_{\text {fee }}$ within the valid interval results in a decreasing WFE $E_{i}$. Thus, if for an individual $P_{f e e}>P_{i}^{\text {WAIP }}, P_{\text {fee }}$ will cause welfare loss, whereas for an individual whose $\mathrm{P}_{\text {fee }}<\mathrm{P}_{\mathrm{i}}^{\text {WATP }}, \mathrm{P}_{\text {fee }}$ will result in welfare gain. It can be seen from the equation (6.11) that when $\mathrm{P}_{\text {fee }}=\mathrm{P}_{i}^{\text {WATP }}$, WFE $\mathrm{F}_{\mathrm{i}}$ is zero. Thus, in case that $\mathrm{P}_{\text {fee }}=\mathrm{P}_{\mathrm{i}}^{\text {WATP }}$, there will be no welfare effect.

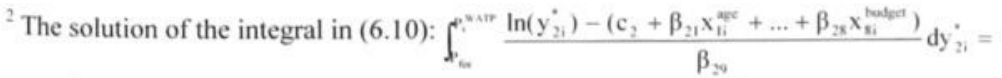

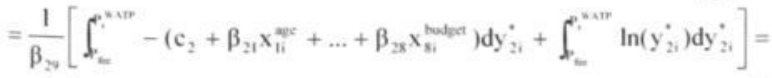

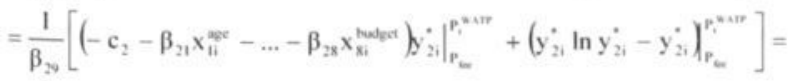

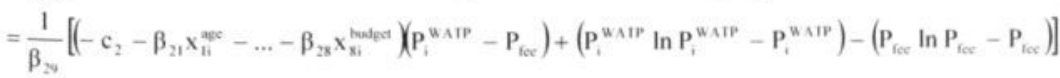


In order to aggregate the individual results for $W_{F E}$ the total sum and the mean values for $W_{F E}$ at different fee levels are estimated. Finally, the average values of $W_{F E}$, in case of different services, are estimated at sample level.

\subsection{Characteristics of the sample}

From the empirical analysis variables for occupation, marital status, number of under-aged and working family members were excluded due to their strong correlation with other social and demographic features (i.e. a bivariate correlation coefficient higher than 0.5 at significance level lower than 0.01). Information about the correlation between all social and demographic characteristics in the survey can be found in appendix C.2. Detailed information for the rest of the social and demographic variables included in the regressions is in appendix C.3.

The average age of the interviewed persons is about 46 years. The sample is evenly divided among the gender groups. The majority of the respondents reside in a big city and only about one third live in small towns or villages. Half of the sample has completed 10-12 years of education and the rest is split between lower and higher education. Most often, respondents perceive themselves as healthy. The respondents' families include on average three household members and less than one chronically sick individual. The mean family budget per month is around 235 Bulgarian levs (BGL). One BGL equals approximately half Euro.

\subsection{Results}

The results on the past health care utilisation by the respondents are summarised in table 6.1. The table presents the means, the medians and the standard deviations of the quantity of health care services used, as well as the number and the size of payments for these services. The table suggests that overall the most frequently used service is the service of general practitioner (about 3 visits per year). Further, no health care service was provided free of charge to every one in the sample.

Even emergency care, that is officially free of charge, was paid for by some respondents. Taken as a whole, the respondents paid a higher price for in-patient than for outpatient care. The mean payments for dental service were diverse. A further review of the data shows that about quarter $(24.7 \%)$ of the respondents who paid, stated that they were not always able to cover the amounts from their family budget.

With respect to the WATP for public health care services, table 6.2. presents the cumulative percentages regarding particular amounts. The lowest WATP amount stated in the survey was 0.50 BGL. Therefore, it is the lowest WATP level included in the table. The table also presents the descriptive statistics of the stated WATP amounts. The table shows that the mean and the maximum of the WATP amounts for dental services are higher than for outpatient care, but the WATP for inpatient care are the highest.

It is interesting to see how the social status of the respondents influences the stated WATP amounts. As explained in the section on data analysis, this is done through a Tobit regression analysis. The results of the Tobit regression are presented in table 6.3. The first part of the table presents the results of the binary Tobit regression. The second part presents the results from the linear Tobit regression and the estimates of $\sigma$ and $\rho$ (as defined in the section on data analysis).

The binary regression coefficients show how the probability of a non-zero WATP statement, regarding a particular health care services, relates to the social status of the respondents. 
It can be seen from table 6.3. that only the coefficients of the family budget are significantly different from zero for all health care services. The coefficients of the other social and demographic characteristics are statistically different from zero in a number of cases. Age, perceived health and place of residence are most often significant variables. The characteristics, for which the coefficients are frequently different from zero, are regarded as key determinants of the stated WATP. It can also be seen from table 6.3. that the level of education, the family budget and the residence place (except for maternity care) always have a positive effect on the probability of a nonzero WATP. It can further be seen that age and perceived health (except for maternity care) always have a negative impact on the probability of non-zero WATP amount. Regarding gender, family size, number of chronically sick family member and quantity of services used, these characteristics have a diverse, but mostly negative, impact on the probability of non-zero WATP.

The results from the linear Tobit regression, in the second part of table 6.3., represent the coefficients that relate the WATP level to the social status given that the stated WATP amount is higher than zero. In case of family budget, these coefficients are nearly always statistically different from zero and in case of education and perceived health they are often different from zero. The signs of the linear regression coefficients are always positive for family budget and education (except for physiotherapeutic services). For age, perceived health, family size and number of chronically sick family members, the linear regression coefficients are frequently negative. The signs of the coefficients for residence place, gender and quantity of services used are rather mixed, but they are more often positive for the firsts characteristic and more often negative for the last two.

The total impact of social status on the probability of a non-zero WATP amount as well as on the expected conditional and unconditional WATP amounts is calculated (see the section on data analysis). The estimates are presented in table 6.4. The first line in the table shows the average probability of a non-zero WATP amount and the average expected (conditional and unconditional) WATP amounts. These amounts are estimated for a hypothetical respondent with a mean social status (see appendix C.3.). The rest of the data in the table show how the stated WATP amount changes when a social or demographic characteristic changes from its minimum to its maximum, keeping all other social and demographic variables at their average values. The figures in table 6.4., imply that the family budget always has a positive and nearly the highest absolute impact on the probability of a non-zero WATP statement and on the expected WATP levels. Only the quantity of services used and the age, in some instances, have a stronger influence on the stated WATP.

If the signs of the changes in the probability and in the respective conditional WATP are equal, the change in the unconditional WATP has the same sign as well. If their signs differ, however, the sign of the change in the unconditional WATP can be diverse. It can be the same as the sign of the probability change. For example, in case of health care services per year, nursing care, operations, emergency care and tooth extractions, the service use increases within its interval. This means that, regarding this particular social or demographic factor (e.g. service use), there is a strong division between respondents (e.g. non-users and frequent users) who are WATP and not WATP. If the change in the unconditional WATP is the same as the change in the conditional WATP, such strong division does not exist. This is, for example, the case with a change in service use for physiotherapy inside or outside hospital, and for placement of dental prosthesis.

The last table in this paper, table 6.5., presents the average expected welfare effect of different fee levels of the public health care services included in the survey. The interval and the step of the fee increase reflect the model limitation given by (6.9). The interval and the step are also selected to present the region around the zero welfare effect appropriately for the discussion. If a charge for a public health care service results in a zero welfare effect, it is considered the socially optimal one 


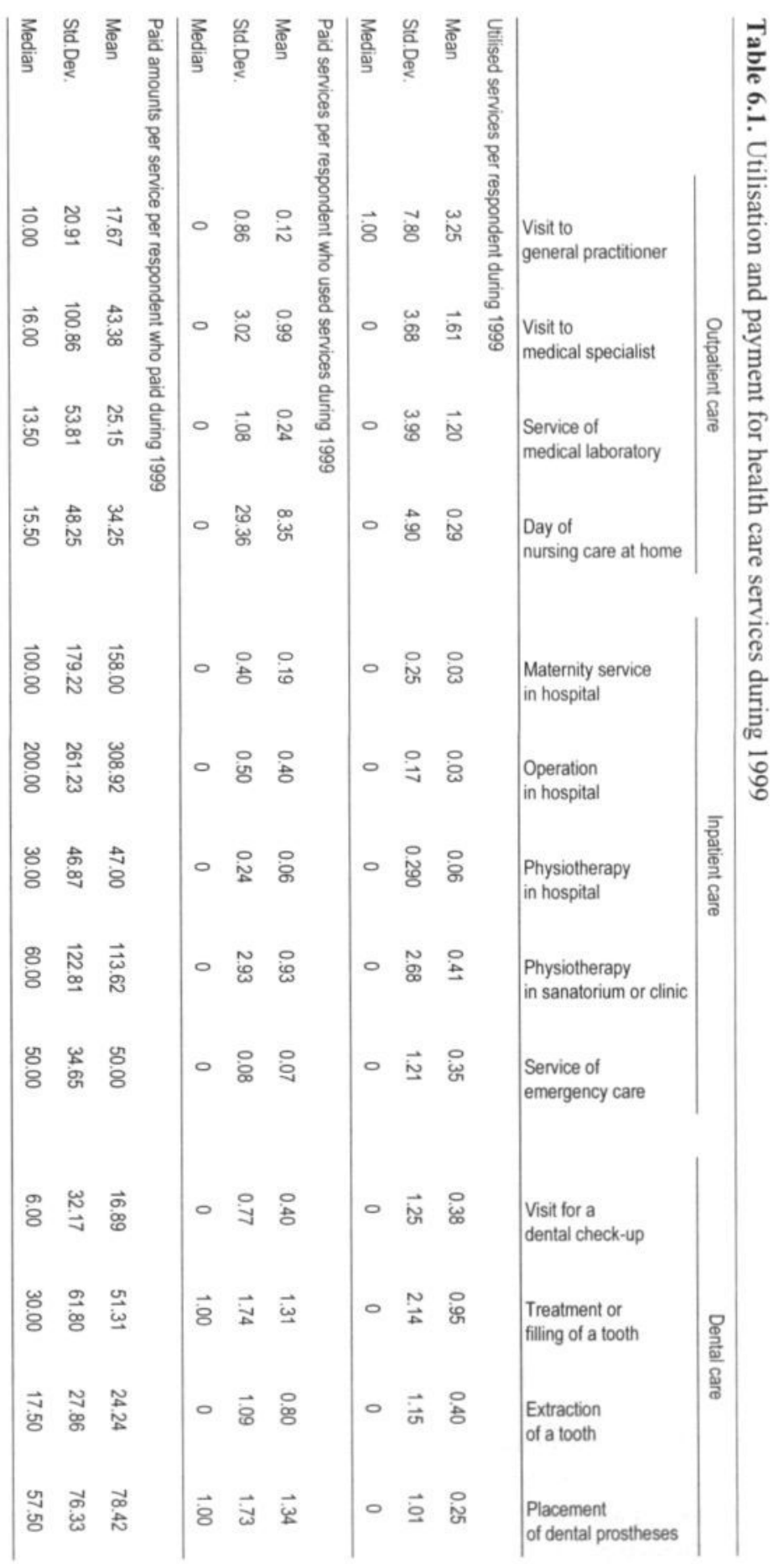


Table 6.2. Valid percentage of respondents that are WATP for different public health care services

\begin{tabular}{|c|c|c|c|c|c|c|c|c|c|c|c|c|c|}
\hline \multirow{2}{*}{\multicolumn{2}{|c|}{$\begin{array}{l}\text { Willingness and } \\
\text { ability to pay for: }\end{array}$}} & \multicolumn{9}{|c|}{ Cumulative percent of respondents willing and able to pay the amounts } & \multicolumn{3}{|c|}{ Descriptive statistics } \\
\hline & & $\begin{array}{l}1000 . \\
\text { BGL }\end{array}$ & $\begin{array}{l}500 .- \\
B G L\end{array}$ & $\begin{array}{l}100 . \\
B G L\end{array}$ & $\begin{array}{l}50 . \\
B G L\end{array}$ & $\begin{array}{l}10 . \\
B G L\end{array}$ & 5.- & $\begin{array}{c}1 .: \\
B G L\end{array}$ & $\begin{array}{l}0.50 \\
\text { BGL }\end{array}$ & $\begin{array}{l}0.00 \\
B G L\end{array}$ & $\begin{array}{l}\text { Median } \\
\text { WATP }\end{array}$ & $\begin{array}{l}\text { Mean } \\
\text { WATP }\end{array}$ & Std.Dev. \\
\hline \multicolumn{2}{|c|}{$\begin{array}{l}\text { Public health care } \\
\text { services per year }\end{array}$} & 0.7 & 3.2 & 47.0 & 69.0 & 80.2 & 80.5 & 80.7 & 80.7 & 100.0 & 70.00 & 109.71 & 347.39 \\
\hline \multirow{4}{*}{ 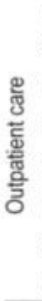 } & $\begin{array}{l}\text { Visit to } \\
\text { general practitioner }\end{array}$ & . & $\cdot$ & $\cdot$ & $\cdot$ & 3.3 & 21.7 & 76.4 & 77.6 & 100.0 & 2.00 & 2.61 & 2.59 \\
\hline & $\begin{array}{l}\text { Visit to } \\
\text { Medical specialist }\end{array}$ & $\cdot$ & $\cdot$ & . & 0.1 & 20.4 & 58.7 & 84.8 & 84.9 & 100.0 & 5.00 & 5.35 & 4.35 \\
\hline & $\begin{array}{l}\text { Service of } \\
\text { Medical laboratory }\end{array}$ & $\cdot$ & . & $\cdot$ & - & 5.9 & 28.5 & 76.3 & 76.6 & 100.0 & 3.00 & 3.08 & 2.91 \\
\hline & $\begin{array}{l}\text { Day of } \\
\text { nursing care at home }\end{array}$ & - & $\cdot$ & - & - & 2.5 & 16.9 & 67.6 & 68.9 & 100.0 & 2.00 & 2.15 & 2.28 \\
\hline \multirow{5}{*}{ 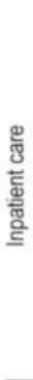 } & $\begin{array}{l}\text { Maternity service } \\
\text { In hospital }\end{array}$ & . & . & 9.2 & 24.8 & 51.9 & 53.2 & 53.4 & 53.4 & 100.0 & 10.00 & 26.51 & 36.03 \\
\hline & $\begin{array}{l}\text { Operation } \\
\text { In hospital }\end{array}$ & 0.3 & 0.4 & 18.7 & 44.9 & 77.6 & 78.2 & 78.4 & 78.4 & 100.0 & 40.00 & 49.14 & 70.36 \\
\hline & $\begin{array}{l}\text { Physiotherapy } \\
\text { In hospital }\end{array}$ & - & - & 2.7 & 17.2 & 65.0 & 66.9 & 68.8 & 69.0 & 100.0 & 20.00 & 22.05 & 26.23 \\
\hline & $\begin{array}{l}\text { Physiotherapy } \\
\text { In clinic/sanatorium }\end{array}$ & $\cdot$ & - & 0.9 & 8.3 & 54.4 & 64.6 & 71.2 & 71.2 & 100.0 & 10.00 & 14.63 & 18.27 \\
\hline & $\begin{array}{l}\text { Service of } \\
\text { emergency care }\end{array}$ & - & . & 0.4 & 5.6 & 44.1 & 54.9 & 57.7 & 57.7 & 100.0 & 5.00 & 10.73 & 15.30 \\
\hline \multirow{4}{*}{ 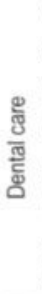 } & $\begin{array}{l}\text { Visit for a } \\
\text { dental check-up }\end{array}$ & - & . & - & . & 3.0 & 25.1 & 68.2 & 68.3 & 100.0 & 2.00 & 2.67 & 2.75 \\
\hline & $\begin{array}{l}\text { Filling/treatment } \\
\text { Of a tooth }\end{array}$ & - & - & . & 0.7 & 65.4 & 76.9 & 82.3 & 82.4 & 100.0 & 10.00 & 11.44 & 9.24 \\
\hline & $\begin{array}{l}\text { Extraction } \\
\text { Of a tooth }\end{array}$ & . & . & . & 0.7 & 56.2 & 70.6 & 80.1 & 80.4 & 100.0 & 10.00 & 9.58 & 8.73 \\
\hline & $\begin{array}{l}\text { Placement of } \\
\text { dental prostheses }\end{array}$ & . & . & 0.3 & 5.8 & 68.9 & 75.8 & 80.5 & 80.6 & 100.0 & 15.00 & 15.85 & 15.01 \\
\hline
\end{tabular}


Level of willingness-and ability-to-pay for:

Outpatient care Inpatient care

Dental care

Socio -

Demographic

Characteristics

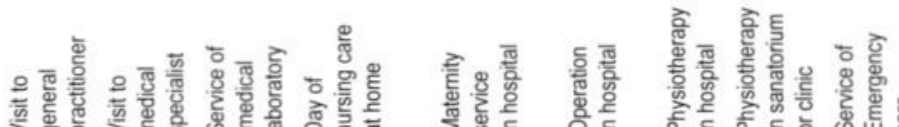

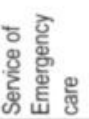

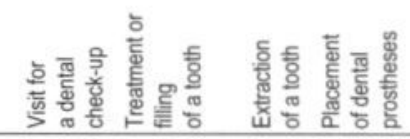

Results from binary regression

\begin{tabular}{|c|c|c|c|c|c|c|c|c|c|c|c|c|c|c|c|}
\hline Constant & $\begin{array}{l}\text { parameter } \\
\text { std. error }\end{array}$ & $\begin{array}{r}1.0064^{4} \\
0.364\end{array}$ & $\begin{array}{r}1.0748^{!} \\
0.346\end{array}$ & $\begin{array}{r}0.9714^{1} \\
0.376\end{array}$ & $\begin{array}{r}1.3462^{1} \\
0.339\end{array}$ & $\begin{array}{r}0.8054^{1} \\
0.314\end{array}$ & $\begin{array}{r}1.1182^{1} \\
0.432\end{array}$ & $\begin{array}{r}1.82221 \\
0.358\end{array}$ & $\begin{array}{r}0.84861 \\
0.301\end{array}$ & $\begin{array}{r}1.2074 \\
0.303\end{array}$ & $\begin{array}{l}0.4667 \\
0.3016\end{array}$ & $\begin{array}{r}1.12811 \\
0.318\end{array}$ & $\begin{array}{r}1.4429^{1} \\
0.351\end{array}$ & $\begin{array}{r}1.2510^{\prime} \\
0.329\end{array}$ & $\begin{array}{r}0.9566^{\prime} \\
0.346\end{array}$ \\
\hline $\begin{array}{l}\text { Respondent je } \\
(18 \rightarrow 85 \text { years) }\end{array}$ & $\begin{array}{l}\text { parameter } \\
\text { std. error }\end{array}$ & $\begin{array}{r}-0.0072 \\
0.003\end{array}$ & $\begin{array}{r}-0.0057 \\
0.003\end{array}$ & $\begin{array}{r}-0.01271 \\
0.004\end{array}$ & $\begin{array}{r}-0.00771 \\
0.003\end{array}$ & $\begin{array}{r}-0.0036 \\
0.003\end{array}$ & $\begin{array}{r}-0.0312^{1} \\
0.005\end{array}$ & $\begin{array}{r}-0.01381 \\
0.003\end{array}$ & $\begin{array}{r}-0.0055 \\
0.003\end{array}$ & $\begin{array}{r}-0.00641 \\
0.0030\end{array}$ & $\begin{array}{r}-0.0053 \\
0.003\end{array}$ & $\begin{array}{r}-0.00911 \\
0.003\end{array}$ & $\begin{array}{r}-0.01271 \\
0.003\end{array}$ & $\begin{array}{r}-0.00971 \\
0.003\end{array}$ & $\begin{array}{r}-0.0034 \\
0.003\end{array}$ \\
\hline $\begin{array}{l}\text { Respondent gender } \\
\text { (male } \rightarrow \text { female) }\end{array}$ & $\begin{array}{l}\text { parameter } \\
\text { std. error }\end{array}$ & $\begin{array}{r}0.0732 \\
0.099\end{array}$ & $\begin{array}{r}-0.0702 \\
0.095\end{array}$ & $\begin{array}{r}0.0211 \\
0.107\end{array}$ & $\begin{array}{r}-0.1451 \\
0.095\end{array}$ & $\begin{array}{r}-0.0621 \\
0.087\end{array}$ & .2 & $\begin{array}{r}-0.24951 \\
0.098\end{array}$ & $\begin{array}{r}-0.0586 \\
0.084\end{array}$ & $\begin{array}{r}-0.2312^{1} \\
0.085\end{array}$ & $\begin{array}{r}-0.0674 \\
0.084\end{array}$ & $\begin{array}{r}-0.0169 \\
0.088\end{array}$ & $\begin{array}{r}-0.1780 \\
0.096\end{array}$ & $\begin{array}{r}-0.1552 \\
0.091\end{array}$ & $\begin{array}{r}-0.1783 \\
0.095\end{array}$ \\
\hline $\begin{array}{l}\text { Respondent education } \\
\text { (no } \rightarrow \text { university) }\end{array}$ & $\begin{array}{l}\text { parameter } \\
\text { std. error }\end{array}$ & $\begin{array}{r}0.0935 \\
0.057\end{array}$ & $\begin{array}{r}0.0625 \\
0.053\end{array}$ & $\begin{array}{r}0.0937 \\
0.060\end{array}$ & $\begin{array}{r}0.0352 \\
0.052\end{array}$ & $\begin{array}{r}0.0048 \\
0.048\end{array}$ & $\begin{array}{r}0.0403 \\
0.070\end{array}$ & $\begin{array}{r}0.0767 \\
0.056\end{array}$ & $\begin{array}{r}0.0940^{1} \\
0.048\end{array}$ & $\begin{array}{r}0.1443^{1} \\
0.049\end{array}$ & $\begin{array}{r}0.0697 \\
0.047\end{array}$ & $\begin{array}{r}0.0250 \\
0.049\end{array}$ & $\begin{array}{r}0.0768 \\
0.055\end{array}$ & $\begin{array}{r}0.0073 \\
0.051\end{array}$ & $\begin{array}{r}0.0724 \\
0.055\end{array}$ \\
\hline $\begin{array}{l}\text { Perceived health } \\
\text { (perfect } \rightarrow \text { bad) }\end{array}$ & $\begin{array}{l}\text { parameter } \\
\text { std. error }\end{array}$ & $\begin{array}{r}-0.1618 \\
0.078\end{array}$ & $\begin{array}{r}-0.2134^{1} \\
0.076\end{array}$ & $\begin{array}{r}-0.0594 \\
0.083\end{array}$ & $\begin{array}{r}-0.1718^{1} \\
0.074\end{array}$ & $\begin{array}{r}-0.1037 \\
0.068\end{array}$ & $\begin{array}{r}0.0390 \\
0.099\end{array}$ & $\begin{array}{r}-0.1796^{1} \\
0.076\end{array}$ & $\begin{array}{r}-0.2070^{\prime} \\
0.067\end{array}$ & $\begin{array}{r}-0.2360^{1} \\
0.065\end{array}$ & $\begin{array}{r}-0.1592^{1} \\
0.067\end{array}$ & $\begin{array}{r}-0.1187 \\
0.068\end{array}$ & $\begin{array}{r}-0.1312 \\
0.073\end{array}$ & $\begin{array}{r}-0.0906 \\
0.070\end{array}$ & $\begin{array}{r}-0.1078 \\
0.075\end{array}$ \\
\hline $\begin{array}{l}\text { Residence place } \\
\text { (city } \rightarrow \text { village) }\end{array}$ & $\begin{array}{l}\text { parameter } \\
\text { std. error }\end{array}$ & $\begin{array}{r}0.1816^{1} \\
0.067\end{array}$ & $\begin{array}{r}0.1639^{1} \\
0.065\end{array}$ & $\begin{array}{r}0.2136^{1} \\
0.073\end{array}$ & $\begin{array}{r}0.0960 \\
0.062\end{array}$ & $\begin{array}{r}0.0376 \\
0.058\end{array}$ & $\begin{array}{r}-0.0058 \\
0.080\end{array}$ & $\begin{array}{r}0.0490 \\
0.065\end{array}$ & $\begin{array}{r}0.0998 \\
0.056\end{array}$ & $\begin{array}{r}0.0963 \\
0.056\end{array}$ & $\begin{array}{r}0.0708 \\
0.056\end{array}$ & $\begin{array}{r}0.0270 \\
0.058\end{array}$ & $\begin{array}{r}0.2100^{1} \\
0.065\end{array}$ & $\begin{array}{r}0.1929 ! \\
0.060\end{array}$ & $\begin{array}{r}0.0801 \\
0.063\end{array}$ \\
\hline $\begin{array}{l}\text { Family size } \\
(1 \rightarrow 11 \text { persons) }\end{array}$ & $\begin{array}{l}\text { parameter } \\
\text { std. error }\end{array}$ & $\begin{array}{r}-0.1120^{1} \\
0.040\end{array}$ & $\begin{array}{r}-0.0273 \\
0.039\end{array}$ & $\begin{array}{r}-0.0640 \\
0.043\end{array}$ & $\begin{array}{r}-0.0921^{1} \\
0.038\end{array}$ & $\begin{array}{r}0.0023 \\
0.035\end{array}$ & $\begin{array}{r}0.0023 \\
0.053\end{array}$ & $\begin{array}{r}-0.0544 \\
0.039\end{array}$ & $\begin{array}{r}-0.0189 \\
0.034\end{array}$ & $\begin{array}{r}-0.0394 \\
0.035\end{array}$ & $\begin{array}{r}0.0205 \\
0.034\end{array}$ & $\begin{array}{r}-0.0461 \\
0.035\end{array}$ & $\begin{array}{r}0.0089 \\
0.040\end{array}$ & $\begin{array}{r}-0.0012 \\
0.036\end{array}$ & $\begin{array}{r}0.0156 \\
0.038\end{array}$ \\
\hline $\begin{array}{l}\text { Chronically sick } \\
(0 \rightarrow 4 \text { members })\end{array}$ & $\begin{array}{l}\text { parameter } \\
\text { std. error }\end{array}$ & $\begin{array}{r}-0.0392 \\
0.070\end{array}$ & $\begin{array}{r}0.0009 \\
0.070\end{array}$ & $\begin{array}{r}-0.0106 \\
0.079\end{array}$ & $\begin{array}{r}-0.0003 \\
0.069\end{array}$ & $\begin{array}{r}-0.0863 \\
0.063\end{array}$ & $\begin{array}{r}-0.1346 \\
0.089\end{array}$ & $\begin{array}{r}0.0148 \\
0.072\end{array}$ & $\begin{array}{r}-0.0359 \\
0.061\end{array}$ & $\begin{array}{r}0.0368 \\
0.061\end{array}$ & $\begin{array}{r}-0.0071 \\
0.062\end{array}$ & $\begin{array}{r}-0.1454^{1} \\
0.062\end{array}$ & $\begin{array}{r}-0.0871 \\
0.067\end{array}$ & $\begin{array}{r}-0.0722 \\
0.066\end{array}$ & $\begin{array}{r}-0.0258 \\
0.066\end{array}$ \\
\hline $\begin{array}{l}\text { Family budget } \\
(25 \rightarrow 1200 \mathrm{BGL})\end{array}$ & $\begin{array}{l}\text { parameter } \\
\text { std. error }\end{array}$ & $\begin{array}{r}0.0024^{1} \\
0.000\end{array}$ & $\begin{array}{r}0.0018^{1} \\
0.000\end{array}$ & $\begin{array}{r}0.00281 \\
0.001\end{array}$ & $\begin{array}{r}0.0025^{1} \\
0.000\end{array}$ & $\begin{array}{r}0.00091 \\
0.000\end{array}$ & $\begin{array}{r}0.0016^{1} \\
0.000\end{array}$ & $\begin{array}{r}0.0020^{\prime} \\
0.000\end{array}$ & $\begin{array}{r}0.0011 \\
0.000\end{array}$ & $\begin{array}{r}0.0013^{\prime} \\
0.000\end{array}$ & $\begin{array}{r}0.0008 \\
0.000\end{array}$ & $\begin{array}{r}0.0012^{1} \\
0.000\end{array}$ & $\begin{array}{r}0.0015^{1} \\
0.000\end{array}$ & $\begin{array}{r}0.0017^{1} \\
0.000\end{array}$ & $\begin{array}{r}0.0016^{1} \\
0.000\end{array}$ \\
\hline $\begin{array}{l}\text { Quantity of service } \\
\text { used (last year'2) }\end{array}$ & $\begin{array}{l}\text { parameter } \\
\text { std. error }\end{array}$ & $\begin{array}{r}-0.0037 \\
0.003\end{array}$ & $\begin{array}{r}-0.0079 \\
0.006\end{array}$ & $\begin{array}{r}-0.0028 \\
0.014\end{array}$ & $\begin{array}{r}-0.0111 \\
0.012\end{array}$ & $\begin{array}{r}0.0063 \\
0.011\end{array}$ & $\begin{array}{r}-0.2795 \\
0.169\end{array}$ & $\begin{array}{r}0.3635 \\
0.308\end{array}$ & $\begin{array}{r}0.0418 \\
0.141\end{array}$ & $\begin{array}{r}0.0217 \\
0.015\end{array}$ & $\begin{array}{r}-0.0782^{1} \\
0.038\end{array}$ & $\begin{array}{r}0.0051 \\
0.035\end{array}$ & $\begin{array}{r}0.0171 \\
0.026\end{array}$ & $\begin{array}{r}-0.0483 \\
0.035\end{array}$ & $\begin{array}{r}-0.0100 \\
0.045\end{array}$ \\
\hline
\end{tabular}

The parameter is statistically different from zero at level $p<0.05$ ordinary least square

${ }^{2}$ Only the female respondents were questioned with regards to hospital maternity care

${ }^{3}$ The range of change depends on the service 
Table 6.3. Results from Tobit regression (continued)

Level of willingness-and ability-to-pay for

Outpatient care

Inpatient care

Dental care

Socio -

Demographic

Characteristics

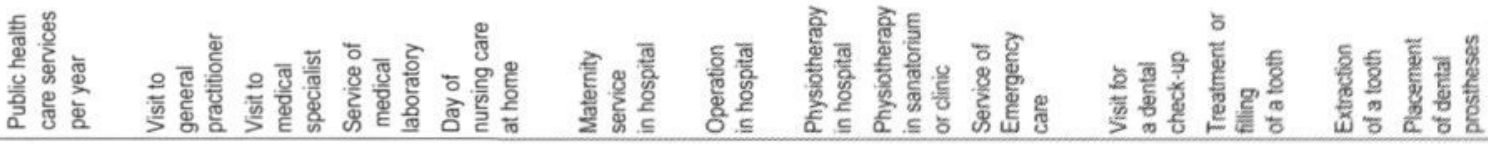

Results from linear regression

\begin{tabular}{|c|c|c|c|c|c|c|c|c|c|c|c|c|c|c|c|}
\hline Constant & $\begin{array}{l}\text { parameter } \\
\text { std. error }\end{array}$ & $\begin{array}{r}4.6700 \\
0.225\end{array}$ & $\begin{array}{r}1.1940^{1} \\
0.161\end{array}$ & $\begin{array}{r}1.65281 \\
0.152\end{array}$ & $\begin{array}{r}1.33351 \\
0.172\end{array}$ & $\begin{array}{r}1.02491 \\
0.229\end{array}$ & $\begin{array}{r}3.86281 \\
0.312\end{array}$ & $\begin{array}{r}3.6954^{\prime} \\
0.196\end{array}$ & $\begin{array}{r}3.4060^{1} \\
0.2624\end{array}$ & $\begin{array}{r}2.7802^{1} \\
0.300\end{array}$ & $\begin{array}{r}2.83211 \\
0.293\end{array}$ & $\begin{array}{r}1.3598 \\
0.170\end{array}$ & $\begin{array}{r}2.55051 \\
0.187\end{array}$ & $\begin{array}{r}2.53581 \\
0.222\end{array}$ & $\begin{array}{r}2.6919 \\
0.218\end{array}$ \\
\hline $\begin{array}{l}\text { Respondent age } \\
(18 \rightarrow 85 \text { years) }\end{array}$ & $\begin{array}{l}\text { parameter } \\
\text { std. error }\end{array}$ & $\begin{array}{r}-0.0037 \\
0.002\end{array}$ & $\begin{array}{r}-0.0018 \\
0.0016\end{array}$ & $\begin{array}{r}-0.0030 \\
0.0016\end{array}$ & $\begin{array}{r}-0.0022 \\
0.002\end{array}$ & $\begin{array}{r}-0.0052^{1} \\
0.002\end{array}$ & $\begin{array}{r}-0.01131 \\
0.005\end{array}$ & $\begin{array}{r}-0.0017 \\
0.002\end{array}$ & $\begin{array}{r}0.0025 \\
0.003\end{array}$ & $\begin{array}{r}-0.0049 \\
0.003\end{array}$ & $\begin{array}{r}-0.0003 \\
0.003\end{array}$ & $\begin{array}{r}-0.0032 \\
0.002\end{array}$ & $\begin{array}{r}0.0001 \\
0.002\end{array}$ & $\begin{array}{r}0.0009 \\
0.002\end{array}$ & $\begin{array}{r}0.9919 \\
0.002\end{array}$ \\
\hline $\begin{array}{l}\text { Respondent gender } \\
\text { (male } \rightarrow \text { female) }\end{array}$ & $\begin{array}{l}\text { parameter } \\
\text { std. error }\end{array}$ & $\begin{array}{r}-0.14911 \\
0.0617\end{array}$ & $\begin{array}{r}-0.0176 \\
0.042\end{array}$ & $\begin{array}{r}0.0270 \\
0.040\end{array}$ & $\begin{array}{r}0.0238 \\
0.047\end{array}$ & $\begin{array}{r}-0.0909 \\
0.048\end{array}$ & .2 & $\begin{array}{r}0.1085^{1} \\
0.055\end{array}$ & $\begin{array}{r}0.0302 \\
0.072\end{array}$ & $\begin{array}{r}0.2080^{1} \\
0.083\end{array}$ & $\begin{array}{r}-0.07317 \\
0.069\end{array}$ & $\begin{array}{r}-0.0224 \\
0.043\end{array}$ & $\begin{array}{r}-0.0107 \\
0.051\end{array}$ & $\begin{array}{r}0.0657 \\
0.061\end{array}$ & $\begin{array}{r}-0.0026 \\
0.081\end{array}$ \\
\hline $\begin{array}{l}\text { Respondent education } \\
\text { (no } \rightarrow \text { university) }\end{array}$ & $\begin{array}{l}\text { parameter } \\
\text { std. error }\end{array}$ & $\begin{array}{r}0.09111 \\
0.035\end{array}$ & $\begin{array}{r}0.0397 \\
0.024\end{array}$ & $\begin{array}{r}0.0577 ! \\
0.023\end{array}$ & $\begin{array}{r}0.08271 \\
0.026\end{array}$ & $\begin{array}{r}0.0742^{1} \\
0.026\end{array}$ & $\begin{array}{r}0.0357 \\
0.046\end{array}$ & $\begin{array}{r}0.0293 \\
0.030\end{array}$ & $\begin{array}{r}0.0100 \\
0.040\end{array}$ & $\begin{array}{r}-0.0700 \\
0.046\end{array}$ & $\begin{array}{r}0.05744 \\
0.039\end{array}$ & $\begin{array}{r}0.06381 \\
0.025\end{array}$ & $\begin{array}{r}0.0830^{1} \\
0.028\end{array}$ & $\begin{array}{r}0.0497 \\
0.034\end{array}$ & $\begin{array}{r}0.0573 \\
0.034\end{array}$ \\
\hline $\begin{array}{l}\text { Perceived health } \\
\text { (perfect } \rightarrow \text { bad) }\end{array}$ & $\begin{array}{l}\text { parameter } \\
\text { std. error }\end{array}$ & $\begin{array}{r}-0.0036 \\
0.052\end{array}$ & $\begin{array}{r}-0.1063^{1} \\
0.039\end{array}$ & $\begin{array}{r}-0.0817 ! \\
0.033\end{array}$ & $\begin{array}{r}-0.0862^{1} \\
0.041\end{array}$ & $\begin{array}{r}-0.1850 \\
0.046\end{array}$ & $\begin{array}{r}-0.0038 \\
0.071\end{array}$ & $\begin{array}{r}-0.0621 \\
0.045\end{array}$ & $\begin{array}{r}0.0028 \\
0.058\end{array}$ & $\begin{array}{r}0.0289 \\
0.068\end{array}$ & $\begin{array}{r}-0.1943^{1} \\
0.061\end{array}$ & $\begin{array}{r}-0.0955^{1} \\
0.039\end{array}$ & $\begin{array}{r}0.0075 \\
0.042\end{array}$ & $\begin{array}{r}-0.0768 \\
0.049\end{array}$ & $\begin{array}{r}-0.0070 \\
0.048\end{array}$ \\
\hline $\begin{array}{l}\text { Residence place } \\
\text { (city } \rightarrow \text { village) }\end{array}$ & $\begin{array}{l}\text { parameter } \\
\text { std. error }\end{array}$ & $\begin{array}{r}-0.0433 \\
0.042\end{array}$ & $\begin{array}{r}0.0246 \\
0.031\end{array}$ & $\begin{array}{r}0.0523 \\
0.028\end{array}$ & $\begin{array}{r}-0.0104 \\
0.032\end{array}$ & $\begin{array}{r}0.0098 \\
0.033\end{array}$ & $\begin{array}{r}-0.0055 \\
0.060\end{array}$ & $\begin{array}{r}0.10231 \\
0.037\end{array}$ & $\begin{array}{r}-0.0621 \\
0.049\end{array}$ & $\begin{array}{r}0.1379 \\
0.057\end{array}$ & $\begin{array}{r}0.0760 \\
0.048\end{array}$ & $\begin{array}{r}0.0505 \\
0.030\end{array}$ & $\begin{array}{r}-0.10571 \\
0.035\end{array}$ & $\begin{array}{r}-0.1320^{\circ} \\
0.041\end{array}$ & $\begin{array}{r}0.0754 \\
0.041\end{array}$ \\
\hline $\begin{array}{l}\text { Family size } \\
(1 \rightarrow 11 \text { persons) }\end{array}$ & $\begin{array}{l}\text { parameter } \\
\text { std. error }\end{array}$ & $\begin{array}{r}-0.0408 \\
0.026\end{array}$ & $\begin{array}{r}-0.0519^{1} \\
0.017\end{array}$ & $\begin{array}{r}-0.0257 \\
0.017\end{array}$ & $\begin{array}{r}-0.0021 \\
0.020\end{array}$ & $\begin{array}{r}-0.0132 \\
0.020\end{array}$ & $\begin{array}{r}-0.0107 \\
0.041\end{array}$ & $\begin{array}{r}-0.0423 \\
0.022\end{array}$ & $\begin{array}{r}.0 .0236 \\
0.030\end{array}$ & $\begin{array}{r}0.0441 \\
0.035\end{array}$ & $\begin{array}{r}0.0089 \\
0.028\end{array}$ & $\begin{array}{r}-0.0187 \\
0.019\end{array}$ & $\begin{array}{r}-0.0361 \\
0.021\end{array}$ & $\begin{array}{r}-0.0262 \\
0.025\end{array}$ & $\begin{array}{r}-0.0465 \\
0.025\end{array}$ \\
\hline $\begin{array}{l}\text { Chronically sick } \\
(0 \rightarrow 4 \text { members })\end{array}$ & $\begin{array}{l}\text { parameter } \\
\text { std. error }\end{array}$ & $\begin{array}{r}-0.0769 \\
0.046\end{array}$ & $\begin{array}{r}-0.0265 \\
0.031\end{array}$ & $\begin{array}{r}-0.0408 \\
0.029\end{array}$ & $\begin{array}{r}-0.0128 \\
0.034\end{array}$ & $\begin{array}{r}-0.0290 \\
0.038\end{array}$ & $\begin{array}{r}.0 .0904 \\
0.062\end{array}$ & $\begin{array}{r}0.0067 \\
0.039\end{array}$ & $\begin{array}{r}0.0266 \\
0.053\end{array}$ & $\begin{array}{r}-0.0980 \\
0.060\end{array}$ & $\begin{array}{r}-0.0433 \\
0.049\end{array}$ & $\begin{array}{r}-0.0275 \\
0.039\end{array}$ & $\begin{array}{r}.0 .0005 \\
0.037\end{array}$ & $\begin{array}{r}0.0000 \\
0.044\end{array}$ & $\begin{array}{r}-0.0442 \\
0.043\end{array}$ \\
\hline $\begin{array}{l}\text { Family budget } \\
(25 \rightarrow 1200 \mathrm{BGL})\end{array}$ & $\begin{array}{l}\text { parameter } \\
\text { std. error }\end{array}$ & $\begin{array}{r}0.0013^{1} \\
0.000\end{array}$ & $\begin{array}{r}0.0010^{1} \\
0.000\end{array}$ & $\begin{array}{r}0.0009^{\prime} \\
0.000\end{array}$ & $\begin{array}{r}0.0003^{1} \\
0.000\end{array}$ & $\begin{array}{r}0.0006^{\prime} \\
0.000\end{array}$ & $\begin{array}{r}0.00111 \\
0.000\end{array}$ & $\begin{array}{r}0.0010^{\prime} \\
0.000\end{array}$ & $\begin{array}{r}0.0006 \\
0.000\end{array}$ & $\begin{array}{r}0.0001 \\
0.000\end{array}$ & $\begin{array}{r}0.0007 \\
0.000\end{array}$ & $\begin{array}{r}0.00051 \\
0.000\end{array}$ & $\begin{array}{r}0.0005 \\
0.000\end{array}$ & $\begin{array}{r}000051 \\
0.000\end{array}$ & $\begin{array}{r}0.0004 \\
0.000\end{array}$ \\
\hline $\begin{array}{l}\text { Quantity of service } \\
\text { used (last year') }\end{array}$ & $\begin{array}{l}\text { parameter } \\
\text { std. error }\end{array}$ & $\begin{array}{r}0.0071 \\
0.002\end{array}$ & $\begin{array}{r}-0.0053 \\
0.004\end{array}$ & $\begin{array}{r}-0.0010 \\
0.006\end{array}$ & $\begin{array}{r}.0 .0063 \\
0.011\end{array}$ & $\begin{array}{r}-0.0004 \\
0.004\end{array}$ & $\begin{array}{r}-0.1588 \\
0.127\end{array}$ & $\begin{array}{r}-0.2625 \\
0.149\end{array}$ & $\begin{array}{r}-0.1051 \\
0.125\end{array}$ & $\begin{array}{r}-0.3100^{1} \\
0.014\end{array}$ & $\begin{array}{r}0.0128 \\
0.046\end{array}$ & $\begin{array}{r}0.0445^{1} \\
0.017\end{array}$ & $\begin{array}{r}0.0102 \\
0.012\end{array}$ & $\begin{array}{r}0.0012 \\
0.027\end{array}$ & $\begin{array}{r}0.0403 \\
0.030\end{array}$ \\
\hline$\sigma$ & $\begin{array}{l}\text { parameter } \\
\text { std. error }\end{array}$ & $\begin{array}{r}0.8652^{1} \\
0.032\end{array}$ & $\begin{array}{r}0.5636^{1} \\
0.015\end{array}$ & $\begin{array}{r}0.56071 \\
0.016\end{array}$ & $\begin{array}{r}0.6312^{1} \\
0.034\end{array}$ & $\begin{array}{r}0.5935^{1} \\
0.040\end{array}$ & $\begin{array}{r}0.6744^{1} \\
0.014\end{array}$ & $\begin{array}{r}0.72951 \\
0.035\end{array}$ & $\begin{array}{r}0.9913: \\
0.038\end{array}$ & $\begin{array}{r}1.1644^{1} \\
0.045\end{array}$ & $\begin{array}{r}0.78781 \\
0.036\end{array}$ & $\begin{array}{r}0.54591 \\
0.035\end{array}$ & $\begin{array}{r}0.7483 \\
0.023\end{array}$ & $\begin{array}{r}0.83899 \\
0.028\end{array}$ & $\begin{array}{r}0.8588^{1} \\
0.030\end{array}$ \\
\hline$\rho$ & $\begin{array}{l}\text { parameter } \\
\text { std. error }\end{array}$ & $\begin{array}{r}-0.6946 \\
0.084\end{array}$ & $\begin{array}{r}0.0768 \\
0.325\end{array}$ & $\begin{array}{r}-0.1749 \\
0.250\end{array}$ & $\begin{array}{r}-0.49011 \\
0.214\end{array}$ & $\begin{array}{r}0.1674 \\
0.727\end{array}$ & $\begin{array}{r}-0.1225 \\
0.303\end{array}$ & $\begin{array}{r}-0.52661 \\
0.184\end{array}$ & $\begin{array}{r}.0 .8885 \\
0.028\end{array}$ & $\begin{array}{r}-0.9223 \\
0.028\end{array}$ & $\begin{array}{r}-0.1673 \\
0.367\end{array}$ & $\begin{array}{r}-0.2347 \\
0.492\end{array}$ & $\begin{array}{r}.0 .9092^{\prime} \\
0.030\end{array}$ & $\begin{array}{r}0.9215^{\prime} \\
0.022\end{array}$ & $\begin{array}{r}0.8468^{1} \\
0.042\end{array}$ \\
\hline
\end{tabular}

The parameter is statistically different from zero at level $p<0.05$ ordinary least square

2 Only the female respondents were questioned with regards to hospital maternity care

${ }^{3}$ The range of change depends on the service 
Table 6.4. Total impact of the socio-demographic characteristics on the level of willingness-and-ability-to-pay

Level of willingness-and ability-to-pay for:

\begin{tabular}{|c|c|c|c|c|c|c|c|c|c|c|c|c|c|c|c|}
\hline \multirow{2}{*}{\multicolumn{2}{|c|}{$\begin{array}{l}\text { Change in } \\
\text { the socio-demographic } \\
\text { characteristics }\end{array}$}} & \multirow[b]{2}{*}{ 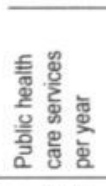 } & \multicolumn{4}{|c|}{ Outpatient care } & \multicolumn{5}{|c|}{ Inpatient care } & \multicolumn{4}{|c|}{ Dental care } \\
\hline & & & 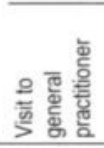 & 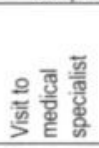 & 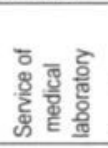 & 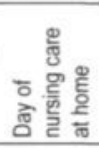 & 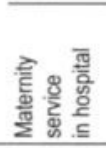 & 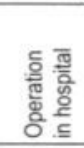 & 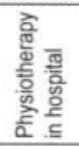 & 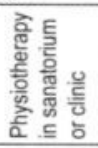 & 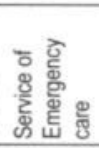 & 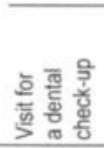 & 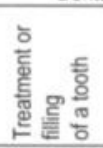 & 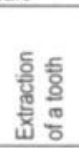 & 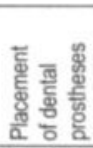 \\
\hline $\begin{array}{l}\text { Average social } \\
\text { status } \\
\text { (all average) }\end{array}$ & $\begin{array}{l}\operatorname{Pr}\left(y_{1}=1\right) \\
E\left(y_{2} \mid y_{1}=1\right) \\
E\left(y_{2}\right)\end{array}$ & $\begin{array}{r}0.85 \\
76.17 \\
39.10\end{array}$ & $\begin{array}{l}0.80 \\
2.78 \\
2.27\end{array}$ & $\begin{array}{l}0.88 \\
5.22 \\
4.25\end{array}$ & $\begin{array}{l}0.79 \\
3.29 \\
2.56\end{array}$ & $\begin{array}{l}0.70 \\
1.69 \\
1.44\end{array}$ & $\begin{array}{r}0.55 \\
33.10 \\
6.83\end{array}$ & $\begin{array}{r}0.80 \\
46.01 \\
21.56\end{array}$ & $\begin{array}{r}0.70 \\
23.85 \\
9.28\end{array}$ & $\begin{array}{r}0.72 \\
12.18 \\
6.01\end{array}$ & $\begin{array}{r}0.58 \\
12.88 \\
4.40\end{array}$ & $\begin{array}{l}0.71 \\
3.15 \\
2.27\end{array}$ & $\begin{array}{r}0.83 \\
11.25 \\
7.42\end{array}$ & $\begin{array}{l}0.80 \\
9.84 \\
6.27\end{array}$ & $\begin{array}{r}0.81 \\
14.02 \\
8.38\end{array}$ \\
\hline $\begin{array}{l}\text { Respondent } \\
\text { age } \\
\text { ( } 18 \rightarrow 85 \text { years) }\end{array}$ & $\begin{array}{l}\Delta \operatorname{Pr}\left(y_{1}=1\right) \\
\Delta E\left(y_{2} \mid y_{1}=1\right) \\
\Delta E\left(y_{2}\right)\end{array}$ & $\begin{array}{r}-0.12 \\
-18.56 \\
-26.51\end{array}$ & $\begin{array}{l}-0.11 \\
-0.33 \\
-0.46\end{array}$ & $\begin{array}{l}-0.19 \\
-1.03 \\
-1.93\end{array}$ & $\begin{array}{l}-0.15 \\
-0.48 \\
-0.74\end{array}$ & $\begin{array}{l}-0.08 \\
-0.57 \\
-0.40\end{array}$ & $\begin{array}{r}-0.70 \\
-24.17 \\
-23.38\end{array}$ & $\begin{array}{r}-0.27 \\
-5.20 \\
-21.35\end{array}$ & $\begin{array}{r}-0.13 \\
4.05 \\
-2.65\end{array}$ & $\begin{array}{l}-0.15 \\
-3.91 \\
-3.46\end{array}$ & $\begin{array}{l}-0.14 \\
-0.26 \\
-1.57\end{array}$ & $\begin{array}{l}-0.21 \\
-0.67 \\
-0.85\end{array}$ & $\begin{array}{r}-0.23 \\
0.08 \\
-3.76\end{array}$ & $\begin{array}{r}-0.19 \\
0.60 \\
-2.27\end{array}$ & $\begin{array}{r}-0.06 \\
1.80 \\
-0.56\end{array}$ \\
\hline $\begin{array}{l}\text { Respondent } \\
\text { gender } \\
\text { (male } \rightarrow \text { female) }\end{array}$ & $\begin{array}{l}\Delta \operatorname{Pr}\left(y_{1}=1\right) \\
\Delta E\left(y_{2} \mid y_{1}=1\right) \\
\Delta E\left(y_{2}\right)\end{array}$ & $\begin{array}{r}0.02 \\
-12.25 \\
-1.82\end{array}$ & $\begin{array}{l}-0.02 \\
-0.05 \\
-0.08\end{array}$ & $\begin{array}{l}0.00 \\
0.14 \\
0.13\end{array}$ & $\begin{array}{r}-0.04 \\
0.08 \\
-0.07\end{array}$ & $\begin{array}{l}-0.02 \\
-0.16 \\
-0.11\end{array}$ & -1 & $\begin{array}{r}-0.06 \\
4.73 \\
-3.33\end{array}$ & $\begin{array}{r}-0.02 \\
0.71 \\
-0.39\end{array}$ & $\begin{array}{r}-0.07 \\
2.29 \\
-0.10\end{array}$ & $\begin{array}{l}-0.03 \\
-0.98 \\
-0.52\end{array}$ & $\begin{array}{l}-0.01 \\
-0.07 \\
-0.05\end{array}$ & $\begin{array}{l}-0.04 \\
-0.12 \\
-0.86\end{array}$ & $\begin{array}{r}-0.04 \\
0.63 \\
-0.23\end{array}$ & $\begin{array}{l}-0.05 \\
-0.04 \\
-1.09\end{array}$ \\
\hline $\begin{array}{l}\text { Respondent } \\
\text { education } \\
\text { (no } \rightarrow \text { university) }\end{array}$ & $\begin{array}{l}\Delta \operatorname{Pr}\left(y_{1}=1\right) \\
\Delta E\left(y_{2} \mid y_{1}=1\right) \\
\Delta E\left(y_{2}\right)\end{array}$ & $\begin{array}{r}0.09 \\
27.91 \\
27.29\end{array}$ & $\begin{array}{l}0.07 \\
0.44 \\
0.45\end{array}$ & $\begin{array}{l}0.08 \\
1.21 \\
1.40\end{array}$ & $\begin{array}{l}0.04 \\
1.09 \\
0.80\end{array}$ & $\begin{array}{l}0.01 \\
0.50 \\
0.31\end{array}$ & $\begin{array}{l}0.06 \\
4.73 \\
2.07\end{array}$ & $\begin{array}{l}0.09 \\
5.40 \\
9.05\end{array}$ & $\begin{array}{l}0.13 \\
0.95 \\
4.07\end{array}$ & $\begin{array}{r}0.19 \\
-3.42 \\
1.66\end{array}$ & $\begin{array}{l}0.11 \\
2.97 \\
1.83\end{array}$ & $\begin{array}{r}0.034 \\
0.81 \\
0.50\end{array}$ & $\begin{array}{l}0.08 \\
3.75 \\
3.47\end{array}$ & $\begin{array}{l}0.01 \\
1.96 \\
1.12\end{array}$ & $\begin{array}{l}0.08 \\
3.22 \\
3.32\end{array}$ \\
\hline $\begin{array}{l}\text { Perceived } \\
\text { health } \\
\text { (perfect } \rightarrow \text { bad) }\end{array}$ & $\begin{array}{l}\Delta \operatorname{Pr}\left(y_{1}=1\right) \\
\Delta E\left(y_{2} \mid y_{1}=1\right) \\
\Delta E\left(y_{2}\right)\end{array}$ & $\begin{array}{r}-0.12 \\
-0.82 \\
-19.28\end{array}$ & $\begin{array}{l}-0.19 \\
-0.84 \\
-0.92\end{array}$ & $\begin{array}{l}-0.04 \\
-1.23 \\
-1.12\end{array}$ & $\begin{array}{l}-0.16 \\
-0.82 \\
-0.91\end{array}$ & $\begin{array}{l}-0.11 \\
-0.86 \\
-0.58\end{array}$ & $\begin{array}{r}0.05 \\
-0.38 \\
1.09\end{array}$ & $\begin{array}{r}-0.16 \\
-8.32 \\
-14.33\end{array}$ & $\begin{array}{r}-0.22 \\
0.20 \\
-5.79\end{array}$ & $\begin{array}{r}-0.25 \\
1.07 \\
-3.08\end{array}$ & $\begin{array}{l}-0.19 \\
-6.91 \\
-3.15\end{array}$ & $\begin{array}{l}-0.12 \\
-0.86 \\
-0.72\end{array}$ & $\begin{array}{r}-0.11 \\
0.25 \\
-1.70\end{array}$ & $\begin{array}{l}-0.08 \\
-2.19 \\
-2.12\end{array}$ & $\begin{array}{l}-0.09 \\
-0.29 \\
-2.09\end{array}$ \\
\hline $\begin{array}{l}\text { Residence } \\
\text { Iplace } \\
\text { (city } \rightarrow \text { village) }\end{array}$ & $\begin{array}{l}\Delta \operatorname{Pr}\left(y_{1}=1\right) \\
\Delta E\left(y_{2} \mid y_{1}=1\right) \\
\Delta E\left(y_{2}\right)\end{array}$ & $\begin{array}{r}0.07 \\
-6.32 \\
9.93\end{array}$ & $\begin{array}{l}0.08 \\
0.14 \\
0.30\end{array}$ & $\begin{array}{l}0.07 \\
0.58 \\
0.99\end{array}$ & $\begin{array}{r}0.05 \\
-0.07 \\
0.11\end{array}$ & $\begin{array}{l}0.03 \\
0.03 \\
0.04\end{array}$ & $\begin{array}{l}-0.00 \\
-0.36 \\
-0.15\end{array}$ & $\begin{array}{r}0.03 \\
10.45 \\
6.67\end{array}$ & $\begin{array}{r}0.07 \\
-2.79 \\
1.09\end{array}$ & $\begin{array}{l}0.06 \\
3.87 \\
2.67\end{array}$ & $\begin{array}{l}0.05 \\
2.11 \\
1.17\end{array}$ & $\begin{array}{l}0.02 \\
0.33 \\
0.23\end{array}$ & $\begin{array}{r}0.09 \\
-2.14 \\
0.11\end{array}$ & $\begin{array}{r}0.09 \\
-2.28 \\
-0.20\end{array}$ & $\begin{array}{l}0.04 \\
2.28 \\
2.23\end{array}$ \\
\hline $\begin{array}{l}\text { Family } \\
\text { size } \\
(1 \rightarrow 11 \text { persons })\end{array}$ & $\begin{array}{l}\Delta \operatorname{Pr}\left(y_{1}=1\right) \\
\Delta E\left(y_{2} \mid y_{1}=1\right) \\
\Delta E\left(y_{2}\right)\end{array}$ & $\begin{array}{r}-0.34 \\
-27.86 \\
-43.27\end{array}$ & $\begin{array}{l}-0.08 \\
-1.26 \\
-0.95\end{array}$ & $\begin{array}{l}-0.16 \\
-1.25 \\
-1.73\end{array}$ & $\begin{array}{l}-0.31 \\
-0.07 \\
-0.87\end{array}$ & $\begin{array}{r}0.01 \\
-0.21 \\
-0.12\end{array}$ & $\begin{array}{r}0.01 \\
-3.44 \\
-0.19\end{array}$ & $\begin{array}{r}-0.17 \\
-17.38 \\
-16.00\end{array}$ & $\begin{array}{l}-0.07 \\
-5.28 \\
-3.11\end{array}$ & $\begin{array}{r}-0.14 \\
6.14 \\
-0.41\end{array}$ & $\begin{array}{l}0.08 \\
1.18 \\
1.22\end{array}$ & $\begin{array}{l}-0.17 \\
-0.56 \\
-0.64\end{array}$ & $\begin{array}{r}0.02 \\
-3.68 \\
-1.73\end{array}$ & $\begin{array}{r}0.00 \\
-2.40 \\
-1.28\end{array}$ & $\begin{array}{r}0.04 \\
-5.76 \\
-2.14\end{array}$ \\
\hline $\begin{array}{l}\text { Chronically sick } \\
\text { family members } \\
(0 \rightarrow 4 \text { members) }\end{array}$ & $\begin{array}{l}\Delta \operatorname{Pr}\left(y_{1}=1\right) \\
\Delta E\left(y_{2} \mid y_{1}=1\right) \\
\Delta E\left(y_{2}\right)\end{array}$ & $\begin{array}{r}-0.04 \\
-21.14 \\
-14.35\end{array}$ & $\begin{array}{r}0.00 \\
-0.28 \\
-0.19\end{array}$ & $\begin{array}{l}-0.01 \\
-0.81 \\
-0.63\end{array}$ & $\begin{array}{r}0.00 \\
-0.17 \\
-0.10\end{array}$ & $\begin{array}{r}-0.13 \\
-0.19 \\
-0.19\end{array}$ & $\begin{array}{r}-0.21 \\
-10.61 \\
-4.65\end{array}$ & $\begin{array}{l}0.02 \\
1.24 \\
1.86\end{array}$ & $\begin{array}{r}-0.05 \\
2.63 \\
-0.82\end{array}$ & $\begin{array}{r}0.05 \\
-4.19 \\
-0.98\end{array}$ & $\begin{array}{l}-0.01 \\
-2.10 \\
-0.54\end{array}$ & $\begin{array}{l}-0.21 \\
-0.33 \\
-0.63\end{array}$ & $\begin{array}{l}-0.10 \\
-0.02 \\
-1.64\end{array}$ & $\begin{array}{r}-0.09 \\
0.00 \\
-1.16\end{array}$ & $\begin{array}{l}-0.03 \\
-2.33 \\
-1.68\end{array}$ \\
\hline $\begin{array}{l}\text { Family } \\
\text { budget } \\
(25 \rightarrow 1200 \mathrm{BGL})\end{array}$ & $\begin{array}{l}\Delta \operatorname{Pr}\left(y_{1}=1\right) \\
\Delta E\left(y_{2} \mid y_{1}=1\right) \\
\Delta E\left(y_{2}\right)\end{array}$ & $\begin{array}{r}0.30 \\
208.92 \\
249.31\end{array}$ & $\begin{array}{l}0.32 \\
5.04 \\
5.48\end{array}$ & $\begin{array}{l}0.29 \\
8.11 \\
9.58\end{array}$ & $\begin{array}{l}0.39 \\
1.30 \\
2.40\end{array}$ & $\begin{array}{l}0.29 \\
1.52 \\
1.47\end{array}$ & $\begin{array}{r}0.54 \\
69.37 \\
73.01\end{array}$ & $\begin{array}{r}0.33 \\
83.42 \\
108.00\end{array}$ & $\begin{array}{r}0.33 \\
21.52 \\
27.96\end{array}$ & $\begin{array}{l}0.35 \\
1.49 \\
7.66\end{array}$ & $\begin{array}{r}0.32 \\
14.18 \\
11.38\end{array}$ & $\begin{array}{l}0.34 \\
2.27 \\
2.85\end{array}$ & $\begin{array}{r}0.26 \\
8.09 \\
12.29\end{array}$ & $\begin{array}{r}0.30 \\
7.08 \\
11.15\end{array}$ & $\begin{array}{r}0.29 \\
7.73 \\
14.14\end{array}$ \\
\hline $\begin{array}{l}\text { Quantity of } \\
\text { service use } \\
\text { (last year }{ }^{2} \text { ) }\end{array}$ & $\begin{array}{l}\Delta \operatorname{Pr}\left(y_{1}=1\right) \\
\Delta E\left(y_{2} \mid y_{1}=1\right) \\
\Delta E\left(y_{2}\right)\end{array}$ & $\begin{array}{r}-0.23 \\
219.65 \\
-3.40\end{array}$ & $\begin{array}{l}-0.28 \\
-1.16 \\
-1.00\end{array}$ & $\begin{array}{l}-0.03 \\
-0.28 \\
-0.42\end{array}$ & $\begin{array}{l}-0.41 \\
-1.55 \\
-1.34\end{array}$ & $\begin{array}{r}0.23 \\
-0.10 \\
0.10\end{array}$ & $\begin{array}{r}-0.39 \\
-15.64 \\
-5.34\end{array}$ & $\begin{array}{r}0.09 \\
-10.71 \\
2.22\end{array}$ & $\begin{array}{r}0.04 \\
-6.49 \\
-0.89\end{array}$ & $\begin{array}{r}0.25 \\
-13.83 \\
-6.54\end{array}$ & $\begin{array}{r}-0.42 \\
2.71 \\
-2.90\end{array}$ & $\begin{array}{l}0.33 \\
4.44 \\
2.28\end{array}$ & $\begin{array}{l}0.10 \\
3.99 \\
5.07\end{array}$ & $\begin{array}{r}-0.35 \\
0.24 \\
-3.43\end{array}$ & $\begin{array}{r}-0.03 \\
6.89 \\
2.24\end{array}$ \\
\hline
\end{tabular}

'Only the female respondents were questioned with regards to hospital maternity care

${ }^{2}$ The total range of change depends on the service 
Table 6.5. Expected welfare effect of different fees for public health care services

\begin{tabular}{|c|c|c|c|c|c|c|c|c|c|}
\hline \multirow{7}{*}{ 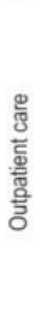 } & $\begin{array}{l}\text { Visit to } \\
\text { general practitioner }\end{array}$ & $\begin{array}{l}\text { Fee amount [BGL] } \\
\text { Average welfare effect }\end{array}$ & $\begin{array}{r}0.00 \\
349\end{array}$ & $\begin{array}{r}0.25 \\
231\end{array}$ & $\begin{array}{r}0.50 \\
132\end{array}$ & $\begin{array}{r}0.75 \\
57\end{array}$ & $\begin{array}{r}1.00 \\
-1\end{array}$ & $\begin{array}{r}1.25 \\
-48\end{array}$ & $\begin{array}{r}1.50 \\
-85\end{array}$ \\
\hline & Visit to & Fee amount [BGL] & 0.00 & 1.50 & 1.75 & 2.00 & 2.25 & 2.50 & 2.75 \\
\hline & medical specialist & Average welfare effect & 396 & 58 & 28 & 3 & -20 & -40 & -58 \\
\hline & Service of & Fee amount [BGL] & 0.00 & 0.50 & 0.75 & 1.00 & 1.25 & 1.50 & 1.75 \\
\hline & medical laboratory & Average welfare effect & 369 & 135 & 65 & 9 & -37 & -75 & -106 \\
\hline & Day of nursing care & Fee amount [BGL] & 0.00 & 0.05 & 0.10 & 0.15 & 0.20 & 0.25 & 0.30 \\
\hline & at patient's home & Average welfare effect & 1145 & 610 & 228 & -89 & -363 & -606 & -824 \\
\hline \multirow{10}{*}{ 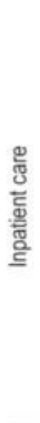 } & Maternity service & Fee amount [BGL] & 0.00 & 5.00 & 6.00 & 7.00 & 8.00 & 9.00 & 10.00 \\
\hline & in hospital ${ }^{1}$ & Average welfare effect & 110 & 17 & 6 & -5 & -15 & -24 & -32 \\
\hline & Operation & Fee amount [BGL] & 0.00 & 8.00 & 9.00 & 10.00 & 11.00 & 12.00 & 13.00 \\
\hline & in hospital & Average welfare effect & 106 & 19 & 12 & 6 & -1 & -6 & -12 \\
\hline & Physiotherapy & Fee amount [BGL] & 0.00 & 5.00 & 6.00 & 7.00 & 8.00 & 9.00 & 10.00 \\
\hline & in hospital & Average welfare effect & 188 & 47 & 29 & 13 & -2 & -16 & -29 \\
\hline & Physiotherapy & Fee amount [BGL] & 0.00 & 3.00 & 4.00 & 5.00 & 6.00 & 7.00 & 8.00 \\
\hline & in sanatorium /clinic & Average welfare effect & 36 & 7 & 1 & -4 & -8 & -12 & -16 \\
\hline & Service of & Fee amount [BGL] & 0.00 & 30.00 & 31.00 & 32.00 & 33.00 & 34.00 & 35.00 \\
\hline & Emergency care & Average welfare effect & -2 & 104 & 43 & -21 & -88 & -157 & -228 \\
\hline \multirow{8}{*}{ 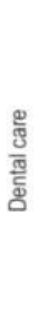 } & Visit for a & Fee amount [BGL] & 0.00 & 5.00 & 6.00 & 7.00 & 8.00 & 9.00 & 10.00 \\
\hline & dental check-up & Average welfare effect & -2 & 21 & 10 & -5 & -24 & -45 & -68 \\
\hline & Treatment / filling & Fee amount [BGL] & 0.00 & 22.00 & 23.00 & 24.00 & 25.00 & 26.00 & 27.00 \\
\hline & of a tooth & Average welfare effect & -2 & 125 & 73 & 17 & -43 & -107 & -175 \\
\hline & Extraction & Fee amount [BGL] & 0.00 & 20.00 & 21.00 & 22.00 & 23.00 & 24.00 & 25.00 \\
\hline & of a tooth & Average welfare effect & -2 & 974 & 489 & -36 & -598 & -1197 & -1830 \\
\hline & Placement & Fee amount [BGL] & 0.00 & 35.00 & 36.00 & 37.00 & 38.00 & 39.00 & 40.00 \\
\hline & of dental prostheses & Average welfare effect & -2 & 20 & 4 & 13 & -31 & -49 & -68 \\
\hline
\end{tabular}

${ }^{2}$ The model does not permit to calculate the welfare effect at zero price level. See the section on data analysis 
It can be seen from table 6.5. that, for a service of medical specialist, overall, a fee up to 2. BGL has a positive welfare effect, whereas the effect of a $2.25 \mathrm{BGL}$ fee is already negative. Thus, the zero welfare effect can be found between these two levels. Similarly, for the rest of the services, the monetary range that contains a zero welfare effect can be found. With a zero welfare effect, the government or another health care supplier reaps all benefits.

\subsection{Discussion}

The results on WATP for public health care services indicate that the majority of the individuals in the sample are in favour of paying for public services with good quality and quick access. This considerable agreement with paying fees and the relatively high WATP could be attributed to the general deterioration of the Bulgarian public health care sector during the last decades (e.g. WHOEuro, 1999). If these facts are taken into account, the considerable WATP for public health care, revealed by this survey, is not surprising.

The mean WATP per year is about 110.-BGL, but the average value of the unconditional expected WATP amounts per year is lower (about 39.- BGL). The mean WATP amounts, however, can be confounded by outliers and can thus cause an overestimation of the WATP. Therefore, the unconditional expected value is taken as a more reliable average measure.

The unconditional expected WATP for public health care services per year can be used to determine the part of the family budget that the respondents are on average prepared to spend on services. In order to do this, it is considered that the mean family income per month is nearly 236.BGL (see appendix C.3.) and the WATP for public health care services per year for a person with an average social status is about 39.- BGL. This implies that a respondent with an average social status is prepared to spend for herself about $1.3 \%$ of their family budgets in order to use better health care services. An average family consists of there 3 members, which means that overall a family is prepared to spend $3.9 \%$ of its budget for public health care services.

It is interesting to point out that the results of another Bulgarian survey, described by Delcheva et.al. (1997), reveal a median WTP for health care between 4 and $6 \%$ of the respondents' income. Although, the two surveys differ in time and types of questions, their results are comparable.

Regarding the particular health care services, more than half of the sample approve of payments if the service is provided with good quality and quick access. The mean and the expected WATP regarding the particular health care services show a consistent pattern. The WATP for outpatient care is lower than for inpatient care. Within the inpatient care, the WATP for hospital services is higher than for other inpatient services. Regarding the dental services, the WATP varies between these two extremes. The WATP amounts for a dental check-up is within the range of outpatient care, while the WATP for the other dental services is within the rage of inpatient care.

The results on the welfare effect of fees confirm that individuals are WATP lower charges for outpatient than for inpatient care, but contrary to the above they show optimum charges for emergency care that are considerably higher than the optimum charges for hospital care. Furthermore, the optimum price levels for outpatient, hospital and physiotherapeutic services outside hospital are lower than the respective mean and expected WATP values, while for dental and emergency services they are higher.

These discrepancies are not surprising because the estimation of the welfare effect includes only those respondents who are WATP for the particular services and accounts for the differences between users and non-users. Regarding hospital operations, for example, the results from the linear regression indicates a negative relation between the number of service used and the stated WATP. 
Consequently, among the respondents who approve of payments for hospital operations, those who actually use the services are less WATP than the non-users. Therefore, the estimated optimum price level is lower than the mean and the expected WATP values.

A similar explanation can be given for the other services, for which the relation between the quantity of service used and the stated WATP is negative. Regarding dental and emergency services, for which this relation is positive, an opposite explanation is valid. Thus, among the respondents who accept to pay fees for emergency care, those who actually use the services are WATP higher prices than those who do not use it. Therefore, the estimated optimum price level is higher than the mean and the expected WATP values.

A positive relation between the WATP for a given health cares service and the quantity of service used is not unusual. Such relation has been found out in other WTP studies as well (e.g. Golan and Shechter, 1993). Regarding dental services, the positive relation between the stated WATP and the service used can be explained by the higher values that the frequent users attach to improved provision of this service. It is also possible that the users of dental services are simply used to pay for these services since the results on past utilisation (see table 6.1.) reveal that dental services are the most frequently paid services.

The positive relation between the WATP for emergency care and the quantity of services used can also be explained by higher values of the users than the non-users, but the comparatively low approval rate of fees for these services should also be considered before drawing conclusions. In particular, it should be pointed out, that the results from the binary regression indicate a negative relation between the WATP and the quantity of service used. Furthermore, the coefficient associated with this relation is statistically different form zero only in case of emergency care. Thus, the users are significantly less in favour of being charged for emergency care than the non-users. This finding should be considered when determining the policy implication of the survey with respect to emergency care.

It is interesting to analyse the mean and the expected WATP, as well as the optimum price levels for potentially alternative health care services. First, within the outpatient care the services of general practitioner can be seen as an alternative to services of medical specialists. In this regard, the WATP amounts and the optimum prices for visits medical specialist are higher than for visits to general practitioner. Consultations with a medical specialist are probably valued higher than consultations with a general practitioner. Second, in case of physiotherapeutic services in hospital the average WATP and the optimum price are considerably higher than outside of the hospital. Thus, the respondents most probably prefer to be treated in a hospital than in a clinic or sanatorium.

Regarding the impact of social status on the WATP, the results from the regression analysis imply that the family budget is the strongest determinant of the stated WATP amounts. The education level is another characteristic that appears to have a considerable influence on the respondents' WATP, although not as strong as the budget size. For respondents with a higher education the probability of approving fees is higher and these respondents are expected to state higher WATP amounts. They may well have higher preferences for improved public health care services. It is also possible that these respondents have better paid jobs and consequently, higher incomes, which also can explain the positive relation between education and the stated WATP.

Three other characteristics can be identified as important determinants of the stated WATP. Thus, the elderly and the unhealthy respondents as well as those living in a big city more often disapprove of fees than the young, the healthy and those living in the cities. The lower acceptance of fees may well be a result of a weak preference for improved public health care, but may also be a result of stronger income constraints. Thus, for example, the elderly (who are actually pensioners) 
are generally people with lower incomes than the younger. Therefore, they more frequently disagree to pay charges and thus oppose an increase of their financial burden. The group of respondents who are in a bad health condition probably recognise that accumulated charges in case of frequent service use can put a claim on a considerable part of their budget.

Regarding gender, family size, number of chronically sick family members, the regression results are rather mixed. The female respondents, as well as respondents from bigger families, from families with more sick members less often approve of fees than the rest of the sample and if they accept to pay the WATP the amounts stated by them are lower compared to the other groups in the sample.

Another interesting point of discussion is how the official fees determined by the Bulgarian Health Insurance Act compare to the optimal prices determined by the survey. The Health Insurance act states that the patient should pay $1 \%$ of the minimum monthly salary for the country when visiting a physician and $2 \%$ of the minimum monthly salary for every day that they stay in a hospital (for a maximum 20 days a year) (The 38th National Assembly, 1998). The minimum monthly salary in Bulgaria is presently fixed at 100.- BGL. This means that patients are required to pay 1.- BGL when visiting general practitioner, medical specialist and dentist and up to 40.- BGL for a hospital services. In case of a medical specialist, the official patient payments are slightly higher than the optimum price level determined by the survey, whereas in case of medical specialist and dentist they are lower (see table 6.5.). With respect to hospital care, however a maximum fee of 40.- BGL appears to be considerably higher than the optimum revealed by the survey.

In order to analyse whether the results can be extrapolated to the country as a whole the representativeness of the sample is examined. The comparison between the social and demographic characteristics of the sample with the official regional statistics shows no significant differences and implies a high probability that the sample is representative for the region (see appendix C.4). Regarding the representativeness of the sample for the country as a whole, the comparison between characteristics of the sample with the national statistic data do not show significantly differences except for distribution of respondents among the residence place (see appendix C.4). Thus, the results might be extrapolated to the country as a whole, but the conclusions related to residence place should be treated with some caution.

\subsection{Conclusions}

The results on the WATP for public health care services indicate that the majority of the individuals in the sample are in favour of paying for improved public health care services. The considerable agreement with paying fees can be expected if the services are provided with good quality and quick access. The analysis of the data suggest that on average, people are prepared to spend about $1.3 \%$ of their family budgets in order to use improved health care services. If all members of an average family are considered, this percentage is $3.9 \%$. Given the comparability of these findings with the findings from another survey in Bulgaria (see Delcheva et al., 1997), it can be concluded that the estimated percentages can be used as a reference when deciding on the limit of the patient payment.

Regarding particular health care services, the results from this survey suggest that the patient payments should depend on the type of service. The fees for outpatient care should be lower than these for inpatient and dental care. Within the outpatient services, the fee for a visit to a general practitioner should be lower than those for a medical specialist and the charges for a day of nursing care at home should be low. With respect to inpatient care, the fees for hospital services should be 
higher than those for inpatient services outside hospital. The implementation of a fee should be avoided due to the high disapproval of fees for that service. Regarding dental services, the fees for dental check-ups should be lower than those for treatment, extraction or placement of prosthesis.

The comparison between the official fees determined by the Health insurance Act and the results on the welfare effect of fees suggests that patient payments in Bulgaria are higher than the optimal prices, revealed by the survey, in case of general practitioner and all inpatient services. They are less than optimal in case of medical specialist and dental services.

The analysis of the welfare effect, however, does not consider the impact of patient payments on the supply side of the health care market. If the health care provider is the actual beneficiary of patient payments, the fee may change the supply of health care. Therefore, before determining the prices in Bulgarian public health care sector, the impact of fees on the behaviour of the health care providers should be studied.

Regarding the social status, the strongest determinant of the stated WATP amounts is the family budget. Therefore, a low family budget should be the primary criterion for the exemption of individuals from the patient payment obligations. In addition, the elderly as well as individuals with a bad health condition should also be considered for exemptions. Special attention should be paid to the appropriate exemption for big families and the families with chronically sick people.

\section{References:}

Amemiya, T. (1985). Advanced Econometrics. Oxford: Basil Blackwell.

Creese, A.L. and Kutzin, J. (1995). Lessons from cost-recovery in health. Forum on Health Sector Reform. Discussion Paper No2, WHO/SHS/NHP/95.5. Geneva: The World Health Organization.

Delcheva, E., Balabanova, D. and McKee, M. (1997). Under-the-counter payments for health care: evidence from Bulgaraia. Health Policy 42:89-100.

Diener, A., O'Brien, B. and Gafni, A. (1998). Health care contingent valuation studies: a review and classification of the literature. Health Economics 7: 313-326.

Getzen, T.E. (1997). Health economics: fundamentals and flow of funds. New York: John Wiley.

Golan, H. and Shechter, M. (1993). Contingent valuation of supplemental health care in Israel. Medical Decision Making 13(4):302-310.

Hall, B.H. and Cummins, C. (1999). Time Series Processor version 4.5: User's guide. Palo Alto: TSP International.

Hoevenagel, R. (1994). The contingent valuation method: scope and validity. PhD thesis. Amsterdam: Vrije Universiteit.

Jones-Lee, M.W., Hammerton, M. and Philips, P.R. (1985). The value of safety: results of a national sample survey. The Economic Journal 95 (March): 49-72.

Long, J.S. (1997). Regression models for categorical and limited dependent variables. Thousand Oaks: Sage Publications. 
Ministry of Health Care (1998). Directive No22/9.12.1997 Conditions and organisation of the payment for medical care in case of patient choice (in Bulgarian). Biblioteka Zakoni APIS 5 (1) №126.

Mitchell, R.C. and Carson, R.T. (1989). Using survey to value public goods: the contingent valuation method. Washington: Resources for the Future.

Morrison, G.C. and Gyldmark, M. (1992). Appraising the use of contingent valuation. Health Economics 1: 233-243.

Phillips, K.A., Homan, R.K., Luft, H.S., Hiatt, P.H., Olson, K.R., Kearney, T.E. and Heard, S.E.(1997). Willingness to pay for poison control centers. Journal of Health Economics 16: 343-357.

Russell, S., Fox-Rushuby, J. and Arhin, D. (1995). Willingness and ability to pay for health care: a selection of methods and issues. Health Policy and Planning 10 (1): 94-101.

The 38th National Assembly (1998). The health insurance act. Sofia: The 38th National Assembly.

WASH (1988). Guidelines for conducting willingness-to pay studies for improved water services in developing countries. WASH Field Report No. 306. Washington:USAID.

WHO-Euro (1999). Better health for better future in Bulgaria: a health policy proposal. Draft 2. Unedited. 23rd February. 
CHAPTER 7

General conclusions and policy implications 


\subsection{Introduction}

The purpose of this thesis was to contribute to the knowledge and insight on patient payments and to enable a more informed discussion of their introduction in the public health care sector in Bulgaria. In particular, the study aimed to examine whether patient payments are suitable for the Bulgarian conditions and acceptable by the population. In order to achieve this goal a household survey was conducted in the region of Varna (the third largest city in Bulgaria). The survey collected data on public attitudes towards patient payments, the importance of quality, access and price to the consumers, and the willingness and ability of consumers to pay for public health care services. The data collection procedure, described in the introduction of the thesis, and the comparison between the characteristics of the sample and the regional and national statistics, presented in appendix C.4., suggest that the overall representativeness of the results for the region and for the country as a whole is acceptable.

The data collection and analysis were based on three quantitative research methods, namely the analysis of self-explicated attribute ranking, conjoint analysis and contingent valuation. The contingent valuation was used to study the willingness and ability of consumers to pay for public health care services. The analysis of the self-explicated attribute ranking and the conjoint analysis were used to examine the importance of quality, access and price to the consumers. Although the self-explicated approach and the conjoint analysis aim to measure the same construct in a different manner, the application of both methods was necessary in order to determine the validity of the results. Various regression procedures were applied to analyse the data.

This concluding chapter aims to outline the general conclusions and policy implications of the study. First, the main findings of the study and answers to the research questions are presented. Then, the objectives and the design of patient payments mechanism in Bulgaria are discussed. Finally, suggestions for further research on patient payments are made.

\subsection{Main findings}

\section{The context of patient payments in Bulgaria}

Patient payments in Bulgaria are implemented together with the establishment of a social health insurance system. The review of the predicaments of the health insurance reforms (chapter 2) indicates that the previous tax-based health care finance resulted in poor quality, low efficiency and questionable sustainability. Therefore, the systems of financing, funding and remuneration needed to be restructured. The analysis of the newly legislated insurance mechanism (chapter 2) suggests that the insurance-based system of the health care finance provides, in principle, a basis for improving efficiency and quality of the public health care services. However, this system of health care finance can cause an uncontrollable increase of costs and can have a negative impact on equity in the public health care sector. Furthermore, the economic recession, the high unemployment rate, the instability of the fiscal system and the high incidence of informal employment do not allow for sufficient a.ld stable financing of the health care system even under an insurance mechanism.

\section{Public attitudes towards the design of patient payments in Bulgaria}

The results and the discussion on public attitudes towards patient payments in Bulgaria (chapter 3) suggest that the majority of the citizens are in favour of the introduction of patient payments for 
public health care services with good quality and quick access. The attitudes towards payments for particular services mainly depend on the type of services. There is a comparatively low agreement with charges for emergency and maternity care. Individuals may well consider that emergency and maternity hospital care are essential services, which should be provided free of charge. They may also believe that the state should be responsible for the provision of adequate emergency and maternity care, not the patients.

There is a considerable disagreement among Bulgarians whether charges should be related to the actual costs of the service or its quality. However, the majority of the people favour limitations on patient payments, in particular income-related limitations. Regarding the beneficiary of patient payments, most individuals support the retention of patient payment at the place of service provision. Individuals may well recognise the danger of revenue absorption by an insurance company or municipality. The results also show considerable support for the exclusion of vulnerable populations from payment obligations. There is wide support for the exemption of disabled people, children, pensioners and chronically sick people.

\section{Responsiveness of Bulgarian consumers to prices in health care sector}

The analysis of the self-explicated attribute importance (chapter 4) and the results of the conjoint analysis (chapter 5) indicate that the size of patient payment plays an important role in the choice of health care provider. The considerable importance of the size of patient payment suggests that Bulgarians are responsive to charges for health care services. The results of the conjoint analysis (chapter 5) imply that the responsiveness to charges is even higher among the elderly, the village dwellers, the less wealthy individuals, members of big families and families with several chronically sick persons. The analysis of the self-explicated attribute importance (chapter 4) confirms that the elderly, members of big families and members of less wealthy families are more concerned with the payment size compared to young people and those who live in smaller and richer families. The negative relation between the importance of patient payments and the family budget is consistent with the theoretical expectation that the marginal utility of income is decreasing and is a confirmation of the validity of the results.

\section{The importance of quality and access to Bulgarian consumers}

The analysis of the self-explicated attribute importance (chapter 4) and the conjoint analysis (chapter 5) suggest that the provider's expertise is the primary concern of health care consumers in Bulgaria. This attribute of health care services is even more important than the size of patient payments. The range of medical equipment and materials appears to be the next important health care attributes. The high importance attached to professional reputation and medical equipment suggests that clinical quality is a highly valued feature.

Access to care appears to be less important than the clinical quality of the services. With regard to access related attributes, consumers are more attracted by services with reduced waiting time than by services that require less travelling time. Thus, shorter waiting times and shorter queues in front of the doctor's office are of higher value to consumers than the proximity of the facilities.

The analysis of the self-explicated data and the conjoint analysis indicate the same rank order of attributes with respect to their relative importance to consumers, except for facility maintenance. In the self-explicated task, facility maintenance is the least important attribute, whereas in the conjoint analysis its importance is higher than the importance of access related attributes. A possible 
explanation for this discrepancy in the results is a response bias associated with the self-explicated approach. In the self-explicated approach, the respondents are explicitly asked to evaluate the importance of the attributes. Therefore, they may attempt to give socially desirable answers when stating the perceived attribute importance. Thus, if the respondents have considered the general believe that the level of facilities maintenance is not directly related to the effectiveness of health care services, they may well have ranked this attribute lower, despite their own preferences. The conjoint analysis is not associated with such response biases, because the respondents are not asked to evaluate the importance of the attributes, but to state their preferences regarding a combination of attribute levels. Thus, in the conjoint task the respondents may have only taken into account their own preferences regarding the high importance of facility maintenance and not the norms or social perceptions. This can explain the higher relative importance of facility maintenance in the conjoint analysis compared to the self-explicated task. The higher consumer preference for well-maintained health care facilities than for easy access to health care services is confirmed by the results of another Bulgarian survey reported by Zafirova and Kehaiova (2001).

Despite the discrepancy regarding the importance attached to facility maintenance, the rankings of the other attributes, revealed by the analysis of the self-explicated data and by the conjoint analysis, are similar. These rankings are also comparable to the results reported by Zafirova and Kehaiova (2001). The similarity of the results is evidence for their validity.

\section{The willingness and ability to pay for public health care}

The results of the contingent valuation study (chapter 6) indicate that the majority of the Bulgarians perceive themselves as willing-and-able to pay for improved public health care services. The analysis also suggests that, on average, individuals are prepared to spend about $1.3 \%$ of their family budget on health care services with good quality and quick access for themselves. If all members of an average family are considered, this percentage is $3.9 \%$. These estimates are comparable with results of another Bulgarian survey (see Delcheva et al., 1997), which is an indication of the validity of the amounts that individuals are willing-and-able-to-pay for health care. It should be mentioned, however, that in the survey there was no distinction between formal and informal payments. It is assumed that the respondents have included eventual gratitude payments in their maximum willingness-and-ability-to-pay.

Regarding particular health care services, individuals state that they are in general willing-andable to pay lower fees for outpatient than for inpatient services and dental care. Within the outpatient services, the willingness-and-ability to pay is higher for a visit to a medical specialist than for a visit to a general practitioner. With respect to inpatient care, individuals are willing-andable to pay higher amounts for hospital services than for inpatient services outside the hospital. There is a high disapproval towards paying fees for emergency care. For dental services, the stated willingness-and-ability-to-pay for check-ups is lower than for other dental services.

The analysis of the stated willingness-and-ability-to-pay further indicates that the elderly, those in a bad health, members of big families and families with chronically sick people are less in favour of paying high fees. These findings are comparable with results of the survey reported by Delcheva et al., (1997). The family budget appears to be the strongest determinant of the stated willingnessand-ability-to-pay. Less wealthy individuals consistently state lower amounts than wealthier individuals. The positive relation between the willingness-and-ability-to-pay and the budget size is in accordance with the theoretical expectation that individuals are prepared to pay higher amounts 
when the income constraints are less tight. The consistency between the theoretical expectations and the stated willingness-and-ability-to-pay amounts is evidence for the validity of the results.

\subsection{The objective of patient payments in Bulgaria}

Patient payments are a demand-side policy tool, which have been employed in countries of all level of development to serve different purposes. Patient payments have been applied in health care sectors to raise revenue, to contain the costs, to improve efficiency and quality and to deal with the informal payments (WHO, 1996). All these objectives derive from the fact that patient payments impose prices in health care sector and thus, have the potential to influence the quantities demanded by the consumers and to generate revenues.

\section{Patient payments as an efficiency improvement tool}

Officially, the aim of patient payments in Bulgaria is to enhance efficiency of health care utilisation (Capital, 1998). Efficiency improvement is a broadly assigned objective to the implementation of charges in public health care facilities. It is expected that if patients have to pay for health care they will evaluate the expected benefits before the actual service use and will utilise only necessary care.

Yet, the contribution of fees to the achievement of this objective is not adequately studied (Akin et al., 1987; Creese, 1991; WHO, 1996). Although, the results of surveys in midle- and low-income countries (e.g. Waddington and Enyimayew, 1990; Yoder, 1989) show that implementation of patient payments decrease the quantity of health care used, there is no strong evidence that unnecessary use of health care was also reduced (Creese, 1991; Huber, 1993). Moreover, it is reported that patient payments have mainly affected the services used by the poor and in areas where the transportation costs were high (Creese and Kutzin, 1995). Surveys in high-income countries (e.g. Kupor et al., 1995; O'Grady et al., 1985; Selby et al., 1996) also report that introduction of patient payments led to a decline in service utilisation. However, these studies rarely focus on whether the reduced services were necessary and whether patient payments were a reason for the decline. The lack of sufficient empirical evidence limits the possibility to advocate patient payments as an effective tool for improving efficiency.

Even from a theoretical point of view, the rationale for applying patient payments as an efficiency improvement tool is often disputed. Although economic theory provide evidences that patient payments can improve efficiency in health care sector, such suppositions are strongly questioned based on the specificity of the health care commodity (Hsiao, 1995; McPake, 1993, WHO, 1996). In particular, it is suggested that the potential existence of supplier-induced demand can wave the eventual improvement of efficiency generated by patient payments. For that reason, it is recommended that the implementation of patient payments should always be combined with an adequate remuneration mechanism. In this regard, a remuneration mechanism, independent from the volume of the service provided, appears to be effective (WHO, 1996).

The official statements that patient payments are aimed at efficiency improvement often cover political expectations that these payments can also control the global expenditure of the health care system. However, there is little scope for applying patient payment as a cost-containment measure. The expenditures in health care sector are primarily driven by supply-side factors (such as type of reimbursement and structure of the referral system), while patient payments are a demand-side policy tool. The empirical evidence shows that the decline in services demanded after the introduction of patient payments has no influence on the overall health care expenditure (WHO, 
1996). Thus, assigning a cost-containment objective to patient payments is unfeasible. Therefore, in high-income countries, patient payments are primarily a supplement to supplied-side strategies (Hialmarsson, 1998; WHO, 1996). In these countries, the general practitioners are placed in the role of 'gate keeper' to the referral services and the payment responsibilities for the referrals are shifted to them (WHO, 1996).

\section{The relation between the formal and the informal patient payments}

The official patient charges in Bulgaria are implemented in a situation of widely spread informal payments. The presence of informal patient payments is an important feature of the health care systems in all Eastern Europe countries (Thompson and Witter, 2000). Empirical evidence from these countries shows that the informal payments represent a significant part of the income of the health care providers. In some circumstances, the informal payments collected by a provider might be several times higher than his/her official income. Informal payments are paid to both health care providers in the hospitals and general practitioners in the policlinics. These payments can take either monetary or non-monetary form (Ensor and Savelyeva, 1998). The nature of the informal payments, however, makes it difficult to obtain a representative estimate of the total volume.

In Bulgaria, under-the-counter payments are common for pharmaceuticals and hotel services in hospitals, such as bed linen and food. Surveys conducted before the introduction of official fees suggest that nearly every second respondent has ever made informal payments in cash (Deltcheva et al., 1997; EOHCS, 1999). Although not fully representative, one survey reports that the median informal payment for outpatient care equal $6 \%$ of the average monthly income and in case of dental services about $8 \%$. For a hospital operation, the median informal payments represented about $83 \%$ of the mean monthly income cash (Deltcheva et al., 1997). These are the only reliable estimates available. There are also no reliable estimates whether after the introduction of official fees these informal payments continue to be paid (EOHCS, 1999).

Given the widely spread informal payments for health care in Bulgaria, there may be political expectations that the introduction of official fees can be a tool for formalising informal contributions (e.g. Deltcheva et al., 1997). The success of such objective is, however, doubtful. The empirical evidence suggests that the introduction of patient payments in such context can result in a mix of formal and informal charges (WHO, 1996). This can increase the financial burden for consumers and can deteriorate equity in the access to public health care services. Therefore, dealing with informal payments is important to prevent increased inequality after patient payments are introduced. The solution to the problem of informal payments, however, should be found in adequate medical supply, appropriate provider remuneration, legislation of sanctions and control (e.g. WHO, 1996; Thompson and Witter, 2000), and not in the introduction of official fees.

\section{Patient payments as an additional source of financing}

Patient payments can raise revenues and for that reason they are often seen as an additional source of health care financing. This characteristic of patient payments is of particular interest in a context of increased fiscal pressure (Rubin and Mendelson, 1996). Such situation is reported in many lowand middle-income countries (including Bulgaria). In these countries, insufficient domestic resources impede the improvement of the health care sector and the provision of health care services for the whole population. Many of these countries were advised to implement some kind of patient payments in order to increase the resources of their public health care sector (Stanton and 
Clemens, 1989). In Bulgaria, the problem of system sustainability is often described as 'the most pressing' problem in the health care system (WHO-Euro, 1999). Thus, the potential of patient payments to generate revenues might well be a motivation for their implementation.

It has to be kept in mind, however, that patient payments revenues cannot present a significant contribution to the public health care financing. In some developing countries, for example, the gross yield from patient payments varies between $1 \%$ to $15 \%$ (with an average of $5 \%$ ) of the health expenditure for public health care services (Bennett and Ngalande-Banda, 1997; Creese, 1991). The gross revenues of patient payments in the rest of the world are not higher than the maximum mentioned above. If the administrative costs for collecting the payments are considered, the net yield of patient payments is even lower. The distinction between the net and gross yield is important, because the cost of payment collection may outweigh the total yield. Such situation is even experienced in high-income countries with a relatively strong administrative system (Creese, 1991). If the net yield of patient payments tends to be negative then patient payments cannot be described as an effective revenue rising option. Even when the net yield from patient payments is positive, its amount most probably represents a very low percentage of the total health care financing (Creese, 1991).

These facts confirm that the political expectations for raising additional health care revenues through patients' payments seem to be over-optimistic (Bennett and Ngalande-Banda, 1997; Creese and Kutzin, 1995). In Bulgaria, there are also no particular reasons to expect that patient payments can raise substantial revenues. The unstable economic development of Bulgaria during the transitional period resulted in a rather low income per capita (1227 USD in 1997), low level of formal employment and significant income polarisation (EOHCS, 1999; OECD, 1997). Poverty still remains a serious social problem (EOHCS, 1999). These facts imply that most Bulgarian health care consumers are not able to pay high patient charges. Based on these facts WHO-Euro (1999) concludes that in the current economic situation in Bulgaria patient payments 'can not realistically amount to much of an additional source of revenue'. Even when patient payments can raise a high gross budget, the considerable administrative costs of the collection of patient payments at national level will most probably absorb the revenues collected (Creese, 1991). Clearly, assigning a revenue rising objective to patient payments is inappropriate in the Bulgarian context.

\section{Patient payments as a quality improvement strategy}

The application of patient payments as a contributory financing force for local health care structures appears to be a more reasonable strategy than its application as an additional financing source for the entire system. The empirical evidence suggests that although small at national level, when retained locally, patient payments can represent an important additional financial resource for health care facilities (Bennett and Ngalande-Banda, 1997; Creese, 1991). In many countries where public health budgets were decreased, patient payments were retained at the level of collection and were successfully reinvested in local health care facilities to revitalise service provision. The utilisation of the payment revenues to cover small expenditures for maintenance, emergency purchases of drugs or spare parts, increased the quality of public health care provision (Bennett and NgalandeBanda, 1997; Creese, 1991; WHO, 1996).

In Bulgaria, the continuous under-funding of the public health care system is also one of the reasons for poor service quality. The insufficient health care funding resulted in a lack of elementary drugs, materials and instruments, and in a lack of maintenance of health care facilities. This is particularly true for the primary health care facilities in small rural settings. The low service 
quality is often stated as the main reason for the low patient satisfaction (Delcheva et al., 1997; WHO-Euro, 1999). To solve these problems, additional financing is necessary. Therefore, given that patient payments are already legislated, it might be appropriate to retain them at the point of their collection (preferably at the health care facility) and to reinvest them to improve the provision of public health care. The revenues of patient payment can be directly allocated to pay, for example, for emergency purchases of elementary supplies, small reparations, improved sanitation and catering, purchasing of bed linen.

The findings reported in this thesis also imply that the majority of the population accepts to pay charges to the health care facility or the provider, if services are provided with good quality and quick access. Thus, special attention should be paid to the conversion of fee revenues into service improvement. The retention of the payment revenues at the local level, as a supplement to public health care financing, can facilitate the improvement of the health care services that patients pay for. The revenues can be reinvested in public health care services based on the preferences of consumers regarding particular service attributes, like those reported in this thesis. This will not only raise patient satisfaction, but can justify the collection of fees at public health care facilities.

The service enhancement at local level appears to be an appropriate objective of patient payment in Bulgaria. The successful application of patient payments as a quality improvement strategy, however, requires decentralised financial control that allows retention of the revenues at the point of collection. The success of such policies also depends on the ability of the local health care managers to promote and support the conversion of the revenues into service improvements (Bennett and Ngalande-Banda, 1997; Creese, 1991; WHO, 1996).

\subsection{The design of patient payments in Bulgaria}

The achievement of the goals of patient payments primarily depends on their design and the context of their application. An additional condition for success is the appropriateness of the design with respect to overall equity in the public health care sector. The literature suggests four main aspects of the design of a patient payment mechanism that can an impact on the outcomes of its implementation. These aspects include the range of health care services provided under patient payments, the type, magnitude and limits of patient payments, and the criteria for exemptions (Bennett and Ngalande-Banda, 1994; WHO, 1996; Kutzin, 1998; Lee, 1989):

\section{Services under patient payments}

The Bulgarian legislation on patient payments distinguishes between two types of payments. On one hand, there are payment obligations for patients who visit the general practitioner with whom they are registered under the social health insurance and who follow the referral from their general practitioner. The payments for these patients are legislated by the Health Insurance Act of 1998 (The $38^{\text {th }}$ National Assembly, 1998). For those who choose their own health care provider there are different payment obligations. These payments are settled by Directive No22 of 9.12.1997 (Ministry of Health Care, 1998).

In case of free consumer choice, patients pay fees for all services they use except for check-ups and tests. If patients follow the referral system under the social health insurance, there is no explicit exclusion of services. The insurance law only specifies that patients can be charged when visiting a doctor or dentist, and for staying in a hospital. Consequently, the use of any health care service included in the insurance package can be subject to charges. The content of the package is 
determined annually. The list of potential services, however, suggests that preventive care, early diagnosing, emergency aid and maternity care may well be provided under the insurance system. Thus, charges for these services can be validated by their inclusion in the insurance package.

These services, however, are essential for the health of the population. They are often deemed too important to depend on the price mechanism for their allocation. Free access to preventive, diagnostic, maternity and emergency care can reduce the need of curative treatment in the future (Creese and Kutzin, 1995). As suggested by economic literature, charging patients for the use of these services can be socially inefficient. For that reason, the cost of their provision should be covered by the government (Jimenez, 1987; Hsiao, 1995; McPake, 1993). A failure to meet this requirement can be seen as an important disadvantage of the patient payment mechanism.

Therefore, the legislation on patient payments in Bulgaria needs to be adjusted and health care services essential for the health of the population should be explicitly excluded from payment obligations. The decision to charge for a given service needs to be determined by an analysis of the service itself not merely by the general political will to introduce fees. The findings in this thesis also suggest a broad public support for such differentiation.

\section{Magnitude of patient payments}

Bulgarian legislation on patient payments settles fixed charges for the use of health care services. Under the social health insurance, these charges are determined as a percentage of the minimum monthly wage. The decision of Bulgarian policy-makers to tie the size of patient payments to the minimum wage is not surprising given the unstable state of the economy. Thus, payment obligations will be changed gradually and simultaneously with a change in the general ability of patients to pay health care charges. Increased ability to pay will inevitably result in higher patient payments. This will probably reduce the political risk of public disaffection when patient payments are increased.

As suggested by the findings in this study, however, Bulgarian consumers are responsive to prices in the health care sector. This implies that their willingness and ability to pay should be taken into account when developing the patient payment mechanism. Thus, special attention should be paid whether Bulgarian health care consumers are willing and able to pay to the legislated fee magnitudes.

A comparison between the official fees determined by the Health insurance Act and the results on the welfare effect of fees suggests, that patient payments in Bulgaria are higher than the optimal prices for a general practitioner and for all inpatient services. Actual prices are lower than the optimal prices for dental services. With respect to payments for a visit to a medical specialist, the legislated patient payments might also be higher than the optimal prices, if access to a specialist requires double payment. This can happen if patients first have to pay to their general practitioners and then to the specialists to whom they are referred.

It should be also considered that the optimal prices suggested in this thesis include gratitude payments. Thus, if after the introduction of official fees the informal payments continue to exist, the unfavourable difference between the legislated and the optimal fee levels might be even higher than the one suggested by this thesis.

The legislation on patient payments in Bulgaria settles different fees if patients visit other than their own general practitioners or if they do not follow the referral system. The implementation of such payment system seems to be reasonable since Bulgarian patients often avoid the referral system. They prefer to be diagnosed in a hospital by a medical specialist rather than by a general practitioner. Lower fees at primary health care facilities compared to those for hospitals specialists 
can help to reduce the frequent crowding in the hospitals. Higher fees for patients who avoid the primary health care levels can further encourage efficient use of public health care services (Creese and Kutzin, 1995). Therefore, the fee tariff should be designed to provide the appropriate insentives. Changes in the fees settled by Health Insurance Act of 1998 and those settled by the Directive No22 of 9.12.1997 should be synchronized to assure that patients who choose freely the health care provider always meet higher payment obligations than those who follow the referral system. Only under this condition, the avoidance of the referral system can be discouraged.

\section{Type and limits of patient payments}

The findings in this study suggest that the Bulgarians are not in favour of patient payments related to service costs or quality. They may well recognise that payments based on actual service costs (for example co-insurance) may easily rise barriers to utilisation of the expensive hospital services. Quality-related payments (for example extra-billing) may diminish access to services with appropriate quality, especially for people with a low income. Therefore, it can be expected that coinsurance and extra-billing are two types of payment that most probably will have little acceptance in Bulgaria. According to the Bulgarian legislation, the payment obligations have the form of copayments, which means that the type of patient payment is in accordance with public attitudes.

Given the high public support for limits on patient payments, co-payments and deductibles seem to be more adequate payment forms. In the former case, the patients pay a fixed amount for a service and in the latter case, patients can be charged up to a ceiling. The fees under these two forms are related neither to service cost nor to service quality, and the size of each payment is, in principle, restricted. Moreover, the absence of a relation between cost and payment is of particular importance for the Bulgarian situation since service costs have never been properly calculated. Although, the introduction of a social health insurance required an exact cost calculation, there could still be doubts about its preciseness. Furthermore, the collection procedure, in case of copayments, is characterised by low administrative costs due to their fixed nature (Barer et al., 1979). Given the costly health insurance system, the inexpensive collection of the co-payments can limit the additional administrative costs within the system.

Co-payments seem to be suitable for the Bulgarian public health care sector. However, there are still some disadvantages associated with their implementation. Most importantly, the fixed charges for health care services have little or no impact on health care efficiency, since they do not provide signals to consumers regarding the actual costs of the health care services (Barer et al., 1979).

Despite what type of payment is selected, the potential accumulation of payments will always require additional payment limitations. The Bulgarian legislation on patient payments does not consider limitations on patient payments except for hospital services. The considerable responsiveness of Bulgarian consumers to prices in health care sector suggests that such limitations are necessary and that the ability to pay needs to be of primary concern when settling payment limits. There is also strong public support for income-based limitations. The findings in this thesis suggest an annual limit of $1.3 \%$ of the family budgets per family member. The existence of informal payments, however, implies that a reduced annual limit should be considered.

\section{System of exemptions}

The introduction of patient payments for publicly provided services tends to distort equity. This is because patient payments are usually not related to individual income, but to the type and quantity 
of health care needed. Because patient payments do not require a distinction between rich and poor, it is expected that the introduction of patient payments will cause a higher financial burden for lower-income recipients than for the wealthier (Gertler and van der Graag, 1990, WHO, 1996). For that reason, patient payments have been described as a potentially highly regressive policy tool (e.g. Wagstaff and van Doorslaer, 1992). Some authors (e.g. Sprinkle, 1994) suggest that the basic effect of the introduction of patient payments with respect to equity is shifting the health care costs from those paying premiums or taxes to those who are already in the disadvantaged position of being sick. The negative effect of patient payments on equity can be further aggravated if there are additional informal charges (WHO, 1996). The potential distortion of equity due to the introduction of patient payments has been the soundest objection against their implementation.

It is true that the inequity effects caused by patient payments can be reduced through the exemption of the poor. Yet, this is not a sufficient condition for ensuring equity (Boaz, 1975). Patient payments can also cause a financial burden for individuals who are not considered poor but who need health care frequently. Therefore, several exemption criteria should be considered.

Bulgarian legislation on patient payments considers a broad exemption mechanism including various criteria related to economic status, health or profession. The findings in this thesis imply considerable public support for such extensive system of exemptions from patient payments.

The family budget should remain the primary criterion for the exemption of individuals from patient payment obligations in Bulgaria. Some other exemptions might also be considered in addition to those already legislated. Special attention should be paid to the explicit exemption from payment obligation for members of big families and families with several chronically sick members, as well as for disabled people, village dwellers and pensioners. Even if these groups are not considered poor, the accumulated patient payments or the combination of patient payments and travelling costs can pose a financial barrier for using health care services (Gertler and Van der Graag, 1990). There is also strong public support for exemptions for these population groups.

Although thoroughly designed, the implementation of an exemption mechanism often fails due to lack of information, inaccurate criteria definitions, high implementation costs, ineffective administration, political factors, or a fear of stigmatisation (Thomas et al., 1998). Therefore, special attention should be paid that the system of exemptions is actually implemented.

\subsection{Suggestions for further research}

Based on the consumer preferences and consumer willingness-and-ability-to-pay, this thesis draws conclusions about the appropriate objective and design of the patient payment mechanism in Bulgaria. The analysis, however, does not consider the impact of patient payments on the supply side of the health care market. If the health care provider is the actual beneficiary of patient payments, the fee may change the supply of health care as well. Therefore, further research may well be focused on the impact of fees on the behaviour of the health care providers.

In addition, the analysis does not consider the magnitude of the informal payments. The parallel existence of formal and informal payments, however, can have adverse equity effects. Therefore, further research may also be focused on the magnitude of the informal payments after the official fees are introduced and on the actual effects of the official fees on the service utilisation.

Further research should also focus on the establishment of the predictive validity of the results of the conjoint analysis and the contingent valuation. This will require a comparison of the results with the outcomes of the real market. 


\subsection{Final considerations}

Patient payments appear to be feasible for the Bulgaria public health care sector and acceptable to the population. The research findings presented in this thesis suggest a rationale for the implementation of patient payments in Bulgaria as a tool for improving the quality of the public health care provision at the local level. No pretence is made, however, that patient payments can rescue the national health system from the problem of reduced quality. The government cannot refrain from its role in mobilising more resources for public health care provision. This could be done by increasing the budget allocated to public health care services as a share of total government expenditure, and by mobilising additional financial support.

Furthermore, given the potential adverse effect of patient payments on equity, there is a need of a well-designed and promptly implemented system of exemptions. Any discouragement in using public health care should be avoided. If the compliance with this prerequisite results in payment for only a small fraction of the population, the net gain of the patient payments is likely to be small or even negative. The latter can occur if the administrative costs for the collection of fees and for the exemption of the vulnerable groups exceed the fee revenues. If this happens, the health policymakers should reconsider the need of patient payments in Bulgaria.

\section{References:}

Akin, J., Birdsall, N. and De Ferranti, D. (1987). Financing health services in developing countries: an agenda for report. World Bank Policy Study. Washington, DC: World Bank.

Barer, M.L., Evans, R.G. and Stoddart, G.L. (1979). Controlling health care costs by direct charges to patients: snare or delusion?. Occasional paper Nol0. Toronto: Ontario Economic Council.

Bennett, S. and Ngalande-Banda, E. (1997).Public and private roles in health: a review and analysis of experience in sub-saharan Africa. WHO/ARA/CC/97.6. Geneva: The World Health Organisation.

Boaz, R.F. (1975). Equity in paying for health care services under a national insurance system. MMFQ/Health and Society (Summer): 337-352.

Capital, editorial team (1998). The insurance system model (in Bulgarian). Capital 15 June, 23: 31-32.

Creese, A. (1991).User charges for health care: a review of recent experiences. Health Policy and Planning 6: 309-319.

Creese, A. and Kutzin, J. (1995). Lessons from cost recovery in health. WHO/SHS/NHP/95.5. Geneva: The World Health Organisation.

Delcheva, E., Balabanova, D. and McKee, M. (1997). Under-the-counter payments for health care: evidence from Bulgaraia. Health Policy 42:89-100.

Ensor, T. and Savelyeva, L. (1998). Informal payments for health care in the Former Soviet Union: some evidence from Kazakstan, Health Policy and Planning 13(1): 41-49.

EOHCS (1999). Health care systems in transition: Bulgaria. European Observatory on health care systems Copenhagen: The World Health Organization/Regional Office for Europe 
Gertler, P. and Van der Graag, J. (1990). The willingness to pay for medical care: evidence from two developing countries. Washington, D.C.: The World Bank.

Hialmarsson, O. (1998). User charging for primary and specialist doctor services in Iceland. In: OECD. User Charging for Government Services: Best Practice Guidelines and Case Studies. Public Management Occasional Paper No 22. Paris: OECD Publication Service.

Hsiao, W.C. (1995). Abnormal economic in health care sector. Health Policy 32: 125-139.

Huber, J.H. (1993). Ensuring access to health care with the introduction of user fees: a kenyan example. Social Sciences and Medicine 36 (4): 485-494.

Jimenez, E. (1987). Pricing policy in social sector: cost recovery for education and health in developing countries. Baltimore: John Hopkins University Press.

Kupor, S.A., Liu, Y.-c., Lee, J. and Yoshikawa, A. (1995). The effect of copaments and income on the utilization of medical care by subscribers to Japan's national health insurance system. International Journal of Health Services 25 (2): 295-312.

Kutzin, J. (1998). The appropriate role for patient cost sharing. In: Saltman, R.B. et. Al. (eds.). Critical Challenges for Health Care Reform in Europe. Buckingham: Open University Press.

Lee, K. (1989). Symptoms, causes and proposed solutions. In: Abel-Smith, B. and Creese, A. (eds.). Recurrent costs in the health sector - problems and policy options in three countries. WHO/SHS/NHP/89.8 . Geneva: World Health Organisation.

McPake, B. (1993). User charges for health services in developing countries: a review of the economic literature. Social Science and Medicine 36 (11): 1397-1405.

Ministry of Health Care (1998). Directive No22/9.12.1997 Conditions and organisation of the payment for medical care in case of patient choice (in Bulgarian). Biblioteka Zakoni APIS 5 (1) №126.

O'Grady, K.F., Manning W.G., Newhouse, J.P. and Brook, R.H. (1985). The impact of cost sharing on emergency department use. New England Journal of Medicine 313: 484-490.

OECD (1997). OECD economic surveys: Bulgaria 1997. Paris: OECD Publications.

Rubin, R.J. and Mendelson, D.N. (1995). A framework for cost sharing policy analysis. PharmacoEconomics 10 (Suppl. 2): 56-67.

Selby, J.V., Fireman, B.H. and Swain, B.E. (1996). Effect of a copayment on the use of the emergency department in a health maintenance organization. New England Journal of Medicine 334: 635-641.

Sprinkle, R.H. (1994). Remodeling health care. Journal of Health Politics, Policy and Law 19 (1): 45-68.

Stanton, B. and Clemens, J. (1989). User fees for health care in developing countries: a case study of Bangladesh. Social Science and Medicine 29 (10): 1199-1205.

The $38^{\text {th }}$ National Assembly (1998). The health insurance act. Sofia: The $38^{\text {th }}$ National Assembly.

Thomas, S., Killingsworth, J.R. and Acharya, S. (1998). User fees, self-selection and the poor in Bangladesh. Health Policy and Planing 13 (1): 50-58.

Thompson, R. and Witter, S. (2000). Informal payments in transitional economies: implications for health sector reform. International Journal of Health Planning and Management 15: 169-187.

Waddington, C.J. and Enyimayew, K.A. (1990). A price to pay, part 2: the impact of user charges in the volta region of china. International Journal of Health Panning and Management 5 (4): 287-312. 
Wagstaff, A. and Van Doorslaer, E. (1992). Equity in the finance of health care: some international comparisons. Journal of Health Economics 11: 361-387.

WHO (1996). European health care reforms: analysis of current strategies. Copenhagen: WHO/Regional Office for Europe.

WHO-Euro (1999). Better health for better future in Bulgaria: a health policy proposal. Draft 2. Unedited. 23rd February.

Yoder, R.A. (1989). Are people willing and able to pay for health services?. Social Sciences and Medicine 29 (1): 35-42.

Zafirova, T. and Kehaiova, M. (2001). An investigation of the consumers' evaluation regarding the hospitals and hospital services in the region of Varna and its application to strategic decision making (in Bulgarian). Godishnik na Ikonomicheskia Universitet Varna 1: 1-47. 


\section{APPENDIX A \\ The English wording of \\ the questionnaire}


ACE Project NoP97-9108-S: Cost-Sharing Policy for Public Health Care Sector in Bulgaria Social Survey: Willingness and Ability of Bulgarian Patient to pay Public Health Care Services

\section{QUESTIONNAIRE}

This survey is a part of a university project and it has pure academic goals.

The information we ask for cannot be associated with your personality.

The participation will be completely confidential and will be highly important for the project.

This survey is supported by Phare ACE Programme 1997 of the European Union

O ACE Project No P97-9108-S/ Maastricht University, 1999

No parts of this questionnaire can be used, translated, stored, published, copied or transmitted in any form (electronic, mechanical, copying, recording and etc.) without the written permission issued by ACE Project P97-9108-S. Address for contact: Maastricht University, Faculty of Health Sciences, BEOZ, PO BOX 616, Maastricht $6200 \mathrm{MD}$, the Netherlands. Person for contact: Milena Pavlova

\section{Part 1}

The first questions concern the health care services that you personally used during the last year - 1999, and the money you paid for receiving these services. Please, try to remember as precisely as possible before you give an answer.

Q.1 How many times did you visit general practitioner during the last year? times

- If you visited: How many times did you pay for general practitioner during the last year?

- If you paid: What was the total annual amount that you paid during the last year? BGL

- Was it possible to pay this amount out of your family budget? Y Yes No

Q.2 How many times did you visit medical specialist during the last year? times

- If you visited:How many times did you pay for medical specialist during the last year?

- If you paid: What was the total annual amount that you paid during the last year?

- Was it possible to pay this amount out of your family budget? $\square$ Yes $\square$ No

Q.3 How many times did you use laboratory services during the last year? times

- If you visited:How many times did you pay for laboratory services during the last year? times

- If you paid:What was the total annual amount that you paid during the last year?

- Was it possible to pay this amount out of your family budget? $\mathrm{Y}$ Yes No

Q.4 How many times did you use nursing care at home during the last year? times

- If you visited:How many times did you pay for nursing care at home during the last year?

- If you paid:What was the total annual amount that you paid during the last year?

- Was it possible to pay this amount out of your family budget? $\mathrm{Y}$ Yes No BGL times

Q.5 How many did you stay in hospital during the last year?

Due to:

pregnancy: times

operation: times

other procedure: times

- If you stay: For how many of your hospitalisations did you pay during the last year? In case of:

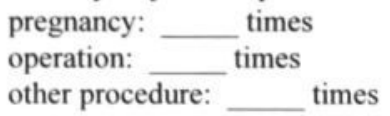


- If you paid: What was the total annual amount that you paid during the last year? In case of:

pregnancy: BGL

operation: BGL

other procedure: BGL

- Was it possible to pay these amounts out of your family budget? $\square$ Yes $\square$ No

Q.6 How many physiotherapeutic procedures did you have during the last year? times

- If you visited:For how many of these procedures did you pay during the last year?

- If you paid:What was the total annual amount that you paid during the last year?

- Was it possible to pay this amount out of your family budget? Yes No

Q.7 How many times did you use emergency care during the last year? times

- If you visited:How many times did you pay for emergency care during the last year?

- If you paid:What was the total annual amount that you paid during the last year? BGL

- Was it possible to pay this amount out of your family budget? $\square$ Yes No

Q.8 How many did you use dental services during the last year?

For:

dental check-up: times

treatment/filling of a tooth:

extraction of a tooth: times

placement of dental prosthesis: times

- If you use: How many times did you pay for dental services during the last year? In case of dental check-up: times treatment/filling of a tooth: extraction of a tooth: placement of dental prosthesis: times

$\overline{\text { times }}^{\text {times }}$
times

- If you paid: What was the total annual amount that you paid during the last year? In case of : dental check-up: BGL treatment/filling of a tooth: extraction of a tooth: BGL BGL placement of dental prosthesis: BGL

- Was it possible to pay this amount out of your family budget?

Y Yes $\square$ No

\section{Part 2}

The following questions concern your preferences for a physician and physician's services. Please, remember that there are no wrong or right answers. We are interested in your personal opinion.

Q.9 The following is a list of six characteristics of physician's services. What is the importance of these characteristics when you are selecting a physician?

Please, mark with 1 the characteristic that is most important for you, with 2 the second important characteristic, then the next important with $3,4,5$ up to 6 . Please, do not repeat numbers.

- Availability of medical equipment and materials

- Professional reputation of the physician

- Maintenance of the building and the physician's office

- Travelling time to the physician's office

- Waiting time in front the physician's office

- Amount of money paid by the patient 
Q.10 Bellow there are short descriptions of the services offered by 16 physicians. What is the level of your preferences for every one of the physicians?

\section{Physician A}

- Full range of equipment and materials

- Not good professional reputation

- Badly maintained building and office

- Short travelling time

- Long waiting time

- 5.- BGL paid by the patient

\section{Physician B}

- Lack of basic equipment and materials

- Unknown professional reputation

- Badly maintained building and office

- Short travelling time

- Long waiting time

- $2.50 \mathrm{BGL}$ paid by the patient

\section{Physician C}

- Full range of equipment and materials

- Good professional reputation

- Well maintained building and office

- Short travelling time

- Long waiting time

- 10.- BGL paid by the patient

\section{Physician D}

- Full range of equipment and materials

- Not good professional reputation

- Bably maintained building and office

- Long travelling time

- Short waiting time

- $2.50 \mathrm{BGL}$ paid by the patient

\section{Physician E}

- Full range of equipment and materials

- Unknown professional reputation

- Badly maintained building and office

- Short travelling time

- Short waiting time

- 10.- BGL paid by the patient
What is the level of your preference for physician A?

$$
\begin{aligned}
& 1=\text { very low } \\
& 2=\text { low } \\
& 3=\text { moderate } \\
& 4=\text { high } \\
& 5=\text { very high }
\end{aligned}
$$

What is the level of your preference for physician B?

$$
\begin{aligned}
& 1=\text { very low } \\
& 2=\text { low } \\
& 3=\text { moderate } \\
& 4=\text { high } \\
& 5=\text { very high }
\end{aligned}
$$

What is the level of your preference for physician $\mathrm{C}$ ?

$$
\begin{aligned}
& 1=\text { very low } \\
& 2=\text { low } \\
& 3=\text { moderate } \\
& 4=\text { high } \\
& 5=\text { very high }
\end{aligned}
$$

What is the level of your preference for physician D?

$$
\begin{aligned}
& 1=\text { very low } \\
& 2=\text { low } \\
& 3=\text { moderate } \\
& 4=\text { high } \\
& 5=\text { very high }
\end{aligned}
$$

What is the level of your preference for physician E?

$$
\begin{aligned}
& 1=\text { very low } \\
& 2=\text { low } \\
& 3=\text { moderate } \\
& 4=\text { high } \\
& 5=\text { very high }
\end{aligned}
$$




\section{Physician F}

- Lack of basic equipment and materials

- Good professional reputation

- Badly maintained building and office

- Long travelling time

- Short waiting time

- 5.- BGL paid by the patient

\section{Physician G}

- Lack of basic equipment and materials

- Not good professional reputation

- Badly maintained building and office

- Long travelling time

- Long waiting time

- 10.- BGL paid by the patient

\section{Physician $\mathbf{H}$}

- Full range of equipment and materials

- Good professional reputation

- Badly maintained building and office

- Long travelling time

- Long waiting time

- 10.- BGL paid by the patient

\section{Physician I}

- Full range of equipment and materials

- Not good professional reputation

- Well maintained building and office

- Short travelling time

- Short waiting time

- 5.- BGL paid by the patient

\section{Physician J}

- Lack of basic equipment and materials

- Good professional reputation

- Well maintained building and office

- Short travelling time

- Short waiting time

- $2.50 \mathrm{BGL}$ paid by the patient
What is the level of your preference for physician F?

$$
\begin{aligned}
& 1=\text { very low } \\
& 2=\text { low } \\
& 3=\text { moderate } \\
& 4=\text { high } \\
& 5=\text { very high }
\end{aligned}
$$

What is the level of your preference for physician G?

$$
\begin{aligned}
& 1=\text { very low } \\
& 2=\text { low } \\
& 3=\text { moderate } \\
& 4=\text { high } \\
& 5=\text { very high }
\end{aligned}
$$

What is the level of your preference for physician $\mathrm{H}$ ?

$$
\begin{aligned}
& 1=\text { very low } \\
& 2=\text { low } \\
& 3=\text { moderate } \\
& 4=\text { high } \\
& 5=\text { very high }
\end{aligned}
$$

What is the level of your preference for physician I?

$$
\begin{aligned}
& 1=\text { very low } \\
& 2=\text { low } \\
& 3=\text { moderate } \\
& 4=\text { high } \\
& 5=\text { very high }
\end{aligned}
$$

What is the level of your preference for physician J?

$$
\begin{aligned}
& 1=\text { very low } \\
& 2=\text { low } \\
& 3=\text { moderate } \\
& 4=\text { high } \\
& 5=\text { very high }
\end{aligned}
$$




\section{Physician K}

- Lack of basic equipment and materials

- Not good professional reputation

- Badly maintained building and office

- Short travelling time

- Short waiting time

- 10.- BGL paid by the patient

\section{Physician L}

- Lack of basic equipment and materials

- Not good professional reputation

- Well maintained building and office

- Long travelling time

- Short waiting time

- 10.- BGL paid by the patient

\section{Physician M}

- Lack of basic equipment and materials

- Unknown professional reputation

- Well maintained building and office

- Long travelling time

- Long waiting time

- 5.- BGL paid by the patient

\section{Physician N}

- Full range of equipment and materials

- Unknown professional reputation

- Well maintained building and office

- Long travelling time

- Short waiting time

- 10.- BGL paid by the patient

\section{Physician O}

- Lack of basic equipment and materials

- Not good professional reputation

- Well maintained building and office

- Short travelling time

- Long waiting time

- 10.- BGL paid by the patient
What is the level of your preference for physician $\mathrm{K}$ ?

$$
\begin{aligned}
& 1=\text { very low } \\
& 2=\text { low } \\
& 3=\text { moderate } \\
& 4=\text { high } \\
& 5=\text { very high }
\end{aligned}
$$

What is the level of your preference for physician L?

$$
\begin{aligned}
& 1=\text { very low } \\
& 2=\text { low } \\
& 3=\text { moderate } \\
& 4=\text { high } \\
& 5=\text { very high }
\end{aligned}
$$

What is the level of your preference for physician M?

$$
\begin{aligned}
& 1=\text { very low } \\
& 2=\text { low } \\
& 3=\text { moderate } \\
& 4=\text { high } \\
& 5=\text { very high }
\end{aligned}
$$

What is the level of your preference for physician N?

$$
\begin{aligned}
& 1=\text { very low } \\
& 2=\text { low } \\
& 3=\text { moderate } \\
& 4=\text { high } \\
& 5=\text { very high }
\end{aligned}
$$

What is the level of your preference for physician $\mathrm{O}$ ?

$$
\begin{aligned}
& 1=\text { very low } \\
& 2=\text { low } \\
& 3=\text { moderate } \\
& 4=\text { high } \\
& 5=\text { very high }
\end{aligned}
$$




\section{Physician P}

- Full range of equipment and materials

- Not good professional reputation

- Well maintained building and office

- Long travelling time

- Long waiting time

- 2.50 BGL paid by the patient
What is the level of your preference for physician P?

$$
\begin{aligned}
& 1=\text { very low } \\
& 2=\text { low } \\
& 3=\text { moderate } \\
& 4=\text { high } \\
& 5=\text { very high }
\end{aligned}
$$

\section{Part 3}

Next questions concern your willingness and ability to pay for public health care services. Please remember that we are interested in your personal opinion.

Imagine that there is a preposition to introduce fees paid by the patients when using public health care services.

The fee revenues will be used for the improvement of the quality and the access of these services.

Therefore, you are asked to state your willingness and ability to pay for improved public health care.

Please, consider both your willingness and your ability to pay when answering the questions.

Q.11 What is the maximum amount of money that you are willing and able to pay for every visit to a general practitioner in order to receive services with good quality and quick access?
Nothing
Less than 2.50 BGL
Between 2.50 to 5.- BGL
Please, point how much:
BGL per visit
More than 5.- BGL
Please, point how much:
BGL per visit
Please, point how much:
BGL per visit

Q.12 What is the maximum amount of money that you are willing and able to pay for every visit to a medical specialist in order to receive services with good quality and quick access?

\section{Nothing}
Less than 5.- BGL
Please, point how much:
BGL per visit
Between 5.- to 10.- BGL
Please, point how much:
BGL per visit
More than 10.- BGL
Please, point how much: BGL per visit

Q.13 What is the maximum amount of money that you are willing and able to pay for every service of a medical laboratory in order to receive services with good quality and quick access?

\section{Nothing}

Less than 5.- BGL

Please, point how much:

BGL per service

Between 5.- to 10.- BGL

Please, point how much: BGL per service

More than 10.- BGL

Please, point how much: BGL per service

Q.14 What is the maximum amount of money that you are willing and able to pay for every day nursing care at your home in order to receive services with good quality and quick access?

Nothing

Less than 2.50 BGL

Between 2.50 to 5.- BGL

More than 5.- BGL
Please, point how much:

Please, point how much:

Please, point how much:
BGL per day

BGL per day

BGL per day 
Q.15 What is the maximum amount of money that you are willing and able to pay for every use of hospital services in order to receive services with good quality and quick access?

For a maternity service in hospital:

\author{
Nothing \\ Less than 50.- BGL \\ Between 50.- to 100.- BGL \\ More than 100.- BGL
}

For a hospital operation:

Nothing
Less than 50.- BGL
Between 50.- to 100.- BGL
More than 100.- BGL

For other hospital procedure:

\section{Nothing}

Less than 50.- BGL

Between 50.- to 100.- BGL

More than 100.- BGL
Please, point how much:

Please, point how much:

Please, point how much:

BGL per service

BGL per service

BGL per service
Please, point how much: Please, point how much: Please, point how much:
BGL per operation BGL per operation BGL per operation

Please, point how much: BGL per procedure Please, point how much: BGL per procedure Please, point how much: BGL per procedure

Q.16 What is the maximum amount of money that you are willing and able to pay for a physiotherapeutic procedure in order to receive service with good quality and quick access?

Nothing

Less than $50 \mathrm{BGL}$

Between 50 to 100.- BGL

More than 100.- BGL
Please, point how much:

Please, point how much:

Please, point how much:
BGL per procedure BGL per procedure BGL per procedure

Q.17 What is the maximum amount of money that you are willing and able to pay for every service of emergency care in order to receive service with good quality and quick access?

\section{Nothing}

Less than 50.- BGL

Between 50.- to 100.- BGL

More than 100.- BGL

Please, point how much:

Please, point how much:

Please, point how much:
BGL per service

BGL per service

BGL per service

Q.18 What is the maximum amount of money that you are willing and able to pay for every use of dental services with good quality and quick access?

For a dental check-up:

Nothing

Less than 5.- BGL

Between 5.- to 10.- BGL

More than 10.- BGL

For a treatment or filling of a tooth:

Nothing

Less than 25.- BGL

Between 25.- to 50.- BGL

More than 50.- BGL

For an extraction of a tooth:

Nothing

Less than 25.- BGL

Between 25.- to 50.- BGL

More than 50.- BGL
Please, point how much:

Please, point how much:

Please, point how much:

BGL per check-up

BGL per check-up

BGL per check-up

Please, point how much:

Please, point how much:

BGL per treatment

Please, point how much: BGL per treatment BGL per treatment
Please, point how much: Please, point how much: Please, point how much:
BGL per extraction BGL per extraction BGL per extraction 
For a placement of a dental prosthesis:

Nothing

Less than 25.- BGL

Please, point how much:

BGL per placement

Between 25.- to 50.- BGL

Please, point how much:

BGL per placement

More than 50.- BGL

Please, point how much: BGL per placement

Q.19 What is the maximum amount of money that you are willing and able to pay for public health care services per year in order to receive services with good quality and quick access? BGL

Q.20 Was it difficult to estimate your willingness and ability to pay for medical services? $\square$ Yes $\square$ No If yes, why?

Q.21 Do you think you should pay higher fees for more expensive medical services? $\square$ Yes $\square$ No

Q.22 Do you think you should pay higher fees for medical services with better quality? $\square$ Yes $\square$ No

Q.23 Do you think, that the patient payments should be limited? $\square$ Yes No

If yes, how do you think this limit should be settled? You may mark more than one method.

As a limit per year

As a limit per service

As a limit per income

Q.24 In your opinion, who should collect and use the patient payments?

The physician, who offers the service

The health institution, where the serviced is offered

The local authorities (the municipality)

The insurance fund

Q.25 In your opinion, which groups of the population should be excluded from patient payments?

You may mark more that one group.

Children under certain age

Pensioners

Unemployed

People with chronic deceases

Pregnant women

Disable persons

\section{Part 4}

At the end, there are some questions concerning your socio-demographic status. The information we require would not be related to your identity. The data is necessary in order to analyze the results of the survey.

Q.26 What is your age? years

Q.27 What is your gender?

male

female

Q.28 Which of the following categories corresponds to your level of current education or current study? primary school secondary school semi-university university 
Q.29 Which of the following categories corresponds to your current occupation and activities?

You may mark more than one category.

student

soldier

worker in a state enterprise

manager of a state enterprize

employee of a private enterprise

private buisiness

unemployed (job-seeking)

unemployed (not seeking for a job)

pensioner (because of age)

pensioner (because of illness)

Q.30 How do you perceive your present health status?

perfect health

good health

not very good

bad health

Q.31 Are you religious? $\square$ Yes $\square$ No

If yes, what is your religion?

Q.32 Which of the following categories corresponds to your marital status?

not married, living with parents

not married, living alone

living with a partner

married, living with a spouse

married, living separately from the spouse

divorced

widow/er

Q.33 Which of the following categories corresponds to your residense place?

big city

small town

village

The following questions concern your family. If you are an unmarried student, please, consider as your

family yourself, your parents and the people living together with them (brothers, sisters, grandparents, etc.)

Q.34 How many people are there in your family?

people

Q.35 How many children under the age of 18 are there in your family? children under 18

Q.36 How many people in your family work at present (incl. you)? people

Q.37 How many people in your family have chronic deceases or are in a bad health (incl. you)? people 
Q.38 The last question concerns your family income.

Which of the following categories corresponds to the amount of your net family income per month? Please, consider the average amount of money that all the members of your family receive per month.
less than 50.- BGL per month
between 50.- and 100.- BGL per month
between 101.- and 200.- BGL per month
between 201.- and 300.- BGL per month
between 301.- and 500.- BGL per month
between 501.- and 800.- BGL per month
between 801 .- and 1000.- BGL per month
more than 1000.- BGL per month

This is the end of the questionnaire.

Thank you for your participation! 


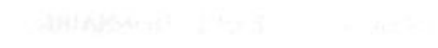

.

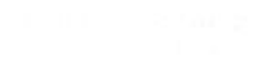

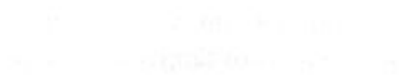

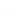

;

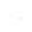

.

. 
APPENDIX B

Анкетна карта

(The questionnaire in Bulgarian) 


\section{ACE Проект No P97-9108-S: Политика на поделяне на стойността за българския обществен сектор на здравеопазването \\ Проучване: Желание и способност на българските пациенти да заплащат обществени здравни услуги}

\section{В Ъ П Р О С Н И К}

Това проучване е част от университетски проект и то има чисто академични цели.

Информацията, за която питаме не може да бъде свързана с Вашата самоличност.

Вашето участие ще бъде напълно анонимно и ще имат висока стойност за проекта.

Проучването е спонсорирано от програма Фар АСЕ 1997 на Европейския Съюз.

(C) ACE Проект No P97-9108-S / Университет Маастрихт, 1999

Никоя част от този въпросник не може да бъде използвана, превеждана, съхранявана, публикувана, размножавана или предавана в каквато и да е форма (електронна, механична, копирна, записваща или др.) без предварително писмено разрешение издадено от: ACE Project No P97-9108-S

Адрес за контакт: Maastricht University, Faculty of Health Sciences, BEOZ PO Box 616, Maastricht 6200 MD, The Netherlands.

Лице за контакт: Милена Павлова 


\section{Чact 1}

Първите въпроси засягат медицински услуги, които Вие лично използвахте през миналата година 1999, и парите, които платихте за използването на тези услуги. Моля, опитайте да си спомните възможно най-точно преди да оттоворите.

В-1. Колко пъти, през миналата година, посетихте общо практикуващ лекар?

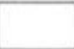

- Ако не е посещаван преминете към В-2

Колко пъти, през миналата година, платихте заобщо практикуващ лекар?

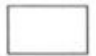

- Ако не е плащано преминете към В-2

Каква беше общата годишна сума, която платихте за общо практикуващ лекар през миналата година?

Беше ли възможно да платите тази сума от своя семеен бюджет? (1=Да / 2=Hе)

B-2. Колко пъти, през миналата година, посетихте медицински специалист?

- Ако не е посещаван преминете към В-3

Колко пъти, през миналата година, платихте за медицински специалист?

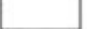

- Ако не е плащано преминете към В-3

Каква беше общата годишна сума, която платихте за медицински специалист през миналата година?

Беше ли възможно да платите тази сума от своя семеен бюджет? (1=Да / $2=\mathrm{He})$

B-3. Колко пъти, през миналата година, използвахте услуги на медицинска лаборатория?

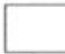

- Ако не са използвани преминете към В-4

Колко пъти, през миналата година, платихте за услуги на медицинска лаборатория?

- Ако не е плащано преминете към В-4

Каква беше общата годишна сума, която платихте за услуги на медицинска лаборатория през миналата година?

Беше ли възможно да платите тази сума от своя семеен бюджет? (1=Да / 2=Не)

B-4. Колко пъти, през миналата година, използвахте домашни грижи на медищинска сестра?

- Ако не са използвани преминете към В-5

Колко пъти, през миналата година, платихте за домашни грижи на медицинска сестра?

- Ако не е плащано преминете към В-5

Каква беше общата годишна сума, която платихте за домашни грижи на медицинска сестра през миналата година?

Беше ли възможно да платите тази сума от своя семеен бюджет? (1=Да / $2=\mathrm{He})$ 


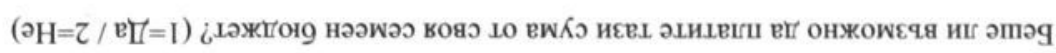

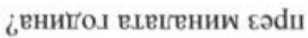

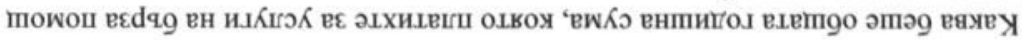

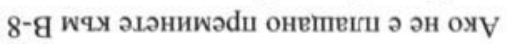

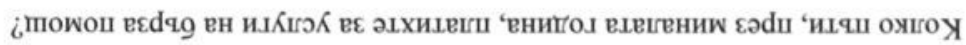

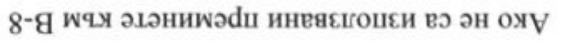

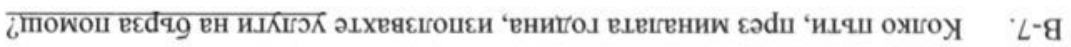

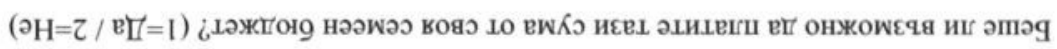
¿внитол е.ецениш єәdи

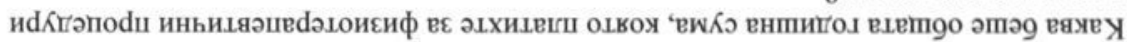

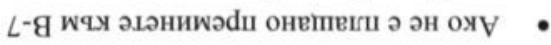

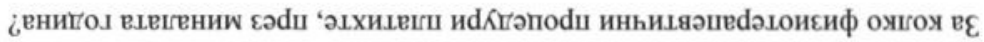
L-g жчм әьәнишәdи инеяеценєен в ән ояУ

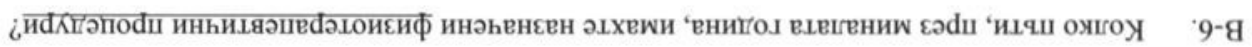

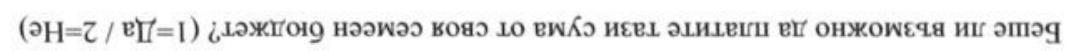

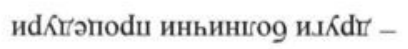

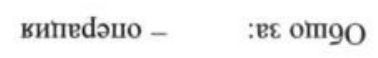

วнегжеd / เюоннәพәd9 -

¿внитол вцегениш єәdи

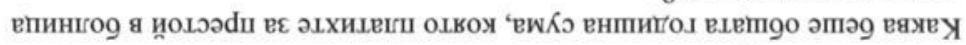
9-g жчм әгәнижәdи онетпег ә ән ояу •

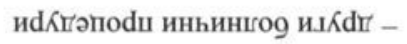

$$
\text { випедәшо - :ен йеьКшг g }
$$

әнегжеd / І Јоннәพәd9 -

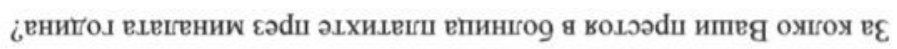

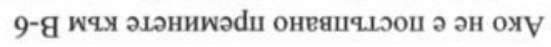

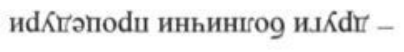

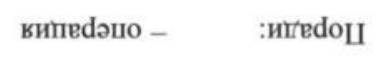

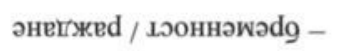

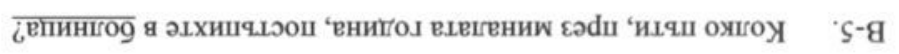


B-8. олко пъти посетихте зъболекар през миналата година?

$$
\begin{array}{ll} 
& - \text { профилактичен преглед } \\
\text { С цел: } & - \text { лечение / пломбиране на зъб } \\
& - \text { изваждане на зъб } \\
& - \text { поставяне на зъбна протеза }
\end{array}
$$

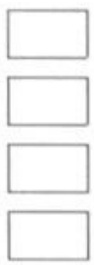

- Ако не е посещаван преминете към ЧАСТ 2

Колко пъти, през миналата година, платихте за зъболекаески услуги?

$$
\begin{array}{cl} 
& - \text { профилактичен преглед } \\
\text { В случай на: } & - \text { лечение / пломбиране на зъб } \\
& - \text { изваждане на зъб } \\
& - \text { поставяне на зъбна протеза }
\end{array}
$$

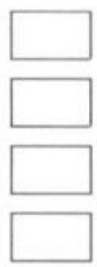

- Ако не е плащано преминете към ЧАСТ 2

Каква беше общата годишна сума, която платихте за зъболекарски услуги през миналата година?

$$
\begin{array}{cl} 
& - \text { профилактичен преглед } \\
\text { Общо за: } \quad-\text { лечение / пломбиране на зъб } & \quad-\text { изваждане на зъб } \\
& - \text { поставяне на зъбна протеза }
\end{array}
$$
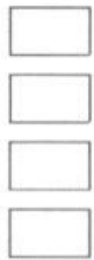

Беше ли възможно да платите тази сума от своя семеен бюджет? (1=Да / $2=\mathrm{He})$

\section{YACT 2}

Следващите въпроси засягат Вашите предпочитания за лекар и лекарски услуги. Моля, помнете, че тези въпроси нямат верни или грешни отговори. Интерес представлява Вашето лично мнение.

В-9. По долу има списък от шест характеристики на лекарски услуги. Каква е важността на всяка от тези характеристики за Вас, когато се обръщате към лекар?

Моля, напишете 1 срещу най-важната за Вас характеристика, 2 срещу втората по важност за Вас характеристика, 3 за следващата по важност, 4,5 до 6. Моля, не повтаряйте числа.

- Наличност на мед. оборудване и материали

- Професионална репутация на лекаря

- Поддръжка на сградата и лекарския кабинет

- Време на придвижване до лекарския кабинет

- Време на чакане пред лекарския кабинет

- Сума, заплащана от пациента

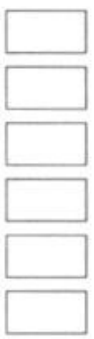




\section{Лекар М}

- Липса на основно оборудване и материали

- Не добра професионална репутация

- Добре подльржана сграда и кабинет

- Дълго време на придвижване

- Кратко време на чакане

- 10.- нови лв., платени от пациента

\section{Лекар $\mathrm{H}$}

- Липса на основно оборудване и материали

- Неизвестна професионална репутация

- Добре подлържана сграда и кабинет

- Дълго време на придвижване

- Дълго време на чакане

- 5.- нови лв., платени от пациента

Лекар О

- Пълна гама от оборудване и материали

- Неизвестна професионална репутация

- Добре подцържана сграда и кабинет

- Дълго време на придвижване

- Кратко време на чакане

- 10.- нови лв., платени от пациента

\section{Лекар П}

- Липса на основно оборудване и материали

- Не добра професионална репутация

- Добре подлържана сграда и кабинет

- Кратко време на придвижване

- Дълго време на чакане

- 10.- нови лв., платени от пациента

\section{Лекар P}

- Пълна гама от оборудване и материали

- Не добра професионална репутация

- Добре подљържана сграда и кабинет

- Дълго време на придвижване

- Дълго време на чакане

- 2.50 нови лв., платени от пациента
Какво е нивото на Вашето предпочитание за лекар М?

$$
\begin{aligned}
& 1=\text { много ниско } \\
& 2=\text { ниско } \\
& 3=\text { средно } \\
& 4=\text { високо } \\
& 5=\text { много високо }
\end{aligned}
$$

Какво е нивото на Вашето предпочитание за лекар $\mathrm{H}$ ?

$$
\begin{aligned}
& 1=\text { много ниско } \\
& 2=\text { ниско } \\
& 3=\text { средно } \\
& 4=\text { високо } \\
& 5=\text { много високо }
\end{aligned}
$$

Какво е нивото на Вашето предпочитание за лекар $\mathrm{O}$ ?

$$
\begin{aligned}
& 1=\text { много ниско } \\
& 2=\text { ниско } \\
& 3=\text { средно } \\
& 4=\text { високо } \\
& 5=\text { много високо }
\end{aligned}
$$

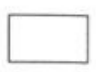

Какво е нивото на Вашето предпочитание за лекар П?

$$
\begin{aligned}
& 1=\text { много ниско } \\
& 2=\text { ниско } \\
& 3=\text { средно } \\
& 4=\text { високо } \\
& 5=\text { много високо }
\end{aligned}
$$

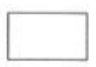

Какво е нивото на Вашето предпочитание за лекар Р?

$$
\begin{aligned}
& 1=\text { много ниско } \\
& 2=\text { ниско } \\
& 3=\text { средно } \\
& 4=\text { високо } \\
& 5=\text { много високо }
\end{aligned}
$$




\section{YACT 3}

Следващите въпроси засягат Вашето желание и способност да плащате обществени медицински услуги. Моля, помнете, че се интересуваме от Вашето лично мнение.

Представете си, че има предложение за въвеждане на такси, които да бъдат заплащани от пациентите при използването на медицински услуги.

Прихода от тези плащания ще бъде използван за подобряване на качеството и достъпа до медицински услуги.

Вие сте запитан/а относно Вашето желание и способност да заплащате за подобряване на качеството и достъпа до медицински услуги.

Моля, обмисляйте внимателно желанието си и способността си да заплащате медицински услуги.

B-11. Каква е максималната сума, която желаете и можете да заплащате при всяко посещение на общо практикуващ лекар, за да ползвате услуги с добро качество и бърз достъп?

1 = Нищо

$2=$ По-малко от 2.50 нови лв.

$3=$ От 2.50 до 5.- нови лв.

$4=$ Повече от 5 .- нови лв.

Моля, посочете, колко нови лв. на посещение.

В-12. Каква е максималната сума, която желаете и можете да заплащате при всяко посещение на медицински специалист, за да ползвате услуги с добро качество и бърз достъп?

$1=$ Нищо

2 = По-малко от 5.- нови лв.

$3=$ От 5.- до 10.- нови лв.

$4=$ Повече от 10.- нови лв.

Моля, посочете, колко нови лв. на посещение.

В-13. Каква е максималната сума, която желаете и можете да заплащате при всяко използване на лабораторни услуги, за да ползвате услуги с добро качество и бърз достъп?

$1=$ Нищо

2 = По-малко от 5.- нови лв.

$3=$ От 5.- до 10.- нови лв.

$4=$ Повече от 10.- нови лв.

Моля, посочете, колко нови лв. на услуга.

B-14. Каква е максималната сума, която желаете и можете да заплащате за всеки ден домашни грижи на медицинска сестра, за да ползвате услуги с добро качество и бърз достъп?

$1=$ Нищо

2 = По-малко от 2.50 нови лв.

$3=$ От 2.50 до 5.- нови лв.

$4=$ Повече от 5.- нови лв.

Моля, посочете, колко нови лв. на ден. 
В-15. Каква е общата максимална сума, която желаете и можете да заплащате при многодневен престой в болница, за да ползвате услуги с добро качество и бърз достъп?

В случай на бременост / раждане в болница:

1 = Нищо

2 = По-малко от 50.- нови лв.

$3=$ От 50.- до 100.- нови лв.

$4=$ Повече от 100.- нови лв.

Моля, посочете, колко нови лв. на случай.

В случай на операция в болница:

1 = Нищо

$2=$ По-малко от 50.- нови лв.

$3=$ От 50.- до 100.- нови лв.

4 = Повече от 100.- нови лв.

Моля, посочете, колко нови лв. на операция.

В случай на друга болнична процедура:

$1=$ Нищо

$2=$ По-малко от 50.- нови лв.

$3=$ От 50.- до 100.- нови лв.

$4=$ Повече от 100.- нови лв.

Моля, посочете, колко нови лв. на процедура.

В-16. Каква е максималната сума, която желаете и можете да заплащате за всяка физиотерапевтична процедура, за да ползвате услуги с добро качество и бърз достъп?

$1=$ Нищо

2 = По-малко от 50.- нови лв.

$3=$ От 50.- до 100.- нови лв.

$4=$ Повече от 100.- нови лв.

Моля, посочете, колко нови лв. на процедура

В-17. Каква е максималната сума, която желаете и можете да заплащате за всяко използване на услугите на бърза помощ, за да ползвате услуги с добро качество и бърз достъп?

$1=$ Нищо

2 = По-малко от 50.- нови лв.

$3=$ От 50.- до 100.- нови лв.

$4=$ Повече от 100.- нови лв.

Моля, посочете, колко нови лв. на услуга

В-18. Каква е общата максимална сума, която желаете и можете да заплащате при посещение на зъболекар, за да ползвате услуги с добро качество и бърз достъп?

За профилактичен преглед при зъболекар:

$1=$ Нищо

2 = По-малко от 5.- нови лв.

$3=$ От 5.- до 10.- нови лв.

$4=$ Повече от 10.- нови лв.

Моля, посочете, колко нови лв. на преглед 
За лечение / пломбиране на зъб:

$1=$ Нищо

2 = По-малко от 25.- нови лв.

$3=$ От 25.- до 50.- нови лв.

$4=$ Повече от 50.- нови лв.

Моля, посочете, колко нови лв. на случай

За изваждане на зъб:

$1=$ Нищо

2 = По-малко от 25.- нови лв.

$3=$ От 25.- до 50.- нови лв.

$5=$ Повече от 50.- нови лв.

Моля, посочете, колко нови лв. на случай

За поставяне на зъбна протеза:

$1=$ Нищо

2 = По-малко от 25.- нови лв.

$3=$ От 25.- до 50.- нови лв. й

$4=$ Повече от 50.- нови лв.

Моля, посочете, колко нови лв. на случай

В-19. Каква е общата максимална сума, която желаете и можете да заплащате годишно за медицински услуги, за да ползвате услуги с добро качество и бьрз достъп?

В-20. Беше ли Ви трудно да определите своето желание и способност да заплащате за медицински услуги? (1=Да / $2=\mathrm{He})$

Ако, да, моля обяснете защо:

В-21. Смятате ли, че би трябвало да заплащате по-високи суми за по-скъпи медицински услуги? ( $1=Д а$ / $2=\mathrm{He})$

B-22. Смятате ли, че би трябвало да заплащате по-високи суми за медицински услуги с по-добро качество? ( $1=Д а$ / $2=\mathrm{He})$

B-23. Смятате ли, че би трябвало да се постави ограничение на плащанията на пациентите? ( $1=$ Да / $2=\mathrm{He})$

Ако да, как смятате, че би трябвало да се постави този максимум?

Можете да посочите повече от единин метод.

- като максимум за година $(1=Д а / 2=\mathrm{He})$

- като максимум за услуга ( $1=Д а$ / $2=\mathrm{He})$

- като максимум за доход ( $1=Д а / 2=\mathrm{He})$ 
В-24. Според Вас, кой би трябвало да събира и използва плащанията на пациентите?

1 = лекаря, който предлага услугата

2 = здравното заведение, където услугата е предложена

3 = местните власти (общината)

4 = застрахователен (осигурителен) фонд

В-25. Според Вас, кои групи от пациенти би трябвало да бъдат изключени от плащания? Можете да посочите повече от едина група.

- никой не трябва да бъде изключен ( $1=$ Да / $2=\mathrm{He})$

- деца под определена възраст ( $1=$ Да / $2=\mathrm{He})$

- пенсионери (1=Да / $2=\mathrm{He})$

- безработни $(1=$ Да / $2=\mathrm{He})$

- хроничноболни $(1=$ Да / $2=\mathrm{He})$

- $\quad$ бременни жени $(1=$ Да / $2=\mathrm{He})$

- $\quad$ хора с умствени или физически увреждания (1=Да / $2=\mathrm{He})$

\section{Част 4}

Последо имаме няколко въпроса относно Вашите социално-демографски характеристики. Информацията за която Ви питаме не може да бъде свързана с Вашата самоличност. Тези данни са необходими за анализиране на резултатите от това проучване.

\section{В-26. На колко години сте?}

В-27. Какъв е вашия пол?

$$
\begin{aligned}
& 1=\text { мъжки } \\
& 2=\text { женски }
\end{aligned}
$$

B-28. Коя от посочените категории отговаря на нивото на Вашето образование или текущо обучение?
1 = начално или основно (училище)
2 = средно (гимназия или техникум)
3 = полувисше (институт или колеж)
4 = висше (институт или университет)

В-29. Кои от посочените категории оттоварят на Вашите текущи занимания и дейности? Можете да посочите повече от една категория.
$1=$ студент
$2=$ войник
3 = работник в държавно предприятие
4 = мениджър в държавно предприятие
$5=$ нает в частна компания
$6=$ частен бизнесмен
7 = безработен (търсещ работа)
$8=$ безработен (нетьрсещ работа)
$9=$ пенсионер (поради възраст)
10 = пенсионер (поради болест) 
В-30. Как преценявате Вашето здраве в момента?

$1=$ перфектно здраве

2 = добро здраве

3 = не много добро здраве

4 = влошено здраве

В-31. Изповядвате ли някаква религия? ( $1=$ Да / $2=\mathrm{He})$

Ако, да, каква е Вашата религия?

B-32. Коя от посочените категории отговаря на Вашето семейно положение?

1 = несемеен, живеещ с родители

2 = несемеен, живеещ сам

3 = живеещ с партньор

4 = семеен, живееш със съпруга/съпругата

5 = семеен, живеещ отделно от съпруга/съпругата

$6=$ разведен

7 = вдовец/вдовица

B-33. Коя от посочените категории отговаря на вида на населеното място, в което живеете?

$1=$ голям град

2 = малък град

$3=$ село

Следващите въпроси засягат вашето семейство. Ако сте несемеен студент, моля, считайте за Ваше семейство себе си, родителите си и хората, живеещи с Вашите родители (братя, сестри и др.)

В-34. От колко човека се състои Вашето семейство?

В-35. Колко деца под 18 години има във Вашето семейство?

В-36. Колко човека във Вашето семейство са хронично болни или са в лошо здравословно състояние (вкл. и Вие)?

В-37. Колко човека във Вашето семейство работят в момента (вкл. и Вие)?

B-38. Коя от посочените категории отговаря на Вашия чист семеен доход за един месец?

Моля, отчетете общата сума пари, която всички членове на Вашето семейство донасят

в къщи през месеца.

1 = по-малко от 50.- $\quad$ нови лв. на месец

2 = между 50.- и 100.- нови лв. на месец

3 = между 101.- и 200.- нови лв. на месец

4 = между 201.- и 300.- нови лв. на месец

5 = между 301.- и 500.- нови лв. на месец

6 = между 501.- и 800.- нови лв. на месец

7 = между 801.- и 1000.- нови лв. на месец

8 = повече от 1000.- нови лв. на месец

С това въпросникът приключва.

Благодарим Ви за Вашето участие! 



\section{APPENDIX C}

Socio-demographic

characteristics of the sample 


\section{Appendix C.1. Description of the socio-demographic variables collected in the survey}

\begin{tabular}{|c|c|c|c|}
\hline of the & $\begin{array}{l}\% \\
\text { Sample }\end{array}$ & & $\begin{array}{c}\% \\
\text { of the Sample }\end{array}$ \\
\hline \multicolumn{2}{|l|}{ Age: } & \multicolumn{2}{|l|}{ Occupation: } \\
\hline $18-30$ years & 21.3 & Student & 6.3 \\
\hline $31-40$ years & 19.1 & State Employee & 22.0 \\
\hline $41-50$ years & 20.1 & Private Employee & 14.9 \\
\hline $51-60$ years & 16.1 & Self-Employed & 6.9 \\
\hline Above 60 years & 23.4 & Unemployed & 15.9 \\
\hline \multicolumn{2}{|l|}{ Gender: } & Not Working & 4.1 \\
\hline Male & 47.8 & Pensioner (due to age) & 26.6 \\
\hline Female & 52.2 & Pensioner (due to illness) & 3.2 \\
\hline \multicolumn{2}{|l|}{ Education: } & Marital Status: & \\
\hline No or Primary Education (<10 years) & 25.6 & Single (living with parents) & 13.7 \\
\hline School Education ( $10+12$ years) & 49.3 & Single (living alone) & 4.8 \\
\hline Semi-University Education ( $12+15$ years) & 8.0 & Living with Partner & 3.7 \\
\hline University Education ( $\geq 15$ years) & 17.0 & Married & 61.3 \\
\hline \multicolumn{2}{|l|}{ Perceived Health Status: } & Divorced & 5.7 \\
\hline Perfect Health & 7.0 & Widow/Widower & 10.8 \\
\hline Good Health & 51.1 & Place of Living: & \\
\hline Not Good Health & 29.4 & Big City & 71.6 \\
\hline Bad Health & 12.2 & Small Town & 12.3 \\
\hline Missing Data & 0.2 & Village & 16.1 \\
\hline \multicolumn{2}{|l|}{ Respondent Family Size: } & Working Family Members: & \\
\hline 1 person & 11.4 & No working people & 29.9 \\
\hline 2 persons & 22.4 & 1 working person & 33.0 \\
\hline 3 persons & 26.1 & 2 working persons & 28.9 \\
\hline 4 persons & 28.7 & 3 and more working persons & 7.8 \\
\hline 5 and more persons & 11.4 & Missing Data & 0.4 \\
\hline \multicolumn{2}{|l|}{ Under-Aged Family Members: } & Net Family Budget per Month: & \\
\hline No children & 62.5 & Less than $50 \mathrm{BGL}$ & 5.2 \\
\hline 1 child & 21.5 & $50-100 \mathrm{BGL}$ & 17.2 \\
\hline 2 and more children & 15.9 & $101-200 \mathrm{BGL}$ & 32.1 \\
\hline Missing Data & 0.1 & $201-300 \mathrm{BGL}$ & 21.6 \\
\hline \multicolumn{2}{|l|}{ Sick Family Members: } & $301-500 \mathrm{BGL}$ & 16.4 \\
\hline No sick persons & 54.7 & $501-800$ BGL & 5.3 \\
\hline 1 sick person & 31.3 & More than $800 \mathrm{BGL}$ & 1.3 \\
\hline 2 and more sick persons & 14.0 & Missing Data & 0.9 \\
\hline
\end{tabular}




\section{Appendix C.2. Bivariate correlation between the socio-demographic variables}

\begin{tabular}{|c|c|c|c|c|c|c|c|c|c|c|c|c|}
\hline & $\stackrel{\Perp}{8}$ & 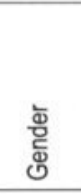 & 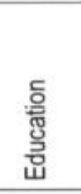 & 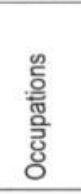 & 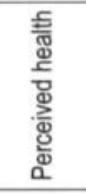 & 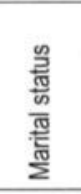 & 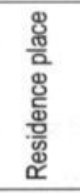 & 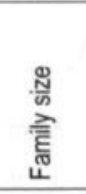 & 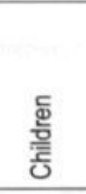 & 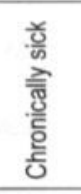 & 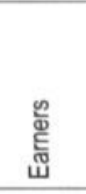 & 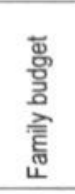 \\
\hline Age & 1.00 & 0.01 & -0.281 & $0.62^{\prime}$ & $0.50^{1}$ & $0.57^{1}$ & $0.13^{1}$ & $-0.34^{1}$ & -0.271 & $0.24^{1}$ & $-0.44^{1}$ & $-0.26^{1}$ \\
\hline Gender & 0.01 & 1.00 & 0.041 & $0.03^{1}$ & $0.12^{1}$ & 0.211 & -0.01 & $-0.05^{1}$ & $0.03^{1}$ & $0.02^{1}$ & $-0.03^{1}$ & $-0.08^{1}$ \\
\hline Education & -0.281 & 0.04 & 1.00 & $-0.38^{1}$ & -0.261 & -0.211 & $-0.30^{1}$ & -0.02 & -0.02 & $-0.19^{1}$ & $0.23^{1}$ & $0.28^{1}$ \\
\hline Occupation & $0.62^{1}$ & 0.03 & $-0.38^{1}$ & 1.00 & $0.46^{1}$ & 0.381 & $0.19^{1}$ & -0.261 & $-0.15^{1}$ & $0.22^{1}$ & -0.571 & $-0.35^{1}$ \\
\hline Perceived health & $0.50^{1}$ & 0.12 & $-0.26^{1}$ & $0.46^{1}$ & 1.00 & $0.28^{1}$ & $0.15^{1}$ & $-0.19^{1}$ & $-0.14^{1}$ & $0.45^{1}$ & $-0.34^{1}$ & -0.281 \\
\hline Marital status & $0.57^{1}$ & 0.21 & -0.211 & $0.38^{1}$ & 0.281 & 1.00 & $0.07^{1}$ & $-0.21^{1}$ & $0.03^{1}$ & 0.02 & -0.261 & $-0.21^{1}$ \\
\hline Residence place & $0.13^{1}$ & -0.01 & $-0.30^{1}$ & $0.19^{1}$ & $0.15^{1}$ & 0.071 & 1.00 & $0.06^{1}$ & $0.05^{1}$ & $0.06^{1}$ & $-0.06^{1}$ & $-0.11^{1}$ \\
\hline Family size & $-0.34^{1}$ & -0.05 & -0.02 & $-0.26^{1}$ & $-0.19^{1}$ & -0.211 & $0.06^{1}$ & 1.00 & $0.59^{1}$ & $0.10^{1}$ & $0.46^{1}$ & $0.28^{1}$ \\
\hline Children & -0.271 & 0.03 & -0.02 & $-0.15^{\prime}$ & $-0.14^{1}$ & 0.031 & $0.05^{1}$ & $0.59^{1}$ & 1.00 & $-0.06^{1}$ & $0.17^{1}$ & $0.12^{1}$ \\
\hline Chronically sick & $0.24^{1}$ & 0.02 & $-0.19^{1}$ & 0.221 & $0.45^{1}$ & 0.02 & $0.06^{1}$ & $0.10^{1}$ & $-0.06^{1}$ & 1.00 & $-0.14^{1}$ & -0.091 \\
\hline Earners & $-0.44^{1}$ & -0.03 & $0.23^{1}$ & -0.571 & $-0.34^{1}$ & $-0.26^{1}$ & $-0.06^{1}$ & $0.46^{\prime}$ & $0.17^{1}$ & $-0.14^{1}$ & 1.00 & $0.58^{1}$ \\
\hline Family budget & $-0.26^{\prime}$ & -0.08 & $0.28^{1}$ & $-0.35^{1}$ & $-0.28^{1}$ & $-0.21^{1}$ & $-0.11^{1}$ & $0.28^{1}$ & $0.12^{1}$ & -0.091 & $0.58^{\prime}$ & 1.00 \\
\hline
\end{tabular}




\section{Appendix C.3. Socio-demographic variables included in the data analysis}

\begin{tabular}{|c|c|c|c|c|c|c|}
\hline \multirow{2}{*}{$\begin{array}{l}\text { Socio-demographic } \\
\text { variable }\end{array}$} & \multirow{2}{*}{ Measurement } & \multirow{2}{*}{ Value range } & \multirow{2}{*}{$\begin{array}{c}\text { Frequency } \\
\%\end{array}$} & \multicolumn{2}{|c|}{ Average value } & \multirow{2}{*}{ St. dev. } \\
\hline & & & & Median & Mean & \\
\hline Age & Scale & From 18 to 85 years & $\cdot$ & - & 46.20 & 16.97 \\
\hline Gender & Nominal & $\begin{array}{l}1=\text { male } \\
2=\text { female }\end{array}$ & $\begin{array}{l}52.3 \\
47.7\end{array}$ & 2 & - & - \\
\hline Education & Ordinal & $\begin{array}{l}1=\text { no or primary school }(<10 \text { years }) \\
2=\text { high school }(10-12 \text { years) } \\
3=\text { semi-university }(12-15 \text { years }) \\
4=\text { university }(>15 \text { years) }\end{array}$ & $\begin{array}{r}24.1 \\
49.8 \\
7.9 \\
17.2\end{array}$ & 2 & $\cdot$ & - \\
\hline Perceived h+-ealth & Ordinal & $\begin{array}{l}1=\text { perfect health } \\
2=\text { good health } \\
3=\text { not good health } \\
4=\text { bad health }\end{array}$ & $\begin{array}{r}7.6 \\
58.7 \\
29.7 \\
12.0\end{array}$ & 2 & - & - \\
\hline Residence place & Ordinal & $\begin{array}{l}1=\text { big city } \\
2=\text { small town } \\
3=\text { village }\end{array}$ & $\begin{array}{l}70.8 \\
11.8 \\
17.4\end{array}$ & 1 & - & - \\
\hline Family size & Scale & From 1 to 11 persons & - & - & 3.15 & 1.40 \\
\hline Chronically sick & Scale & From 0 to 4 persons & - & - & 0.61 & 0.78 \\
\hline Family budget & Scale & From 25 to $1200 \mathrm{BGL}$ & - & - & 235.41 & 182.36 \\
\hline
\end{tabular}




\section{Appendix C.4. Sample, regional and national statistics}

\begin{tabular}{|c|c|c|c|}
\hline & $\begin{array}{c}\text { Sample statistics } \\
\text { May-June } 2000\end{array}$ & $\begin{array}{l}\text { Regional statistics } \\
\text { for } 1999^{1}\end{array}$ & $\begin{array}{l}\text { National statistics } \\
\quad \text { for } 19992,3\end{array}$ \\
\hline Individuals per age groups: 4.5 & $\%$ & $\%$ & $\%$ \\
\hline $20-29$ years & 18 & 21 & 19 \\
\hline $30-39$ years & 20 & 17 & 17 \\
\hline $40-49$ years & 19 & 19 & 18 \\
\hline $50-59$ years & 17 & 18 & 17 \\
\hline $60+$ years & 25 & 26 & 28 \\
\hline Total: & 100 & 100 & 100 \\
\hline Individuals per gender groups: 4.5 & $\%$ & $\%$ & $\%$ \\
\hline Male ( age > 19 years) & 48 & 48 & 48 \\
\hline Female $($ age $>19$ years $)$ & 52 & 52 & 52 \\
\hline Total: & 100 & 100 & 100 \\
\hline Individuals per residence place: ${ }^{4}$ & $\%$ & $\%$ & $\%$ \\
\hline Urban( age > 19 years) & 83 & 80 & 68 \\
\hline Rural ( age > 19 years) & 18 & 20 & 33 \\
\hline Total: & 100 & 100 & 100 \\
\hline \multirow[t]{2}{*}{ Average family budget per month: } & BGL & BGL & BGL \\
\hline & 235.04 & - & 276.73 \\
\hline
\end{tabular}

Source: National Statistical Institute. Information note from $14-05$ (in Bulgarian). Sofia: National Statistical Institute, 2000

2 Source: National Statistical Institute. Statistical reference book 2000 (in Bulgarian). Sofia: National Statistical Institute, 2000.

${ }^{3}$ Source: National Statistical Institute. Household Budgets (in Bulgarian). hitp //umw nsi bg/BudgetHome/BudgetHomeAll htm, 25-04-2001.

${ }^{4}$ The distribution of the sample among the categories does not significantly differ from the regional statistics (Chi-square test, $p \geq 0.05$ )

${ }^{5}$ The distribution of the sample among the categories does not significantly differ from the national statistics (Chi-square test, $p \geq 0.05$ ) 


\section{Patient payments in the Bulgarian public health care sector: Are they feasible?}

\section{Summary}

Patient payments are becoming a characteristic of public health care in Bulgaria, but there is still little empirical evidence to their implementation. To enable a more informed discussion over patient payment policies in Bulgaria, this study aims to analyse whether these payments are suitable and feasible for the Bulgarian socio-economic conditions, and acceptable to the population. The research in this thesis is focussed on consumer preferences for health care services and on the size of patient payments that consumers are willing and able to pay.

Chapter 1 introduces the socio-political background of the study and the system of patient payments legislated in Bulgaria. The chapter also outlines the process of data collection and the method of analysis applied in the study.

Chapter 2 analyses the context of patient payments in the Bulgarian public health care sector. The chapter reviews the problems in the health care system and discusses current reforms of the health care finance mechanism. The analysis indicates that the official fees for public health care services are introduced in a context of insufficient financing of the health care system, low efficiency and inadequate quality of the health care services, incidences of inequity in access to care and widely spread informal payments.

The next four chapters present analyses of the survey results. The survey was conducted in Bulgaria between May and June 2000 before the complete introduction of official patient payments. Data are collected on public attitudes towards alternative mechanisms of patient payments, consumer preferences for attributes of health care services and individual willingness-and-abilityto-pay for public health care services.

Based on the data from the survey, in chapter 3, public attitudes towards alternative designs of patient payment mechanism are analysed. Mann-Whitney U-tests and binary logistic regression are applied to analyse differences between the various social groups. The discussion implies that the majority of the citizens are in favour of paying fees if the services are provided with good quality and quick access.

Chapter 4 and chapter 5 analyse the importance that Bulgarian health care consumers attach to quality-, access- and price-attributes in health care sector. Chapter 4 presents an analysis of the selfexplicated attribute importance, while chapter 5 analyses the relative attribute importance based on a rating conjoint analysis. In both chapters, the impact of socio-demographic characteristics on the relative attribute importance is examined using multiple regression procedures. Both analyses show that the quality of health care services is the primary concern of Bulgarian consumers, followed by the size of patient payments and the access to services.

In chapter 6 the willingness and ability of Bulgarian consumers to pay for public health care services is studied. The impact of the socio-demographic status on the stated willingness-andability-to-pay amount is estimated using Tobit regression. Further, the potential welfare effects of various fee levels are calculated. Based on the analysis of the welfare effects, optimal prices for different health care services are determined. The results indicate that the patient charges for outpatient services should be lower than these for inpatient and dental care, and suggest that the implementation of fees for emergency care is unfavourable. 
The last chapter of the thesis, chapter 7, outlines the general conclusions and policy implications of the study. The chapter provides direct answers to the research questions and discusses the implications of these results for the design of patient payments in Bulgaria. The discussion suggests a rationale for the implementation of patient payments in Bulgaria as a tool for improving the quality of the health care provision at the local level. The potential adverse impact of these payments on equity, however, raises questions about their appropriateness as a quality improvement strategy. 


\section{Eigen patiënten bijdragen in de publieke gezondheidszorg van Bulgarije: Een haalbare zaak?}

\section{Samenvatting}

Eigen bijdragen van patiënten worden een kenmerk van de publieke gezondheidszorg in Bulgarije, maar er bestaat weinig empirisch materiaal met betrekking tot de implementatie ervan. In dit proefschrift wordt onderzocht of eigen patiëntbijdragen in de Bulgaarse situatie haalbaar zijn en of ze aanvaardbaar zijn voor de bevolking. Het onderzoek, verricht in het kader van dit proefschrift, richt zich vooral op de consumentenvoorkeuren en op de bereidwilligheid en het vermogen om te betalen.

Hoofdstuk 1 geeft een overzicht van de sociaal-politieke context van het onderzoek en het huidige ziektekostenstelsel in Bulgarije. Dit hoofdstuk beschrijft tevens de wijze waarop de data voor het onderzoek zijn verzameld en geanalyseerd.

Hoofdstuk 2 behandelt de problemen in de Bulgaarse gezondheidszorg en de huidige financiële hervormingen van de gezondheidssector. Uit de analyse blijkt dat de recente invoering van eigen bijdragen voor publieke gezondheidszorg heeft plaatsgevonden in een context van ernstige onderfinanciering, geringe efficiency, gebrekkige kwaliteit, ongelijke toegankelijkheid en een uitgebreid stelsel van informele betalingen.

De volgende vier hoofdstukken bevatten analyses van de onderzoeksresultaten. De data waarop dit onderzoek is gebaseerd, zijn in mei en juni 2000 verzameld in Bulgarije, op een moment dat het systeem van eigen patiëntbijdragen nog maar gedeeltelijk was ingevoerd. Er zijn gegevens verzameld over de houding van de bevolking t.a.v. eigen bijdragen, voorkeuren van consumenten voor eigenschappen van gezondheidszorgdiensten en de bedragen die de zorgconsumenten zouden willen en kunnen betalen.

Op basis van de gegevens uit het onderzoek wordt in hoofdstuk 3 de houding van de bevolking t.a.v. alternatieve vormen van eigen bijdragen geanalyseerd. Mann-Whitney U-testen en binaire logistische regressie zijn toegepast om de verschillen tussen de verschillende sociale groepen te analyseren. Uit de analyse blijkt dat de meerderheid van de bevolking geen bezwaar heeft de tarieven te betalen als de diensten van goede kwaliteit en snel toegankelijk zijn.

Hoofdstuk 4 en 5 analyseren het belang dat Bulgaarse zorgconsumenten toekennen aan kwaliteit, goede toegankelijkheid en de prijs van de gezondheidszorg. Hoofdstuk 4 bevat een analyse van het absolute belang dat de zorgconsumenten toekennen aan onderscheiden zorgeigenschappen, terwijl in hoofdstuk 5 het relatieve belang van zorgattributen wordt geanalyseerd aan de hand van een rating conjoint analyse. In beide hoofdstukken wordt het effect van socio-demografische factoren onderzocht met behulp van multiple regressie. Uit beide analyses blijkt dat de kwaliteit van de gezondheidszorgdiensten voor de Bulgaarse consumenten op de eerste plaats komt, gevolgd door de hoogte van de financiële bijdragen van patiënten en de toegankelijkheid.

In hoofdstuk 6 worden de bereidwilligheid en het vermogen van de Bulgaarse consumenten om te betalen voor publieke gezondheidszorgdiensten onder de loep genomen. Het effect van de sociodemografische factoren is bepaald met behulp van Tobit regressie. Daarnaast zijn de potentiële welzijnseffecten van verschillende tariefhoogten berekend en optimale prijzen voor verschillende gezondheidszorgdiensten vastgesteld. Het blijkt dat optimale tarieven voor poliklinische diensten 
lager uitvallen dan voor ziekenhuisopname en tandheelkundige zorg, terwijl eigen bijdragen voor spoedgevallen ongunstig zouden zijn.

Het laatste hoofdstuk van dit proefschrift, hoofdstuk 7 , bevat de antwoorden op de onderzoeksvragen en behandelt de beleidsimplicaties van het onderzoek. Er wordt geconcludeerd dat eigen bijdragen een middel kunnen zijn om de kwaliteit van de Bulgaarse gezondheidszorg op lokaal niveau te verbeteren. Vanwege een mogelijk negatief gevolg van deze eigen bijdragen op gelijke toegankelijkheid van de gezondheidszorg, wordt echter tevens de vraag gesteld of het wel een geëigend instrument is voor kwaliteitsverbetering. 


\section{Плащания на пациенти в българския обществен сектор на здравеопазването: Допустими ли са те?}

\section{Резюме}

Плащанията на пациентите се превръщат в основна характеристика на обществените здравни услуги в България, но все още има малко изследвания, които засягат тяхното въвеждане. За да предостави емпирични резултати, които да подпомогнат дискусиите, свързани с плащанията на пациентите в България, тази дисертация цели да изследва дали тези плащания са подходящи за бълграската социално-икономическа обстановка и дали са приемливи за населението. Изследването е съсредоточено върху предпочитанията на потребителите на здравни услуги и върху размера на сумите, които те желаят и могат да плащат.

Глава 1 представя политическия контекст на изследването и законите, определящи системата от плащания на пациентите в България. Същевременно тази глава описва процеса на събиране на данни и методите за тяхното анализиране.

Глава 2 анализира състоянието на българското здравеопазване като контекст, в който се въвеждат плащания на пациенти. Тази глава представя обзор на основните проблеми в обществения сектор на здравеопазването и анализира модела на текущите финансовие реформи. Анализът показва, че официалните плащания на пациентите в България се въвеждат в условия на значителен недостиг на финансови средства, ниска ефективност и незадоволително качество на услугите, известна неравнопоставеност на потребителите и широко разпространени неформални плащания.

Следващите четири глави представят анализ на данните, събрани в хода на социологическо проучване. Проучването е проведено в България през май и юни 2000-та година, преди системата от плащания на пациентите да бъде изцяло въведена. Събрани са данни върху общественото отношение към плащанията на пациентите, предпочитанията на потребителите относно харакеристиките на здравните услуги, и индивидуалното желание и възможност на даден потребител да заплаща здравни услуги.

Използвайки данни от проучването, глава 3 анализира общественото отношение към алтернативни механизми на плащания на пациентите. За целта са приложени статистически тестове и регресионен анализ, чрез които са изследвани различията между отделните социално-демографски групи. Анализът на резултатите показва, че мнозинството от гражданите одобряват събирането на такси от пациентите, ако обществените здравни услуги се предлагат с добро качество и са лесно достъпни.

В глави 4 и 5 се анализира важността, която потребителите на здравни услуги в България отдават на атрибутите качество, цена и достъп. Глава 4 представя анализ на важността на тези атрибути, посочена директно от потребителите, докато глава 5 анализира относителната важност на атрибутите, извлечена индиректно по метода conjoint анализ. Влиянието на социално-демографските характеристики върху важността на атрибутите е изследвано с помощта на регресия. Анализът показва, че като цяло българските потребители на здравни услуги отдават най-голямо значение на качеството на тези услуги, следвано от тяхната цена и достьп.

Глава 6 разглежда размера на сумите, които българските граждани заявяват, че желаят и могат да заплащат за обществени здравни услуги. Влиянието на социално-демографските характеристики върху размера на тези суми е изследвано чрез Тоbit регресия. Главата още 
представя потенциалния икономически ефект на различни размери плащания върху благоденствието на гражданите и определя оптималните цени за различни видове здравни услуги. Резултатите показват, че таксите за услуги, които не изискват престой в болница, би трябвало да са по-ниски от тези на болничните и зъболекарските услуги, а плащания от страна на пациента при използване на спешната медицинска помощ са нежелателни.

Последната глава на дисертацията, глава 7, обобщава заключенията и очертава изводите на изследването засягащи политиката на здравеопазването в България. Представени са директни оттовори на изследователските въпоси и е обсъдено значението на тези резултати за целта и модела на плащанията на пациентите в България. Дискусията показва, че тези плащания могат да бъдат използвани ефективно за подобряване качеството на здравните услуги на местно равнище. Неблагоприятното влияние на тези плащания върху равнопоставеността на пациентите, обаче, повдига въпроса, дали събирането на такси от пациентите е най-добрата стратегия за подобряване на качеството на здравните услуги в България. 



\section{Words of thanks}

It was a privilege to carry out my $\mathrm{PhD}$ study at the Department of Health Organization, Policy and Economics, Faculty of Health Sciences, Maastricht University. It was also a privilege to write this thesis under the guidance of my promoters Prof. Dr. Wim Groot and Prof. Dr. Frits van Merode from the same department. I am thankful to them for believing in me and for taking the challenge to supervise my project. I am very much indebted to both of them for their willingness to read the numerous drafts of the thesis, and for their beneficial advises and comments.

Further, I would like to acknowledge the EU's Phare ACE Programme and Stichting Fonds Doctor Catharina van Tussenbroek for financing my project. Without their assistance, my $\mathrm{PhD}$ study might have been impossible.

I would also like to acknowledge the members of the evaluation commission for their beneficial comments, particularly for those regarding the concluding chapter of the thesis. Their suggestions were essential for the preparation of the final manuscript.

I gratefully thank my former colleague Dr. Eddy Adang for his comments on the first drafts of my survey questionnaire. He helped me to improve the clarity of the questions and to refine their structure. My thanks are also for my colleague Dr. Aggie Paulus who was willing to review and comment the questionnaire.

Regarding the data collection, I wish to thank the APEA-BBSS Gallup International for conducting the survey and especially to the thousand Bulgarian respondents who agreed to participate in the survey. Without their contribution, it would not be possible to write this thesis. My special thanks are also for Desisslava Vankova for her gratuitous assistance during the pilot survey in Bulgaria.

Since my $\mathrm{PhD}$ study was not only difficult to accomplish, but also difficult to initiate, I would like to thank two persons who actually made it possible. I gratefully thank Prof. Dr. Hans Maarse from the Maastricht University, who helped me to resolve administrative problems surrounding my $\mathrm{PhD}$ project. My grateful thanks are also for Dr. Rob Baltussen who, as a supervisor of my MPH thesis, provoked in me interest in doing a $\mathrm{PhD}$ study and encouraged the preparation of my research proposal.

I would also like to thank my colleagues form the Department of Health Organization, Policy and Economics for creating a nice working environment, and especially to Susanne Kümpers and Irmgard Eijkelberg for the lively year and a half when we shared an office together.

Finally, my grateful thanks to my parents, my husband, my sister and my friends who always stood by me during the last five years; to family Schraven-Paras for being my family in the Netherlands; and to one dear Spanish friend, Ana Garcia Fernandez, who was with me in the most difficult times.

\section{My special thanks to all of you!}





\section{Curriculum vitae}

Milena Pavlova was born on September 23rd, 1971 in Varna, Bulgaria. After completing an English language school in 1990, she began her study in computer sciences at the Technical University of Varna. During her university study, she was involved as assistant researcher in projects in the field of non-invasive diagnostics. In 1994, she spent six months at the University of Reading, UK, where she wrote parts of her graduation thesis focused on statistical methods in pattern recognition. After defending her thesis, in 1995, the Technical University of Varna awarded her the title computer engineer. Between 1995 and 1996, she was employed as an assistant manager in the export and marketing department of 'Drouzhba Style', Varna. In August 1996, she was accepted to follow the Master of Public Health programme at the University of Maastricht, the Netherlands, which she finished in 1997 by writing a thesis on Bulgarian health insurance reforms. Between 1997 and 1998, she prepared a proposal for a PhD project and in March 1998 the project was officially admitted in the $\mathrm{PhD}$ programme of the University of Maastricht. After receiving financial support from the European Union for this project, in September 1998, she began her research work at the department of Health Organisation, Policy and Economics, Faculty of Health Science, Maastricht University. Recently she has become assistant professor at the same department. 
